\title{
Reflexiones sobre las políticas alimentario- nutricionales de la Argentina, antes y durante la pandemia del COVID-19
}

Agustín Salvia, Sergio Britos y Eugenio Díaz-Bonilla (editores) 


\section{ÍNDICE DE CONTENIDOS}

\section{INTRODUCCION, RESUMEN EJECUTIVO Y CONCLUSIONES}

Sergio Britos, Eugenio Díaz Bonilla, Ricardo Rapallo y Agustín Salvia 1

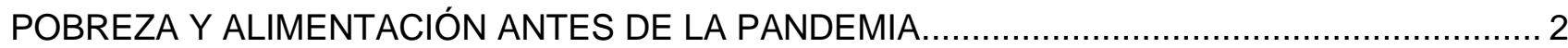

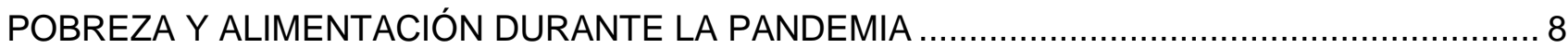

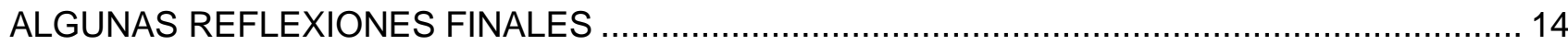

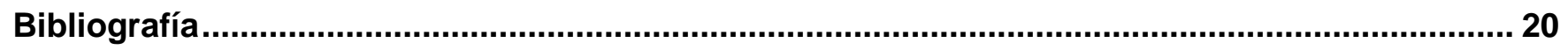

CAPITULO I. INDICADORES DE PROBREZA Y RIESGOS ALIMENTARIOS ANTES DE LA

PANDEMIA

lanina Tuñon y Santiago Poy...................................................................................................... 22

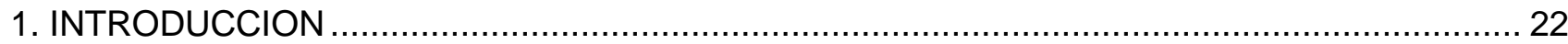

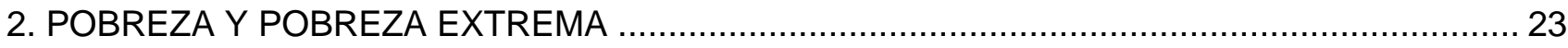

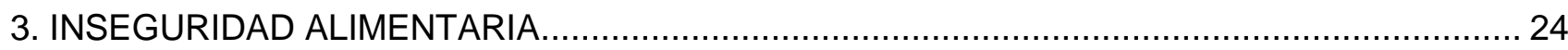

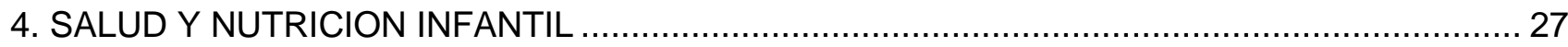

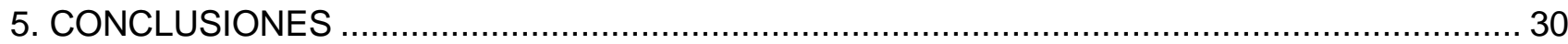

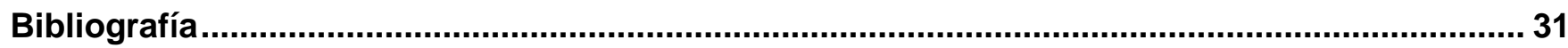

CAPÍTULO II. PROGRAMAS DE INGRESOS ANTES DE LA PANDEMIA

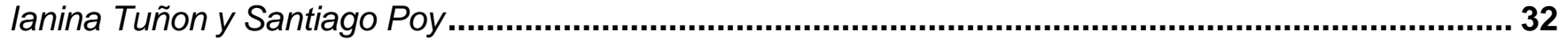

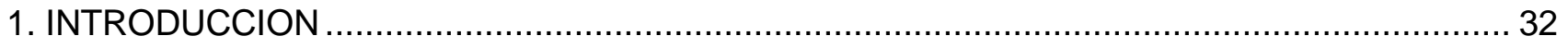

2. LOS COMPONENTES DEL SISTEMA DE PROTECCIÓN SOCIAL A LA NIÑEZ Y LA

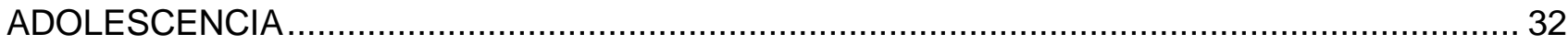

3. LOS SISTEMAS DE PROTECCIÓN PARA LA INFANCIA EN CONDICIONES DE VULNERABILIDAD

4. EVIDENCIAS SOBRE LOS EFECTOS DE LA AUH EN EL DESARROLLO HUMANO Y SOCIAL

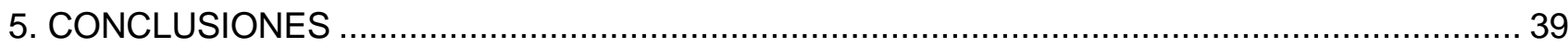

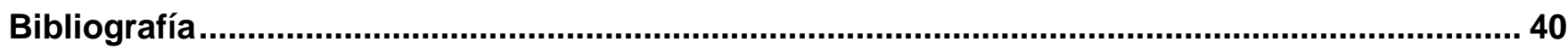

CAPÍTULO III. PROGRAMAS ALIMENTARIO-NUTRICIONALES MATERNO-INFANTILES ANTES DE LA PANDEMIA

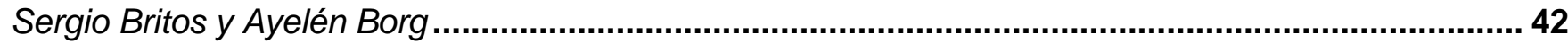

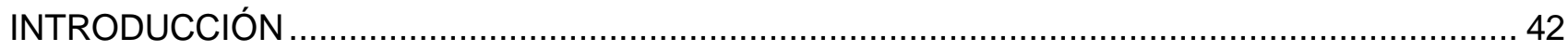

2. POLÍTICAS NUTRICIONALES EN EL SEGMENTO MATERNO-INFANTIL ......................... 43 
3. EI PLAN NACER/SUMAR COMO ESTRATEGIA GLOBAL EN EL SEGMENTO MATERNOINFANTIL.

4. ESTRATEGIAS DE PROMOCIÓN PARA LA ALIMENTACIÓN SALUDABLE ............................ 52

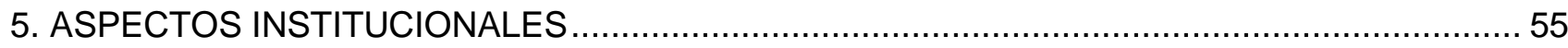

6. CONCLUSIONES Y RECOMENDACIONES A LA IMPLEMENTACIÓN INICIAL DEL PLAN ARGENTINA CONTRA EL HAMBRE Y DE LOS 1000 DIAS

Bibliografía.

ANEXO. CANASTAS DE ALIMENTOS COMO ELEMENTO PARA LA TOMA DECISIONES EN POLÍTICAS RELACIONADAS CON LA SEGURIDAD ALIMENTARIA: EL DILEMA DE LA CANASTA BÁSICA Y LOS MODELOS SALUDABLES.

Bibliografía anexo

CAPÍTULO IV. POLÍTICAS DE ASISTENCIA ALIMENTARIA Y PROGRAMAS RELACIONADOS, ANTES DE LA PANDEMIA

María Eugenia Herrrera Vegas

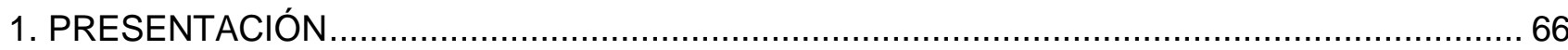

2. INSTITUCIONALIDADES SECTORIALES DEL ESTADO NACIONAL $\ldots \ldots \ldots \ldots \ldots \ldots \ldots \ldots \ldots \ldots \ldots . \ldots \ldots$

3. PRINCIPALES POLÍTICAS ALIMENTARIAS NACIONALES. ....................................... 75

4. INSTITUCIONALIDADES SECTORIALES DEL ESTADO PROVINCIAL Y MUNICIPAL............ 85

5. POLÍTICAS ALIMENTARIAS PROVINCIALES Y MUNICIPALES ...................................... 87

6. CORRESPONSABILIDAD DE ORGANIZACIONES SOCIALES Y EMPRESAS ......................89

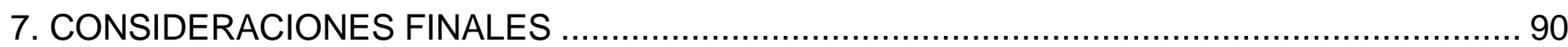

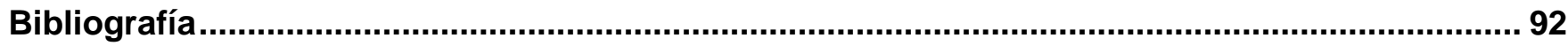

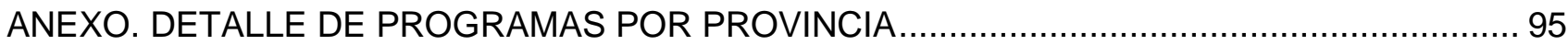

CAPITULO V. SITUACIÓN SOCIOECONÓMICA Y ALIMENTARIA Y POLÍTICAS PÚBLICAS EN CONTEXTO DE PANDEMIA COVID-19 EN LA ARGENTINA

Agustín Salvia y Sergio Britos.

1. BALANCE SOCIO ECONÓMICO Y ALIMENTARIO DE LA CRISIS SANITARIA EN CONTEXTO

DE ASPO-COVID-19.

2. POLÍTICAS PÚBLICAS EN RESPUESTA A LA CRISIS SOCIOECÓNOMICA Y ALIMENTARIA

EN EL CONTEXTO DE EMERGENCIA SANITARIA COVID-19. 130

3. REFLEXIONES FINALES: BALANCE GENERAL Y PERSPECTIVAS POST-PANDEMIA COVID19.

- Bibliografía 
ANEXO I. PROGRAMAS DE PROTECCIÓN SOCIAL FRENTE A LA CRISIS EN CONTEXTO DE ASPO-COVID-19 EN EL ÁREA METROPOLITANA DE BUENOS AIRES. ............................... 153

ANEXO II. RESULTADOS MODELO DE REGRESIÓN RIESGO DE EXPERIMENTAR INSEGURIDAD ALIMENTARIA.

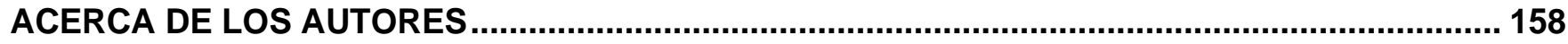

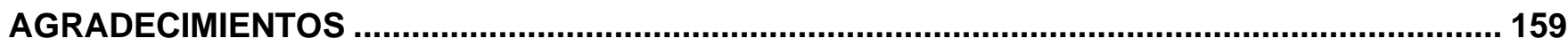




\title{
INTRODUCCION, RESUMEN EJECUTIVO Y CONCLUSIONES
}

\author{
Sergio Britos, Eugenio Díaz Bonilla, Ricardo Rapallo y Agustín Salvia.
}

El nuevo Gobierno de la Argentina lanzó a principios del año 2020 el Plan Argentina contra el Hambre (PACH) (Res. MDS 8/2020), con el objetivo general de "garantizar la seguridad y soberanía alimentaria" de todas las familias en particular las de mayor vulnerabilidad social. Como objetivos específicos se mencionan a) implementar un sistema que complemente los ingresos de hogares vulnerables para la compra de alimentos, priorizando "a padres y/o madres con niños y niñas de hasta 6 años, mujeres embarazadas a partir de los 3 meses y personas con discapacidad que se encuentren en situación de vulnerabilidad social"; b) fortalecer las prestaciones alimentarias dirigidas a provincias, municipios, y organizaciones locales; c) favorecer la producción diversificada de alimentos saludables por parte de familias, comunidades y entidades de la economía solidaria, el cooperativismo y la agricultura familiar; d) acompañar a las familias para incorporar hábitos saludables de alimentación, higiene y nutrición; y e) diseñar e implementar un sistema de monitoreo y evaluación de resultados e impactos del Plan.

El presidente Alberto Fernández en su reunión con el Director General de la FAO en febrero de 2020 solicitó apoyo a la FAO para este Plan, y en general acordaron fortalecer la cooperación para combatir la pobreza, la inseguridad alimentaria y la malnutrición, y construir una propuesta de producción sostenible. Con el fin de facilitar un diálogo informado sobre las respuestas más apropiadas que el país podría impulsar para enfrentar los problemas alimentarios, la FAO, en colaboración con el Instituto Internacional de Investigación en Políticas alimentarias (IFPRI), acordó desarrollar varios estudios sobre la situación de la seguridad alimentaria y la nutrición en la Argentina, y de las distintas políticas y programas existentes.

Este trabajo es parte del trabajo conjunto FAO (Regional de América Latina) y el IFPRI, que están colaborando desde 2018 en la implementación de un programa de alcance regional sobre políticas y programas públicos, sistemas alimentarios, y malnutrición, con énfasis en sobrepeso y obesidad. Como parte de ese programa se ha estructurado una red de instituciones públicas, privadas, académicas, y de la sociedad civil para facilitar el diálogo sobre políticas y programas que contribuyan a mejorar la disponibilidad y acceso a dietas saludables, con especial énfasis en las poblaciones más vulnerables. Se han producido varios estudios y documentos, que se encuentran en un portal de internet que fue creado a los efectos de mantener la comunicación entre las entidades y personas que participan en este diálogo (https://lac.foodsystems-obesity.org/).

El Observatorio de la Deuda Social de la Universidad Católica de Argentina (UCA), que es parte de la red de instituciones dentro del programa FAO-IFPRI, tiene una larga trayectoria en el análisis de políticas y programas sociales en la Argentina, y de su impacto sobre variables de interés, incluyendo pobreza e inseguridad alimentaria. Por ello, la FAO, el IFPRI y la UCA, junto con colaboradores de otras importantes instituciones argentinas, como el CEPEA (Centro de Estudios sobre Políticas y Economía de la Alimentación), acordaron la realización de una serie de trabajos de síntesis en apoyo al PACH. Esos trabajos se han integrado como capítulos de esta publicación. Cuando ya estaban completados esos estudios, la Argentina fue alcanzada por la pandemia global relacionada con el COVID-19. Esto llevó a la necesidad de ampliar y actualizar esos análisis a la luz de las nuevas circunstancias. 
En consecuencia, el presente documento está organizado de la siguiente manera. Esta introducción sirve de resumen ejecutivo y cierra con algunas conclusiones y recomendaciones. Luego, los Capítulos I a IV presentan el análisis socio-económico y alimentario y las políticas y programas antes de la emergencia de la pandemia, mientras que el Capítulo $\mathrm{V}$ actualiza el análisis para el período durante la pandemia. El Capítulo I realiza el análisis de la evolución de los indicadores relevantes sobre pobreza y seguridad alimentaria. Luego en tres capítulos sucesivos se analizan políticas y programas específicos. El Capítulo II trata los programas de transferencias de ingresos y medidas relacionadas. El Capítulo III se focaliza especialmente en el Ministerio de Salud, enfatizando los programas materno-infantiles. Posteriormente el Capítulo IV analiza principalmente los programas del Ministerio de Desarrollo Social, del Ministerio de Agricultura, Ganadería y Pesca, del Ministerio de la Producción (y otros aspectos productivos), y los programas de las provincias y municipios (especialmente los comedores escolares). Por último, el Capítulo $\mathrm{V}$ actualiza estos datos para el período durante la pandemia: se examinan los efectos socioeconómicos provocados por las políticas sanitarias, así como las respuestas adoptadas por el gobierno para su alivio, especialmente aquellas destinadas a paliar las consecuencias regresivas en materia de pobreza, desempleo e inseguridad alimentaria y nutricional.

En lo que sigue se van a resumir esos capítulos dividiendo los análisis pre-pandemia, y durante la misma. Al final se presentan algunas conclusiones y recomendaciones.

\section{POBREZA Y ALIMENTACIÓN ANTES DE LA PANDEMIA}

\section{Situación económica y social antes del COVID-19}

El Capítulo I (preparado por lanina Tuñón y Santiago Poy) muestra la evolución de una serie de indicadores hasta antes de la pandemia, relacionados con pobreza y pobreza extrema, inseguridad alimentaria y salud y nutrición infantil. Allí se muestra que la pobreza por ingresos marcó en el primer semestre de 2019 su valor más alto desde 2010 (pobreza total, 34.5\%; indigencia, 7.1\%), y que ese flagelo afecta de manera creciente a niños/as y adolescentes de 0 a 17 años (los datos son actualizados en el Capítulo V para el final de 2019 y el período de la pandemia). En el mismo año la tasa de inseguridad alimentaria reportada según ESDA fue de $22.1 \%$, mientras que 9.3\% padecían inseguridad alimentaria severa; ${ }^{1}$ nuevamente la población de 0 a 17 años aparecía como la más afectada. ${ }^{2}$ En relación a los dos indicadores utilizados para medir la primera meta del Objetivo 2 "Hambre Cero" de la Agenda de Desarrollo Sostenible para el $2030,{ }^{3}$ Argentina muestra un deterioro de las cifras de subalimentación desde el trienio 2013-2015, habiendo pasado de una prevalencia menor del $2,5 \%$ en esos años, al 3,8\% en la actualidad. De igual forma, la inseguridad alimentaria grave o moderada ascendió del $19,2 \%$ al 35,8 \%, aproximadamente en el mismo periodo (FAO, FIDA, OMS, WFP, UNICEF, 2020).

Pero, por otra parte, se había registrado una disminución de la mortalidad infantil (aunque los datos llegan solamente hasta 2017), y ciertos datos antropométricos (tales como la suficiencia de talla para la edad o la del bajo peso para la talla, dan una visión complementaria de las condiciones de

\footnotetext{
${ }^{1}$ Según el informe FAO, OMS, WFP, IFAD, UNICEF (2020) La prevalencia de inseguridad alimentaria grave pasó de 5,8\% (2014-16) a $12,9 \%(2017-2019)$.

${ }^{2}$ Debe notarse que la línea de pobreza extrema o indigencia es el valor mínimo de la canasta básica de alimentos para no pasar hambre. Por ello, en principio el porcentaje de población cuyos ingresos no alcanzan a ese valor (indigentes) sufren, por definición, de inseguridad alimentaria. Los números de inseguridad alimentaria severa (9.3\%) y de indigencia (7.1\%) están aproximadamente en línea, pero no son iguales ya que se miden con metodologías diferentes.

${ }^{3}$ Dicho Objetivo presenta cinco metas, de las cuales, las dos primeras se relacionan con la reducción del hambre, la inseguridad alimentaria y todas las formas de malnutrición. Para monitorear la primera de las metas se utilizan los indicadores de subalimentación (comúnmente utilizado para medir el hambre), y el de inseguridad alimentaria severa o moderada.
} 
inseguridad alimentaria) se habían mantenido a niveles bajos en 2018-2019. Por el contrario, lo que ha estado aumentando es el sobrepeso y la obesidad de niños/as y adolescentes, aún en los grupos de bajos ingresos, aunque, como sucede en otros países, el fenómeno es más pronunciado en los quintiles intermedios mientras que baja algo en los más altos (el Capítulo III de Britos y Borg también discute este problema). Debe notarse que el sobrepeso infantil en Argentina se sitúa en el $10 \%$ en 2019 , por encima del promedio mundial (5,6\%), y el de la región de América Latina y el Caribe $(7,5 \%)$.

El Capítulo I también muestra que la dieta de los ingresos más bajos muestra una composición menos saludable (por ejemplo, un mayor porcentaje de consumo de bebidas azucaradas y golosinas) que los grupos con mayores ingresos (aunque, en general, las cantidades consumidas de todos los productos es mayor en estos últimos grupos). Esto sugiere que los grupos más vulnerables deben estar sufriendo deficiencias en vitaminas, minerales y macro y micronutrientes esenciales (lo que limita el desarrollo de las capacidades intelectuales y físicas), y que, en el futuro, van a ser más susceptibles a enfermedades no transmisibles (como diabetes, problemas cardiovasculares y cáncer). Como se menciona en el Capítulo V, esto también eleva los riesgos frente al COVID-19.

Una conclusión es que el PACH debe considerar no solamente la desnutrición (o subalimentación, a veces referida como "hambre" o falta de calorías) sino los otros dos problemas de malnutrición: deficiencias en vitaminas, minerales y macro y micronutrientes esenciales (lo que se llama a veces "hambre oculta"), y el sobrepeso y obesidad (que llevan a enfermedades no transmisibles, como diabetes, problemas cardiovasculares, y cáncer). En conjunto, estos problemas representan lo que se denomina las tres cargas de malnutrición. Como señala la autora "el diagnóstico es claro en términos del crecimiento de la pobreza e inseguridad alimentaria en la población infantil del país, y las desigualdades sociales y regionales. Sin embargo, también permite advertir que la problemática de la obesidad y el sobrepeso es transversal a las diferentes infancias, lo cual agrega complejidad a la definición del problema y búsqueda de soluciones."

\section{La Asignación Universal por Hijo y otros programas relacionados con ingresos}

El Capítulo II (también preparado por lanina Tuñón y Santiago Poy) analiza los instrumentos de políticas basados principalmente en transferencias de ingresos y pagos por hijos. Se discuten cuatro mecanismos principales: a) las Asignaciones Familiares; b) la Asignación Universal por Hijo para Protección Social (AUH) complementada con la Asignación Universal por Embarazo para Protección Social (AUE); c) la deducción del impuesto a las ganancias (o "crédito fiscal") para trabajadores autónomos o asalariados de altos ingresos; y d) la pensión vitalicia para madres de siete o más hijos de muy bajos recursos (P7H). Es decir que coexisten "un subsistema contributivo para trabajadores formales, un mecanismo indirecto vía deducción fiscal para trabajadores de altos ingresos y un subsistema no contributivo de asignaciones que incluye a la $\mathrm{AUH}$, las pensiones no contributivas por siete o más hijos y otros programas subnacionales."

El capítulo explica la operatoria de estos distintos instrumentos y calcula los porcentajes de población cubierta de niños/as y adolescentes en los aglomerados urbanos relevados por la encuesta de la UCA, antes del impacto del COVID-19. Se muestra que en 2019 un 37\% de los niños/as y adolescentes eran beneficiarios de la $\mathrm{AUH} ; 5.3 \%$ recibían la $\mathrm{P} 7 \mathrm{H}$ u otros programas de lucha contra la pobreza subnacionales incompatibles con la $\mathrm{AUH} ; 36.1 \%$ estaban cubiertos con el sistema de $\mathrm{AFH}$; $5.9 \%$ tenían la deducción de impuesto a las ganancias; y alrededor de un $16 \%$ no tenía cobertura.

Pero esos porcentajes varían por decil de ingresos. Por ejemplo, en el decil más bajo, un $58 \%$ recibía la $\mathrm{AUH}$ y otro $9 \%$ se beneficiaba de la $\mathrm{P} 7 \mathrm{H}$, mientras que la $\mathrm{AFH}$ (que implica un trabajo formal) solamente cubría algo más del $13 \%$. Pero, por otra parte, casi el $20 \%$ no recibía ninguna cobertura. 
En el otro extremo de los ingresos, el $61 \%$ era cubierto por el crédito fiscal y otro $32 \%$ por la AFH (con solamente un $5 \%$ sin cobertura).

Es decir que en promedio el sistema de protección social ha alcanzado altos niveles de cobertura, pero algo más del $16 \%$ de la población en promedio, y casi un $20 \%$ en el decil más pobre, no tiene protección. Además, los datos muestran que en los deciles 6 a 10, que no pueden ser considerados pobres, la encuesta del Observatorio de la Deuda Social de la UCA encuentra un porcentaje no trivial que recibe AUH (por ejemplo, aproximadamente 18\%, 13\%, y $11 \%$ en los deciles 6 a 8, respectivamente; el porcentaje de los receptores de la AUH se reduce, pero no desaparece, en los deciles 9 y 10). Es decir, que, si bien en términos comparativos con otros países los desvíos pueden parecer no muy grandes, sería importante una mejor focalización que incremente la cobertura de los que no la tienen y reduzca la de los grupos de ingresos superiores.

Dentro de eso conjunto, obviamente, el principal instrumento para la protección de los grupos vulnerables de la niñez y adolescencia es la AUH, que, en el período pre-COVID, alcanzaba a 2.2 millones de hogares y 3.9 millones de niños/as. Los autores notan que en 2018 el monto total llegó al $0.42 \%$ del PIB. El monto de la transferencia individual de la $\mathrm{AUH}$, aunque se lo actualiza periódicamente, ha ido perdiendo valor en moneda constante, estando en 2019 un 13\% por debajo de los valores de 2009. La autora calcula que, en promedio, cada hogar recibe 1.8 beneficios, y si se toma una familia tipo de dos adultos y dos menores, entonces las transferencias cubrirían un $12.5 \%$ de los gastos considerados en la línea de pobreza y $31.4 \%$ de los correspondientes a la línea de indigencia de ese hogar de referencia.

Es decir que, en las condiciones pre-COVID, había al menos dos temas por considerar para hacer este instrumento más eficaz en la lucha contra la pobreza y la inseguridad alimentaria: uno era mejorar la focalización (cubriendo más plenamente los deciles más pobres, y reduciendo los desvíos a los deciles superiores); y el otro era actualizar los montos. En este segundo aspecto, la nueva tarjeta alimentaria es un mecanismo de actualización del monto para un grupo de las familias que reciben AUH (ver más adelante en esta Introducción y el capítulo IV) con la asignación especial para alimentos. El Capítulo $V$ analiza cómo se ha ampliado el espectro de transferencias en razón de la pandemia.

El capítulo presenta una serie de evaluaciones que muestran impactos positivos en la reducción de la pobreza (o de la brecha de pobreza ${ }^{4}$ ) y la inseguridad alimentaria, mientras que las evaluaciones relacionadas con los aspectos de atención de salud (por ejemplo, vacunaciones y visitas periódicas a centros de atención) son menos definitivas (no se reportan evaluaciones de los aspectos educativos).

Los autores estiman que la nueva tarjeta alimentaria en el contexto del PACH puede ayudar a mejorar los niveles transferencias que han ido perdiendo valor ajustados por la inflación (ver en el Capítulo $\mathrm{V}$ el impacto positivo de este instrumento en la reducción de la inseguridad alimentaria durante la pandemia). También considera que, para tener adecuado impacto en una mejor alimentación debe ser acompañada con "cambios sociales y culturales que pueden ser desarrollados a través de estrategias de comunicación, participación y formación adecuadas... enfatizando la relevancia de la alimentación de alta densidad nutricional en períodos críticos, y el sentido de la regularidad en los consumos de alimentos con mayor valor biológico."

${ }^{4}$ La brecha de pobreza es la diferencia entre el nivel efectivo de ingresos y la línea de pobreza considerada. 


\section{Programas del Ministerio de Salud y relacionados}

El Capítulo III (de Sergio Britos y Ayelén Borg) considera especialmente los programas del Ministerio de Salud. En particular se analizan:

a) los programas de atención nutricional de las mujeres embarazadas y niños/as menores de 2 años que se ejecutan dentro de la actual Dirección Nacional de Maternidad, Infancia y Adolescencia (Dinamia);

b) el programa NACER (financiando prestaciones de salud dirigidas a embarazadas y niños menores de 6 años que carecían de cobertura de salud) y su ampliación en el programa SUMAR (que extendió los beneficios a los niños y adolescentes hasta los 19 años y mujeres entre 20 y 64 años de edad); estos programas cubren intervenciones que van más allá de los aspectos alimentarios y nutricionales;

y c) una serie de programas y actividades para la promoción de alimentación saludable y prevención de obesidad en niños, adolescentes y adultos.

El capítulo analiza en detalle esos tres grupos de políticas y programas. Acá se mencionan brevemente algunos de los temas analizados.

Respecto del primer grupo, ejecutado por la Dinamia del Ministerio de Salud, se mencionan tres líneas de trabajo: a) promoción de la lactancia materna y alimentación complementaria; b) las Guías alimentarias para la Población Argentina (GAPA) y para la Población Infantil (GAPI) usadas para la educación alimentaria; y c) prevención y recuperación de niños/as con desnutrición.

Britos y Borg discuten en mayor detalle la alimentación complementaria de leche fortificada, que es comprada por la administración nacional y luego distribuida por las provincias, que reciben la leche de acuerdo con una ecuación que considera datos de pobreza, mortalidad infantil y población de cada jurisdicción. Hasta 2018 la prestación alimentaria estuvo administrada por el Ministerio de Salud (en el marco del Programa de Atención de la Madre y el Niño), pero desde 2019 pasó al Ministerio de Desarrollo Social como parte de las políticas alimentarias (más detalles se discuten en el capítulo IV que se focaliza en las actividades de ese Ministerio). Los autores notan los problemas que existían durante el período per-COVID en la operatoria del programa y en la utilización por parte de las familias de la leche suplementaria.

En relación con el tema de la prevención y recuperación de la desnutrición infantil los autores notan cierta superposición y descoordinación entre las actividades del Ministerio de Salud y las realizadas por el Ministerio de Desarrollo Social (Secretaría Nacional de Niñez, Adolescencia y Familia, SENNAF). El tema de la atención nutricional en los primeros años de vida ha sido históricamente responsabilidad del Ministerio de Salud, desde la perspectiva normativa, y también mediante la operación de más de 7000 Centros de Atención Primaria de Salud o CAPS (además de los aspectos de promoción de la lactancia materna y la distribución de leche fortificada, mencionados antes). Pero más recientemente, el Ministerio de Desarrollo Social (desde la Secretaría de Niñez, Adolescencia y Familia, SENNAF) ha desarrollado mecanismos de atención de las necesidades alimentarias de niños que asisten a Espacios de Primera Infancia (EPI) y pasó a operar unos 40 centros de prevención y recuperación de desnutrición infantil, que funcionan por medio de convenios con organizaciones de la sociedad civil (más sobre estas actividades en el capítulo IV). Los autores señalan que las actividades de estos centros (cuyo número es reducido) no parecen estar articuladas con las acciones desarrolladas por los CAPS y los establecimientos hospitalarios del Ministerio de Salud. 
Finalmente en lo que hace al problema de sobrepeso y obesidad se analizan una serie de iniciativas, todas relativamente recientes, tales como el Plan Nacional "Argentina Saludable" de 2009; las limitaciones de ácidos grasos trans y de sal en alimentos; el "Programa Nacional de promoción de alimentación saludable y prevención de obesidad," de 2016 en el ámbito del Ministerio de Salud (Dirección de Promoción de la Salud y Prevención de enfermedades no transmisibles); la actualización de las Guías alimentarias para la Población Argentina (GAPA); la elaboración de documentos sobre etiquetado frontal de alimentos; publicidad, promoción y patrocinio de alimentos; el análisis de entornos escolares saludables (el único que fue formalizado en una resolución ministerial (Res. 564/2019); y el lanzamiento del "Plan Nacional de prevención de obesidad en niños, niñas y adolescentes” (Plan ASI) en 2019.

En particular, este plan considera cuatro componentes: 1) educación alimentaria y nutricional y de actividad física; 2) comunicación, sensibilización y participación social; 3) mejora de la calidad nutricional en los programas sociales alimentarios y promoción de sistemas alimentarios sostenibles para la producción y disponibilidad de alimentos frescos; y 4) regulación de entornos y productos. El plan ASI está concebido como una actividad coordinada de Salud, Educación, Desarrollo Social, los Ministerios relacionados con la Producción, y organizaciones no gubernamentales, tanto a nivel nacional como provincial.

Desde esta perspectiva, los autores consideran que el PACH debería ser articulado con el componente del Plan ASI que procura el mejoramiento de la calidad nutricional de los programas alimentarios gubernamentales, incluyendo temas como análisis de los modelos de gestión, presupuesto, modalidades de compra y calidad nutricional de los programas alimentarios.

\section{Programas del Ministerio de Desarrollo Social}

En el Capítulo IV, María Eugenia Herrera Vegas analiza especialmente los programas relacionados con la alimentación del Ministerio de Desarrollo Social (y de otros Ministerios y gobiernos provinciales, mencionados en la siguiente sección).

Respecto del Ministerio de Desarrollo Social, la autora enfatiza sus funciones como a) titular de la presidencia honoraria del Consejo Nacional de Coordinación de Políticas Sociales (CNCPS); b) unidad ejecutora del Programa Nacional de Seguridad alimentaria (PNSA); y c) autoridad de aplicación en la protección de derechos de niños y adolescentes en situación de vulnerabilidad, a través de la Secretaría Nacional de Niñez, Adolescencia y Familia (SENNAF).

En lo que hace al Consejo Nacional de Coordinación de Políticas Sociales, la autora nota, primero, que a diferencia de otros Consejos que tienen alcance federal (los de Educación, o de Salud, por ejemplo), el CNCPS funciona solamente a nivel del estado nacional; y, en segundo lugar, menciona que aún a ese nivel, ha habido dificultades para articular los programas sectoriales, y para llevar adelante el plan nacional de monitoreo y evaluación. Parte de los problemas provienen de la confusión acerca de la autoridad que pueda tener (o no) este ente y su titular, sobre otros funcionarios con rango ministerial. Estos temas (discutidos en mayor detalle en este Capítulo IV) siguen presentes en relación con la instrumentación de una nueva política alimentaria integral como parte del plan "Plan Argentina contra el Hambre."

El Ministerio de Desarrollo Social es también la unidad ejecutora del Programa Nacional de Seguridad alimentaria (PNSA), establecido en 2003, y que procuró unificar diferentes programas de los ministerios nacionales de Desarrollo Social (tales como el Programa Alimentario Nutricional Complementario y el Fondo Participativo de Inversión Social, FOPAR); Educación (Acciones Compensatorias para Escuelas Críticas); Salud (algunas acciones del Plan Materno Infantil); y Agricultura (Programa Pro-Huerta del INTA). La autora nota, citando evaluaciones, que el PNSA no ha llevado 
a una rearticulación y coordinación de los programas vigentes sino solamente a su posicionamiento bajo un mismo paraguas.

En 2020 y antes del COVID-19, el PNSA se había expandido con la distribución de casi 1.5 millones de Tarjetas Alimentar recipientes de la $\mathrm{AUH}$, con un alcance estimado en algo más de 2 millones de mujeres embarazadas, bebés, niños y niñas de 0 a 6 años. Esto implicaba aproximadamente la mitad de la población atendida con AUH. La autora estimó el gasto adicional en aproximadamente $\$ 952$ millones de dólares (que con las estimaciones del FMI sobre la economía argentina para 2019-2020, sería un $0.2 \%$ del PIB, comparado con alrededor de $0.4 \%$ del PIB en 2018 para la $\mathrm{AUH})$.

El Ministerio de Desarrollo Social tiene el diseño, instrumentación, monitoreo y evaluación de políticas de asistencia alimentaria, pero opera mayormente a través de la Administración Nacional de Seguridad Social (ANSES), el Banco de la Nación y los gobiernos provinciales.

Finalmente, el Ministerio de Desarrollo Social, a través de la SENNAF, ejecuta el Plan Nacional de Primera Infancia, con sus dos componentes: Ios "Espacios de Primera Infancia" (EPIs) (que atiende a algo más de 100 mil niños y niñas menores de 4 años, y el plan "Primera Infancia, Acompañamos la Crianza", o "PIAC") (que en 2018 había realizado visitas domiciliarias a unas 64,000 familias, mediante la operación de 1750 facilitadores). Como se mencionó antes en el Capítulo III, la autora también nota que estas funciones no necesariamente están coordinadas con las que lleva adelante el Ministerio de Salud a través de los CAPS, hospitales y otros centros para atención materno-infantil. Este capítulo señala que en esta línea de actividades debe contabilizarse asimismo el sistema de Jardines Maternales y de Infantes de gestión provincial dentro del sector educación, con alcance a casi 1.2 millones de niños/as de 45 días a 5 años.

\section{Programas relacionados con la producción de alimentos}

El Capítulo IV también discute varias políticas nacionales de producción alimentaria, incluyendo el programa ProHuerta y programa Proyectos Especiales, ambos del Ministerio de Agricultura Ganadería y Pesca, como parte del PNSA. El primero es el más importante con una cobertura estimada de casi 600.000 huertas familiares, 13.000 huertas escolares y 6.500 huertas comunitarias. Los Proyectos Especiales son también una iniciativa del Ministerio de Desarrollo Social de la Nación y el INTA, para apoyar a comunidades rurales y periurbanas de todo el país con miembros de grupos vulnerables. Según la autora en los años 2016 y 2017 se desarrollaron más de 600 proyectos que alcanzaron a 50 mil familias. En 2019 parece haber tenido lugar un desplazamiento de recursos de ProHuerta hacia los Programas Especiales, pero sin que se explique la razón.

En el capítulo se nota también que estos programas no tienen evaluaciones de la efectividad de las acciones, y que tienden a operar con limitada coordinación con otros programas públicos (tanto productivos como de asistencia alimentaria), posiblemente dispersando o duplicando la cobertura, y dejando vacíos o discontinuidades en las intervenciones.

La autora menciona asimismo dependencias del Ministerio de Producción que pueden tener convergencia con funciones de la Dirección Nacional de Alimentos y Bebidas del Ministerio de Agricultura, sin que estén aún claras las complementariedades (o no) entre ambos ministerios. El Ministerio de Producción también es responsable de la política Precios Cuidados para combatir la inflación en alimentos prioritarios, pero que opera en paralelo a las políticas de asistencia alimentaria. En este y en el Capítulo $V$ se nota que la canasta de bienes con precios controlados incluye algunos bienes de baja calidad nutricional (como bebidas carbonatadas con azúcares), respecto de los cuales especialistas en nutrición sugieren más bien subir sus precios con impuestos. 
Este Ministerio también tiene bajo su órbita el Instituto Nacional de Tecnología Industrial (INTI), creado en la segunda mitad de los 1950s como el INTA, y que cuenta con centros regionales y redes de laboratorios y profesionales especializados que ayudan con el desarrollo y transferencia de tecnologías. Entre sus líneas estratégicas se encuentran el programa de Agro-alimentos y el programa de Desarrollo e Innovación en Tecnologías alimentarias. Considerando que la investigación del INTA se centra mayormente en la producción primaria, sería importante reforzar el trabajo del INTI sobre el resto de la cadena productiva, especialmente en lo que hace a la reformulación de alimentos procesados para una mejor nutrición y los aspectos relacionados con las pérdidas y desperdicio más allá de la producción primaria.

En la sección de producción el capítulo también revisa brevemente dos instituciones descentralizadas dedicadas a la sanidad, inocuidad y calidad de los alimentos: el Servicio Nacional de Sanidad y Calidad Agroalimentaria (SENASA) (en el Ministerio de Producción) y la Administración Nacional de Medicamentos, Alimentos y Tecnología Médica (ANMAT) (en el Ministerio de Salud). Es importante tener una clara definición de los espacios y temas regulatorios de cada uno de esos organismos para evitar tanto duplicaciones como vacíos normativos en los temas de sanidad e inocuidad de los alimentos. $^{5}$

\section{Programas provinciales y otros}

El último bloque de programas e intervenciones revisadas en el Capítulo IV de María Eugenia Herrera Vegas se refiere a las políticas de asistencia alimentaria administradas por provincias, municipios y organizaciones de la sociedad civil. El capítulo menciona que entre las 24 provincias y 2165 municipios hay un estimado de 88 programas y acciones de seguridad alimentaria (que se detallan en el anexo a este capítulo). Las dos intervenciones más comunes son las tarjetas alimentarias y los comedores escolares. La autora identifica unas 22 tarjetas provinciales (con nombres como Más Vida, Sapukay, Crecer, Familia, Única de Ciudadanía, Peñi Social, etc.) y cita estimaciones de 2019 que muestran 18.469 comedores escolares y 1165 comedores comunitarios contabilizados por el Estado Nacional. Hay también apoyos del PNSA a merenderos, y las provincias operan otros programas de menor tamaño y dispersos, que son difíciles de cuantificar.

Otra línea mencionada en el capítulo, que depende del CNCPS, son apoyos públicos a organizaciones de la sociedad civil y de la comunidad que se dedican a acciones sociales que incluyen asistencia alimentaria, así como actividades de responsabilidad por parte de empresas privadas. No parece haber evaluaciones de estas intervenciones.

\section{POBREZA Y ALIMENTACIÓN DURANTE LA PANDEMIA}

Los capítulos anteriores examinaron aspectos críticos de la situación alimentaria y de la pobreza en la Argentina, así como las características y los alcances que registran las políticas públicas orientadas a abordar estos problemas hasta antes de la llegada a la Argentina de la pandemia generada por el COVID-19. El Capítulo V de Agustín Salvia y Sergio Britos analiza la situación económica y

\footnotetext{
${ }^{5}$ Debe notarse que ciertamente hay toda una variedad de políticas macroeconómicas y sectoriales que inciden también sobre la producción agro-alimentaria, desde el sector primario hasta las diferentes etapas del procesamiento, transporte y comercialización. Acá se ha acotado el estudio a los aspectos productivos mencionados en el texto principal.
} 
alimentaria desde la emergencia sanitaria generada por la pandemia, así como las políticas seguidas por el gobierno (hasta fines de junio y principios de julio) para atender las mayores demandas sociales. El capítulo cierra con algunas recomendaciones.

En función de este objetivo, el documento ofrece una primera parte en donde se hace una actualización de datos sobre la situación económica, el empleo, la pobreza, la (in)seguridad alimentaria y malnutrición durante el primer semestre del presente año. En una segunda parte, se estima la inversión probable en las diferentes políticas de protección social reforzadas y/o introducidas por el gobierno en procura de aliviar la caída del consumo, el empleo y los ingresos de los sectores más pobres, y, finalmente, se describe las características y alcances de las principales políticas asociadas a la seguridad alimentaria de la población.

\section{Impactos socio-ocupacionales y alimentario-nutricionales de la pandemia}

Los autores notan que la pandemia ha obligado a la Argentina -al igual que muchos otros países- a implementar políticas preventivas de aislamiento social, preventivo y obligatorio (ASPO), con efectos regresivos en materia socioeconómica y cambios socio-culturales todavía impredecibles. Esto ha tenido lugar en un escenario económico y social que venía muy deteriorado por casi una década de estancamiento e inflación, agravado por la crisis de 2018-2019.

Los indicadores, que eran poco alentadores desde antes de la pandemia, se han deteriorado aún más, de manera que, en la apreciación de los autores, el año 2020 será recordado como uno de los más críticos de la historia económica argentina: el PIB podría caer un 10\%; la inflación llegaría a un 40-50\%; y el empleo total caería entre 6-7\% (especialmente en las actividades relacionadas con servicios presenciales y entre las PyMES). Aún entre los ocupados, según encuestas citadas por los autores, casi el $20 \%$ no cobró ni tuvo ingresos durante la cuarentena y alrededor de $44 \%$ vio reducidos sus ingresos; por lo cual, y más allá de que los programas sociales de transferencia de ingresos aumentaron cobertura, la pobreza podría afectar al menos a un 45\% de la población.

Los autores también analizan la situación de inseguridad alimentaria a partir de una encuesta para el Área Metropolitana de Buenos Aires (AMBA), considerando la variación entre julio-octubre 2019 y mayo 2020. De acuerdo con esos datos la inseguridad alimentaria total (que es la suma de la inseguridad alimentaria severa más la inseguridad alimentaria moderada) alcanzó para mayo de 2020 al 20\% de los hogares del AMBA, mientras que las situaciones de mayor privación afectaron al $9 \%$ de los hogares. Para ambos casos se registra un deterioro respecto de la situación del año 2019 , dónde los niveles alcanzaban al $18 \%$ y al $6 \%$ respectivamente. Un aspecto destacable es que el aumento de la incidencia en estos indicadores tuvo también lugar entre hogares que no eran pobres por ingresos en 2019, así como en hogares de estratos socio-ocupacionales de "trabajadores integrados" (es decir con empleos formales).

Un dato adicional importante que surge de la encuesta fue que al analizar a los hogares con y sin AUH-Tarjeta Alimentar se observó que la caída en inseguridad alimentaria severa era más importante entre los hogares pobres en 2019 que luego no fueron beneficiarios, con respecto de los que sí lo fueron. Este aspecto es luego corroborado por el análisis econométrico reportado por los autores sobre los factores asociados con la posibilidad de caer en inseguridad alimentaria en el contexto del COVID-19. Allí se muestra que mientras que el acceso a ayuda social AUH o cualquier otra, diferente de la Tarjeta Alimentar, resultaba no significativo en términos estadísticos, el ser beneficiario de AUH más el complemento de Tarjeta Alimentar reducía las chances de pasar a la situación de inseguridad alimentaria severa en un $60 \%$.

Otros factores que mostraban significación estadística respecto de la probabilidad de caer en alguna de las formas de inseguridad alimentaria fueron a) la situación ocupacional de "trabajador 
marginal" (pero inclusive los trabajadores integrados al mercado laboral formal tenían 4 a 5 veces más chances de pasar a experimentar inseguridad alimentaria que los hogares de estratos medios profesionales, que era el grupo de comparación); b) el hecho de haber pasado a trabajar menos horas, ser despedido, suspendido o no poder desarrollar sus actividades laborales; c) el haber sido pobre previamente; y d) el vivir en el Conurbano (los hogares que viven allí presentaban entre 2 y 3 veces más de probabilidades de experimentar un deterioro de su situación de seguridad alimentaria).

Asimismo, los autores reportan los resultados de otra encuesta, realizada por el CEPEA, sobre los hábitos de consumo durante la pandemia, con una muestra de algo más de 3500 sujetos y basada en un formulario que indagó la frecuencia de consumo de 14 grupos, categorías o subcategorías de alimentos que reflejan lo que las Guías Alimentarias (GAPA) recomiendan como de consumo regular (diario). Sobre la base de esa información se calcularon dos indicadores simplificados: uno sobre consumo saludable (frecuencia de consumo de alimentos de alta densidad de nutrientes) y otro de puntaje global de la dieta (combinando el consumo de todas las variedades de alimentos).

Los resultados reportados por los autores muestran que algo menos del 13\% de la población general $(11,9 \%$ entre quienes son desocupados o trabajadores informales y $14,9 \%$ en hogares con niños) manifestaron consumir los cinco grupos alimentarios de mejor calidad nutricional en las frecuencias recomendadas en las GAPA. Por el contrario, algo más de la mitad de la muestra reportó consumos entre regulares y bajos (subiendo a un $63 \%$ entre quienes se encontraban desocupados o con trabajo informal). Respecto de la calidad total de la dieta, menos del $9 \%$ de la población general logró el mejor resultado, mientras que algo más del $70 \%$ de la población en general y un $76,4 \%$ entre desocupados y trabajadores informales, registraron puntajes globales de la dieta entre regular y bajo. Las mayores brechas de consumos saludables ocurrían en legumbres, frutas, hortalizas no feculentas, lácteos (en especial yogur) y carnes frescas (en ese orden). En cuanto a los productos de baja densidad de nutrientes, las brechas de exceso de consumo son casi idénticas entre alimentos con harinas muy refinadas y azúcares.

En conjunto, los datos muestran el deterioro de los indicadores de pobreza no solamente en los hogares que eran previamente vulnerables, sino también de grupos que no eran considerados pobres antes de la pandemia. Respecto de la alimentación, la información presentada muestra no solamente un deterioro en la inseguridad alimentaria medida como carencia de las calorías necesarias para llevar adelante una vida activa ("hambre" o el primer problema de malnutrición), sino también un deterioro en la calidad de la dieta relacionada con los otros dos problemas que suman el triple problema de malnutrición: por una parte, deficiencias en vitaminas, minerales y micronutrientes esenciales, y, por otra, el sobrepeso y obesidad.

\section{Políticas públicas de protección social en el contexto de la pandemia}

Los autores analizan las políticas de transferencia de ingresos y/o asistencia alimentaria a sectores vulnerables seguidas por el gobierno de la Argentina, cuyo impacto presupuestario estiman fue hasta julio de 2020 de $3,7 \%$ (8\% del PBI semestral), siendo esperable al menos un $6 \%$ a fin del año. La medidas incluyen acciones sanitarias orientadas a reducir los riesgos de propagación del COVID-19 a través de una aislamiento generalizado, mientras que se pusieron en marcha medidas orientadas a sostener un piso mínimo de protección en materia de trabajo, ingresos y seguridad alimentaria, buscando aliviar el impacto regresivo de la cuarentena sobre el consumo, el empleo y los ingresos de las familias, la oferta de bienes y servicios básicos, el abastecimiento y los precios de alimentos y otros bienes esenciales. Los autores analizan las políticas clasificadas en cuatro categorías: a) protección social y empleo; b) producción, abastecimiento y consumo de alimentos; c) seguridad alimentaria; y d) otras medidas de promoción productiva. Entre las medidas de protección social los autores destacan: 
1) la asignación de un bono especial (por única vez) para los más de 3,9 millones de beneficiarios de la Asignación Universal por Hijo y/o Asignación por Embarazo (\$3.103, el equivalente a una asignación), a cobrar a partir del mes de abril;

2) la asignación de un bono especial (por única vez) para los más de 3 millones de jubilados y pensionados (\$3.000 para quienes cobrasen el mínimo y lo necesario para alcanzar $\$ 18.891$, para quienes cobrasen más que el mínimo), y para el casi 1,5 millón de beneficiarios de las pensiones no contributivas;

3) un refuerzo especial de la Tarjeta Alimentar (por única vez) a un millón quinientas mil familias (a cobrar a fines de abril) de un monto igual al de la asignación, variable según la composición familiar ( $\$ 4.000$ para familias con un niño y $\$ 6.000$ para familias con dos o más niños); y

4) la asignación de un Ingreso Familiar de Emergencia (IFE) en un pago (\$10.000) para las personas de 18 a 65 años (argentinas, naturalizadas o con residencia en el país mayor a dos años) desocupadas, que trabajen en la economía informal, o sean monotributistas sociales o de las categorías más bajas. En su primera ronda, el IFE alcanzó a 8,9 millones de personas y se estudia actualmente su eventual continuidad.

En lo que hace a empleo se mencionan una serie de medidas tales como el derecho a tomar licencias y/o al trabajo remoto, la prohibición de despidos y suspensiones, el otorgamiento de créditos para pago de sueldos, y la habilitación de prórrogas al vencimiento de deudas, entre otras facilidades fiscales instrumentadas a través de la AFIP. Más avanzada la crisis se creó el Programa de Asistencia de Emergencia al Trabajo y la Producción (ATP), que permite el pago directo a través del Estado de hasta el $50 \%$ de las remuneraciones a trabajadores registrados del sector privado, en montos que no pueden ser inferiores a un Salario Mínimo Vital y Móvil (\$16.875) ni superar el doble de esa referencia (\$33.750). Este Programa incluyó también una ampliación de la prestación por desempleo e involucró la postergación del pago de contribuciones patronales y su reducción hasta el 95\% según rama o sector. Hasta mediados de mayo se estimaba que recibieron o recibirán el salario complementario más de 2 millones de trabajadores ocupados en unas 240,000 empresas. Las empresas de menos de 100 empleados habían recibido el 57\% de los desembolsos estatales; un $27 \%$ fue a compañías de entre 100 y 800 personas; y el 16\% lo recibieron empresas de más de 800 empleados.

\section{Producción, abastecimiento y consumo de alimentos}

En este grupo de políticas, el capítulo describe varias iniciativas. El Ministerio de Desarrollo Productivo lanzó una línea de créditos a tasa subsidiada (24\%), mediante la cual, hasta principios de junio se habían asistido a 136.000 empresas (mayormente PyMEs), especialmente en los sectores de comercio (32\%), la industria (29\%) y el sector agropecuario (13\%). Por su parte, el Ministerio de Agricultura, Ganadería y Pesca desarrolló un conjunto de dieciséis lineamientos sobre buenas prácticas para diferentes producciones agropecuarias, que aunque varían entre las distintas cadenas productivas, se refieren, en general, a las precauciones para detección de síntomas de Covid19 , la higiene personal, el escalonamiento seguro de turnos de trabajo, distanciamiento, previsiones de elementos desinfectantes, limpieza de elementos y vehículos, prevenciones en relación a la circulación por rutas y caminos, limpieza de áreas de contacto entre compradores y vendedores, y precauciones en relación con aglomeraciones (Ministerio de Agricultura, Ganadería y Pesca, 2020). Junto con la Bolsa de Comercio de Rosario, se puso en funcionamiento una herramienta digital destinada a transportistas y trabajadores de cadenas productivas para la provisión de información esencial sobre prácticas sanitarias y otras relacionadas con el buen funcionamiento logístico para el movimiento de alimentos. 
Los autores notan que al arranque del ASPO, los controles sobre la circulación por rutas y caminos dificultaron la logística de traslado de alimentos desde sus lugares de producción hasta acopios o centros de distribución y comercialización, afectando especialmente el sector frutihortícola, con su impacto sobre los precios de esos productos. La necesidad de tramitar permisos de circulación parece haber afectado a la operación de verdulerías, así como de diferentes ferias barriales y mercados populares, en los grandes centros urbanos. De todas maneras, los autores consideran que las cadenas alimentarias parecen haberse estabilizado, manteniéndose una oferta constante bajo un relativo control de precios.

Entre otras iniciativas acordadas por el sector privado los autores destacan el "Compromiso Social de Abastecimiento" desarrollado por el Mercado Central de Buenos Aires, que suministra productos frutihortícolas a uno 13 millones de personas distribuidas entre Capital y el Gran Buenos Aires.

Respecto a la política de precios, se registran medidas relativas al control de posibles abusos de precios y comercialización. Para eso se reguló una Ley de Abastecimiento, se determinó que los precios debían ser retrotraídos al 6 de marzo, se mantuvo una normativa específica de Precios Máximos en varios rubros (que actualmente viene siendo prorrogada) y se ofreció una aplicación a la población para verificar precios y denunciar incumplimientos. En el Ministerio de Desarrollo Productivo, la Dirección de Análisis y Evaluación de Mercados utiliza un registro de Precios Claros para monitorear la inflación diaria de unos 900 productos de consumo masivo en los supermercados (alimentos y bebidas y productos de cuidado personal y limpieza).

\section{Políticas alimentarias}

Los autores analizan una variedad de iniciativas en esta sección. En primer lugar, el Decreto 260/2020 (ampliatorio de la emergencia sanitaria en virtud de la pandemia por COVID-19) estableció que el Ministerio de Desarrollo Social deberá articular los dispositivos para la asistencia en la emergencia con las recomendaciones de la autoridad sanitaria (Ministerio de Salud). En ese marco se creó un Comité de Emergencia Social para la planificación y seguimiento de las acciones que se desarrollen en los ámbitos jurisdiccionales entre el Gobierno nacional, los provinciales, municipales, organizaciones de la sociedad civil, religiosas y de distintos movimientos sociales. Los temas que forman la agenda de este Comité se relacionan con el conjunto de problemáticas y necesidades que se potencian por las condiciones de aislamiento impuestas por la pandemia.

Segundo, en ese contexto se destacan como acciones prioritarias del Ministerio de Desarrollo Social dos componentes del PACH orientas al objetivo de garantizar la seguridad alimentaria en poblaciones vulnerables: i) la Tarjeta Alimentar y, ii) la asistencia alimentaria directa a través de comedores escolares, merenderos y comedores comunitarios. En lo que hace a la Tarjeta Alimentar, con la pandemia ya manifestada el total de titulares de ese programa era de 1,5 millones en mayo, alcanzando un conjunto de 2,8 millones de beneficiarios. La Tarjeta Alimentar asigna mensualmente, $\$ 4$ mil a familias con un solo hijo hasta 6 años, o $\$ 6$ mil pesos cuando tiene más de un hijo de esa edad, para compras de alimentos, con excepción de bebidas alcohólicas y azucaradas. A finales de abril se había implementado un refuerzo económico extraordinario por única vez (de igual monto al de las transferencias habituales) con el objetivo de atender necesidades alimentarias adicionales atribuibles a la emergencia por COVID-19. Como se mencionó antes, la encuesta del AMBA del ODSA-UCA mostró que la Tarjeta Alimentar ha sido una herramienta útil, ya que los hogares y niños/as en situación de pobreza en 2019, que eran beneficiarios de AUH y de la Tarjeta Alimentar, se habrían visto menos afectados por la inseguridad alimentaria, que los que no han tenido el beneficio complementario de la tarjeta. 
Los autores notan que esta modalidad también permite monitorear los tipos de consumos de alimentos, y los datos de febrero, marzo y abril de beneficiarios de tres áreas (Metropolitana de Buenos Aires, Santa Fe y Rosario), muestran que casi el 39\% de la cantidad de los productos adquiridos y el $51 \%$ de los gastos corresponden a alimentos que el PACH identifica como recomendables, mientras que un $21 \%$ del gasto total se destina a productos no recomendables (fundamentalmente productos alimentarios con altos contenidos de azúcar o sodio); y el resto (aproximadamente 28\%) a otros productos, de calidad intermedia según la clasificación del Ministerio. Los diez primeros rubros de gasto en orden descendente son carnes (frescas y procesadas), lácteos, harinas y cereales (azucarados y no), aceite, productos azucarados (azúcar/jugos en polvo/dulces y golosinas), yerba, verduras, frutas, aderezos y puré de tomates.

Dentro de la asistencia alimentaria directa los autores consideran que el sistema de transferencias por convenios con Gobiernos y organizaciones sociales para refuerzos de comedores escolares, comunitarios y compra directa de alimentos del Ministerio de Desarrollo Social permitió responder en forma rápida y en gran escala al aumento registrado en la demanda alimentaria a partir de la pandemia y el ASPO. Encuestas de ODSA-UCA en el Área Metropolitana de Buenos Aires muestran que mientras que en julio-octubre de 2019 , el $9 \%$ de los hogares de esta región recibían o recogían viandas o alimentos de un comedor escolar o comunitario, a principio de mayo de 2020 esta cifra ascendió al 16\% para esos mismos hogares. En el caso de los hogares con niños, niñas o adolescentes, el estudio registró que un $28 \%$ de ellos recibieron algún tipo de asistencia alimentaria directa.

Dadas las restricciones de presencia en las escuelas y de concentración de personas, muchos comedores escolares y comunales adoptaron modalidades de entrega de comidas para ser consumidas en las casas, lo que permitió seguir atendiendo a las poblaciones afectadas. Las dos modalidades principales han sido viandas con comidas listas que se retiran en las escuelas y módulos o bolsos con alimentos que se recogen por lo general, de manera quincenal.

Sin embargo, los autores notan que los diferentes programas de comedores (escolares, comunitarios) y las transferencias para programas alimentarios a provincias, municipios y organizaciones sociales, no responden a un diseño nutricional que ayude a superar los déficits en hortalizas, frutas, legumbres y lácteos y modere los excesos de consumo de carbohidratos complejos de baja calidad y azúcares. Por el contrario, consideran que las restricciones impuestas por el ASPO habrían reforzado los rasgos obesogénicos de esa asistencia alimentaria.

\section{Otros programas alimentarios y nutricionales}

Finalmente, se analizan otros programas en el contexto del COVID-19. Primero, los autores notan que programas previos a la emergencia como la promoción de mercados populares y ferias barriales, que trataban de vincular la producción local con las compras a través del PACH y el ProHuerta, parecen haber sufrido las restricciones relacionadas con la cuarentena. De todas maneras, en el último caso señalan que no obstante las restricciones del ASPO se pudo realizar la entrega de semillas de la temporada otoño-invierno; también se realizaron actividades de entrega de animales de granja (para producción de huevos y carne), siguiendo protocolos de higiene sanitaria; y las actividades de capacitación pasaron a un formato virtual.

Segundo, se menciona que el actual contexto de crisis sanitaria parece haber impactado en programas nutricionales del Ministerio de Salud, como el Materno-Infantil, a través de su prestación de leche fortificada (ya que la regularidad de distribución de leche fortificada habría sido afectada, junto con la movilidad de la población a los centros sanitarios), y al Programa Nacional de Promoción de Alimentación Saludable y Prevención de Obesidad (cuyas acciones parecen limitadas a la preparación de documentos e investigaciones). 
Tercero, los autores también mencionan dos iniciativas no gubernamentales en programas Alimentarios-nutricionales en el contexto del COVID-19: SEAMOS UNO (una iniciativa solidaria que reúne aportes de empresas y organizaciones del sector privado, instituciones religiosas de diferentes cleros y organizaciones sociales como Caritas, el Banco de Alimentos y el Centro de Investigación y Acción Social de la Compañía de Jesús) y PROTEIN PLUS (una iniciativa de la ONG Solidagro basada en una experiencia previa denominada "Soja Plus" que se basa en donaciones de soja y otras legumbres por parte de productores, que luego son procesadas para tener alimentos con proteínas vegetales).

\section{Recomendaciones respecto a las políticas alimentarias}

En función de los objetivos alimentarios planteados por el Gobierno Argentino a través del Programa Argentina Contra el Hambre, y otros previos en materia de salud nutricional, y considerando el impacto de la pandemia los autores proponen algunas recomendaciones:

- "Introducir en el Programa Argentina Contra el Hambre un abordaje comunitario centrado en el trabajo directo con productores/proveedores locales de alimentos, centros de abasto y organizaciones comunitarias que prestan servicios alimentarios regulares destinados a la población en situación de pobreza y vulnerabilidad social.

- Asegurar un piso de calidad nutricional (acorde a la problemática prevalente) y fortalecer los diseños logísticos necesarios para la dieta de los comedores escolares, de manera prioritaria para las regiones, sectores y grupos más pobres y vulnerables, garantizando en todo el país una dieta mínima de alta calidad nutricional (empezando por el desayuno).

- Fortalecer a las organizaciones comunitarias y de la sociedad civil que brindan servicios alimentación y cuidado en función de aumentar su capacidad de gestión y a mejorar la calidad y las condiciones en que desarrollan la diversidad de servicios que prestan a sus comunidades.

- Promover la ampliación de la oferta alimentaria favoreciendo la inclusión de núcleos de productores de la economía local y popular como abastecedores del conjunto de políticas alimentarionutricionales, bajo marcos legales, reglas claras, estables y asequibles en el orden laboral, tributario, comercial y de prácticas de inocuidad alimentaria y de impacto ambiental.

- Ampliar el Programa alimentar al conjunto de los sectores vulnerables que seguramente, en el post COVID-19 excederán a los beneficiarios de la Asignación Universal por Hijo; en particular, poblaciones de riesgo nutricional.

- Actualizar sus montos en forma periódica en base a un índice de precios que asegure la accesibilidad a una canasta priorizada de hortalizas, frutas, legumbres y lácteos (principales alimentos con brecha negativa de consumo en la población).

- Potenciar la vinculación del Programa Alimentar a esa canasta priorizada de alimentos -clave no solo per se sino en términos de fortalecimiento del sistema inmune- antes de posibles rebrotes de COVID-19.

- Ampliar significativamente la oferta de educación alimentaria a través de mensajes efectivos, concretos, persistentes y redundantes."

\section{ALGUNAS REFLEXIONES FINALES}

La Argentina viene transitando un largo ciclo de crisis y estancamiento. La pandemia ha agravado los problemas estructurales de un sistema socioeconómico desigual y estancado desde hace varias décadas. En lo que hace a los problemas alimentarios, el resultado más probable es de un mayor 
deterioro (en los tres aspectos de la malnutrición mencionados), no solamente en los sectores de pobreza estructural, sino también en grupos de nuevos pobres.

Como se nota en el Capítulo V, las medidas tomadas durante la pandemia parecen haber amortiguado el impacto de la actual crisis sobre las condiciones de vida, pero seguramente no alcanzan para compensar la caída económica, la destrucción de empleos y el aumento de la pobreza. También debe notarse que existe mucha incertidumbre respecto de la evolución de la pandemia (y de las medidas de cuarentena y aislamiento necesarias) y de la economía argentina durante, y luego de, esta emergencia sanitaria. Por ello, las conclusiones y recomendaciones que siguen deben ser consideradas como preliminares.

El proceso de definición, implementación y control de las políticas públicas requiere responder una serie de preguntas. Primero, hay que definir el problema que se quiere resolver y cuantificar su importancia. Segundo, hay que determinar por qué es necesaria la intervención pública para resolverlo, y si el gobierno puede intervenir adecuadamente. Tercero, se deben definir objetivos cuantitativos o verificables en el tiempo, respondiendo la pregunta "¿qué significa "resolver el problema"? Cuarto, hay que formular una o varias hipótesis sobre las razones del problema, y una "teoría del cambio" que explique cuáles son las posibles estrategias, enfoques, intervenciones e instrumentos que llevarían a los impactos y efectos esperados (es decir a aquellos resultados que "resolverían el problema"). La quinta pregunta tiene que ver con cuáles serían los arreglos institucionales, de personal y presupuestarios necesarios para llevar adelante las intervenciones consideradas. En particular, hay que considerar las posibles fallas de gobierno en sus distintos niveles e instituciones, que pueden impedir su diseño e implementación. Sexto, se necesita un plan de implementación que defina qué hacer (actividades específicas, más allá de términos genéricos como "coordinación", articulación", etc.); quién lo hará (no puede haber actividades sin ejecutores responsables); cuándo (calendario); cómo (aspectos operativos, organizativos y tecnológicos); y con qué (presupuesto, personal, otros recursos). Finalmente, se necesitan mecanismos de monitoreo y evaluación. Obviamente esos pasos y preguntas están en muchos casos relacionados y no pueden abordarse linealmente. Con este marco conceptual se presentan a continuación algunas reflexiones para el "Plan Argentina contra el Hambre."

\section{Un contexto dominado por desequilibrios macroeconómicos}

Lo primero que hay que notar es que muchos de los problemas de pobreza e inseguridad alimentaria que el PACH quiere resolver (ver la siguiente sección) tienen una causa más general, relacionada con las crisis recurrentes del país, que no permiten un patrón de crecimiento sostenido en el tiempo. Es reconocido el hecho que la Argentina está entre los países con mayor frecuencia de recesiones en el último medio siglo (desde principios de los sesenta hasta la actualidad, la Argentina ha sufrido caídas del PBI per cápita en un $42 \%$ de los años) y una parte importante de esas recesiones ha estado relacionada con la volatilidad del tipo de cambio, que en la Argentina se ha movido entre períodos de "represión" (con un valor del tipo de cambio relativamente fijo o que se ajusta menos que la inflación y por ende termina sobrevaluándose) y de "explosión" (cuando la situación se hace insostenible y el tipo de cambio salta violentamente hacia otro valor nominal) (ver Díaz-Bonilla 2017).

Cuando se produce la "explosión" del tipo de cambio, usualmente el país sufre una recesión, particularmente si el período de "represión" llevó a una alta dolarización del sistema bancario, como sucedió durante el período de la Convertibilidad. En promedio, la Argentina creció alrededor del 1,1\% per cápita desde la década de 1960 hasta 2019 (menos de la mitad que Chile y España, y una sexta parte que Corea, por ejemplo). Pero esto es una combinación de una caída promedio del $1,6 \%$ durante los años en que hubo una devaluación de más del $40 \%$ y un crecimiento del 3,0\% en 
promedio en los años sin devaluaciones (o con devaluaciones inferiores al 40\%). Las devaluaciones explosivas llevan a un salto brusco de los precios internos, lo que sube el costo de la canasta básica que se usa para calcular la línea de pobreza. La combinación de inflación y recesión hace que el número de personas en condiciones de pobreza e inseguridad alimentaria se eleve considerablemente.

Estar en condiciones de poner a la Argentina en un sendero de crecimiento sin crisis recurrentes que llevan a aumentos violentos de la pobreza y la inseguridad alimentaria, requiere un marco macroeconómico que evite usar el tipo de cambio nominal como instrumento antiinflacionario sino que estabilice el tipo de cambio real (TCR, es decir ajustado por la inflación, y preferiblemente usando una canasta de monedas) a un nivel que ayude con el crecimiento y la sostenibilidad de las cuentas externas y evite crisis financieras. La actual pandemia no va a permitir asegurar el ordenamiento fiscal en un horizonte de corto y aún mediano plazo, y el financiamiento monetario va a seguir siendo necesario, junto con controles importantes en el mercado de cambios. Pero debe plantearse un programa que en un plazo razonable consiga poner las cuentas fiscales en orden y que vaya alineando la oferta de dinero en línea con la demanda (la que se expandiría con un TCR más estable).

Obviamente, la pandemia ha complicado aún más el diseño e implementación de un marco macroeconómico consistente que evite las crisis recurrentes del pasado y que permita a la economía entrar en un período de desarrollo sostenido con generación de empleo. Pero acordar ese marco macroeconómico y un programa consensuado de desarrollo sigue siendo una tarea central que requiere un acuerdo social amplio. En lo que sigue nos centramos en los aspectos más específicos de las políticas sociales y sectoriales.

\section{Objetivos del Plan Argentina contra el Hambre}

Los considerandos de la Resolución 8/2020 del Ministerio de Desarrollo Social que crea el PACH se refieren solamente al tema de carencias alimentarias de la población, pero el anexo de dicha resolución utiliza el incremento de los indicadores de pobreza y de los de inseguridad alimentaria como justificación del programa.

Como se mencionó previamente, la línea de indigencia es el costo de la canasta mínima de alimentos para satisfacer los requerimientos calóricos y a la misma se le añade un porcentaje para cubrir otras necesidades básicas con el cual se construye la línea de pobreza total. Por su parte los indicadores de subalimentación e inseguridad alimentaria que calcula la FAO están basados en metodologías diferentes, que se supone que identificarían a aquellas personas que no consumen la cantidad mínima de calorías necesarias para sostener el metabolismo basal y un nivel mínimo de actividades, o bien estima las personas que no tienen acceso a alimentos nutritivos y suficientes por falta de recursos económicos o de otro tipo. Finalmente, los indicadores antropométricos (como peso relacionado con altura y edad, mencionados en el Capítulo I), de mortalidad/morbilidad (también presentados en el mismo capítulo), o de adecuación de la ingesta de vitaminas, minerales, proteínas, y similares (temas no cubiertos acá6), son en general guías más precisas de la situación alimentaria de la población.

Si el objetivo fuera entonces poner a toda la población por encima de la línea de indigencia (como manera de asegurar que todos tienen le ingreso mínimo para comprar la canasta alimentaria básica en energía), las preguntas son a) cuál es porcentaje de población por debajo de la línea de indigencia (el capítulo I menciona que es el $7.1 \%$ ); y b) cuál es la "brecha de pobreza" (es decir la distancia que le fata al ingreso del indigente para llegar al valor de la línea de indigencia. La respuesta a

${ }^{6} \mathrm{Al}$ respecto se pueden ver datos en Enrique O. Abeyá Gilardon (2016). También puede consultarse a Britos y Borg (2017). 
esas dos preguntas debería compararse con la cobertura actual (que como se vio en el Capítulo II deja a aproximadamente un $19 \%$ del decil más pobre sin cobertura, mientras que hay cobertura en varios de los deciles más altos) y con el valor de la prestación (que también se mencionó que un $31.4 \%$ de la canasta básica alimentaria de una familia de cuatro miembros). Por otra parte, si el objetivo fuera cubrir solamente a niños/as y adolescentes, habría que hacer el mismo ejercicio, pero notando que el porcentaje de indigencia entre 0 y 17 años en el primer semestre de 2019 se estimó en el $17.1 \%$.

En este sentido, la Tarjeta Alimentar, en el marco del Plan Argentina contra el Hambre (PACH), no expande la cobertura (ya que se entrega a familias que reciben el $A U H$ ), pero para los que la reciben significa una reducción de la brecha respecto de la línea de indigencia (o quizás su eliminación; los datos del Banco Mundial, antes de la pandemia, mostraban una brecha de pobreza con la línea de 1.9 dólares PPP/día/persona de menos del 1\%). Pero el PACH enfatiza también el derecho a la buena alimentación, lo que es más amplio que el acceso al nivel básico de calorías y requeriría considerar los tres problemas de malnutrición mencionados, incluyendo no solamente la carencia de calorías, sino también la falta de minerales, vitaminas, y otros nutrientes básicos, y los problemas de sobrepeso y obesidad. Esto requiere especificar con mayor detalle el alcance de esos problemas, los grupos afectados, y los objetivos que se esperan obtener con el PACH, indicando también si ellos abarcan a toda la población, o a un subconjunto de la misma.

Todo ello implica que si el problema es la calidad de la dieta y el acceso a dietas saludables se requerirían varias acciones, incluyendo al menos a) mejorar en forma sustantiva y sostenible la consistencia entre las guías alimentarias (GAPA) y las respuestas gubernamentales; b) estrategias efectivas para la educación alimentaria, que hagan uso de herramientas modernas para la viralización de mensajes y que estos sean lo más concretos posibles (por ejemplo: recetas y buenas prácticas para el mejor aprovechamiento de alimentos) y c) implementación de estrategias efectivas de etiquetado frontal de alimentos y evaluación de su impacto en la mejoría de calidad de dieta a través de indicadores reconocidos por la evidencia científica.

La PACH considera otros objetivos relacionados con a) madres embarazadas (a partir de los 3 meses) y familias con niños y niñas de hasta 6 años, mujeres embarazadas y b) prestaciones alimentarias (incluyendo comedores escolares), que están cubiertos por otros programas e instrumentos, discutidos en los capítulos III y IV. Algunos de los temas a considerar incluyen:

i. una mejor definición de los objetivos y operaciones de los programas de los Ministerios de Salud y de Desarrollo Social en lo que hace a los programas alimentarios en la primera infancia (consistencia con las guías alimentarias infantiles).

ii. el programa de leche fortificada y su relación y articulación con la necesaria y urgente promoción efectiva de la lactancia materna

iii. la cobertura y calidad de la dieta de los comedores escolares y comunitarios.

Finalmente, la PACH considera el tema de la producción de alimentos, y el capítulo IV menciona los programas de apoyo a pequeños productores especialmente. Uno de los aspectos por analizar es la definición de expectativas de producción por productos y regiones, basándose en la experiencia de programas como el ProHuerta y los Programas Especiales del MAGyP. Los datos del nuevo censo pueden ser útiles para identificar las zonas y tipos de productores que requerirían atención prioritaria, considerando, como se menciona en el Capítulo IV, la existencia de zonas que pueden carecer de una oferta adecuada local de alimentos frescos y nutritivos.

En todo caso, parece necesario tratar de delimitar el ámbito de las intervenciones para no poner esfuerzos en múltiples direcciones que si bien necesarias, pueden hacer que el programa finalmente acordado sea muy difícil de manejar. 


\section{Programas e instrumentos del Programa}

Una pregunta central es si, aun considerando la pandemia, el instrumento central sigue siendo la Tarjeta Alimentar, con su articulación con la $\mathrm{AUH}$, o si debiera considerarse la posibilidad de otro instrumento, como por ejemplo un ingreso básico universal (IBU). Acá, sin descartar la segunda opción, nos centramos en la tarjeta, su fortalecimiento, y las mejoras en sus impactos en seguridad alimentaria y nutrición. Esto requeriría:

- Revisión de las complementariedades con el programa Asignación Universal por Hijo, con foco en los retos en las zonas rurales en relación a posibles brechas de cobertura y barreras de uso efectivos.

- Priorización de beneficiarios de la Tarjeta bajo un enfoque territorial y grupos vulnerables (partiendo sobre la base de los instrumentos de focalización existentes, incluyendo el ANSES, y complementando con análisis adicionales, incluyendo explorar la implementación de un Índice de Pobreza Multidimensional -IPM-) según niveles de pobreza y nutrición al menos (a pesar de los desafíos de datos disponibles).

- Mejoras en los niveles de beneficios, ampliación de la cobertura (considerando que un porcentaje de los deciles más bajos aún no está cubierto), y mejoras en la focalización (para evitar los deslizamientos hacia deciles de mayores ingresos, mencionados en el Capítulo II).

- Promoción de actividades para garantizar el acceso a una dieta saludable a través de la Tarjeta Alimentara, mejorando sensiblemente las acciones de educación alimentaria y la formación de promotores comunitarios del Plan como agentes de cambio hacia una nutrición más saludable.

En este sentido hay que homogeneizar el discurso, los objetivos y las operaciones de los programas, reconociendo que es necesario responder a un triple problema de malnutrición (problemas por déficit, exceso y monotonía dietaria).

Un segundo programa a considerar (en apoyo al Ministerio de Desarrollo Social) es la mejora de la producción y comercialización de alimentos economía solidaria, social y popular, el cooperativismo y la agricultura familiar. Para ello se requiere considerar lo siguiente:

- El fortalecimiento de las capacidades de las organizaciones de la agricultura familiar en lo que hace a los procesos de producción, organización, e inocuidad para aumentar la oferta de los alimentos saludables y vincularlas a los procesos de compras públicas para comedores escolares y para facilitar que la producción de sus alimentos provea de forma mayoritaria a la demanda de la Tarjeta Alimentar. Se necesitan mejoras de la capacidad organizativa, financiamiento, cumplimiento de certificaciones y requerimientos vinculados a la Tarjeta, y del aumento sostenible de producción de alimentos saludables y mayor rentabilidad económica.

Un tercer tema (en apoyo al Ministerio de Agricultura, especialmente la Secretaria de Agricultura Familiar y el INTA, en estrecha coordinación con la Secretaria de Economía Social del Ministerio de Desarrollo Social) es armar un programa para la erradicación del hambre, la pobreza y la malnutrición en territorios rezagados de Argentina. Esto requiere considerar diferentes aspectos:

- Identificación de territorios, establecimiento de criterios para la selección y promoción de diálogo y consulta entre actores de distintos sectores y niveles (nacional, provincial y territorial). 
- Apoyar la coordinación entre los Ministerios de Agricultura, Desarrollo Social y otros, en la definición conjunta de una estrategia que ayude a transitar de la protección a la promoción, y cuyos detalles se definen la implementación de la estrategia a nivel territorial.

- Desarrollo de planes de inversión para solucionar los problemas prioritarios identificados, incluyendo un plan de inversiones en infraestructura (caminos rurales, conectividad, electricidad agua y otros) en apoyo de centros poblacionales rurales. Esto debe hacerse promoviendo espacios de diálogo entre los actores para caracterizar la potencialidad económica del territorio- incluyendo la identificación de "nichos" productivos y sus respectivos mercados-, que no solo permitan garantizar niveles básicos de subsistencia, sino para crear mejores oportunidades económicas de desarrollo, identificar cuellos de botella y diseñar soluciones para vincular a esas economías a los mercados.

Un cuarto programa a considerar es el desarrollo de entornos alimentarios saludables (en apoyo especialmente del Ministerio de Salud, en coordinación con Ministerio de la Producción y el Ministerio de Agricultura). Esto requiere:

- la integración de diferentes instrumentos con distinto grado de avance en su diseño o implementación. Nos referimos al análisis de competitividad de cadenas productivas y a la expansión de la oferta suficiente y diversa de alimentos buen perfil nutricional (alimentos a promover); el acceso económico a estos alimentos, la puesta en marcha y empoderamiento para un buen uso del etiquetado frontal y la ley de góndolas en supermercados.

\section{Organización y gobernanza de los programas}

Estos temas implican especialmente el trabajo de la Jefatura de Gabinete y el Consejo de DesarroIlo Social, en la generación de instrumentos y capacidades para el monitoreo implementación del Plan a corto y largo plazo, y para el diseño de los incentivos/presupuestos/inversiones necesarias para la coordinación intersectorial y niveles federal/provincial. Debe haber especial énfasis en los mecanismos de incentivos de coordinación a nivel territorial.

En particular, vale la pena notar en este tema los diferentes enfoques que se han tomado a lo largo del tiempo en Argentina para "coordinar," "articular" u otros conceptos similares la variedad de políticas sociales. Por ejemplo, Repetto (2010) indica que se han identificado "tres expresiones asociadas, de modos diversos, a intentos de conformar Autoridad Social en este nivel de gobierno: a) una serie de intentos por consolidar la oferta de programas focalizados a cargo del Estado Nacional, destacando los planes sociales presentados en 1993 y en 1995, así como las propuestas efectuadas por la Jefatura de Gabinete de Ministros, tanto en la gestión de Menem (en 1996), como en la gestión de De la Rúa (en 2000); b) la creación de una instancia que además de intentar ejercer autoridad ejecutaba o ejecutaría programas (Secretaría de Desarrollo Social en 1995 y Ministerio de Seguridad Social en el marco del debate sobre la construcción de una Agencia Social en el 2001; y c) la puesta en marcha formal del Gabinete Social (a partir de 1997) y su reemplazo por el Consejo Nacional de Coordinación de Políticas Sociales (en el 2002)." Sin embargo, las diferentes experiencias no parecen haber resuelto el tema de la coordinación o articulación de programas sociales.

Parte de los problemas tienen que ver con el uso o de planes generales (sin objetivos cuantitativos e instrumentos definidos), o de enfoques organizativos (simplemente cambiando o reasignando funciones en organigramas), cuando lo que se requiere son mecanismos de programación y coordinación orientados a la acción y resultados. A su vez, esto requiere la confección de padrones únicos de personas atendidas por los diferentes programas, junto con mecanismos de monitoreo desde las propias familias y personas participantes. 
Se parte del supuesto básico que los problemas de funcionamiento no se resuelven necesariamente con cambios organizativos y de funciones, sino que requieren fundamentalmente una implementación disciplinadamente del ciclo de Programación, Ejecución y Control (PEC).

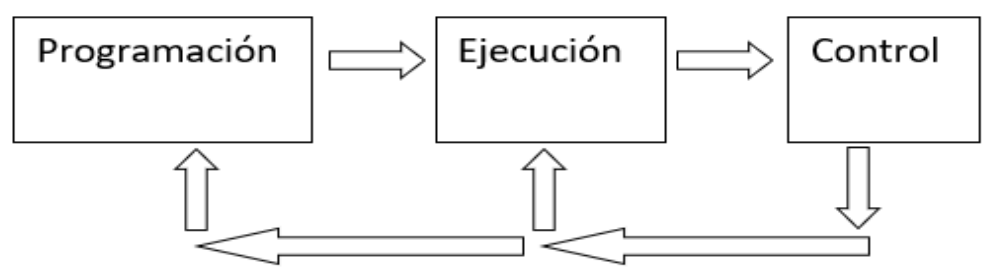

Este ciclo tiene como componentes un mecanismo obligatorio de programación y coordinación (al menos anual), orientado a la acción y resultados, y de control de ejecución (al menos semestral) y con un sistema de monitoreo usando sistemas digitales con las familias participantes. No se requerirían nuevas instituciones o burocracia que se sumen a la complejidad actual, sino que se basan en el uso operacional y programático de recursos e instituciones existentes. Ese centro coordinador/operacional dentro del gobierno argentino sería la Jefatura de Gabinete (por el manejo presupuestario), que debe llevar a una programación presupuestaria y operacional (con metas concretas y verificables).

\section{Estadísticas, sistemas de información, y monitoreo y evaluación}

Lo anterior requiere sistemas de información y estadísticas adecuados, incluyendo, su adecuado y preciso geo-referenciamiento a nivel territorial, para poder llevar adelante las tareas fundamentales de monitoreo y evaluación. Como se mencionó, se necesita un registro integrado de familias participantes, que permitan hacer un seguimiento de los diferentes programas en los que participan y puedan ir recolectando los bienes y servicios recibidos, así como los cambios en ingresos, consumo, dietas, indicadores de salud y otras variables relevantes.

Esta información debería integrar los datos del Ministerio de Salud sobre mediciones antropométricas y el desarrollo de controles de salud (que se realizan en la red de CAPS y en el Programa de Salud Escolar (PROSANE), que anualmente realiza el control a niños de primero y sexto grados), mejorando una cobertura que es heterogénea entre localidades. Esa información debería traducirse en diagnósticos y visiones compartidas, que informen las actividades de los diferentes ministerios y agencias.

Por otra parte, está la información de las encuestas, tales como las de factores de riesgo (ENFR), de nutrición y salud (ENNyS), y las del INDEC sobre pobreza e indigencia y gasto de los hogares. Esto permite caracterizar mejor la situación general, pero no asegura el cruce de información sobre las familias y personas participantes de los diferentes programas, que es la manera más directa para el monitoreo y evaluación de los mismos.

Solamente con información adecuada se podrán diseñar, ejecutar, monitorear y evaluar programas que permitan eliminar los problemas de hambre y malnutrición en la Argentina.

\section{BIBLIOGRAFÍA}

Abeyá Gilardon, Enrique (2016) Una evaluación crítica de los programas alimentarios en Argentina. Salud Colectiva, VOL. 12 NúM. 4 (2016). Diciembre 19, 2016

Britos S. Borg A. (2017). Consumo de alimentos fuente de micronutrientes en la población argentina: adecuación a las recomendaciones de las nuevas guías alimentarias; Diaeta (Buenos Aires) 2017; 35(159):25-31 
Díaz-Bonilla, E. (2017). Instituciones, crecimiento y desarrollo económico en Argentina. En Los desafíos del Bicentenario: Argentina 1816-2016, Gobierno de Tucumán. Tomo II: Perspectivas en crecimiento y desarrollo económico: Estado, gestión, y políticas públicas, Capítulo 1.1, Pp 5-26. http://cdm15738.contentdm.oclc.org/cdm/ref/collection/p15738coll5/id/6329

FAO, IFAD, UNICEF, WFP and WHO. 2020. The State of Food Security and Nutrition in the World 2020. Transforming food systems for affordable healthy diets. Rome, FAO.

Repetto, F. (2010). Argentina: aspectos político-institucionales que dificultan la construcción de una autoridad social. En Rolando Franco y Miguel Székely (2010). Institucionalidad social en América Latina. CEPAL y UNFPA. 


\section{CAPITULO I. INDICADORES DE PROBREZA Y RIESGOS ALIMENTARIOS ANTES DE LA PANDEMIA}

lanina Tuñón y Santiago Poy

\section{INTRODUCCION}

El diagnóstico que se realiza, a continuación, procura visibilizar la magnitud y evolución de la problemática de la pobreza infantil en el país antes de la pandemia actual, que suele quedar oculta en los promedios poblacionales y reducida a medidas indirectas de pobreza monetaria. Sin duda, las condiciones materiales de vida de los hogares con niños/as es un indicador clave en perspectiva del desarrollo humano de las infancias, pero resulta insuficiente para representar el estado de bienestar y pleno ejercicio de derechos fundamentales como la seguridad alimentaria que se constituye en un derecho habilitante en términos del ejercicio de otros tantos como el derecho a la salud y la educación. En este sentido, algunas de las políticas públicas más destacadas de la última década han estado orientadas a esta población en términos de transferencias de ingresos condicionadas como la Asignación Universal por Hijo (AUH), a la que se ha sumado más recientemente la Tarjeta Alimentar. ${ }^{7}$ Sin embargo, el monitoreo y evaluación de las condiciones de vida de las infancias requiere de mayor integralidad en sus indicadores, y seguimiento en el tiempo, con el objetivo de lograr una mejor definición de los problemas que sufren las infancias y abordar soluciones de política pública más efectivas en términos de sus resultados.

Es así que en esta primera sección se describe el comportamiento de distintos indicadores socioeconómicos y socioalimentarios, en el período 2010-2019 en la Argentina, poniendo énfasis en la situación de niños/as y adolescentes menores de 18 años. Los indicadores analizados se organizan en torno a tres ejes: 1) las condiciones de vida, para lo cual se emplean indicadores de pobreza e indigencia; 2) la seguridad alimentaria, examinando la prevalencia de inseguridad alimentaria y la cobertura de asistencia alimentaria; 3) la salud y la nutrición infantil, tomando en consideración indicadores de salud, nutrición y antropometría entre niños/as y adolescentes.

Los indicadores presentados fueron construidos a partir de fuentes estadísticas oficiales, como la Encuesta Permanente de Hogares (EPH) del Instituto Nacional de Estadística y Censos (INDEC), la Encuesta Nacional de Nutrición y Salud (ENNYS) o los registros de la Dirección de Estadísticas e Información de Salud (DEIS) del Ministerio de Salud de la Nación, y de los microdatos de la Encuesta de la Deuda Social Argentina (EDSA) del Observatorio de la Deuda Social Argentina.

\footnotetext{
${ }^{7}$ Los desarrollos posteriores a la emergencia de la pandemia relacionado con el COVID-19 se discuten en el capítulo V.
} 


\section{POBREZA Y POBREZA EXTREMA}

En la Argentina, la metodología oficial para la medición de la pobreza adopta el enfoque "indirecto" de acuerdo con el cual se comparan los ingresos familiares -normalizados según una escala de unidades de consumo equivalente - con el valor monetario de una Canasta Básica Alimentaria (Iínea de indigencia o pobreza extrema) o una Canasta Básica Total o ampliada (línea de pobreza). En la actualidad, el INDEC mide la pobreza y la indigencia a partir de la EPH para la población urbana que reside en aglomerados de 100 mil habitantes y más (alrededor del $62 \%$ de la población total del país). La medición de la pobreza y la indigencia se reporta de manera semestral ${ }^{8}$.

Entre 2010 y 2019, la economía argentina atravesó distintas etapas de política económica y laboral en un contexto internacional volátil. De acuerdo con datos oficiales del INDEC, el Producto Interno Bruto (PIB) creció $2,1 \%$ en toda la década, en tanto que la población se incrementó $10,2 \%$, lo que implicó una retracción del PIB per cápita. Al contexto de estancamiento económico se añade un ciclo de alza sostenida de la tasa de inflación que, en 2019, alcanzó el 53,8\%. En este marco, durante el primer semestre de 2019 , la indigencia afectó al 7,1\% de las personas y la pobreza al $34,5 \%$. Mientras que la indigencia se mantuvo estable entre puntas del período (era 7,3\% en 2010), la pobreza se incrementó (era $30,2 \%$ en 2010). Este empeoramiento es más significativo si se considera la evolución posterior a la crisis de 2018: la indigencia se incrementó de 4,2\% a 7,1\% entre el segundo semestre de 2017 y el primero de 2019 (2,9pp.) y la pobreza pasó de 23,9\% a 34,5\% un aumento de 10,6 pp.- en el mismo lapso (Cuadro 1).

Una característica de la pobreza y de la indigencia en la Argentina es la sobrerrepresentación que adquieren en la infancia y la adolescencia. En el primer semestre de 2019, el 12,7\% de los niños/as y adolescentes de 0 a 17 años vivían en hogares con ingresos bajo la línea de indigencia -frente a una tasa general de 7,1\%-, situación acentuada entre los de 5 a 12 años (13,7\%). Por otra parte, $52,5 \%$ de los niños/as y adolescentes vivían en hogares pobres (frente a una tasa general del $34,5 \%$ ) -la cifra más elevada de toda la década-, dando cuenta de las particulares dificultades que enfrentan los hogares con niños/as para afrontar el contexto macroeconómico y de las debilidades de los sistemas compensatorios de transferencias monetarias directas. En este caso, también el grupo de 5 a 12 años presentaba las mayores tasas de pobreza por ingresos.

\footnotetext{
${ }^{8}$ La reanudación de la publicación oficial de cifras de pobreza e indigencia a partir de 2016 involucró una revisión integral de los diferentes insumos que se emplean en su medición. Los investigadores que deseen construir series de pobreza e indigencia que abarquen el período anterior a 2016 deben adoptar decisiones que favorezcan la comparabilidad de las estimaciones. Se presenta aquí una recons trucción de la serie para el período 2010-2015 de acuerdo con el procedimiento detallado en Poy (2018).
} 
Cuadro 1. Incidencia de la indigencia y la pobreza(a). Total de aglomerados urbanos, 2010-2019 (en porcentajes).

\begin{tabular}{|c|c|c|c|c|c|c|c|c|c|c|c|c|c|c|c|c|c|c|c|}
\hline & & \multicolumn{2}{|c|}{2010} & \multicolumn{2}{|l|}{2011} & \multicolumn{2}{|l|}{2012} & 2013 & \multicolumn{2}{|c|}{2014} & \multicolumn{2}{|c|}{2015} & \multicolumn{2}{|c|}{2016} & \multirow{2}{*}{$\begin{array}{c}2017 \\
1 \\
\end{array}$} & \multicolumn{2}{|c|}{2018} & \multicolumn{2}{|c|}{2019} \\
\hline & & I & II & I & II & I & II & I & II & I & II & 1 & 1 & II & & II & I & II & I \\
\hline \multirow{2}{*}{$\frac{\bar{\pi}}{\stackrel{0}{0}}$} & Pobreza & 30,2 & 29,4 & 27,1 & 25,0 & 25,0 & 24,5 & 24,7 & 24,2 & 27,4 & 29,4 & 27,1 & 31,5 & 28,3 & 27,5 & 23,9 & 26,1 & 31,0 & 34,5 \\
\hline & Indigencia & 7,3 & 6,9 & 6,4 & 5,6 & 5,9 & 5,5 & 5,1 & 5,4 & 6,4 & 6,2 & 5,2 & 5,6 & 5,5 & 5,9 & 4,2 & 4,3 & 6,0 & 7,1 \\
\hline \multirow{2}{*}{$\begin{array}{l}\tilde{\sigma} \\
\tilde{\sigma} \\
0\end{array}$} & Pobreza & 45,9 & 44,7 & 41,9 & 38,6 & 39,3 & 38,2 & 38,8 & 38,0 & 41,8 & 44,2 & 41,1 & 48,1 & 44,5 & 43,0 & 38,3 & 41,6 & 47,8 & 52,5 \\
\hline & Indigencia & 12,5 & 11,8 & 11,0 & 9,4 & 10,0 & 9,5 & 8,6 & 9,1 & 10,6 & 10,4 & 8,6 & 9,1 & 9,4 & 10,6 & 7,4 & 7,6 & 10,5 & 12,7 \\
\hline \multirow{2}{*}{$\begin{array}{l}\text { \% } \\
\text { ग }\end{array}$} & Pobreza & 39,0 & 40,3 & 36,2 & 32,3 & 34,3 & 34,5 & 34,1 & 33,4 & 37,0 & 39,9 & 37,2 & 45,7 & 41,9 & 40,1 & 35,2 & 37,5 & 46,0 & 50,0 \\
\hline & Indigencia & 10,7 & 10,3 & 8,7 & 6,9 & 7,8 & 9,0 & 7,1 & 8,6 & 8,8 & 8,9 & 7,9 & 8,0 & 8,3 & 10,4 & 7,0 & 7,1 & 10,1 & 11,5 \\
\hline \multirow{4}{*}{ 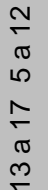 } & Pobreza & 47,6 & 45,4 & 42,7 & 39,5 & 40,4 & 39,0 & 40,2 & 38,7 & 42,4 & 44,4 & 41,9 & 48,1 & 44,8 & 44,0 & 39,0 & 43,4 & 47,9 & 54,0 \\
\hline & Indigencia & 12,8 & 11,5 & 11,4 & 9,5 & 10,6 & 10,1 & 8,9 & 9,0 & 11,0 & 10,8 & 8,6 & 9,6 & 9,6 & 11,1 & 7,7 & 7,9 & 10,6 & 13,7 \\
\hline & Pobreza & 49,6 & 47,7 & 46,2 & 43,2 & 42,3 & 40,4 & 41,0 & 41,1 & 45,4 & 48,0 & 43,3 & 50,2 & 46,3 & 44,2 & 40,2 & 42,4 & 49,3 & 52,5 \\
\hline & Indigencia & 13,8 & 13,6 & 12,7 & 11,8 & 11,0 & 9,0 & 9,6 & 9,8 & 11,7 & 11,2 & 9,3 & 9,2 & 10,1 & 10,1 & 7,1 & 7,8 & 10,8 & 12,1 \\
\hline
\end{tabular}

(a) Se presenta una reconstrucción de la incidencia de la pobreza a partir de microdatos de la Encuesta Permanente de Hogares para el período 2010-2015 y, desde entonces, la serie oficial del INDEC. La reconstrucción tuvo en cuenta una homogeneización del método de imputación de ingresos no declarados y la estructura de la Canasta Básica Total (CBT) y Canasta Básica Alimentaria (CBA) informada en el documento Metodología 22 de INDEC (2016). Una explicación detallada de la metodología implementada se encuentra en Poy (2018). La serie fue empalmada para que se adecue a la serie oficial del INDEC desde 2016.

Fuente: elaboración propia a partir de microdatos de la EPH-INDEC.

En materia de pobreza e indigencia infantil, se advierten algunos contrastes regionales que caracterizan al país. En ambos indicadores las infancias de las provincias que componen la región Noreste experimentan las mayores privaciones socioeconómicas $(58,5 \%$ de pobreza y $11 \%$ de indigencia). En contrapartida, las infancias y adolescencias de las provincias patagónicas son las más protegidas $(40,1 \%$ y $6,3 \%)$. Las infancias de las regiones del centro y el oeste del país (Gran Buenos Aires, Pampeana, Cuyo y Noroeste) presentan niveles similares al promedio nacional de privaciones en materia de pobreza e indigencia por ingresos.

\section{INSEGURIDAD ALIMENTARIA}

Desde el año 2010, la Encuesta de la Deuda Social Argentina (EDSA), mide la inseguridad alimentaria a través de un índice que computa la cantidad de respuestas afirmativas de una escala de seis preguntas que refieren a aspectos subjetivos y objetivos respecto de una ventana temporal de referencia de los últimos 12 meses $^{9}$. Esta escala permite ubicar la situación alimentaria del hogar en un rango que va desde una situación de inseguridad alimentaria grave o severa hasta la seguridad alimentaria (Tuñón et al., 2012; Tuñón y Poy, 2018). En este sentido, el indicador de inseguridad alimentaria expresa la reducción involuntaria de la porción de comida y/o la percepción de ex-

\footnotetext{
${ }^{9}$ Las preguntas que se realizan en la EDSA son: ¿En los últimos 12 meses, alguna vez se quedaron sin dinero o recursos para obtener una alimentación sana y variada? ¿En los últimos 12 meses, por falta de dinero o recursos alguna vez usted u otro adulto del hogar dejó de desayunar, almorzar o cenar? ¿Disminuyeron usted u otro adulto en su hogar la porción de alguna de sus comidas porque no hubo suficiente dinero para comprar alimentos? En los últimos 12 meses, disminuyó la porción de alguna de las comidas de los niños/as $(0$ a 17 años) de su hogar porque no hubo suficiente dinero para comprar alimentos? En los últimos 12 meses, tuvieron alguna vez hambre los niños/as ( 0 a 17 años) porque no pudieron comprar suficiente comida?
} 
periencias de hambre por problemas económicos. En particular, los hogares clasificados en situación severa son aquellos en los cuales alguno de los adultos o niños/as experimentó "hambre" por problemas económicos durante los últimos 12 meses. ${ }^{10}$

De manera complementaria al análisis de la situación de inseguridad alimentaria, se evalúa el acceso a la asistencia alimentaria directa por parte de las infancias y adolescencias. Se trata de indicadores que consideran si los niños/as y adolescentes reciben algún tipo de alimentación gratuita directa como copa de leche, refrigerio, almuerzo o merienda en comedores, en la escuela u otros espacios públicos o privados. Resulta pertinente evaluar en qué medida la situación de inseguridad alimentaria a nivel de los hogares es acompañada por la cobertura de sistemas públicos o privados de asistencia.

Cuadro 2. Inseguridad alimentaria y asistencia alimentaria. Total de aglomerados urbanos, 2010-2019(a) (en porcentajes).

\begin{tabular}{|c|c|c|c|c|c|c|c|c|c|c|c|}
\hline & & 2010 & 2011 & 2012 & 2013 & 2014 & 2015 & 2016 & 2017 & 2018 & 2019 \\
\hline \multirow{2}{*}{$\begin{array}{l}\frac{\pi}{0} \\
\stackrel{0}{\circ}\end{array}$} & Inseguridad alimentaria & 15,6 & 13,0 & 13,7 & 14,5 & 15,6 & 14,6 & 15,0 & 15,3 & 20,2 & 22,1 \\
\hline & Inseguridad alimentaria severa & 7,3 & 6,2 & 6,5 & 6,6 & 6,2 & 5,8 & 6,3 & 6,0 & 7,9 & 9,3 \\
\hline \multirow{3}{*}{$\begin{array}{l}\tilde{\sigma} \\
\tilde{\sigma} \\
0\end{array}$} & Inseguridad alimentaria & 21,8 & 18,3 & 19,9 & 20,1 & 21,8 & 20,3 & 21,5 & 21,7 & 29,3 & 30,2 \\
\hline & Inseguridad alimentaria severa & 11,2 & 9,5 & 10,1 & 10,2 & 8,6 & 8,9 & 9,7 & 9,6 & 13,0 & 14,2 \\
\hline & Recibe asistencia alimentaria & 26,1 & 23,5 & 23,2 & 25,0 & 29,3 & 28,5 & 29,7 & 33,8 & 34,9 & 39,9 \\
\hline \multirow{3}{*}{ 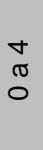 } & Inseguridad alimentaria & 20,8 & 20,0 & 18,5 & 16,4 & 19,5 & 21,1 & 23,0 & 22,4 & 31,0 & 30,0 \\
\hline & Inseguridad alimentaria severa & 8,4 & 9,7 & 7,0 & 7,5 & 7,1 & 7,8 & 8,3 & 10,0 & 12,9 & 12,1 \\
\hline & Recibe asistencia alimentaria & 15,0 & 13,6 & 12,7 & 12,8 & 17,3 & 17,6 & 17,9 & 21,1 & 26,8 & 24,8 \\
\hline \multirow{3}{*}{$\frac{\stackrel{N}{\sigma}}{\sim}$} & Inseguridad alimentaria & 22,3 & 18,6 & 19,3 & 20,7 & 22,4 & 19,6 & 20,7 & 21,3 & 29,9 & 31,6 \\
\hline & Inseguridad alimentaria severa & 11,6 & 10,2 & 11,0 & 11,3 & 8,2 & 9,3 & 10,6 & 8,8 & 13,9 & 15,3 \\
\hline & Recibe asistencia alimentaria & 39,6 & 34,5 & 33,1 & 35,7 & 43,1 & 41,7 & 44,2 & 47,7 & 45,9 & 55,2 \\
\hline \multirow{3}{*}{$\begin{array}{l}\hat{\sigma} \\
\tilde{\sigma} \\
\stackrel{m}{\sigma}\end{array}$} & Inseguridad alimentaria & 21,9 & 16,2 & 22,1 & 22,6 & 22,9 & 20,7 & 21,1 & 21,7 & 26,7 & 28,2 \\
\hline & Inseguridad alimentaria severa & 13,7 & 8,2 & 12,2 & 11,2 & 10,9 & 9,3 & 9,8 & 10,3 & 11,9 & 14,4 \\
\hline & Recibe asistencia alimentaria & 17,2 & 16,5 & 18,7 & 20,5 & 20,4 & 18,9 & 19,2 & 24,8 & 25,6 & 31,1 \\
\hline
\end{tabular}

(a) En esta serie los valores de la EDSA-Bicentenario (2010-2016) se estiman a partir de aplicar un coeficiente de empalme que toma como parámetro la EDSA-APE completa (2017) a nivel de cada indicador y sus diferentes categorías y/o aperturas. Este coeficiente se aplica una vez estimados los resultados generados por la parte muestra EDSA-APE comparable (2017) conformada por los puntos de muestra solapados con la EDSA-Bicentenario (2017).

Fuente: EDSA- Bicentenario (2010-2016) - EDSA-Agenda para la equidad (2017-2025), Observatorio de la Deuda Social Argentina, UCA.

La incidencia de la inseguridad alimentaria a nivel urbano siguió una pauta consistente con la evolución de la pobreza monetaria y la indigencia. Entre 2010 y 2019 se incrementaron la inseguridad alimentaria severa y total $(7,3 \%$ a $9,3 \%$ y $15,6 \%$ a $22,1 \%$, respectivamente) a nivel del conjunto de la población. En particular, se verificó un significativo incremento de la inseguridad alimentaria en el bienio 2018-2019 en comparación con los años precedentes: en su umbral total, se incrementó de $15,3 \%$ a $20,2 \%$ entre 2017 y 2018 y alcanzó $22,1 \%$ en 2019 (6,8 pp.); mientras la inseguridad severa pasó de $6 \%$ a $7,9 \%$ y $9,3 \%$ en el mismo lapso (3,3 pp.).

Al igual que en el caso de los indicadores socioeconómicos habituales, la población de niños/as y adolescentes tiene una mayor propensión relativa a experimentar estas privaciones que el promedio. En 2019, 30,2\% de los niños/as y adolescentes residían en hogares en los que se había redu-

\footnotetext{
${ }^{10}$ Ver también la Introducción con las referencias sobre el desempeño de Argentina en relación con la Agenda de Desarrollo Sostenible para el año 2030, y el Objetivo 2, denominado "Hambre Cero."
} 
cido la porción de comida involuntariamente y/o se había experimentado hambre por motivos económicos y $14,2 \%$ de las infancias experimentaban privaciones severas. En este caso, no se advierten diferencias sustantivas según los grupos de edad de los niños/as.

En este marco, se aprecia también una intensificación de la cobertura alimentaria de la infancia y la adolescencia a partir de diversos mecanismos. Entre 2010 y 2019, la proporción de niños/as y adolescentes que reciben asistencia alimentaria se incrementó significativamente de $26,1 \%$ a $39,9 \%$. Este aumento involucró a los distintos grupos de edad. Sin embargo, los niños/as de 5 a 12 años son quienes encuentran mayores niveles de cobertura alimentaria: en 2019, 55,2\% recibía alimentación gratuita, frente a $24,8 \%$ y $31,1 \%$ de los/as niños/as de 0 a 4 y de 13 a 17 años. La mayor propensión a tener cobertura alimentaria entre los niños/as de 5 a 12 obedece a la tasa de escolarización casi absoluta en esta subpoblación -en comparación con los otros grupos etarios- y a la consiguiente percepción de asistencia alimentaria en instituciones escolares.

Cabe considerar las heterogeneidades regionales que caracterizan a la Argentina en materia de riesgo crítico de inseguridad alimentaria $(10 \%$ de los hogares que tienen el puntaje más alto en la índice factorial que predice la inseguridad alimentaria). Se aborda a continuación el riesgo alimentario de las infancias de 0 a 4 años a nivel nacional, pudiendo distinguir la situación de distintas provincias y las desigualdades urbano-rurales. Esta aproximación se basa en la georreferenciación del riesgo de inseguridad alimentaria severa a nivel de radios censales para los hogares con niños/as de 0 a 4 años en el total del país (Márquez, 2017).

\section{Gráfico 1. Porcentaje de hogares con niños/as de 0 a 4 años en el $10 \%$ de los hoga-} res con riesgo crítico de inseguridad alimentaria. Total del país, 2010 (en porcentajes).

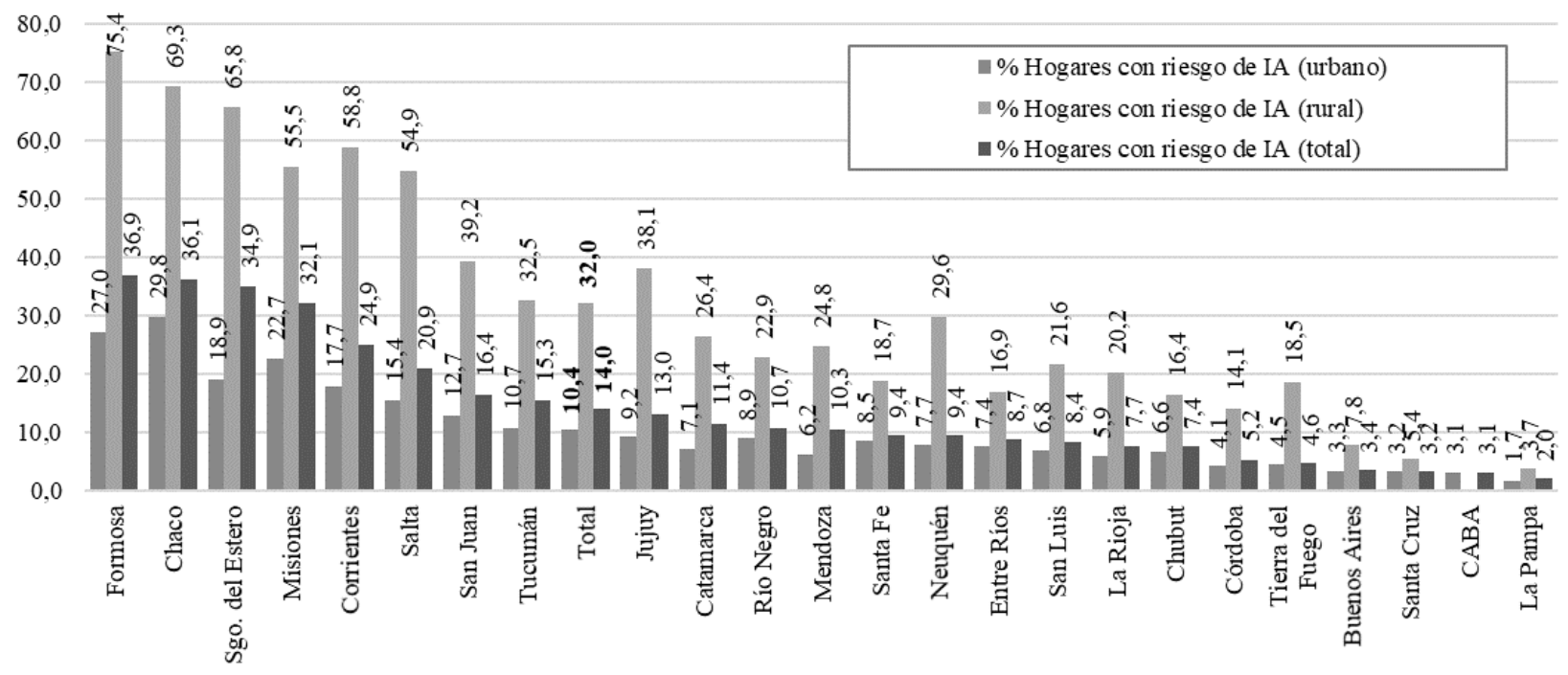

Fuente: elaboración propia en base a EDSA-Bicentenario (2010-2016), Observatorio de la Deuda Social Argentina, UCA y Censo Nacional de Población, Hogares y Vivienda 2010.

La probabilidad de experimentar riesgo crítico de inseguridad alimentaria se incrementa sensiblemente en entornos rurales en comparación con los urbanos (Gráfico 1). Mientras que a nivel nacional el $14 \%$ de los hogares experimentan riesgo crítico de inseguridad alimentaria, esta proporción es $32 \%$ entre los hogares rurales y $10,4 \%$ en los urbanos. Al clivaje urbano-rural-poco enfatizado en la Argentina debido a la ausencia de fuentes disponibles- se añaden significativas diferencias entre provincias. Los hogares con niños/as de 0 a 4 años de las provincias del Noreste argentino Formosa, Chaco, Santiago del Estero y Misiones- experimentan los mayores niveles de riesgo crítico de inseguridad alimentaria, con tasas que más que duplican el promedio nacional. En estas provincias, además, se aprecia el mayor riesgo que enfrentan los hogares que residen en entornos 
rurales con respecto al resto (con tasas que alcanzan el 75,4\% y el 69,3\% en Formosa y Chaco, respectivamente).

De manera complementaria, cabe señalar que la mayor concentración de niños/as y adolescentes en riesgo de inseguridad alimentaria se encuentra en las provincias con mayor densidad poblacional además de aquellas que presentan mayores niveles de riesgo. Así, las provincias de Buenos Aires, Misiones, Chaco, Santiago del Estero y Salta concentran las mayores cantidades de niños de 0 a 4 años en situación de riesgo crítico de inseguridad alimentaria. Se estima con base en el Censo de Poblaciones del 2010 del INDEC que alrededor de 265.499 hogares con niños/as de 0 a 4 años estarían en situación de riesgo crítico de inseguridad alimentaria en el país.

Gráfico 2. Número de niños/as de 0 a 4 años en el $10 \%$ de los hogares con riesgo crítico de inseguridad alimentaria. (en números absolutos).

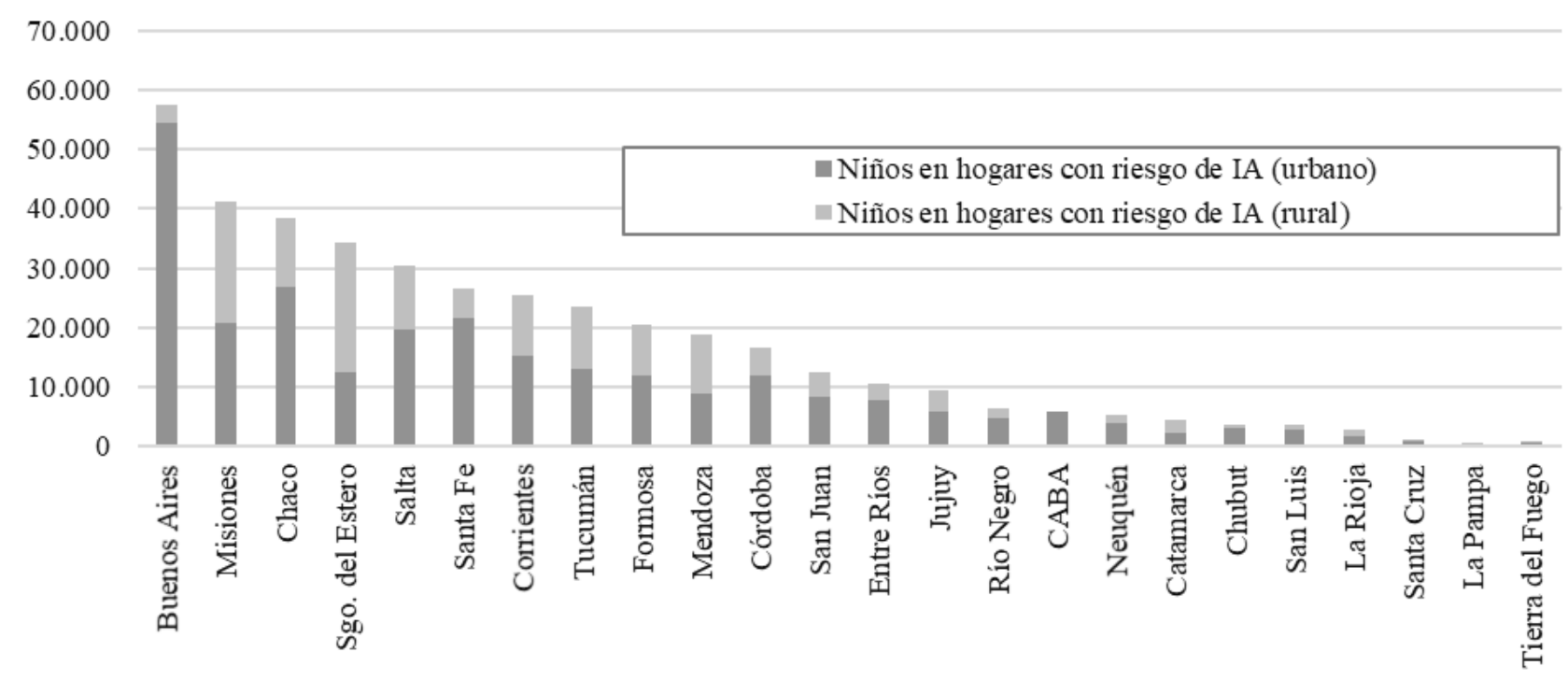

Fuente: elaboración propia en base a EDSA-Bicentenario (2010-2016), Observatorio de la Deuda Social Argentina, UCA y Censo Nacional de Población, Hogares y Vivienda 2010.

\section{SALUD Y NUTRICION INFANTIL}

La última dimensión considerada abarca indicadores de salud y nutrición en la infancia y la adolescencia. En primer lugar, se presenta información que surge de los registros recopilados por el Ministerio de Salud de la Nación a través de la Dirección de Estadísticas e Información de Salud (DEIS). En segundo lugar, se presentan indicadores de la Encuesta Nacional de Nutrición y Salud (ENNyS). La ENNyS es una encuesta representativa de individuos que residen en hogares particulares en localidades urbanas de 5.000 habitantes y más que se realizó entre 2018 y $2019^{11}$.

En los últimos años se registró una reducción sostenida de la tasa de mortalidad infantil, de 11,9\%o a 9,3\% entre 2010 y 2017 (último dato disponible). En el mismo lapso, se redujo también la tasa de mortalidad de niños/as de 1 a 4 años -de $0,5 \%$ a 0,4\%o-. A pesar de estos avances, las desigualdades regionales han persistido: la región Noreste continuó siendo la más desaventajada mientras

\footnotetext{
${ }^{11}$ La ENNyS surge de una muestra probabilística estratificada por región y polietápica en cuatro fases de selección aleatoria, con arreglo proporcional a la población. En la primera etapa se seleccionan aglomerados urbanos (conformados por ciudades y/o localidades); en la segunda, radios censales; en la tercera fase se seleccionan hogares y en la cuarta los miembros de cada hogar (Ministerio de Salud, 2019a).
} 
que la región Patagónica revela los mejores indicadores sociodemográficos. Los indicadores antropométricos se mantuvieron relativamente estables a lo largo del período. El porcentaje de nacidos vivos con muy bajo peso al nacer se mantuvo en $1,1 \%$ y el de aquellos con bajo peso tuvo una leve oscilación de 7,2\% a 7,3\%. En este último indicador, también se aprecia el peor desempeño relativo de la región Noreste, a la cual se añade la región Centro (en especial, la Provincia de Buenos Aires).

Cuadro 3. Indicadores de mortalidad y antropometría infantil. Argentina, 2010-20132017 (en porciento y por mil).

\begin{tabular}{|c|c|c|c|c|c|c|c|c|c|c|c|c|}
\hline & \multicolumn{4}{|c|}{2010} & \multicolumn{4}{|c|}{2013} & \multicolumn{4}{|c|}{2017} \\
\hline & 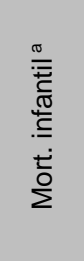 & 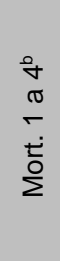 & 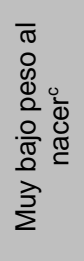 & 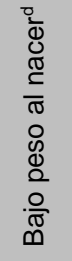 & 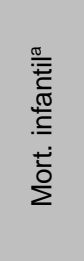 & 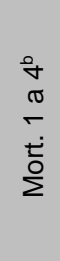 & 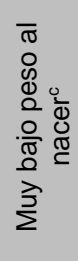 & 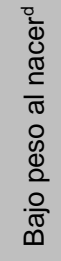 & 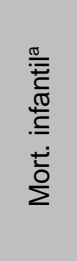 & 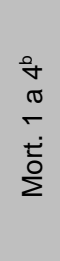 & 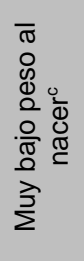 & 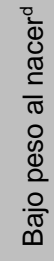 \\
\hline Total del país & 11,9 & 0,5 & 1,1 & 7,2 & 10,8 & 0,5 & 1,1 & 7,4 & 9,3 & 0,4 & 1,1 & 7,3 \\
\hline Centro & 11,2 & 0,5 & 1,1 & 7,4 & 10,4 & 0,4 & 1,2 & 7,7 & 9,1 & 0,4 & 1,1 & 7,6 \\
\hline Cuyo & 11,5 & 0,6 & 1,1 & 7,1 & 9,7 & 0,5 & 1,0 & 6,8 & 8,8 & 0,4 & 1,2 & 6,8 \\
\hline Noroeste & 13,7 & 0,6 & 1,1 & 6,9 & 12,7 & 0,5 & 1,2 & 6,9 & 10,2 & 0,5 & 1,2 & 6,9 \\
\hline Noreste & 15,2 & 0,7 & 0,9 & 7,3 & 12,4 & 0,6 & 1,1 & 7,4 & 11,3 & 0,5 & 1,1 & 7,5 \\
\hline Patagónica & 9,2 & 0,5 & 1,0 & 6,5 & 10,1 & 0,4 & 1,1 & 6,3 & 7,6 & 0,4 & 1,0 & 6,5 \\
\hline
\end{tabular}

Notas: (a) Cociente entre el número de muertes de menores de un año y el total de nacidos vivos, por mil. / (b) Cociente entre el número de muertes de menores de niños/as de 1 a 4 años y el total de niños/as de esa edad / (c) Porcentaje de nacidos vivos con peso inferior a 1.500 gramos / (d) Porcentaje de nacidos vivos con peso inferior a 2.500 gramos.

Fuente: elaboración propia a partir de Ministerio de Salud de la Nación (2013, 2015, 2019b).

A partir de la información de la ENNyS se aprecia que 1,7\% de los niños/as de 0 a 4 años presentan bajo peso, 1,6\% emaciación y 7,9\% baja talla. Mientras que los primeros dos indicadores no revelan diferencias estadísticamente significativas según quintil de ingresos familiares, los niños/as de los quintiles más desfavorecidos reportan una proporción de baja talla significativamente mayor que sus pares de los quintiles más ricos. Por otro lado, si se toman indicadores de malnutrición como el sobrepeso y la obesidad, se advierte que 13,6\% de los niños/as de 0 a 4 años padecen exceso de peso, sin que se verifiquen diferencias estadísticamente significativas según quintil de ingresos.

Por otra parte, entre la población de 5 a 17 años, el 1,4\% reporta delgadez y 3,7\% baja talla. En este grupo poblacional, el exceso de peso abarca a $41,1 \%$ de los niños/as y adolescentes. Mientras $20,7 \%$ tiene sobrepeso, 20,4\% presenta obesidad. Cabe apreciar que no se verifican diferencias estadísticamente significativas entre los niños/as y adolescentes de distintos quintiles de ingreso.

En el caso de los adultos de 18 años y más, las evidencias de malnutrición se amplían: más de dos tercios presentan exceso de peso $(67,9 \%)$, de los cuales un tercio $(33,9 \%)$ corresponde a obesidad. El nivel de ingresos familiares desempeña un papel estructurante de la prevalencia de exceso de peso, pues las personas de menores ingresos tienen mayores chances de experimentarla que las de menores ingresos. 
Cuadro 4. Indicadores antropométricos por grupo de edad, según quintil de ingreso normalizado (unidades de consumo equivalentes). Argentina, 2018-2019 (en porcentajes).

\begin{tabular}{|c|c|c|c|c|c|c|}
\hline 0 a 4 años (a) & Total & Q1 & Q2 & Q3 & Q4 & Q5 \\
\hline Bajo peso & 1,7 & 2,6 & 1,5 & 1,3 & 1,0 & 1,0 \\
\hline Emaciación & 1,6 & 1,3 & 1,2 & 1,2 & 2,0 & 2,6 \\
\hline Baja talla & 7,9 & 11,5 & 7,5 & 7,6 & 5,4 & 4,0 \\
\hline Sobrepeso & 10,0 & 8,8 & 8,4 & 15,4 & 10,2 & 8,9 \\
\hline Obesidad & 3,6 & 3,2 & 3,2 & 4,3 & 3,9 & 3,6 \\
\hline Exceso de peso (sobrepeso y obesidad) & 13,6 & 12,0 & 11,6 & 19,7 & 14,1 & 12,5 \\
\hline \multicolumn{7}{|l|}{5 a 17 años (b) } \\
\hline Delgadez & 1,4 & 1,6 & 0,9 & 1,2 & 2,4 & 0,7 \\
\hline Baja talla & 3,7 & 3,8 & 5,4 & 4,1 & 2,4 & 1,3 \\
\hline Sobrepeso & 20,7 & 20,0 & 19,9 & 18,8 & 23,0 & 23,1 \\
\hline Obesidad & 20,4 & 20,3 & 20,1 & 23,3 & 19,7 & 18,4 \\
\hline Exceso de peso (sobrepeso y obesidad) & 41,1 & 40,3 & 40,0 & 42,1 & 42,7 & 41,5 \\
\hline \multicolumn{7}{|l|}{18 años y más (c) } \\
\hline Sobrepeso & 34,0 & 30,6 & 33,2 & 35,4 & 35,7 & 34,1 \\
\hline Obesidad & 33,9 & 36,9 & 36,5 & 34,3 & 34,2 & 29,0 \\
\hline Exceso de peso (sobrepeso y obesidad) & 67,9 & 67,5 & 69,7 & 69,7 & 69,9 & 63,1 \\
\hline
\end{tabular}

Notas: (a) bajo peso: personas cuyo "peso corporal para la edad", expresado como puntaje z, es menor a -2 desvíos estándar de los Patrones de Crecimiento de la OMS / emaciación: personas cuyo "peso para la talla" expresado como puntaje z, es menor a -2 desvíos estándar / baja talla: personas cuyo "talla para la edad", expresado como puntaje z, es menor a -2 desvíos estándar/ sobrepeso: a partir del Índice de Masa Corporal (IMC) se define como sobrepeso a quienes tienen un IMC para la edad, expresado como puntaje $z$, mayor a 2 desvíos estándar y menor o igual a 3 / obesidad: se incluye a quienes tienen un IMC para la edad, expresado como puntaje z, mayor a 3 desvíos estándar.

(b) delgadez: quienes tienen un IMC para la edad, expresado como puntaje z, menor a 2 desvíos estándar / baja talla: personas cuya "talla para la edad", expresado como puntaje z, es menor a -2 desvíos estándar/ sobrepeso: quienes tienen un IMC para la edad, expresado como puntaje z, mayor a 1 desvío estándar y menor o igual a 2 / obesidad: quienes tienen un IMC para la edad, expresado como puntaje z, mayor a 2 desvíos estándar.

(c) sobrepeso: personas con IMC igual o superior a $25 \mathrm{~kg} / \mathrm{m}^{2}$ e inferior a $30 \mathrm{~kg} / \mathrm{m}^{2}$ / obesidad: porcentaje de personas con IMC igual o superior a $30 \mathrm{~kg} / \mathrm{m}^{2}$.

Fuente: elaboración propia a partir de Encuesta Nacional de Nutrición y Salud (ENNYS).

Si se toma en cuenta el consumo de alimentos no recomendados se advierte que $36,7 \%$ de las personas de 2 años y más consumen bebidas azucaradas al menos una vez al día, 17,2\% productos de pastelería o facturas, $15,1 \%$ productos de copetín y $36 \%$ consume golosinas. El consumo de estos alimentos es decreciente conforme la edad. Por su parte, es importante notar que el consumo de alimentos no recomendados se incrementa entre los grupos socioeconómicos más desaventajados, en especial, las bebidas azucaradas (jugos en polvos y/o concentrados, gaseosas, aguas saborizadas, etc.), los productos de copetín (papas fritas, palitos de maíz, etc.) y las golosinas (caramelos, alfajores, chupetines, chicles, barras de cereal, etc.). 
Cuadro 5. Consumo de alimentos no recomendados (al menos una vez al día) por grupo de edad (en porcentajes).

\begin{tabular}{|lcccc|}
\hline & Total & $\mathbf{2}$ a 12 & 13 a 17 & 18 y más \\
Bebidas con azúcar & 36,7 & 46,0 & 46,1 & 32,9 \\
Facturas o productos de pastelería & 17,2 & 27,8 & 23,3 & 13,4 \\
Productos de copetín & 15,1 & 26,5 & 25,9 & 10,5 \\
Golosinas & 36,0 & 62,1 & 52,5 & 26,6 \\
\hline
\end{tabular}

Fuente: elaboración propia a partir de Encuesta Nacional de Nutrición y Salud (ENNYS).

\section{Cuadro 6. Consumo de alimentos no recomendados (al menos una vez al día) por quintil de ingreso normalizado (en porcentajes).}

\begin{tabular}{|lcccccc|}
\hline & Total & Q1 & Q2 & Q3 & Q4 & Q5 \\
Bebidas con azúcar & 36,7 & 46,9 & 45,5 & 39,1 & 31,7 & 20,9 \\
Facturas o productos de pastelería & 17,2 & 19,5 & 19,3 & 15,6 & 17,5 & 14,1 \\
Productos de copetín & 15,1 & 22,0 & 18,2 & 12,9 & 12,0 & 10,5 \\
Golosinas & 36,0 & 42,4 & 38,0 & 31,1 & 33,7 & 34,9 \\
\hline
\end{tabular}

Fuente: elaboración propia a partir de Encuesta Nacional de Nutrición y Salud (ENNYS).

\section{CONCLUSIONES}

Hasta antes de la crisis del COVID-19, la situación socioeconómica y socioalimentaria de la Argentina se ha caracterizado por distintos claroscuros. La pobreza por ingresos marcó en el primer semestre de 2019 su valor más alto desde 2010 en un contexto económico de crisis y alta inflación $(34,5 \%)$. La pobreza por ingresos se ha ido "infantilizando" de manera creciente en la última década y en la actualidad afecta a $52,5 \%$ de los niños/as y adolescentes de 0 a 17 años. En este marco, en 2019 se reportó una tasa de inseguridad alimentaria de $22,1 \%$, mientras que 9,3\% padecían inseguridad alimentaria severa. Estas cifras eran de 30,2\% y de 14,2\% entre la población de 0 a 17 años. Asimismo, el análisis descriptivo presentado reveló que la prevalencia de la inseguridad alimentaria severa es mayor en la región Noreste del país y en las regiones rurales en comparación con las urbanas.

Estos indicadores se complementan con otros de salud infantil y antropometría que revelan distintas facetas de la situación socioalimentaria. La tasa de mortalidad infantil se ha reducido en los últimos años, aunque persisten asimetrías regionales. Se han mantenido estables indicadores antropométricos como la prevalencia de bajo y muy bajo peso al nacer. Asimismo, la información oficial disponible revela otra arista de la situación socioalimentaria: 13,6\% de los menores de 5 años presentan exceso de peso, proporción que asciende a 41,1\% y a 67,9\% entre los de 5 a 17 y 18 años y más, respectivamente. Sólo entre los adultos se aprecian diferencias estadísticamente significativas según nivel de ingresos. En cambio, el consumo de alimentos no recomendados permanece fuertemente asociado al quintil de ingresos de pertenencia.

El diagnóstico es claro en términos del crecimiento de la pobreza e inseguridad alimentaria en la población infantil del país, y las desigualdades sociales y regionales, aún antes de la pandemia actual. Sin embargo, también permite advertir que la problemática de la obesidad y el sobrepeso es transversal a las diferentes infancias, lo cual agrega complejidad a la definición del problema y búsqueda de soluciones. 
Es fácil advertir que los hogares requieren realizar diversos consumos para sostener la vida de sus miembros y desarrollar la misma, en alimentos, pero también en servicios, vestimenta y transporte, por mencionar algunos. En este sentido, parece clave un monitoreo a lo largo de un período de tiempo prologando sobre una muestra de hogares en un diseño de panel que permita la evaluación de las trayectorias de consumo de las familias y el monitoreo de dispositivos de comunicación, formación u otros programas complementarios de la transferencia de ingresos.

\section{BIBLIOGRAFÍA}

Márquez, A. (2017) Estimación y georreferenciación de la probabilidad de padecer inseguridad alimentaria, Documento de Trabajo del Observatorio de la Deuda Social Argentina. Recuperado 15/2/2020 de: http://wadmin.uca.edu.ar/public/ckeditor/Observatorio\%20Deuda\%20Social/Presentaciones/2019/CARTOGRAFIA-INSEGURIDAD-ALIMENTARIA/2019-OBSERVATORIOGEORREFERENCIACION-INSEGURIDAD-ALIMENTARIA-VF-1.pdf

Ministerio de Salud de la Nación (2013). Indicadores básicos 2013, Buenos Aires: Dirección de Estadística e Información de Salud. Recuperado 15/2/2020: http://www.deis.msal.gov.ar/index.php/indicadores-basicos

(2015). Indicadores básicos 2015, Buenos Aires: Dirección de Estadística e Información de Salud. Recuperado 15/2/2020: http://www.deis.msal.gov.ar/index.php/indicadores-basicos

(2019a) 2da Encuesta Nacional de Nutrición y Salud (ENNyS 2) Indicadores Priorizados septiembre 2019, Buenos Aires: Ministerio de Salud de la Nación. Recuperado 15/2/2020: http://www.msal.gob.ar/images/stories/bes/graficos/0000001602cnt-2019-10 encuesta-nacional-de-nutricion-y-salud.pdf

(2019b). Indicadores básicos 2019, Buenos Aires: Dirección de Estadística e Información de Salud. Recuperado 15/2/2020: $<$ http://www.deis.msal.gov.ar/index.php/indicadores-basicos >

Poy, S. (2018). Incidencia de la pobreza y la indigencia a partir de la Encuesta Permanente de Hogares. Documento de Trabajo del Observatorio de la Deuda Social Argentina, Buenos Aires: ODSA-UCA. Recuperado 15/2/2020: <http://wadmin.uca.edu.ar/public/ckeditor/Universidad/Prensa/2018-Prensa-Observatorio-Incidencia-Pobreza-Indigencia.pdf>

Tuñón, I., Poy, S. (2018), La privación más urgente en la infancia: déficit alimentario y protección social Documento de Trabajo del Observatorio de la Deuda Social Argentina, Buenos Aires: ODSA-UCA. Recuperado 15/2/2020: <http://uca.edu.ar/es/noticias/la-privacion-mas-urgente-enla-infancia:-deficit-alimentario-y-proteccion-social>

Tuñón, I., Salvia, A., Musante, B. (2012). "Principales factores asociados a la inseguridad alimentaria de los hogares con niños, niñas y adolescentes", en Lerner G. (comp.) Libro de Ponencias del V Congreso Mundial de la Infancia y la Adolescencia, Buenos Aires: Secretaría de Desarrollo Social de la Nación. Recuperado 15/2/2020: <https://www.aacademica.org/ianina.tunon/54.pdf> 


\section{CAPÍTULO II. PROGRAMAS DE INGRESOS ANTES DE LA PANDEMIA}

lanina Tuñón y Santiago Poy

\section{INTRODUCCION}

En este capítulo se presentan las características de los distintos componentes del sistema de protección social a la infancia y la adolescencia, tal como existían antes de la crisis del COVID-19, procurando enfatizar en una de las principales políticas públicas orientadas a las infancias más vulnerables del país que son las transferencias monetarias condicionadas. Si bien las mismas han alcanzado una amplia cobertura y adecuada focalización, todavía restan desafíos de plena participación y una evaluación precisa de su impacto en aspectos esenciales del sostenimiento de la vida y el desarrollo humano. Existe evidencia del efecto positivo de las transferencias en la merma de la inseguridad alimentaria severa y estabilización de la indigencia monetaria, sin embargo, también se advierte sobre sus limitaciones para erradicar estas expresiones de la pobreza extrema en un contexto macroeconómico inflacionario y recesivo.

En este sentido, parece oportuno sumar al diagnóstico una caracterización del sistema de protección social y en particular los alcances de una de las iniciativas más relevantes del Estado argentino de la última década, orientado a la población más vulnerable a la pobreza que son las niñas, los niños y adolescentes.

La segunda sección del capítulo describe cada uno de los mecanismos a través de los cuales el Estado argentino transfiere ingresos a las familias con niños/as. El tercer apartado enfatiza los programas orientados a la lucha contra la pobreza, en especial, en el programa Asignación Universal por Hijo para Protección Social (AUH) examinando distintas características de su evolución. El cuarto apartado sintetiza evidencias acerca del impacto de la AUH en los ingresos familiares, la pobreza, la inseguridad alimentaria e indicadores de salud. Un último apartado presenta conclusiones.

\section{LOS COMPONENTES DEL SISTEMA DE PROTECCIÓN SOCIAL A LA NIÑEZ Y LA ADOLESCENCIA ${ }^{12}$}

En la Argentina, la protección social de niños/as y adolescentes está estrechamente ligada al tipo de inserción de sus padres en el mercado de trabajo y a sus niveles de ingresos. Existen tres mecanismos principales a través de los cuales el Estado transfiere ingresos a los hogares con niños/as: a) las Asignaciones Familiares; b) la Asignación Universal por Hijo para Protección Social (AUH) -complementada con la Asignación Universal por Embarazo para Protección Social (AUE)-; y c) la deducción del impuesto a las ganancias para aquellos trabajadores autónomos o asalariados de altos ingresos (también conocida como "crédito fiscal") que tienen menores de edad a cargo. De 12 Toda la información presentada fue elaborada sobre datos de la Administración Nacional de la Seguridad Social (ANSES)
(<https://www.anses.gob.ar $>)$, el área de Estudios, Informes y Estadísticas de la Seguridad Social del Ministerio de Trabajo, Empleo y
Seguridad Social (MTEYSS) (<https://www.argentina.gob.ar/trabajo/seguridadsocial/estudios\#bess $>)$ y de la Plataforma de Seguridad Ali-
mentaria y Nutricional (<https://plataformacelac.org $>)$. 
acuerdo con la normativa vigente (Ley 24.714), los primeros dos mecanismos integran el "Régimen de Asignaciones Familiares", mientras que el tercero constituye una vía indirecta de transferencia que resulta de lo que el Estado deja de recaudar en concepto de impuesto a las ganancias.

La Asignación Familiar por Hijo ${ }^{13}$ (AFH, también conocida como "salario familiar") es una prestación monetaria por carga de familia. Pueden acceder a ella los trabajadores registrados en relación de dependencia en la actividad privada, los beneficiarios de la Ley de Riesgos del Trabajo y del Seguro de Desempleo, los jubilados y pensionados del Sistema Integrado Previsional Argentino (SIPA), los beneficiarios de pensiones no contributivas por invalidez y de la Pensión Universal del Adulto Mayor (PUAM). A partir de 2016, las personas inscriptas y con aportes al Régimen Simplificado para Pequeños Contribuyentes ("monotributistas") también pueden acceder a la AFH. Por fuera de este sistema existen otros regímenes de asignaciones familiares para trabajadores del sector público a nivel nacional y de las distintas jurisdicciones subnacionales.

La AFH es una transferencia monetaria decreciente según el nivel de ingreso del grupo familiar y tiene diferentes escalas según la zona geográfica de residencia (atendiendo así a las diferencias socioeconómicas regionales). El valor general es de $\$ 2.746$ mensuales, pueden cobrarla aquellos trabajadores cuyo ingreso familiar mensual es inferior a $\$ 129.190$ brutos (y que viven en hogares en los que ninguno de los integrantes gana más de \$64.595) y los monotributistas de las categorías más bajas (hasta la J). Según registros administrativos de ANSES -de junio de 2019-, la Asignación Familiar por Hijo y por Hijo con discapacidad es recibida por 4.691.141 niños/as y adolescentes. La Administración Nacional de la Seguridad Social (ANSES) informó para el año 2018 un gasto de 89 mil millones de pesos (equivalente al 0,61\% del Producto Interno Bruto).

En el marco de la crisis de 2009, el Estado argentino amplió el régimen de protección social dirigido a la población en situación de vulnerabilidad a través de la Asignación Universal por Hijo, a la que posteriormente se añadió una Asignación Universal por Embarazo. La AUH es una transferencia monetaria dirigida a los trabajadores informales y desocupados, temporarios, monotributistas sociales y trabajadores/as de casas particulares cuyo ingreso es inferior al Salario Mínimo, Vital y Móvil. Más allá de la existencia de un tope en los ingresos de los trabajadores informales para cobrar la prestación, en la práctica resulta difícil corroborar su cumplimiento. Pueden cobrar el beneficio las madres, padres o adultos a cargo de los niños/as, hasta un máximo de cinco hijos/as. En distintas jurisdicciones existen otros programas de transferencias que suelen ser incompatibles con el cobro de la AUH.

La AUH implica condicionalidades referidas al control sanitario y la asistencia escolar. Todos los años, los adultos titulares deben presentar una Libreta que certifique su cumplimiento. Para niños/as menores de 5 años, se requiere la inscripción al Programa SUMAR y el cumplimiento del calendario de vacunación. Para los niños/as y adolescentes de 5 años y más se debe certificar el control médico y la asistencia a la escuela. Estas condicionalidades inciden sobre el pago de la $\mathrm{AUH}$, que se realiza en dos partes. En una primera etapa, la ANSES liquida el $80 \%$ de la prestación y en una segunda etapa el $20 \%$ acumulado restante, siempre que se haya presentado la documentación que certifique el cumplimiento de las condicionalidades. En la actualidad, la AUH es una transferencia de 2.746 mensuales (igual a la AFH) y, según registros administrativos de ANSES, en junio de 2019 fue percibida por 3.923.040 millones de niños/as y adolescentes de todo el país. Los montos liquidados por AUH durante 2018 fueron de 61,4 mil millones de pesos (equivalente al $0,42 \%$ del PIB).

Así como la AUH está enfocada en la población vulnerable en términos socioeconómicos, desde 1989 existe una pensión vitalicia para las madres de siete o más hijos $(\mathrm{P} 7 \mathrm{H})$ de muy bajos recursos

\footnotetext{
${ }^{13}$ Además de otorgar beneficios por hijo y por hijo con discapacidad, el sistema de asignaciones familiares incluye otras transferencias no periódicas por nacimiento, adopción, maternidad, prenatal y matrimonio.
} 
(Ley 23.746). La P7H es una prestación mensual y vitalicia destinada a las madres que tengan o hayan tenido siete o más hijos, de cualquier edad, estado civil y nacionalidad. Pueden acceder a ella las mujeres que no cuentan con ninguna jubilación ni pensión o que carecen de bienes o ingresos suficientes para garantizar la subsistencia del grupo familiar conviviente. Se considera ingresos insuficientes cuando el ingreso familiar es inferior a dos haberes jubilatorios mínimos. Las titulares deben ser argentinas, naturalizadas con al menos un año de residencia continuada en el país o extranjeras que hayan residido de manera continua en el país durante los últimos 15 años. En caso de fallecimiento de la titular, pueden cobrar la pensión los hijos/as menores de edad. La P7H otorga un beneficio equivalente a un haber previsional mínimo (\$14.068 en diciembre de 2019) y, de acuerdo con el Boletín Estadístico de la Seguridad Social (MTEYSS, 2019) del Ministerio de Trabajo, Empleo y Seguridad Social de la Nación (MTESS) en 2019 la recibieron 303.166 personas.

Por último, una vía "indirecta" de transferencia de ingresos es la deducción del impuesto a las ganancias en aquellos trabajadores autónomos o asalariados de altos ingresos (también conocida como "crédito fiscal"). Aquellos que tributan el impuesto a las ganancias pueden deducir cargas de familia por el número de menores a cargo. A diferencia de los otros pilares del sistema de protección, cuya gestión depende de la ANSES, este mecanismo indirecto está bajo la órbita de la Administración Federal de Ingresos Públicos (AFIP). En la actualidad, pueden deducir carga familiar del impuesto a las ganancias quienes perciben ingresos mensuales superiores a $\$ 64.145$ (casados) y $\$ 73.104$ (casados con dos hijos).

De acuerdo con los microdatos de la Encuesta de la Deuda Social Argentina (EDSA), en 2019 un $37 \%$ de los niños/as y adolescentes en los aglomerados urbanos relevados eran beneficiarios de la AUH y sólo $5,3 \%$ se encontraban alcanzados por la P7H u otros programas de lucha contra la pobreza subnacionales incompatibles con la AUH (Gráfico 1). Por su parte, 36,1\% estaban alcanzados por el sistema de AFH de ANSES y 5,9\% por la deducción de impuesto a las ganancias. Se aprecia la estrecha relación que existe entre el estrato socioeconómico (evaluado según decil de ingreso per cápita familiar del hogar) y el tipo de protección social al que acceden los niños/as y adolescentes. $\mathrm{La} \mathrm{AUH}$, la $\mathrm{P} 7 \mathrm{H}$ y otros programas similares tienden a ser frecuentes entre los niños/as de los hogares de los tres deciles inferiores. La AFH es más habitual entre los niños/as y adolescentes del cuarto al octavo decil. Finalmente, entre los deciles superiores (el noveno y el décimo) es frecuente la cobertura por deducción del impuesto a las ganancias.

\section{Gráfico 1. Cobertura de sistemas de protección social a la infancia y adolescencia} según decil de ingreso per cápita familiar del hogar. Aglomerados urbanos, 2019.

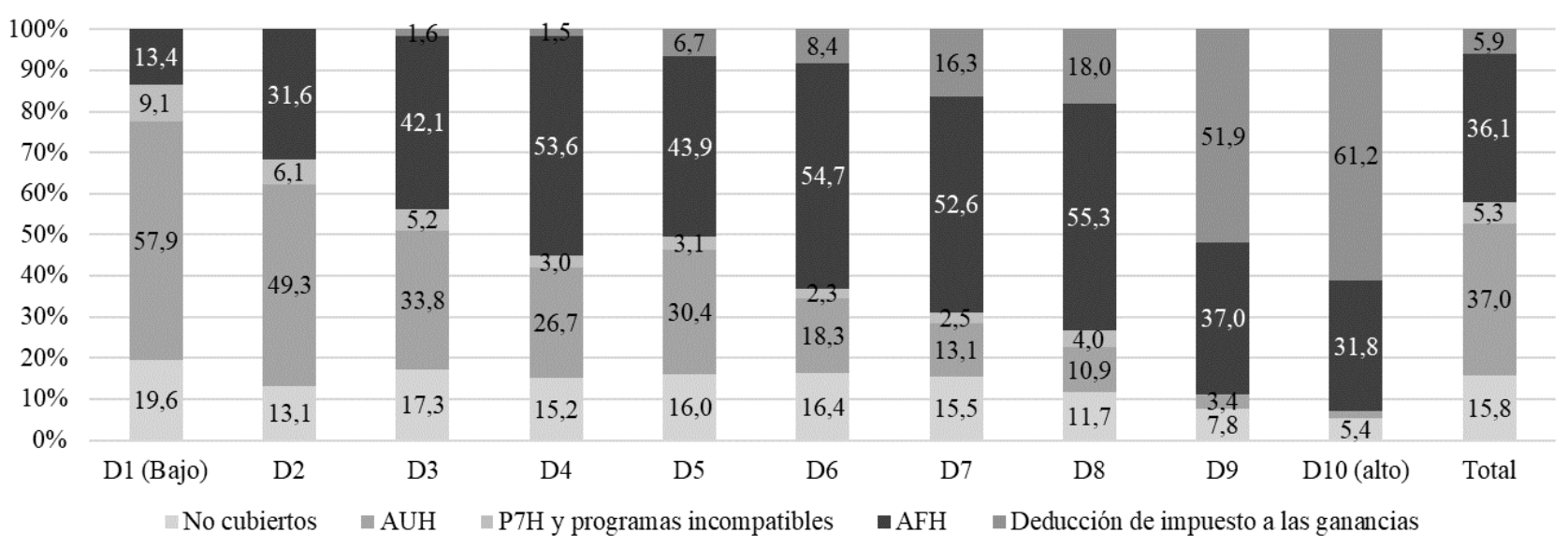

Fuente: EDSA- Bicentenario (2010-2016) - EDSA-Agenda para la equidad (2017-2025), Observatorio de la Deuda Social Argentina, UCA. 


\section{LOS SISTEMAS DE PROTECCIÓN PARA LA INFANCIA EN CONDICIONES DE VULNERABILIDAD}

La AUH fue establecida mediante un Decreto presidencial de 2009 (1602/09) y, desde entonces, no sufrió modificaciones sustantivas en términos de su encuadre institucional o población objetivo. Si bien existieron otras políticas masivas de lucha contra la pobreza -en especial, durante la crisis de 2001/2002-, la AUH tiene un enfoque diferente y se inscribe en los programas "condicionados" de transferencia de ingresos que se generalizaron en la región durante la década de los 2000 (como Bolsa Familia o Prospera). En la actualidad, es la principal política del Estado argentino para atender a la vulnerabilidad en la infancia y la adolescencia y romper la transmisión intergeneracional de la pobreza.

Si bien el acceso a la información no es exhaustivo, se puede estimar que la AUH/AUE ha representado entre el $0,40 \%$ y $0,59 \%$ del PIB entre 2010 y 2018, con una clara tendencia ascendente (Cuadro 1). Algunos ejercicios de simulación han mostrado que sin estas transferencias la tasa de indigencia urbana se incrementaría en un $70 \%$, mientras que su incidencia sobre la tasa de pobreza rondaría un aumento de menos del $5 \%$. Esto estaría dando cuenta de la particular focalización de estos programas sobre la población más pobre. En el igual sentido, estos mismos estudios dan cuenta que serían necesarias inversiones adicionales -por sobre las actuales transferenciasde $0,4 \%$ del PIB para salir de la indigencia, de $2,5 \%$ para poder acceder una canasta saludable y de $3,8 \%$ del PIB para salir de la pobreza (Tuñón y Salvia, 2018). 
Cuadro 1. Gasto en AUH y AUE por año como \% del PIB

\begin{tabular}{|cccc|c|c|}
\hline $\begin{array}{c}\text { Gasto AUH } \\
\text { (AR\$) }\end{array}$ & $\begin{array}{c}\text { Gasto AUE } \\
\text { (AR\$) }\end{array}$ & $\begin{array}{c}\text { PIB } \\
\text { (millones AR \$) }\end{array}$ & $\begin{array}{c}\text { Gasto AUH como \% } \\
\text { del PIB }\end{array}$ & $\begin{array}{c}\text { Gasto AUH+AUE } \\
\text { como \% del PIB }\end{array}$ \\
\hline 2010 & - & - & - & - & $0,40 \%$ \\
2011 & - & - & - & - & $0,40 \%$ \\
2012 & - & - & - & - & $0,40 \%$ \\
2013 & 16.714 .756 .760 & 326.871 .420 & 3.348 .308 & $0,50 \%$ & $0,51 \%$ \\
2014 & 23.663 .214 .675 & 515.098 .905 & 4.579 .086 & $0,52 \%$ & $0,53 \%$ \\
2015 & 32.928 .535 .628 & 722.520 .840 & 5.954 .511 & $0,55 \%$ & $0,57 \%$ \\
2016 & 47.240 .772 .053 & 949.223 .664 & 8.228 .160 & $0,57 \%$ & $0,59 \%$ \\
2017 & 61.335 .438 .910 & 1.278 .762 .389 & 10.644 .779 & $0,58 \%$ & $0,59 \%$ \\
2018 & 76.737 .539 .277 & 1.537 .328 .337 & 14.605 .790 & $0,53 \%$ & $0,54 \%$ \\
\hline
\end{tabular}

Fuente: El gasto total en AUH y AUE entre 2013 y 2018 proviene de ANSES que informa el $80 \%$ de los montos liquidados. Se estimó el $20 \%$ restante a partir de los valores informados. Los datos de gasto de 2010-2012 provienen de la Secretaría de Política Económica y Planificación del Desarrollo (2015) Incluir para crecer: la inversión nacional entre 2004 y 2014. Buenos Aires: MECON., Gráfico 11 (p. 18)

En junio de 2019 había 2.208.323 titulares de la AUH en todo el país por 3.923.040 niños/as que recibían el beneficio (Cuadro 2). De acuerdo con información de ANSES, por la prioridad que se otorga a la madre en el cobro de la $\mathrm{AUH}$, el $96 \%$ de los titulares son mujeres. Asimismo, el $51,8 \%$ de los titulares tienen un hijo/a menor de 18 años a cargo y $28,1 \%$ tienen dos ${ }^{14}$. En el Cuadro 2 , se aprecia que entre 2009 y 2019 el número de niños/as beneficiarios se incrementó 15,1\%, mientras que el de titulares lo hizo al 34,7\%. Ello explica que el promedio de beneficios se haya reducido sensiblemente entre 2009 y 2019 de 2,1 a 1,8 por titular.

Cuadro 2. Titulares de AUH y P7H, niños/as beneficiarios y montos de los beneficios. Años 2009-2019(a) (en números absolutos e índices 2009=100).

\begin{tabular}{|c|c|c|c|c|c|c|c|c|c|}
\hline & \multicolumn{6}{|c|}{ Asignación Universal por Hijo (AUH) } & \multicolumn{3}{|c|}{ Pensión 7 Hijos (P7H) } \\
\hline & $\begin{array}{l}\text { Niños/as } \\
\text { beneficia- } \\
\text { rios }\end{array}$ & $\begin{array}{c}\text { Titulares } \\
\text { AUH }\end{array}$ & $\begin{array}{l}\text { Beneficio } \\
\text { (AR\$ corr.) }\end{array}$ & $\begin{array}{c}\text { Beneficio } \\
\text { (AR\$ Dic } \\
2019 \\
100=2009 \text { ) }\end{array}$ & $\begin{array}{l}\text { Ratio Be- } \\
\text { neficio / } \\
\text { CBT }\end{array}$ & $\begin{array}{l}\text { Ratio Bene- } \\
\text { ficio / CBA }\end{array}$ & $\begin{array}{c}\text { Titulares } \\
\text { P7H }\end{array}$ & $\begin{array}{l}\text { Beneficio } \\
\text { (AR\$ corr.) }\end{array}$ & $\begin{array}{c}\text { Beneficio } \\
\text { (AR\$ Dic } \\
2019 \\
100=2009 \text { ) }\end{array}$ \\
\hline dic-09 & 3.408 .222 & 1.639 .588 & 180 & 100,0 & $26 \%$ & $67 \%$ & 234.904 & 827 & 100,0 \\
\hline dic-10 & 3.513 .064 & 1.748 .635 & 220 & 97,7 & $25 \%$ & $59 \%$ & 281.741 & 1.046 & 101,1 \\
\hline dic-11 & 3.507 .223 & 1.892 .862 & 270 & 98,5 & $26 \%$ & $57 \%$ & 302.082 & 1.434 & 113,8 \\
\hline dic-12 & 3.314 .179 & 1.793 .231 & 340 & 97,6 & $25 \%$ & $56 \%$ & 318.605 & 1.880 & 117,4 \\
\hline dic-13 & 3.459 .574 & 1.883 .594 & 460 & 103,7 & $27 \%$ & $57 \%$ & 330.434 & 2.477 & 121,5 \\
\hline dic-14 & 3.574 .765 & 1.975 .703 & 644 & 104,7 & $27 \%$ & $60 \%$ & 336.766 & 3.232 & 114,3 \\
\hline dic-15 & 3.684 .138 & 2.051 .233 & 837 & 105,1 & $27 \%$ & $61 \%$ & 332.880 & 4.299 & 117,4 \\
\hline dic-16 & 3.957 .826 & 2.196 .864 & 1.103 & 99,4 & $26 \%$ & $62 \%$ & 319.532 & 5.661 & 111,1 \\
\hline dic-17 & 3.956 .042 & 2.200 .057 & 1.412 & 102,0 & $26 \%$ & $66 \%$ & 310.543 & 7.247 & 113,9 \\
\hline dic-18 & 3.994 .424 & 2.234 .187 & 1.816 & 88,8 & $22 \%$ & $55 \%$ & 307.507 & 9.309 & 99,0 \\
\hline dic-19 & 3.923 .040 & 2.208 .323 & 2.746 & 87,9 & $22 \%$ & $54 \%$ & 303.166 & 14.068 & 98,0 \\
\hline
\end{tabular}

Notas: (a) Se incluye AUH y AUH para hijo discapacitado. En 2019, el número de titulares, el número de titulares y beneficiarios corresponde a junio $(A \cup H)$ y septiembre $(\mathrm{P} 7 \mathrm{H})$ por falta de datos más actualizados.

Fuente: elaboración propia con base en datos de ANSES, BESS (MTEYSS), INDEC y Observatorio de la Deuda Social Argentina, UCA. ${ }^{14}$ Esta información se encuentra disponible en la plataforma de Datos Abiertos de ANSES: <https://www.anses.gob.ar/informacion/datos-
abiertos-asignaciones-universales> 
El monto de la transferencia por AUH se actualiza periódicamente de acuerdo con la fórmula de movilidad del resto de las prestaciones de la seguridad social. En el año 2009, la transferencia cubría $26 \%$ de una Canasta Básica Total por adulto equivalente (o "línea de pobreza") y $67 \%$ de una Canasta Básica Alimentaria ("línea de indigencia"). En 2019, la capacidad de compra de la AUH se había reducido fuertemente luego de la aceleración inflacionaria y la insuficiente actualización de la prestación: permitía adquirir $22 \%$ de la línea de pobreza equivalente o $54 \%$ de la línea de indigencia. Si se considera que, en promedio, cada hogar recibe 1,8 beneficios y se toman en cuenta los requerimientos de consumo de un hogar con dos adultos y dos menores (3,09 unidades de consumo según el Instituto Nacional de Estadística y Censos), las transferencias permitían adquirir $12,5 \%$ de la línea de pobreza y $31,4 \%$ de la línea de indigencia de ese hogar de referencia. En síntesis, la capacidad protectoria de la AUH frente a la pobreza y la indigencia se revela limitada por los montos que representa -en comparación con el umbral referido- e, inclusive, se ha reducido en los últimos años de crisis económica.

La P7H constituye una transferencia de naturaleza distinta a la AUH puesto que no está orientada directamente a la infancia sino a las madres que tienen siete o más hijos/as. De acuerdo con información del MTEYSS (MTEYSS, 2019), entre 2009 y 2019 el número de titulares de P7H se incrementó 29\% alcanzando en la actualidad a más de 300 mil personas (Cuadro 1). Por su parte, el beneficio promedio de la asignación tuvo oscilaciones semejantes a las de la $\mathrm{AUH}$, aunque, entre puntas, se aprecia un menor deterioro de su capacidad de compra. En efecto, entre 2009 y 2019 el monto de la P7H en términos reales se redujo $2 \%$, mientras que la $\mathrm{AUH}$ lo hizo $12,1 \%$. Ahora bien, si se considera que la $\mathrm{P} 7 \mathrm{H}$ alcanzó su mayor capacidad adquisitiva en 2015 , la reducción entre dicho año y 2019 fue de $16,5 \%$.

\section{EVIDENCIAS SOBRE LOS EFECTOS DE LA AUH EN EL DESARROLLO HUMANO Y SOCIAL}

Diversas investigaciones han dado cuenta de los impactos de la AUH sobre distintas dimensiones del desarrollo humano y social de los hogares perceptores y de los niños/as y adolescentes. Aquí se enumeran los principales resultados sobre el ingreso familiar, la pobreza, la inseguridad alimentaria e indicadores de salud.

Un conjunto de estudios, por lo general, apelando a diseños cuasiexperimentales, abordaron los efectos de la AUH sobre los ingresos familiares (Bustos et al., 2012; Garganta y Gasparini, 2017; Maurizio y Vázquez, 2014; Salvia et al., 2015) han identificado efectos positivos de la AUH sobre el ingreso per cápita familiar. Con microdatos de la Encuesta de la Deuda Social Argentina (EDSA) para el período 2010-2012, Salvia et al. (2015) encuentran que la AUH incrementó 8,5\% el ingreso per cápita familiar de los niños/as y adolescentes beneficiarios en comparación con los del grupo de control. Sobre la base de microdatos de la Encuesta Permanente de Hogares (EPH) del INDEC, Bustos et al. (2012) observan -a partir de distintos ejercicios de propensity score matching- resultados positivos sobre el ingreso per cápita familiar de los hogares perceptores de la AUH, y Garganta y Gasparini (2017) sobre el ingreso total familiar de los beneficiarios.

Salvia et al. (2015) encuentran una reducción estadísticamente significativa de la probabilidad de experimentar indigencia entre los niños/as beneficiarios de la AUH frente al grupo de control (una reducción relativa del riesgo de $36 \%$ ). En cambio, los resultados en materia de pobreza no son significativos. Un estudio reciente (Cetrángolo y Curcio, 2017) estima el efecto de la AUH sobre la tasa de pobreza en 2016 descontando del ingreso familiar los montos de los beneficios. Identifican una 
reducción de apenas 3\% de la tasa (casi 1 pp.) y que 10\% de los hogares perceptores abandona la condición de pobreza gracias al beneficio. Concluyen que el mayor impacto no es en la reducción de la tasa sino en el incremento del ingreso de los hogares pobres y, por lo tanto, en la reducción de la brecha de pobreza (Cetrángolo y Curcio, 2017: 16).

Los estudios basados en microdatos de la EDSA constatan un efecto positivo y estadísticamente significativo de la AUH sobre la inseguridad alimentaria severa ${ }^{15}$ para los niños/as y adolescentes beneficiarios (Cuadro 3). A partir de ejercicios de propensity score matching, se advierte una reducción de 2,6 pp. en el riesgo de inseguridad alimentaria severa, lo que representa una reducción relativa del riesgo de $19 \%$ a favor de los beneficiarios de la AUH sobre el grupo de control (Salvia et al., 2015). El efecto de la AUH en la reducción de la inseguridad alimentaria severa es similar entre los niños/as y adolescentes de distintos grupos de edad y levemente más intenso entre los niños/as que experimentan privaciones estructurales (evaluadas mediante el índice de Necesidades Básicas Insatisfechas).

Cuadro 3. Evaluación del impacto de AUH sobre la inseguridad alimentaria severa en muestra apareada de niños y adolescentes. Años 2010-2012. Diferencias de proporciones, riesgos relativos y pruebas de hipótesis.

\begin{tabular}{|c|c|c|c|c|c|}
\hline & $\begin{array}{c}\text { Experimental } \\
\text { CON AUH }\end{array}$ & $\begin{array}{l}\text { Control } \\
\text { SIN AUH }\end{array}$ & Dif. (p.p.) & Sig. & $\mathbf{R R}$ \\
\hline Total & 10,7 & 13,2 & $-2,6$ & $* * *$ & 0,81 \\
\hline \multicolumn{6}{|c|}{ Grupo de edad del niño } \\
\hline 0-4 años & 10,5 & 13,1 & $-2,6$ & *** & 0,80 \\
\hline 5-12 años & 10,0 & 12,4 & $-2,3$ & 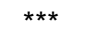 & 0,81 \\
\hline 13-17 años & 12,1 & 14,9 & $-2,7$ & $* * *$ & 0,82 \\
\hline \multicolumn{6}{|c|}{ Grupo de edad de la madre } \\
\hline Hasta 24 años & 13,0 & 14,9 & $-1,9$ & *** & 0,87 \\
\hline Entre 25 y 34 años & 10,1 & 13,1 & $-3,0$ & *** & 0,77 \\
\hline 35 años y más & 10,5 & 12,8 & $-2,3$ & *** & 0,82 \\
\hline \multicolumn{6}{|c|}{ Necesidades Básicas Insatisfechas (NBI) } \\
\hline Con NBI & 15,8 & 19,2 & $-3,4$ & *** & 0,82 \\
\hline Sin NBI & 7,5 & 9,4 & $-1,9$ & $* \star \star$ & 0,80 \\
\hline
\end{tabular}

Nota: $p$-valor $<0,1^{*} / p$-valor $<0,05^{* *} / p$-valor $<0,01^{* * *}$

Fuente. Salvia et al. (2015) sobre la base de EDSA-Bicentenario, Observatorio de la Deuda Social Argentina

Como se señaló, la AUH incluye condicionalidades relativas al control sanitario periódico y el cumplimiento del calendario de vacunación. Son escasos los estudios que hayan abordado el impacto del programa sobre distintos indicadores de salud, principalmente por la insuficiencia de datos disponibles (Goldschmit, 2017; Walsh et al., 2020). A partir de microdatos de la Encuesta Nacional de Protección y Seguridad Social (ENAPROSS) de 2016, Goldschmit (2017) evalúa los comportamientos de salud de los hogares y observa que la AUH no tiene impacto sobre la realización de consultas médicas en los últimos 12 meses ni sobre la calidad de la atención recibida, mientras que sí tiene efectos sobre la modalidad de obtención de medicamentos. A partir de microdatos de la EDSA, Walsh et al. (2020) realizan cuatro ejercicios de propensity score matching y examinan los

\footnotetext{
${ }^{15}$ En la EDSA, el indicador de inseguridad alimentaria expresa la reducción involuntaria de la porción de comida y/o la percepción de experiencias de hambre por problemas económicos. Los hogares clasificados en situación severa son aquellos en los cuales alguno de los adultos o niños/as experimentó "hambre" por problemas económicos durante los últimos 12 meses.
} 
impactos de la AUH sobre la población de niños/as y adolescentes (de 3 a 17 años) en función de dos variables: el cumplimiento del calendario de vacunación y la realización de una consulta médica anual. Todos los ejercicios realizados exhiben que la AUH no tiene impacto sobre estos indicadores. Con respecto a la vacunación, concluyen que la falta de efecto podría explicarse porque la cobertura en la Argentina es prácticamente universal y el calendario se encuentra ampliamente difundido, además de que es requisito para ingresar a la escuela primaria. Con respecto al control médico, señalan que puede ocurrir que la condicionalidad sea más efectiva en la infancia temprana que en el grupo de 3 a 17, que algunos cambios en las condicionalidades durante los primeros años del programa no hayan sido claros para los beneficiarios o que los controles de cumplimiento por parte de las autoridades hayan sido limitados en un marco de insuficiente oferta de servicios de salud, en especial, al comienzo de la implementación de la $\mathrm{AUH}^{16}$.

Cuadro 4. Evaluación del impacto de AUH sobre resultados en salud en muestra apareada de niños y adolescentes. Años 2012-2017.

\begin{tabular}{|l|l|r|r|}
\hline \multirow{2}{*}{ Método de apareamiento } & & \multicolumn{2}{|c|}{ Resultados en salud } \\
\cline { 3 - 4 } & & Vacunación & Examen médico \\
\hline \hline 5-Vecinos más próximos & Tratamiento & 0.984 & 0.739 \\
(Caliper, .01) & Control & 0.985 & 0.734 \\
& Efecto (p.p.) & -0.09 & 0.47 \\
10-Vecinos más próximos & sig. & $\mathrm{n} / \mathrm{s}$ & $\mathrm{n} / \mathrm{s}$ \\
(Caliper, .01) & Tratamiento & 0.984 & 0.739 \\
& Control & 0.984 & 0.736 \\
& Efecto (p.p.) & 0.00 & 0.24 \\
Radius Matching & sig. & $\mathrm{n} / \mathrm{s}$ & $\mathrm{n} / \mathrm{s}$ \\
(Caliper, .01) & Tratamiento & 0.984 & 0.739 \\
& Control & 0.983 & 0.736 \\
& Efecto (p.p.) & 0.08 & 0.25 \\
Radius Matching & sig. & $\mathrm{n} / \mathrm{s}$ & $\mathrm{n} / \mathrm{s}$ \\
(Caliper, .05) & Tratamiento & 0.984 & 0.739 \\
& Control & 0.983 & 0.736 \\
& Efecto (p.p.) & 0.06 & 0.27 \\
& sig. & $\mathrm{n} / \mathrm{s}$ & $\mathrm{n} / \mathrm{s}$ \\
\hline
\end{tabular}

Nota: $\mathrm{p}$-valor $<0,1^{*} / \mathrm{p}$-valor $<0,05^{* *} / \mathrm{p}$-valor $<0,01^{* * *}$

Fuente: Adaptado de Walsh et al. (2020) sobre la base de EDSA-Bicentenario y EDSA-Agenda para la Equidad, Observatorio de la Deuda Social Argentina.

\section{CONCLUSIONES}

En la Argentina actual, el sistema de protección social a la niñez y la adolescencia se basa de modo prioritario en transferencias monetarias de ingresos a las familias. El sistema de protección se caracteriza por su fragmentación y fuerte vínculo con la inserción sociolaboral de los adultos de referencia. Coexiste un subsistema contributivo para trabajadores formales, un mecanismo indirecto vía deducción fiscal para trabajadores de altos ingresos y un subsistema no contributivo de

${ }^{16}$ Algunos estudios discuten el papel de las condicionalidades de la AUH. Véanse al respecto Straschnoy (2017) y UNICEF (2018). 
asignaciones que incluye a la $\mathrm{AUH}$, las pensiones no contributivas por siete o más hijos y otros programas subnacionales. El sistema de protección ha alcanzado altos niveles de cobertura (superiores al $85 \%$ ) y persiste una estratificación socioeconómica de los distintos subsistemas.

La principal política de protección a la infancia y la adolescencia en condiciones de vulnerabilidad es la AUH, que alcanza a 3,9 millones de niños/as. Esta transferencia cubre, en 2019, una quinta parte de la línea de pobreza por adulto equivalente y la mitad de una línea de indigencia. En los últimos dos años perdió casi $13 \%$ de capacidad adquisitiva. Distintos estudios coinciden en señalar un impacto positivo en distintas dimensiones del desarrollo humano y social, como la inseguridad alimentaria severa o la extrema pobreza. También destacan que su capacidad es limitada para sacar a los hogares de la pobreza por el monto insuficiente de la prestación en el contexto de una macroeconomía inflacionaria y recesiva.

Tras diez años de la implementación de la $\mathrm{AUH}$, esta transferencia de ingresos no fue complementada con ninguna otra acción orientada específicamente a la seguridad alimentaria de los hogares. Incluso el control de las condicionalidades con respecto a la atención preventiva de la salud del niño/a sano ha sido dispar a lo largo del tiempo. Si bien existe un debate que reviste diferentes aristas en torno a las condicionalidades de los programas de transferencia de ingresos, cabe revisar las mismas en relación con la atención integral de la salud de niños/as, y oferta de servicios de atención de calidad que incluyan dispositivos de formación y comunicación en el espacio específico de la seguridad alimentaria.

La reciente implementación de la Tarjeta Alimentar, se constituye en otra modalidad de transferencia de ingresos no contributiva orientada a esta población de referencia, pero cuyo uso se procura sea únicamente el consumo de alimentos. Es claro que se trata de una iniciativa que se superpone con otros sistemas de transferencia de ingresos vigentes, y que orientar los consumos de los hogares requiere de cambios sociales y culturales que pueden ser desarrollados a través de estrategias de comunicación, participación y formación adecuadas a los formatos de las principales redes sociales horizontales que acompañen estas políticas públicas enfatizando la relevancia de la alimentación de alta densidad nutricional en períodos críticos, y el sentido de la regularidad en los consumos de alimentos con mayor valor biológico. Incluso se considera que el espacio de la comunicación en tiempo real en horarios claves de preparación de los alimentos puede constituirse en un estímulo poderoso fundado en las herramientas que nos brinda la economía del comportamiento.

\section{BIBLIOGRAFÍA}

Bustos, J. M., Giglio, G., Villafañe, S. (2012). "Asignación Universal por Hijo: alcance e impacto por regiones del país”, Serie Estudios Trabajo, ocupación y empleo, 11, 17-43.

Cetrángolo, O., Curcio, J. (2017). “Introducción”, en: O. Cetrángolo y J. Curcio (coords.), Análisis y propuestas de mejoras para ampliar la Asignación Universal por Hijo 2017, Buenos Aires: ANSES - Ministerio de Desarrollo Social - UNICEF - IIEEP UBA - CEDLAS - CNCPS.

Garganta, S., Gasparini, L. (2017). "El impacto de la AUH sobre los ingresos de los hogares: Un ejercicio de diferencias dobles”, en: $\mathrm{O}$. Cetrángolo y J. Curcio (coords.), Análisis y propuestas de mejoras para ampliar la Asignación Universal por Hijo 2017, Buenos Aires: ANSES - Ministerio de Desarrollo Social - UNICEF - IIEEP UBA - CEDLAS - CNCPS. 
Goldschmit, A. (2017). "Análisis y caracterización de la condicionalidad en salud que establece la AUH", en: O. Cetrángolo y J. Curcio (coords.), Análisis y propuestas de mejoras para ampliar la Asignación Universal por Hijo 2017, Buenos Aires: ANSES - Ministerio de Desarrollo Social UNICEF - IIEEP UBA - CEDLAS - CNCPS.

Maurizio, R., Vázquez, G. (2014). “Efectos del programa Asignación Universal por Hijo en el comportamiento laboral de los adultos", Revista de la CEPAL, 113, pp. 121-144.

Ministerio de Trabajo, Empleo y Seguridad Social [MTEYSS] (2019). Boletín estadístico de la seguridad social (BESS) septiembre 2019, Buenos Aires: MTEYSS. Recuperado 15/2/20: https://www.argentina.gob.ar/trabajo/seguridadsocial/estudios\#bess

Salvia, A., Tuñón, I., Poy, S. (2015). "Asignación Universal por Hijo para Protección Social: impacto sobre el bienestar económico y el desarrollo humano de la infancia" Revista Población \& Sociedad, 22 (2), pp. 101-134.

Straschnoy, M. (2017). Análisis evaluativo de las condicionalidades de la Asignación universal por hijo. Política y Cultura, 47, 143-164.

Walsh, M., Poy, S., y Tuñón, I. (2020). El impacto de las condicionalidades de salud en los programas de transferencias condicionadas: el caso de la AUH en Argentina. Revista Desarrollo y Sociedad, UNIANDES, Colombia (en proceso editorial).

Tuñón, I.; Salvia, A. (2018). Pobreza persistente: trayectoria, desafíos e incentivos para su erradicación. Ensayos sobre desarrollo sostenible. La dimensión económica de la Agenda 2030 en la Argentina - Buenos Aires: Programa de las Naciones Unidas para el Desarrollo.

UNICEF (2018). Asignación Universal por Hijo. Una contribución al debate sobre el rol de las condicionalidades, Buenos Aires: UNICEF. Recuperado 15/2/20: https://www.unicef.org/argentina/media/3726/file/Asignaci\%C3\%B3n\%20Universal\%20por\%20Hijo.pdf 


\section{CAPÍTULO III. PROGRAMAS ALIMENTARIO- NUTRICIONALES MATERNO-INFANTILES ANTES DE LA PANDEMIA}

Sergio Britos y Ayelén Borg

\section{INTRODUCCIÓN}

Este capítulo examina las principales estrategias y programas alimentario-nutricionales, antes de la crisis generada por el COVID-19, que atienden la problemática de malnutrición que afecta en particular a los niños en la Argentina. Se lo hace desde la especificidad propia de las acciones y políticas que se originan en el ámbito de las políticas sectoriales de Salud y que -a nivel de las familias y sujetos beneficiarios- se relacionan con otras de transferencia de ingresos y de asistencia socialalimentaria que se describen en el capítulo precedente y el posterior respectivamente.

Una particular complejidad que no puede soslayarse en el análisis es la propia estructura federal de gobierno de la Argentina, en la que interactúan múltiples organismos en la dimensión nacional y otros tantos en cada una de las 24 jurisdicciones provinciales, además de los propios de más de 2300 gobiernos locales, algunos de los cuales por su dimensión llegan a tener más relevancia que algunas provincias.

En este marco, las políticas alimentarias pueden segmentarse entre aquellas que atienden las cuestiones más estructurales y evolutivas de la nutrición a lo largo del ciclo de vida (Lutter, 2012), y las que se orientan de manera más preponderante a ofrecer respuestas ante eventos adversos o derivados de situaciones de crisis que vulneran derechos. En general, las primeras suelen ser la resultante de una formulación que se inicia en un diagnóstico de la situación alimentario-nutricional y sus factores determinantes; y las prestaciones que las conforman suelen responder a estándares o criterios de rigurosidad variable, aunque presentes en su diseño. Las segundas no desconocen los resultados de diagnósticos de diversa índole, aunque suelen presentar rasgos más laxos en sus estándares y diseño nutricional o técnico.

La cobertura y concentración de acciones en la etapa crítica del embarazo y los primeros dos años de vida (primeros 1000 días) en especial en población de alta vulnerabilidad social es clave en materia de cuidados nutricionales y de salud y sus efectos trascienden y comprometen a momentos distantes en el ciclo de vida (Lutter, 2012).

La detección temprana del embarazo; controles de salud y nutrición periódicos de la mujer embarazada; suplementación con nutrientes potencialmente deficitarios; atención de calidad en el momento del parto; lactancia exitosa y exclusiva los primeros seis meses de vida; inicio oportuno y con adecuada consejería de la alimentación complementaria a partir del sexto mes; aseguramiento de alimentos de alta densidad de nutrientes en la ventana de los 1000 días; educación alimentaria con énfasis en los aspectos sensoriales y el desarrollo del gusto por alimentos de buena calidad nutricional (también en la misma ventana temporal); vigilancia sensible del crecimiento físico y desarroIlo; y promoción activa para el mantenimiento de la lactancia materna. Se trata de diez acciones estratégicas que habitualmente se despliegan en los clásicos programas materno-infantiles (Bryce, 2008). 
Luego del segundo año de vida, las estrategias de alimentario-nutricionales deben seguir promoviendo -en particular en grupos de alta vulnerabilidad social- una alimentación saludable, preponderantemente conformada por los alimentos de los primeros cinco grupos de las Guías Alimentarias para la Población Argentina (GAPA) y de alta densidad de nutrientes y mantener mensajes y estrategias efectivas de educación alimentaria- con prioridad en los casi 1500 días posteriores hasta el ingreso a la escolaridad- que es cuando los hábitos alimentarios principales suelen consolidarse. Estas dos acciones (alimentación saludable y educación alimentaria) son prioritarias entre las estrategias nutricionales en primera infancia.

Ambos tipos de intervenciones (que no conforman un conjunto excluyente y limitado solo a ellas) forman parte, no en forma completa ni suficientemente coordinada, de distintas políticas en el nivel nacional y -con mucha heterogeneidad- en los provinciales, con la finalidad de asegurar una nutrición saludable en el momento más crítico del ciclo de vida o bien atender la problemática de la malnutrición extendida en nuestros niños.

En lo que sigue de este capítulo se describe la operatoria de los principales programas nacionales que abordan estas intervenciones claves y que conforman -en un rasgo distintivo comparado con los programas de asistencia alimentaria- un subconjunto de estrategias con mayor cercanía a lineamientos o estándares alimentarios propios del rol de la nutrición en el ciclo de vida. El segundo apartado tiene el propósito de presentar el núcleo de programas que atienden la salud nutricional de las mujeres embarazadas y niños pequeños, en particular hasta el segundo año de vida. El tercer apartado presenta la descripción del Plan Nacer, luego extendido y su nombre modificado como Plan Sumar, que constituye desde hace ya 16 años el pilar de la estrategia sanitaria más global e implementados con el objetivo de aumentar la cobertura y mejorar la calidad de atención en salud materno-infantil. El objetivo del apartado cuarto es presentar la historia y estado actual de los programas del área de Salud que, desde un enfoque regulatorio y educativo, se orientan a la promoción de alimentación saludable y prevención de obesidad infantil. El quinto apartado repasa las cuestiones institucionales y la coherencia interna y externa de las acciones descriptas en los apartados anteriores; y finalmente el último apartado (punto 6) presenta algunas conclusiones y recomendaciones en el contexto de las medidas y programas anunciados en diciembre 2019 con el inicio de la nueva gestión gubernamental.

\section{POLÍTICAS NUTRICIONALES EN EL SEGMENTO MATERNO-INFANTIL}

La atención nutricional de las mujeres embarazadas y niños menores de 2 años se ejecuta desde hace por lo menos ocho décadas en el ámbito de programas que dependen de la actual Dirección Nacional de Maternidad, Infancia y Adolescencia (DINAMIA) del Ministerio de Salud nacional. La DINAMIA es el órgano de formulación y ejecución de diferentes líneas de acción orientadas a los niños, adolescentes y mujeres en edad reproductiva. Las acciones nutricionales contemplan asistencia técnica y financiera, diseño de normativas y capacitación a equipos de salud de las diferentes jurisdicciones subnacionales.

En el ámbito nutricional y en forma específica, la DINAMIA elabora y capacita sobre normas de control del crecimiento y estado nutricional; promoción activa de la lactancia materna y alimentación complementaria; educación alimentaria referenciada en las Guías Alimentarias para la Población Argentina (GAPA) y para la Población Infantil (GAPI); y captación y rehabilitación de la población con malnutrición. 
Históricamente, esta Dirección ha sido responsable de tres normativas clave en la atención nutricional de embarazadas y niños: las guías de evaluación del estado nutricional mediante antropometría; los criterios de entrega de leche fortificada y las guías alimentarias en sus dos versiones: GAPA y GAPI. Más recientemente la DINAMIA también elaboró y difundió el documento sobre Orientaciones para la prevención, detección y tratamiento de la obesidad infantil, complementario de la primera.

\section{Distribución de leche}

A partir de la sanción de la Ley 24459 en el año 2001, el insumo alimentario (leche) que distribuye no solo la DINAMIA sino todos los programas alimentarios del nivel nacional deben ser fortificada con hierro, zinc y vitamina $\mathrm{C}$ como parte de la estrategia adoptada para la prevención de anemia por deficiencia de hierro.

La entrega de leche está condicionada a un control de salud, valoración del estado nutricional y cumplimiento del calendario de vacunación. La frecuencia y cantidad de entrega es: a) Embarazadas: $2 \mathrm{~kg} / \mathrm{mes}$ desde el $5^{\circ}$ mes de embarazo y hasta el momento del parto; b) Madres que amamantan: $2 \mathrm{~kg} /$ mes durante 6 meses; c) Niños de 6 meses a 1 año: $2 \mathrm{~kg} / \mathrm{mes}$ para complementar alimentación; d) Niños de 1 a 2 años: 1kg/mes; e) Niños con diagnóstico de riesgo de desnutrición: $2 \mathrm{~kg} / \mathrm{mes}$. Anualmente, la DINAMIA realiza una proyección de la cantidad de leche que se requerirá para el ejercicio presupuestario del año posterior en base a estimaciones propias sobre la cobertura efectiva de atención en centros públicos de salud y cantidad de controles. De esa manera, la última estimación (Oficina Nacional de presupuesto; presupuesto 2019) alcanza unos 12 millones de kilos de leche fortificada.

Hasta 2018 la prestación alimentaria se realizó en el marco del Programa de Atención de la madre y el niño (Ministerio de Salud), mientras que a partir de 2019 pasó a ejecutarse como parte del conjunto de acciones del programa Políticas Alimentarias del Ministerio de Desarrollo Social. Las compras son ejecutadas por la administración nacional y la leche es distribuida a las provincias según un algoritmo de coparticipación que pondera datos de pobreza, mortalidad infantil y población de cada jurisdicción. La cobertura efectiva de leche en cada locación es una variable dependiente de la logística propia de cada provincia y su articulación cada municipio.

Por otra parte, es conocido que en los últimos años algunas provincias compran leche con sus propias partidas presupuestarias, aunque esa leche no es necesariamente fortificada ya que no se origina en programas nacionales. Según algunas estimaciones aproximadamente el $80 \%$ de la leche distribuida se origina en las compras del nivel nacional, aunque el porcentaje es variable entre jurisdicciones. La distribución de leche a madres y niños en cada provincia normalmente se adecua a la disponibilidad efectiva de recursos (leche o dinero) y a la población que cada provincia prioriza, lo que determina que la cantidad y frecuencia de recepción sea variable en cada jurisdicción y aún dentro de ellas.

Por otra parte, a nivel del efector de salud (centro de atención primaria de salud o CAPS), es históricamente conocido que el criterio de entrega adquiere cierta flexibilidad en función de la disponibilidad efectiva y el cronograma de recepción de leche y los propios criterios que le imprime el equipo de salud. En ocasiones el stock de leche disponible se diversifica en la población asistente al centro de salud independientemente de los criterios normativos.

Todas estas características son conocidas, aunque nunca han sido objeto de alguna medición rigurosa (compras locales de leche, condición de fortificación, frecuencia y cantidad efectiva distribuida en base a stocks y cumplimiento del criterio normativo de distribución). Uno de los pocos datos pu- 
blicados analizó la cobertura (aparente) de entrega de leche en el consolidado nacional, comparado con la meta física de cada año, resultando un 51\% promedio en la serie 1997-2012 (Abeyá, 2016).

Una investigación realizada por nuestro equipo (Britos, 2015) sobre una muestra de 301 niños de la ciudad de Rosario, beneficiarios del programa materno-infantil halló que, si bien la leche fortificada del programa resultó la más consumida (dos tercios de la muestra), solo el 34\% de las madres entrevistadas manifestó que sus niños la consumieron el día previo al recordatorio dietético. La preparación de la leche (en polvo) se realizó en forma correcta (dilución recomendada) solo en el $9 \%$ de los casos; $60 \%$ de las madres la diluyeron a menos del $12 \%$ y $33 \%$ a menos del $10 \%$.

La principal fortaleza que se le adjudica a la DINAMIA y al despliegue de sus acciones alimentarionutricionales reside en su capacidad normativa y en el criterio técnico-profesional de sus equipos y sus acciones de asistencia técnica, capacitación y promoción activa de lactancia materna y alimentación complementaria luego del sexto mes de vida. La estimación presupuestaria de la meta de 12 millones de $\mathrm{kg}$ de leche fortificada (valor U\$S 5,34/kg) es de aproximadamente $\$ 3844$ millones anuales (cálculos propios en base a estimación presupuestaria y precios de mercado).

\section{Prevención y recuperación de desnutrición}

Desde una institucionalidad diferente, en el Ministerio de Desarrollo Social (Secretaría Nacional de Niñez, Adolescencia y Familia, SENNAF) y en el marco del Plan Nacional de Primera Infancia (Decreto PE 574/2016), existen unos 40 centros de prevención y recuperación de desnutrición infantil que atienden a unos 2.835 niños (presupuesto 2019) y que funcionan por medio de convenios con organizaciones de la sociedad civil para el seguimiento nutricional y garantía de alimentación adecuada a la edad y condición nutricional de los niños. En el mismo año de creación del programa (2016), el Ministerio de Desarrollo Social firmó un convenio con la Fundación CONIN (Corporación para la Nutrición Infantil) con el propósito de difundir su metodología como pilar de las acciones en los centros de prevención y recuperación.

La Fundación CONIN es un centro privado que inició su labor en 1993 y desarrolla programas integrales orientados a acompañar al grupo familiar a través de acciones de asistencia y educación en salud, nutrición, estimulación, promoción humana y desarrollo de habilidades en particular en las mujeres. No se conoce la articulación entre las acciones nutricionales de estos centros y las propias de la DINAMIA. Algunos testimonios de equipos y referentes de salud refieren la existencia de contradicciones y superposiciones entre la participación de CONIN y las propias acciones desarrolladas por los CAPS y los establecimientos hospitalarios de referencia para casos de niños desnutridos. El presupuesto 2019 preveía una partida de 50 millones de pesos para el fortalecimiento de estos centros.

\section{EI PLAN NACER/SUMAR COMO ESTRATEGIA GLOBAL EN EL SEGMENTO MATERNO-INFANTIL}

El Plan Nacer surge (Res. Ministerio de Salud 198/2003) en 2003 en un contexto (posterior a la aguda crisis de 2001 y a la prórroga de la declaración de la emergencia sanitaria) en que los indicadores de salud informaban resultados preocupantes. Su objetivo fue fortalecer la estrategia de atención primaria de la salud, en particular en los segmentos de mayor vulnerabilidad social. En 
aquellos años más de la mitad de la población carecía de cobertura del sistema de seguro de salud. El porcentaje de la población sin cobertura alcanzaba valores de $63 \%$ en Corrientes y $52 \%$ en Misiones y San Luis (CIPPEC 2012). Entre 2000 y 2002, la tasa de mortalidad infantil de Argentina aumentó de 16,6 a 16,8 por cada 1000 nacidos vivos, y en las provincias más pobres del noreste y noroeste del país la mortalidad infantil fue de hasta 25 por cada 1000 nacidos vivos (Cortez y Romero 2013).

A través del Plan Nacer se comenzó a otorgar financiamiento nacional para asegurar prestaciones de salud dirigidas a embarazadas y niños menores de 6 años que carecían de cobertura de salud. Inicialmente se implementó en nueve provincias del norte argentino. Tres años más tarde, el programa se extendió hacia el resto de las provincias y en 2012 (Res. Ministerio Salud 1195/2012), con el fin de extender los beneficios a los niños y adolescentes hasta los 19 años y mujeres entre 20 y 64 años, se puso en marcha el Programa SUMAR, el cual no es más que el resultado de la ampliación del Plan Nacer.

Una de las principales características del Plan Nacer es que las acciones se acompañaron de un proceso de gestión del financiamiento por resultados con la intención de optimizar las capacidades institucionales y con foco en problemas prioritarios. La gestión del financiamiento por resultados se basa en un conjunto de metas trazadoras que miden el desempeño de los CAPS y funcionan como un mecanismo de incentivo para que los mismos realicen mejoras en sus procesos, además de promover la evaluación de las acciones llevadas a cabo.

Originalmente se incluyeron 10 medidas sanitarias trazadoras (una de las cuales es la alimentación) que buscaban priorizar las acciones dirigidas a disminuir la morbimortalidad materna e infantil, aumentar la accesibilidad al sistema de salud por los adolescentes, aumentar la prevención oportuna del cáncer en mujeres; promover la inclusión de la población indígena, y aumentar la cobertura efectiva básica. Actualmente las metas son 14 y son monitoreadas de manera cuatrimestral (gráfico 1).

\section{Gráfico 1. Matriz de medidas sanitarias trazadoras del Programa Nacer/Sumar}

\begin{tabular}{|c|c|c|c|}
\hline$\stackrel{\circ}{1}$ & $\begin{array}{l}\text { ATENCIÓN TEMPRANA DE EMBARAZO } \\
\text { Mujeres embarazadas atendidas antes de la semana } 13 \text { de } \\
\text { gestación. }\end{array}$ & & $\begin{array}{l}\text { COBERTURA DE INMUNIZACIONES A LOS } 24 \text { MESES } \\
\text { Niños de } 2 \text { años que recibieron las vacunas cuádruple bacteriana } \\
\text { (o quíntuple) y antipoliomielítica entre } 15 \text { meses y } 2 \text { años. }\end{array}$ \\
\hline & $\begin{array}{l}\text { SEGUIMIENTO DE EMBARAZO } \\
\text { Realización de los controles en mujeres embarazadas. }\end{array}$ & & $\begin{array}{l}\text { COBERTURA DE INMUNIZACIONES A LOS } 7 \text { AÑoS } \\
\text { Niños de } 7 \text { años que recibieron las vacunas triple bacteriana, triple } \\
\text { viral (o doble viral) y antipoliomielítica entre los } 5 \text { años y los } 7 \text { años. }\end{array}$ \\
\hline & $\begin{array}{l}\text { EFECTIVIDAD DEL CUIDADO NEONATAL } \\
\text { Evalúa la calidad de atención de niños con peso al nacer entre } 750 \\
\text { y } 1.500 \text { grs. y con sobrevida a los } 28 \text { dias desde el nacimiento. }\end{array}$ & & $\begin{array}{l}\text { SEGUIMIENTO DE SALUD DEL ADOLESCENTE } \\
\text { DE } 10 \text { A } 19 \text { AÑOS } \\
\text { Realización de los controles en adalescentes de } 10 \text { a } 19 \text { años. }\end{array}$ \\
\hline 4 & $\begin{array}{l}\text { SEGUIMIENTO DE SALUD DEL NIÑO MENOR DE } 1 \text { AÑo } \\
\text { Realización de los controles en niños menores de } 1 \text { año. }\end{array}$ & & $\begin{array}{l}\text { PROMOCIÓN DE DERECHOS Y CUIDADOS EN SALUD } \\
\text { SEXUAL Y/O REPRODUCTIVA } \\
\text { Talleres sobre cuidado sexual y/o reproductivo brindados a adolescentes } \\
\text { entre } 10 \text { y } 19 \text { años y mujeres hasta } 24 \text { años (intra o extramuro). }\end{array}$ \\
\hline & $\begin{array}{l}\text { EQUIDAD INTRAPROVINCIAL EN EL SEGUIMIENTO } \\
\text { DE SALUD DE MENORES DE } 1 \text { AÑ̃ } \\
\text { Evalúa el desempeño y la calidad de atención a nivel provincial } \\
\text { de la trazadora } 4 \text { (controles de niños menores de } 1 \text { año). }\end{array}$ & & $\begin{array}{l}\text { PREVENCIÓN DE CÁNCER CÉRVICO UTERINo } \\
\text { Mujeres de } 25 \text { a } 64 \text { años con lesiones de alto grado o carcinoma de } \\
\text { cuello uterino diagnosticados en el último año. }\end{array}$ \\
\hline 6 & $\begin{array}{l}\text { CAPACIDAD DE DETECCIÓN DE CASOS DE } \\
\text { CARDIOPATÍA CONGÉNITA EN EL MENOR DE } 1 \text { AÑo } \\
\text { Niños menores de } 1 \text { año con diagnóstico de cardiopatía } \\
\text { congénita y reporte al Centro Coordinador de Derivaciones. }\end{array}$ & & $\begin{array}{l}\text { CUIDADO DEL CÁNCER DE MAMA } \\
\text { Mujeres hasta } 64 \text { años con diagnóstico de cáncer de mama } \\
\text { efectuado en el último año. }\end{array}$ \\
\hline & $\begin{array}{l}\text { SEGUIMIENTO DE SALUD DEL NIÑo DE } 1 \text { A } 9 \text { AÑos } \\
\text { Realización de los controles en niños de } 1 \text { a g años. }\end{array}$ & & $\begin{array}{l}\text { EVALUACIÓN DEL PROCESO DE ATENCIÓN DE LOS } \\
\text { CASOS DE MUERTES INFANTILES Y MATERNAS } \\
\text { Evalúa el proceso de atención de los casos de muertes matemo- } \\
\text { infantiles. }\end{array}$ \\
\hline
\end{tabular}

Fuente: Ministerio de Salud de la Nación, 2014. 
El proceso de financiamiento ocurre en tres etapas, en la primera, el gobierno nacional transfiere a las provincias un pago capitado ajustado por desempeño, es decir que las jurisdicciones reciben el $60 \%$ de una base capitada en función de la nominalización de la población y el $40 \%$ restante por el cumplimiento de determinadas metas sanitarias. En una segunda instancia, las provincias pagan a los establecimientos de salud por un paquete básico de servicios del Plan de Servicios de Salud (PBS) a través de Seguros Provinciales de Salud. Los seguros, también se definen en función del desempeño.

Una vez que los establecimientos locales reciben el financiamiento, redireccionan y administran los recursos de manera autónoma, según prioridades y necesidades específicas, aunque siguiendo los lineamientos generales de la autoridad nacional. La utilización de los fondos se organiza según categorías y subcategorías de gastos. La autonomía en la asignación de recursos que tienen los equipos de salud facilita la toma de decisiones para la priorización teniendo en cuenta los diferentes contextos, lo que ha permitido generar estrategias que han impactado positivamente en el abordaje territorial de la salud de poblaciones originarias.

Originalmente el presupuesto se originaba en su totalidad en fondos nacionales; con el tiempo las provincias comenzaron a cofinanciar el Plan, pero manteniendo el nivel nacional su rol de coordinación. La modalidad de financiamiento por resultados ha generado un sistema de registros, auditoría y evaluación novedoso, por medio del cual se hace un seguimiento de la utilización de los fondos por medio de rendiciones de cuentas. Los establecimientos de salud deben facturar solamente los servicios incluidos en el PBS, nominalizándolo por beneficiario.

En 2014 se estableció la estrategia de priorización de efectores, en base a la cual se asignan los fondos según desempeño; esa estrategia es la que permite un adecuado seguimiento de resultados, dando lugar a procesos de reformulación y mejoramiento. De esta forma se evalúan los progresos y se generan aprendizajes en un proceso continuo de identificación de nuevos desafíos y ajustes a la estrategia. La gestión por resultados ha generado dentro del programa la cultura de aprendizaje y de evaluación.

En el mismo año se presentaron una serie de informes de resultados que describen los logros alcanzados en diferentes aspectos (Sabignoso, 2014). Uno de ellos es la capacidad prestacional en base a la cantidad de establecimientos que prestan servicios y la eficacia de los mismos. Esta serie de estudios permitieron comprobar que los incentivos financieros a los profesionales de salud influyen en la calidad del servicio. La tasa de inicio temprano de la atención prenatal fue $34 \%$ mayor en un grupo en los que se pagaron incentivos a los profesionales que en el grupo de comparación $(0,42$ frente a 0,31$)$.

Tomando como referencia la población beneficiaria de Tucumán y Misiones se evaluaron algunas prestaciones del Plan Nacer. Se observó una mejoría en el peso al nacer promedio de niños nacidos de madres con cobertura del Programa (70 gramos mayor que el de aquellos sin programa); la cantidad de niños con muy bajo peso al nacer (menor que 1.500 gramos) se redujo en un $26 \%$ para los niños con cobertura; el resultado del test Apgar ${ }^{17}$ se incrementó y se identificó un incremento en la probabilidad de cuidado prenatal temprano (antes de la semana 13 de gestación) de 8,5\% y de $17,6 \%$ antes de la semana 20.

Para ese entonces, se asoció el Plan Nacer a un aumento en la aplicación de vacunas a embarazadas reduciendo un $32 \%$ la probabilidad de muerte al nacer y un 19\% la probabilidad de bajo peso al nacer. El Conicet ha colaborado con el Plan Sumar realizando un análisis de datos de 1,4 millones de niños menores de 5 años en situación de vulnerabilidad que fueron atendidos en más de 6.500

\footnotetext{
${ }^{17}$ El test Apgar es una prueba que se realiza a los recién nacidos poco después del nacimiento. Evalúa la frecuencia cardíaca, tono muscular y otros signos para determinar si necesita ayuda médica adicional o de emergencia.
} 
centros de salud durante los años 2005 y 2013. Los resultados de este análisis reflejaron una reducción del $45 \%$ en la prevalencia de retraso en el crecimiento y del $38 \%$ en la prevalencia de bajo peso (Nuñez, 2015).

Para alcanzar los resultados esperados, durante toda su trayectoria, el plan Nacer articula acciones con diferentes organismos, direcciones y programas como la Dinamia, el Programa Nacional de Salud Integral en la Adolescencia (PNSIA), el Programa Nacional de Salud Sexual y Procreación Responsable (PNSSTPR), el Programa Nacional de Cáncer Cérvico Uterino (PNCCU) y el Instituto Nacional del Cáncer (INC).

Con el comienzo de la Asignación Universal por Hijo (AUH) y la Asignación por embarazo, el Plan Nacer tuvo un rol de colaboración que permitió agilizar el proceso de identificación de beneficiarios gracias al sistema de información con el que cuenta. En concreto, más de 200 mil beneficiarios del Nacer que no formaban parte del padrón utilizado para la identificación de beneficiarios de la AUH comenzaron a recibir la asignación.

En el año 2010 se generó una articulación entre el Plan Nacer y el Programa Nacional de Cardiopatías Congénitas (PNCC).Teniendo en cuenta que las cardiopatías congénitas tienen una elevada incidencia en la mortalidad infantil, y que su diagnóstico y tratamiento oportuno deben ser prioridad sanitaria de la salud infantil, el Plan Nacer generó acuerdos institucionales a través de los cuales se estableció que todas las jurisdicciones incorporaran estrategias y adapten las herramientas e instrumentos del Plan Nacer para la detección y tratamiento de estas patologías, teniendo en cuenta la complejidad que suponen.

Por otra parte, la Facultad de Ciencias Económicas de la Universidad Nacional de La Plata realizó un estudio que evaluó el costo de incluir nuevas prestaciones, y analizó la capacidad de atención disponible (Sabignoso, 2014). Como resultado, la estructura de gestión financiera del Plan Nacer tuvo modificaciones que implicaron la creación de un Fondo Solidario Federal y se determinó que los Seguros Provinciales de Salud tengan a cargo la gestión de las cardiopatías de baja y mediana complejidad. Los ingresos que reciben los establecimientos participantes del PNCC son adicionales a su presupuesto tradicional. Esta articulación implicó por parte del Plan Sumar una gran inversión en equipamiento, en el desarrollo de herramientas de comunicación y de capacitación profesional. Además, a través de la modalidad del Plan Nacer se obtuvo una mejor organización y mayor eficiencia en la gestión para la resolución de las patologías congénitas.

Desde los inicios del programa hasta agosto del 2019 la cantidad de beneficiarios alcanzó un total de alrededor de 28.8 millones de personas. En total se han financiado más de 174 millones de prestaciones de salud (Reporte de gestión del programa Sumar, agosto 2019).

Los establecimientos que prestan servicios del Programa se encuentran distribuidos a lo largo del todo el país. Casi la mitad de estos están en la zona centro (Buenos Aires, Córdoba, Entre Ríos, Santa Fe y C.A.B.A.), y un 30\% en el noreste y noroeste argentino. En menor proporción se encuentran en la zona de Cuyo y en la Patagonia. En total existen 8018 establecimientos sanitarios con convenio (Cuadro 1) 
Cuadro 1. Distribución por regiones de beneficiarios, establecimientos y fondos del Plan Nacer/Sumar

\begin{tabular}{|c|c|c|c|c|c|}
\hline $\begin{array}{l}\text { Cantidad de beneficiarios actua- } \\
\text { les }\end{array}$ & $\begin{array}{c}\text { NOA } \\
\text { (Catamarca, } \\
\text { Santiago del } \\
\text { Estero } \\
\text { Tucumán, } \\
\text { Salta y Jujuy) }\end{array}$ & $\begin{array}{c}\text { NEA } \\
\text { (Formosa, } \\
\text { Chaco, } \\
\text { Corrientes } \\
\text { y Misiones) }\end{array}$ & $\begin{array}{l}\text { CENTRO } \\
\text { (Buenos Ai- } \\
\text { res, Córdoba, } \\
\text { Entre Ríos, } \\
\text { Santa Fe y } \\
\text { C.A.B.A.) }\end{array}$ & $\begin{array}{c}\text { CUYO } \\
\text { (Mendoza, } \\
\text { San Juan, } \\
\text { San Luis } \\
\text { y La Rioja) }\end{array}$ & $\begin{array}{c}\text { PATAGONIA } \\
\text { (La Pampa, } \\
\text { Neuquén, } \\
\text { Río Negro, } \\
\text { Chubut, Santa } \\
\text { Cruz y Tierra } \\
\text { del Fuego) }\end{array}$ \\
\hline niños/as de 0 a 5 años & 345.591 & 302.358 & 1442.680 & 200.431 & 110.441 \\
\hline niños/as de 6 a 9 años & 213.118 & 197.833 & 936.836 & 114.937 & 75.641 \\
\hline adolescentes de 10 a 19 años & 467.344 & 472.077 & 200.181 & 262.694 & 154.183 \\
\hline mujeres de 20 a 64 años & 701.076 & 552.747 & 2.964 .320 & 392.646 & 248.005 \\
\hline hombres de 20 a 64 años & 629.578 & 573.586 & 2.870 .470 & 339.462 & 215.683 \\
\hline $\begin{array}{l}\text { Establecimientos de salud con } \\
\text { convenio }\end{array}$ & 1.433 & 1.087 & 3.900 & 921 & 677 \\
\hline $\begin{array}{l}\text { Total de fondos transferidos } \\
2019\end{array}$ & 260.292 .963 & 232.934 .291 & 692.823 .312 & 118.419 .622 & 58.968 .608 \\
\hline
\end{tabular}

Fuente: Reporte de gestión del programa Sumar, agosto 2019

En 2018 el Ministerio de Salud difundió un documento que refleja el estado de sobrepeso y obesidad de niños, niñas y adolescentes que recibieron atención médica bajo el Programa Sumar durante los años 2014 y 2016 , evidenciando una tendencia en aumento en la que el exceso supera el $30 \%$. Los resultados muestran además que el exceso de peso aumenta con la edad alcanzando el porcentaje más alto en la adolescencia (37\%). Si bien la malnutrición por bajo peso está presente en un $8 \%$ de la población estudiada, presenta una tendencia decreciente según los datos del Plan Sumar.

La información es muy consistente con los datos de la segunda Encuesta Nacional de Nutrición y Salud -ENNyS II- (Ministerio de Salud, 2019), que, realizada en 2018 también reflejó que el bajo peso, la emaciación y la baja talla se mantienen en valores similares a los obtenidos en la primera edición de la ENNyS (2005). En el 2018 los valores de estos indicadores antropométricos en niños menores a 5 años fueron de 1.7\%, 1.6\% y 7.9\% (bajo peso, emaciación y baja talla respectivamente). La delgadez y baja talla en la población de 5 a 17 años no supera el 1,4\% y $7 \%$ respectivamente. Mientras que, por otro lado, se observa una tendencia en ascenso en la prevalencia de exceso de peso, la cual, afecta al $13.6 \%$ de los niños menores de 5 años, y adquiere valores del orden del $41.1 \%$ en la adolescencia. En adultos el exceso de peso tiene una prevalencia de 67,9\%.

Ambos estudios dan cuenta aportan indicios de que las estrategias llevadas a cabo para la detección temprana y cuidado del embarazo, los cuidados neonatales y controles clínicos pueden haber alcanzado el impacto esperado sin embargo es necesario replantear la problemática del exceso de peso como una medida trazadora debido al impacto negativo que tiene en la salud (lo que se analiza a continuación). 
Cuadro 2. Resumen de los principales hitos de las políticas nutricionales en el segmento materno-infantil descriptos en los apartados 2 y 3

\begin{tabular}{|c|c|c|c|c|}
\hline Hito & Año & Instrumento & Principales líneas & Observaciones o avances \\
\hline $\begin{array}{l}\text { "Ley Palacios", crea- } \\
\text { ción de la original } \\
\text { Dirección de Mater- } \\
\text { nidad e } \\
\text { Infancia }\end{array}$ & 1936 & Ley 12341 & $\begin{array}{l}\text { La Ley es la primera respuesta del } \\
\text { Estado para atender los problemas } \\
\text { de salud, nutrición y alimentación de } \\
\text { la población materno-infantil en situa- } \\
\text { ción de pobreza }\end{array}$ & $\begin{array}{l}\text { En } 1952 \text { empieza la distribución de leche } \\
\text { en el marco del programa }\end{array}$ \\
\hline $\begin{array}{l}\text { Fortificación de la } \\
\text { leche con } \\
\text { hierro, zinc y } \\
\text { vitamina C }\end{array}$ & 2001 & Ley 24459 & $\begin{array}{l}\text { Establece la fortificación obligatoria } \\
\text { de todas las leches que se distribu- } \\
\text { yen desde programas alimentarios } \\
\text { nacionales }\end{array}$ & $\begin{array}{l}\text { No se conocen evaluaciones de su im- } \\
\text { pacto }\end{array}$ \\
\hline $\begin{array}{l}\text { Plan Nacional de } \\
\text { 1ra infancia }\end{array}$ & 2016 & $\begin{array}{l}\text { Decreto Poder } \\
\text { Ejecutivo } \\
(574 / 2016)\end{array}$ & $\begin{array}{l}\text { Entre sus diferentes líneas de acción } \\
\text { contempla el fortalecimiento de cen- } \\
\text { tros de prevención y tratamiento de } \\
\text { desnutrición }\end{array}$ & $\begin{array}{l}\text { No existen dispositivos formales que esta- } \\
\text { blezcan la integralidad y articulación entre } \\
\text { estos centros y las acciones de rutina de } \\
\text { los centros de atención primaria de salud }\end{array}$ \\
\hline Plan Nacer & 2009 & $\begin{array}{l}\text { Resolución Minis- } \\
\text { terio Salud } \\
(198 / 2003)\end{array}$ & $\begin{array}{l}\text { Establece seguros públicos de salud } \\
\text { para la población materno-infantil sin } \\
\text { cobertura con la finalidad de garanti- } \\
\text { zar un conjunto priorizado de presta- } \\
\text { ciones }\end{array}$ & \\
\hline Plan Sumar & 2012 & $\begin{array}{l}\text { Resolución Minis- } \\
\text { terio Salud } \\
\text { (1195/2012) }\end{array}$ & $\begin{array}{l}\text { Extiende los seguros del Plan Nacer } \\
\text { a niños y adolescentes hasta } 19 \text { años } \\
\text { y mujeres de } 20 \text { a } 64 \text { años }\end{array}$ & $\begin{array}{l}\text { Ambas versiones (Nacer-Sumar) confor- } \\
\text { man, desde su creación (2009) y posterior } \\
\text { ampliación (2012) la principal estrategia } \\
\text { de seguros públicos de salud en cuyo } \\
\text { marco se desarrollan las prestaciones ali- } \\
\text { mentario-nutricionales del ámbito de Salud }\end{array}$ \\
\hline
\end{tabular}

Fuente: elaboración propia 


\section{Plan Argentina contra el Hambre y Plan 1000 días en el contexto de las políticas nu- tricionales del segmento materno-infantil}

La actual gestión de Gobierno, iniciada en diciembre de 2019 anunció, aún antes de haber asumido el gobierno el combate contra la inseguridad alimentaria o hambre como una de sus principales políticas.

En sus fundamentos, la Resolución de creación del Plan (Res. Ministerio de Desarrollo Social 8/2020) reconoce a la inseguridad alimentaria como el problema social más importante por enfrentar. Su objetivo general es la garantía de la seguridad y soberanía alimentaria de toda la población, en particular la de mayor vulnerabilidad económica y social. Y sus objetivos específicos, seis, comprenden la implementación de un sistema que complemente los ingresos del hogar con destino a alimentos, en especial en familias con embarazadas, niños menores de 6 años y personas con discapacidad; fortalecer las prestaciones alimentarias en general; favorecer la economía y producción local y cooperativa de alimentos y la agricultura familiar; promover hábitos saludables de alimentación y diseñar un sistema de monitoreo y evaluación de los resultados del Plan.

Desde su inicio las autoridades han reconocido el diagnóstico de elevada prevalencia de malnutrición por sobrepeso en la infancia y promueve la direccionalidad de sus acciones hacia hábitos y consumo de alimentos que contribuyan de manera saludable.

El avance que hasta el momento representa el punto más visible del Plan es la Tarjeta AlimentAR, un dispositivo a través del cual se transfiere a las familias beneficiarias (familias que perciben la Asignación Universal por Hijo -AUH-, con embarazadas, niños menores de 6 años o personas discapacidad) un monto mensual de $\$ 4000$ o $\$ 6000$ dependiendo de que existan uno o más niños respectivamente.

La tarjeta es un instrumento previsto para la compra de alimentos, con excepción de bebidas alcohólicas; y si bien no hay ninguna restricción a los productos elegidos por sus titulares, existe una importante estrategia de sensibilización e información para que las familias prioricen la compra de los alimentos de mejor calidad nutricional. Para reforzar este concepto, la Mesa Técnica del Plan (con representantes del ámbito académico y profesional de la nutrición) ha elaborado un listado de alimentos de elección recomendada.

Como parte de la estrategia de implementación de la Tarjeta AlimentAR, las autoridades (Ministerio de Desarrollo Social y Consejo Nacional de Coordinación de Políticas Sociales) están desplegando un importante esfuerzo para favorecer los procesos de producción local y agricultura familiar, instalación de ferias, conformación de promociones de productos provenientes de la economía local. El objetivo es ampliar y diversificar la oferta de alimentos, actualmente muy concentrada en pocas empresas en rubros significativos de consumo y comercialización.

Más recientemente, el propio presidente de la Nación ha anunciado la próxima creación de un Plan identificado como "de los 1000 días". Es poco aun lo que se conoce del mismo, cuya implementación se ha presentado como parte y complemento de la propuesta de legalización de la interrupción voluntaria del embarazo.

El concepto de 1000 días refiere al tiempo que transcurre entre el embarazo y los primeros dos años de vida; se trata de una ventana estratégica de intervenciones en salud, nutrición y desarrollo infantil debido a la trascendencia que adquieren las mismas en su proyección a mejores estándares de nutrición y salud en el ciclo de vida. La concentración, fortalecimiento e integralidad de las acciones en esa ventana temporal es ampliamente recomendada y su importancia reconocida desde los primeros aportes de David Barker (Barker D, 1993) relacionados a la programación fetal. El aseguramiento de un paquete de intervenciones relacionadas a la salud de la madre y control de su embarazo; parto seguro y de calidad; promoción activa de la lactancia materna, exclusiva primero y luego extendida; alimentación complementaria oportuna y de calidad luego del sexto mes de vida y extendida en el 1er año; control y vigilancia activa y sensible del crecimiento; educación (alimentaria y relativa a cuidados del niño); preparación para una buena crianza y provisión de bienes relacionados con el crecimiento y desarrollo tempranos son algunas de las medidas que se promueven como parte de las estrategias de cuidados especiales en los 1000 días críticos.

Antes de la pandemia, se suponía que, una vez conocido el diseño del mismo, se iba a observar una importante integración de sus acciones con las propias de la Dinamia y del Plan Nacer/Sumar. 


\section{ESTRATEGIAS DE PROMOCIÓN PARA LA ALIMENTACIÓN SALUDABLE}

El Programa Nacional de Promoción de la alimentación saludable y prevención de obesidad se inicia en 2016 aunque sus orígenes se remontan probablemente a la sanción de la Ley 26396 (2008) sobre prevención y control de trastornos alimentarios. Esta Ley, en particular en sus artículos 6to, $7 \mathrm{mo}, 8 \mathrm{vo}$ y $9 \mathrm{no}$ aportaba la base para la formulación de una estrategia de promoción de la alimentación saludable. Sin embargo, hasta el momento el instrumento legislativo solamente desarrolló los dispositivos vinculados con el tratamiento de la obesidad y trastornos alimentarios.

No obstante, un año después, la resolución del Ministerio de Salud 1083/09 aprobó la Estrategia Nacional para la prevención y control de enfermedades no transmisibles y creó el Plan Nacional "Argentina Saludable" en cuyo marco se identificó a la mala alimentación como uno de tres factores determinantes relevantes de enfermedades crónicas.

En el marco de la Estrategia y el Plan "Argentina Saludable" empezaron a desarrollarse diferentes líneas de acción de promoción, educación y comunicación de hábitos saludables en alimentación; estudios de factibilidad y acuerdos con la industria alimentaria para la reformulación de alimentos y bebidas y reducción del contenido de nutrientes críticos; y, por último, promoción de entornos saludables, en particular en el ámbito de municipios.

Uno de los primeros hitos de la Estrategia fue la incorporación al Código Alimentario Argentino (CAA) de un artículo que limita el contenido de ácidos grasos trans en alimentos (límites máximos de $2 \%$ y $5 \%$ del total de grasas de aceites/margarinas y de todo el resto de alimentos respectivamente); la resolución respectiva fijó un plazo para la reformulación de productos (hasta 2014) y fue posterior a una estrategia basada en mesas de diálogos y acuerdos progresivos entre el Ministerio de Salud y la industria local. La estrategia nacional en materia de reducción de ácidos grasos trans en alimentos es todavía reconocida como un caso exitoso líder en la región.

Una segunda experiencia previa a la institucionalización del Programa Nacional en 2016 fue el desarrollo de la Iniciativa (conjunta entre los Ministerio de Salud y de Agricultura) "Menos Sal Más Vida", orientada a la concientización de la población en relación con la necesidad de disminuir el consumo de alimentos con alto contenido de sodio y el menor agregado de sal a las comidas; lograr acuerdos voluntarios con la industria (similares al caso de ácidos grasos trans) para la reformulación de alimentos y disminuir el uso de sal en la producción de pan en panaderías.

En el mismo marco, en 2013 se sancionó la Ley 26905 cuyo principal objetivo es la reducción del consumo de sodio en la población y un conjunto de líneas de acción orientadas a promover hábitos saludables en torno a la ingesta de sodio. La ley fija los valores máximos de sodio que deberán contener ciertos grupos de alimentos, y los plazos de adecuación que tendrán las empresas elaboradoras. Y promueve la adhesión de las provincias para adecuar sus legislaciones en relación con el retiro del salero en restaurantes.

En 2015 más de 9.000 panaderías se habían adherido a la iniciativa "Menos Sal Más Vida", asegurando una disminución de $25 \%$ en el agregado de sal al pan artesanal. El objetivo propuesto es que en este año (2020) el consumo de sal no supere los $5 \mathrm{~g}$ por persona.

En 2015 y también como antecedente de la creación del Programa Nacional de promoción de la alimentación saludable y prevención de obesidad se actualizaron las Guías Alimentarias para la Población Argentina (GAPA), en el ámbito del Ministerio de Salud y como corolario del trabajo de una Comisión Asesora integrada por diferentes actores gubernamentales y provenientes de 
universidades, sociedades científicas, asociaciones profesionales y organizaciones de la sociedad civil con experiencia en la temática. Las GAPA constituyen la referencia oficial y estándar para el diseño de políticas públicas en aspectos regulatorios, de asistencia, capacitación, promoción y evaluación en materia de alimentación, según resolución del Ministerio de Salud (Res. 693/2019).

Posteriormente, en 2016 y por resolución ministerial (Res. 732/2016) se crea el Programa Nacional de promoción de alimentación saludable y prevención de obesidad, en el ámbito del Ministerio de Salud (Dirección de Promoción de la Salud y Prevención de enfermedades no transmisibles). Sus lineamientos estratégicos son muy amplios e incluyen la promoción de una dieta y de alimentos procesados saludables, la prevención y control del sobrepeso y obesidad y su vigilancia epidemiológica; el fortalecimiento de redes de atención; la educación a profesionales de salud; la comunicación masiva y la investigación en la temática.

En el marco del Programa se creó la Comisión Nacional del mismo y diferentes comités y subcomités de trabajo con actores gubernamentales, de universidades, sociedades científicas, asociaciones profesionales y organizaciones de la sociedad civil, especialistas en las temáticas de: etiquetado frontal de alimentos; publicidad, promoción y patrocinio de alimentos; entornos escolares saludables y reformulación de productos y reducción de nutrientes críticos (azúcar).

Como resultado del trabajo desarrollado entre 2017 y 2019, se generaron diferentes documentos base para la definición de estándares para el diseño de políticas públicas en las respectivas temáticas de cada uno: etiquetado frontal de alimentos; entornos escolares saludables; y publicidad, promoción y patrocinio de alimentos. De estos documentos, solo el segundo se formalizó a través de una resolución ministerial (Res. 564/2019) que lo identifica como la guía oficial para el diseño de entornos escolares saludables preventivos de obesidad. Hasta el momento, tres provincias (Jujuy, Corrientes y Neuquén) han firmado convenios para la aplicación de la guía en sus respectivas jurisdicciones.

Otro avance relevante en materia de programas alimentarios es el lanzamiento del Plan Nacional de prevención de obesidad en niños, niñas y adolescentes (Plan ASI), creado por resolución ministerial (Res. 996/2019). Este Plan se concibe como una política sanitaria integral para detener el crecimiento del sobrepeso y la obesidad infantil. Contempla cuatro componentes significativos: Educación Alimentaria y Nutricional y de Actividad Física; Comunicación, Sensibilización y Participación Social; Mejora de la calidad nutricional en los programas sociales alimentarios y promoción de sistemas alimentarios sostenibles para la producción y disponibilidad de alimentos frescos; y el cuarto, Regulación de entornos y productos. El Plan plantea la conformación de mesas de gestión para su implementación, integradas por los ministerios de Educación, Desarrollo Social y Producción, y organizaciones no gubernamentales, tanto a nivel nacional como provincial.

Por el momento, el Plan ASI ha avanzado en la suscripción de convenios de adhesión con 14 provincias, las que se encuentran en diferentes estados de avance en la conformación de mesas de diálogo y acuerdos intersectoriales en sus respectivas jurisdicciones. El Plan también ha avanzado en la articulación con el Ministerio de Educación para establecer una agenda de trabajo orientada en principio en dos cuestiones: la educación alimentario nutricional de docentes de escuelas de gestión pública y la implementación de la Guía de entornos escolares saludables. En el marco de esa articulación, en el último semestre de 2019 se desarrolló el 1er curso virtual de educación alimentario nutricional que fue cursado por más de 500 docentes de diferentes provincias y el Consejo Federal de Educación resolvió (Res. CFE 350/2019) iniciar el desarrollo progresivo de un Plan estratégico de entornos escolares saludables basado en las Guías respectivas y en el marco del Plan ASI. 
El tercer componente del Plan ASI aborda la cuestión del mejoramiento de la calidad nutricional de los programas alimentarios gubernamentales. Una de sus primeras acciones en este sentido fue la convocatoria a una mesa de trabajo con referentes no gubernamentales con experiencia reciente en estudios o propuestas de reformulación alineadas con este componente del Plan ASI. El primer caso elegido fue el de alimentación o comedores escolares, respecto del cual el equipo del Plan ASI inició un análisis de los modelos de gestión, presupuesto, modalidades de compra y calidad nutricional de la oferta de estos programas en varias provincias.

Aún no se conocen resultados de estos análisis y líneas de acción previstas desde el Plan Así y desde el Gobierno Nacional hacia los programas provinciales de alimentación escolar. Por el momento la asistencia del nivel nacional se circunscribe a cofinanciar los presupuestos provinciales para asistir a unos 18700 establecimientos con una partida (presupuesto 2019) de \$1828 millones (aproximadamente entre $\$ 550$ y $\$ 600$ diarios por escuela para todos sus comensales).

\section{Cuadro 3: Resumen de los principales hitos de las estrategias de promoción de ali- mentación saludable y prevención de obesidad en los últimos 10 años}

\begin{tabular}{|c|c|c|c|c|}
\hline Hito & Año & Instrumento & Principales líneas & Observaciones o avances \\
\hline $\begin{array}{l}\text { Ley sobre Trastornos } \\
\text { alimentarios y preven- } \\
\text { ción obesidad }\end{array}$ & 2008 & Ley 23096 & $\begin{array}{l}\text { Establece el marco para definir } \\
\text { estrategia de promoción de ali- } \\
\text { mentación saludable y preven- } \\
\text { ción de obesidad }\end{array}$ & $\begin{array}{l}\text { Reglamentación acotada al tra- } \\
\text { tamiento de obesidad }\end{array}$ \\
\hline $\begin{array}{l}\text { Estrategia Nacional } \\
\text { para la prevención y } \\
\text { control de enfermeda- } \\
\text { des no transmisibles }\end{array}$ & 2009 & $\begin{array}{l}\text { Resolución Min. } \\
\text { Salud (1083/09) }\end{array}$ & $\begin{array}{l}\text { Establece las bases para acuer- } \\
\text { dos con la industria alimentaria } \\
\text { para reducción de nutrientes crí- } \\
\text { ticos y promueve entornos salu- } \\
\text { dables (municipios) }\end{array}$ & $\begin{array}{l}\text { Logros y posterior institucionali- } \\
\text { zación (incorporación al Código } \\
\text { Alimentario) en reducción de } \\
\text { ácidos grasos trans; estrategia } \\
\text { similar luego con sodio (Inicia- } \\
\text { tiva Menos Sal más Vida) }\end{array}$ \\
\hline $\begin{array}{l}\text { Ley sobre reducción de } \\
\text { sodio en alimentos }\end{array}$ & 2013 & Ley 26905 & $\begin{array}{l}\text { Establece valores máximos de } \\
\text { sodio en alimentos y promueve } \\
\text { estrategias para disminuir el } \\
\text { agregado de sal }\end{array}$ & $\begin{array}{l}\text { Se convierte en un hito rele- } \\
\text { vante para disminuir progresi- } \\
\text { vamente la ingesta de sodio }\end{array}$ \\
\hline $\begin{array}{l}\text { Guías Alimentarias para } \\
\text { la población argentina } \\
\text { (GAPA) }\end{array}$ & 2015 & $\begin{array}{l}\text { Resolución Min. } \\
\text { Salud } \\
(693 / 2019)\end{array}$ & $\begin{array}{l}\text { Actualiza las primeras GAPA } \\
(2006)\end{array}$ & $\begin{array}{l}\text { Difusión y utilización limitadas } \\
\text { hasta el momento }\end{array}$ \\
\hline $\begin{array}{l}\text { Programa Nacional de } \\
\text { promoción de alimenta- } \\
\text { ción saludable y preven- } \\
\text { ción de obesidad }\end{array}$ & 2016 & $\begin{array}{l}\text { Resolución Min. } \\
\text { Salud } \\
(732 / 2016)\end{array}$ & $\begin{array}{l}\text { Crea el Programa, que se con- } \\
\text { vierte en el ámbito institucional } \\
\text { para el diseño de políticas en la } \\
\text { temática }\end{array}$ & $\begin{array}{l}\text { Mesas de trabajo con otros Mi- } \\
\text { nisterios y ámbitos no guberna- } \\
\text { mentales y académicos en tres } \\
\text { líneas fundamentales: entornos } \\
\text { escolares saludables; etique- } \\
\text { tado frontal de alimentos y res- } \\
\text { tricción de publicidad, promo- } \\
\text { ción y patrocinio; solo en el pri- } \\
\text { mero (entornos) se generaron } \\
\text { estándares respectivos (Res. } \\
\text { Min. Salud 564/2019); inicio de } \\
\text { mesas de acuerdos para reduc- } \\
\text { ción de azúcar }\end{array}$ \\
\hline $\begin{array}{l}\text { Plan Nacional de pre- } \\
\text { vención de obesidad en } \\
\text { niños, niñas y adoles- } \\
\text { centes (Plan ASI) }\end{array}$ & 2019 & $\begin{array}{l}\text { Resolución Min. } \\
\text { Salud } \\
(996 / 2019)\end{array}$ & $\begin{array}{l}\text { Crea el Plan, con cuatro líneas } \\
\text { estratégicas: educación alimen- } \\
\text { taria; sensibilización y comunica- } \\
\text { ción; mejora de calidad nutricio- } \\
\text { nal en programas alimentarios; y } \\
\text { regulación de entornos }\end{array}$ & $\begin{array}{l}\text { Despliegue inicial de acciones } \\
\text { en educación alimentaria a do- } \\
\text { centes de escuelas y convenios } \\
\text { de adhesión al Plan ASI en } 14 \\
\text { provincias, con poco desarrollo } \\
\text { de acciones al momento. }\end{array}$ \\
\hline
\end{tabular}

Fuente: elaboración propia 


\section{ASPECTOS INSTITUCIONALES}

La institucionalidad de las acciones o programas gubernamentales que atienden el derecho a una alimentación adecuada o saludable a la población en condición de vulnerabilidad social requiere una buena articulación intersectorial, entre varias áreas ministeriales y distintos niveles de gobierno (nación, provincias, municipios). Para la articulación intersectorial, y ello también abarca la incidencia de actores no gubernamentales (universidad, ámbitos académicos, organizaciones de la sociedad civil) son necesarios buenos diagnósticos y una visión común desde la cual formular las acciones, utilizar sinérgicamente los recursos y evaluar resultados e impactos.

En los últimos años la Argentina ha avanzado en la disponibilidad de diagnósticos adecuados en relación con la problemática alimentario-nutricional. Las encuestas nacionales de factores de riesgo (ENFR) (cuatro ediciones), de nutrición y salud (ENNyS) (dos), las estadísticas de antropometría escolar (dos), lactancia materna y los cortes de información sobre situación nutricional del Programa Sumar se suman a las estadísticas propias del INDEC sobre pobreza e indigencia y gasto de los hogares.

Todavía no se ha completado la difusión de los resultados de la última ENNyS, entre los cuales y por primera vez será posible reconstruir un mapa de consumo de alimentos en la población materno-infantil y escolar. Esa información será relevante para entender y luego intervenir sobre los alimentos según su frecuencia y oportunidad de consumo y su incidencia en la ingesta de nutrientes esenciales que deben promoverse y críticos que deben disminuirse.

En este capítulo se intenta presentar el conjunto de estrategias que se originan en el área gubernamental de Salud, las que tienen una doble coherencia: por un lado, con la evidencia científica y con el diagnóstico de salud y nutrición; y por otro lado con la centralidad de las acciones que se despliegan en las áreas similares en el territorio (provincias y municipios). Efectivamente, los lineamientos y directrices que se diseñan en el Ministerio de Salud (nacional) suelen ser referencia para las acciones de las redes sanitarias locales y en ello tiene un rol destacado la capilaridad de las capacitaciones desarrolladas por el propio equipo nacional. Esa coherencia al interior de las áreas de Salud sin embargo pierde integralidad y se fragmenta cuando se observa el conjunto más amplio de programas, incluyendo tanto los de transferencia de ingresos como los de asistencia alimentaria (tarjetas, comedores, módulos de alimentos). A la vez, tales fragmentación y baja integración se potencian cuando se consideran las diferentes capacidades de gestión provinciales y municipales.

Dos ejemplos que ilustran esta baja coherencia entre la visión del área de Salud y los demás Ministerios son los programas de comedores escolares (provinciales aunque con componente de "refuerzo" del Ministerio de Desarrollo Social de Nación), cuyo diseño nutricional presenta amplias brechas con los lineamientos de las GAPA; lo mismo sucede cuando se analizan estas mismas guías alimentarias y el listado de alimentos que integra el Programa Precios Cuidados (un programa que se basa en acuerdos de precios y abastecimiento entre el Ministerio de Producción y elaboradores y comercializadores). Si bien se entiende que se trata de un programa cuyos objetivos no se referencian en nutrición y salud, se pierde una oportunidad por incluir alimentos de buena calidad nutricional. El listado del programa Precios Cuidados es casi una antítesis de los lineamientos de las GAPA.

El Ministerio de Salud siempre se ha caracterizado por su rol de rectoría en la definición de normas relacionadas con la atención nutricional de los niños y las mujeres y más recientemente (en particular desde 2016) está empezando a hacer lo propio con la alimentación de la población en general (actualización de guías alimentarias, estándares sobre entornos escolares saludables o avances para la adopción de sistemas de perfiles nutricionales y etiquetado frontal de alimentos). 
La atención nutricional en los primeros años de vida ha sido históricamente su responsabilidad, tanto en lo normativo como en la capacitación de una amplia red de efectores (más de 7000 CAPS en todo el país), la promoción activa de la lactancia materna y la prestación alimentaria (leche fortificada) en niños con estado nutricional normal o en riesgo (pero ambulatorios) y la rehabilitación en el caso de niños con desnutrición. La existencia de centros especiales de prevención y rehabilitación de desnutrición es muy marginal e incipiente; su dependencia institucional no corresponde al Ministerio de Salud sino al de Desarrollo Social y la articulación entre ambos es débil según testimonios de actores del área.

Por otra parte, el Ministerio de Desarrollo Social concentra su responsabilidad en el financiamiento de las acciones propias de prestaciones alimentarias; en los últimos dos años la propia ejecución presupuestaria de la partida de leche fortificada del programa materno-infantil ha pasado al área de Desarrollo Social.

Otras acciones desarrolladas por ese Ministerio en relación con la atención nutricional y alimentaria de los niños se ubican institucionalmente en el ámbito de la Secretaría de Niñez, Adolescencia y Familia (SENNAF); en particular la atención de las necesidades alimentarias de niños que asisten a Espacios de Primera Infancia (EPI) y en los centros de prevención y recuperación de desnutrición. Todas estas acciones tienen una cobertura y alcance territorial marcadamente inferior a las de la DINAMIA.

El inicio de 2020 encuentra una nueva y muy amplia (por su extensión y cobertura) ventana de articulación necesaria entre las áreas gubernamentales de Salud y Desarrollo Social: el Plan Argentina contra el Hambre, su tarjeta AlimentAR y la próxima implementación del Plan de los 1000 días. Se supone que el Consejo Nacional de Políticas Sociales es la instancia de articulación. Merece destacarse que las acciones priorizadas por el Plan contra el Hambre se focalizan precisamente en las mismas que promueve la DINAMIA y ejecuta a través de sus acciones histórica y en el marco más reciente del Plan Nacer/Sumar. El uso de las tarjetas, su direccionalidad hacia consumos saludables y las acciones que se diseñen para la ventana de los 1000 días tienen un marco y antecedente muy valioso en la DINAMIA y en las preexistentes guías alimentarias GAPA y GAPI.

El Ministerio de Educación históricamente ha tenido una baja participación en las acciones alimentarias y nutricionales; aun cuando podría tener un rol de rectoría en materia de lineamientos sobre los entornos escolares, recién en 2019 y por iniciativa del Ministerio de Salud se elaboraron los primeros estándares respectivos y hacia el final de ese año se inició (por primera vez en la historia) una instancia de capacitación (virtual, a través del campus del Instituto Nacional de Formación Docente -INFOD-) en educación alimentaria dirigida a docentes del nivel primario.

El Ministerio de Salud también tiene el rol central en las mediciones antropométricas y el desarrollo de controles de salud, tanto a través de su propia red de CAPS como por medio del Programa de Salud Escolar (PROSANE), que anualmente realiza el control a niños de 1 ro y 6 to grados. Su cobertura efectiva sin embargo es heterogénea entre jurisdicciones. Por otro lado, la calidad de la respuesta cuando se identifican casos de malnutrición severa encuentra obstáculos en la dificultad para coordinar con los servicios de salud locales, quienes mayormente se guían por la práctica de la atención a la demanda espontánea.

Una nota de advertencia que merece destacarse es que no se conocen o al menos no se encuentra documentado en los últimos años el desarrollo de instancias formalizadas de articulación efectiva de los tres Ministerios con base en los diagnósticos mencionados y traducidas a la confección de una hoja de ruta que parta de lineamientos estratégicos con una visión compartida acerca del problema (malnutrición con preponderancia de sobrepeso en valores altos de prevalencia, persis- 
tencia de desnutrición de tipo crónica y baja calidad de dieta, en un contexto de severas dificultades en la accesibilidad económica a una dieta saludable y pobreza creciente) y oriente respuestas coordinadas e intersectoriales.

\section{CONCLUSIONES Y RECOMENDACIONES A LA IMPLEMENTACIÓN INICIAL DEL PLAN ARGENTINA CONTRA EL HAMBRE Y DE LOS 1000 DIAS}

Este capítulo ha intentado describir, hasta antes de la pandemia actual, la operatoria y articulaciones entre estrategias, programas o planes clave en la atención alimentaria y nutricional de la primera infancia: el programa materno-infantil de la DINAMIA, el rol del PROSANE, la irrupción (en 2009 y más visiblemente a partir de 2016) del Programa Nacional de promoción de alimentación saludable y prevención de obesidad, y en su marco el Plan ASI; por otra parte, el desarrollo del Plan Nacer, luego Sumar, como estrategia más global para la optimización de la cobertura y calidad de atención de la problemática de salud y nutrición materno-infantil.

Se trata del conjunto de estrategias de mayor visibilidad y ponderación y que conforman una hoja de ruta y columna vertebral de la atención alimentaria y nutricional materno-infantil. Todos los programas responden institucionalmente al Ministerio de Salud, clave por su adherencia a lineamientos con base científico-técnica y su liderazgo y capilaridad hacia los establecimientos sanitarios y escuelas. EI rol del PROSANE y la reciente experiencia de capacitación en educación alimentaria a través del INFOD (Ministerio de Educación) son promisorias en relación con la articulación entre ambos Ministerios.

El Plan Argentina contra el Hambre (Res. MDS 8/2020), en su objetivo general y sus dos primeros objetivos específicos (implementar un sistema complementario de ingresos del hogar para comprar alimentos con prioridad a madres y niños hasta 6 años; y fortalecer el conjunto de prestaciones alimentarias jurisdiccionales) ofrece como ya se mencionó, un claro espacio de articulación con los programas descriptos en este capítulo.

Como primer punto, las guías alimentarias infantiles (GAPI) y las GAPA son el marco para delimitar el universo de alimentos prioritarios para su compra a través de la tarjeta creada por el Plan Argentina c/ Hambre. En enero de este año, la Mesa Técnica del Plan (conjunto de referentes y organizaciones del campo de la alimentación y nutrición) estableció un listado que se conoció como "canasta básica saludable", cuya efectiva implementación aún no ha sido reglamentada. La integración de esa canasta, si bien es un significativo avance en la institucionalidad del Plan, ofrece aún espacios de optimización que pueden ser trabajados contrastándola con las recomendaciones de GAPI y GAPA (ver anexo para una discusión del tema). La posiblemente próxima adopción de algún sistema de perfiles nutricionales y etiquetado frontal de alimentos debería también ser una instancia clara de coordinación entre los alimentos prioritarios para su compra con la tarjeta del Plan y los que se interpreten como más nutritivos por el etiquetado.

La próxima actualización de las GAPI y las recomendaciones que se desprendan de las mismas deberán ser internalizadas en las estrategias de educación alimentaria del Plan. De la misma forma que las recomendaciones de las GAPA deberían reflejarse en su operatoria, priorización de alimentos y dispositivos que se diseñen en cumplimiento de su objetivo de fortalecimiento del conjunto de prestaciones jurisdiccionales. En síntesis, debería haber una clara consistencia y coherencia entre 
el marco alimentario del Plan Argentina c/Hambre y las recomendaciones de ambas guías alimentarias.

La oportunidad que ofrece el dispositivo tecnológico (tarjeta) del Plan debería articularse con el rol de consejería y educación alimentaria que despliegan territorialmente los CAPS, facilitando información oportuna que permita ajustar y adecuar los mensajes y orientaciones hacia las familias y sirviendo como instancia de planificación de las estrategias locales.

El Plan Argentina contra el Hambre también ofrece posibilidades de coordinación con el Plan ASI en la medida en que la principal manifestación de malnutrición en la infancia es el sobrepeso y la baja calidad de dieta. La población objetivo del Plan ASI se superpone en gran medida con las del Plan contra el hambre, situación que favorece una necesaria articulación.

Los aspectos relacionados con la pandemia actual se discuten en el capítulo V.

\section{BIBLIOGRAFÍA}

Abeyá Gilardón, E. (2016) “Una evaluación crítica de los programas alimentarios en Argentina”. Salud Colectiva. 2016;12(4):589-604. doi:

10.18294/sc.2016.935. https://www.scielosp.org/pdf/scol/2016.v12n4/589-604

Aulicino C., Gerenni F., Acuña M. (2015) "Primera infancia en Argentina: Políticas a nivel nacional". Documento de trabajo 143. Serie Primera Infancia. CIPPEC, 2015.

Barker D.; Fetal nutrition and cardiovascular disease in adult life. Lancet 1993; 341:938-41

Britos S.; Saraví A.; Rubén MM. (2015) "Calidad de la dieta de niños entre 6 y 24 meses de edad beneficiarios del Programa Materno-Infantil de Rosario". CEPEA, Univ. Del Centro Educativo Latinoamericano (UCEL). 2015 (trabajo no publicado).

Bryce J., Coitinho D., Darnton Hill I., Pelletier D.; Andersen P. (2008) "Maternal and child undernutrition: effective action at national level"; The Lancet Series: Maternal and child undernutrition. vol 371 issue 9611, 510:526, 2008.

Cortez R., Romero D. (2013) "Increasing Utilization of Health Care Services Among the Uninsured Population: The Plan Nacer Program". Universal Health Coverage (UNICO) Serie de estudios NN12. Washington, DC: World Bank; 2013. http://documents.worldbank.org/curated/en/662701467997619961/Argentina-Increasing-utilization-of-health-care-services-amongthe-uninsured-population-the-Plan-Nacer-program

Lutter Ch., Lutter R. (2012) "Fetal and Early Childhood Undernutrition, Mortality, and Lifelong Health". Science 2012: Vol. 337, Issue 6101, pp. 1495-1499

Ministerio de Salud de la Nación (2009) "Evaluación del estado nutricional de niños, niñas y embarazadas mediante antropometría”. http://www.msal.gob.ar/images/stories/bes/graficos/0000000256cnt-a07-manual-evaluacion-nutricional.pdf

(2010) "Guías Alimentarias para la población infantil. Consideraciones para equipos de salud". 2010 http://msal.gob.ar/images/stories/bes/graficos/0000000319cnt-A04-guias-alimentarias-pob-inf-equipos.pdf

(2013a) "Sobrepeso y obesidad en niños y adolescentes. Orientaciones para su prevención, diagnóstico y tratamiento en atención primaria de la salud”; Ministerio de Salud. 2013 http://www.msal.gob.ar/images/stories/bes/graficos/0000000377cnt-sobrepeso-yobesidad-en-ninios.pdf 
(2013b) "Análisis del proceso institucional de generación de una política social de impacto multisectorial: el Plan Nacer y la Asignación Universal por Hijo y por Embarazo". http://www.msal.gob.ar/sumar/images/stories/pdf/analisis-del-proceso-de-generacion-de-una-politica-social-de-impacto-multisectorial-el-plan-nacer-y-la-asignacion-universal.pdf

(2013c) "El Plan Nacer y su efecto en la satisfacción de los usuarios de los sistemas de salud provinciales documento de divulgación de resultados".

http://www.msal.gob.ar/sumar/images/stories/pdf/el-plan-nacer-y-su-efecto-en-la-satisfaccion-delos-usuarios-de-los-sistemas-de-salud-provinciales.pdf

(2013d) "Evaluación de la incorporación del Plan Nacer al Pro-

grama Nacional de Cardiopatías Congénitas". Documento de divulgación de resultados.

http://www.msal.gob.ar/sumar/images/stories/pdf/evaluacion-de-la-incorporacion-del-plan-naceral-programa-nacional-de-cardiopatias-congenitas-pncc.pdf

(2013e) "Evaluación de la Motivación de los equipos de salud con

la estrategia de gerenciamiento propuesto por el Plan Nacer". Documento de divulgación de re-

sultados. http://www.msal.gob.ar/sumar/images/stories/pdf/evaluacion-de-la-motivacion-de-losequipos-de-salud-con-la-estrategia-de-gerenciamiento-propuesta-por-el-plan-nacer.pdf

(2013f) "Evaluación de las capacidades administrativas generadas a partir de la implementación del Plan Nacer". Documento de divulgación de resultados.

http://www.msal.gob.ar/sumar/images/stories/pdf/evaluacion-de-las-capacidades-administrativas-generadas-a-partir-de-la-implementacion-del-plan-nacer.pdf

(2014a) "Plan de producción y aplicación de fondos".

http://www.msal.gob.ar/sumar/images/stories/pdf/plan-produccion-aplicacion-fondos.pdf

(2014b) "Profundizando la Integración del Sector Público de la Sa-

lud y la Seguridad Social". http://www.msal.gob.ar/sumar/images/stories/pdf/profundizando-integracion-sector-publico-ss.pdf

(2014c) "Fortalecer la cultura de gerenciamiento por resultados en el sector público de la salud en argentina". http://www.msal.gob.ar/sumar/images/stories/pdf/estrategia-priorizacion-establecimientos-sumar.pdf

(2014d) "Generación de una cultura evaluativa en el sector salud:

principales resultados de la agenda de estudios y evaluación del Plan Nacer/Programa SUMAR". http://www.msal.gob.ar/sumar/images/stories/pdf/generacion-cultura-evaluativa-sector-salud.pdf

(2015) "Cinco años de implementación del Programa Nacional de Cardiopatías Congénitas integrado en el modelo de gestión del Programa SUMAR". http://www.msal.gob.ar/sumar/images/stories/pdf/5-anos-implementacion-pncc.pdf

(2016) "Guías Alimentarias para la población argentina".

Documento técnico metodológico. 2016

(http://www.msal.gob.ar/images/stories/bes/graficos/0000001007cnt-2017-06 guia-alimentariapoblacion-argentina.pdf)

(2019) 2da Encuesta Nacional de Nutrición y Salud (ENNyS 2) Indicadores Priorizados septiembre 2019, Buenos Aires: Ministerio de Salud de la Nación. Recuperado 15/2/2020: http://www.msal.gob.ar/images/stories/bes/graficos/0000001602cnt-2019-10 encuesta-nacional-de-nutricion-y-salud.pdf

Ministerio de Salud y Desarrollo Social y UNICEF, (2018) "Sobrepeso y obesidad en niños, niñas y adolescentes según datos del primer nivel de atención en la Argentina". https://www.unicef.org/argentina/sobrepeso-y-obesidad 
Ministerio de Salud y Desarrollo Social de la Nación (2019a) "Guía de Programas Sociales". (2019b) “Informe de gestión 2019". Dirección Nacional de Promoción de la Salud y Control de Enfermedades no Transmisibles. (2019c) "Reporte de gestión del programa Sumar". Agosto 2019. http://www.msal.gob.ar/sumar/images/stories/pdf/rg-2019-8.pdf

Nuñez P. (2015) “Investigación sobre resultados del Plan Nacer/ Programa SUMAR”; Conicet. Instituto Nacional de Medicina Tropical. Ministerio de Salud. 2015

Oficina Nacional de Presupuesto; UNICEF (2019) "Gasto en niñez y adolescencia del presupuesto nacional" 2019. https://www.unicef.org/argentina/informes/gasto-en-ninez-y-adolescencia-delpresupuesto-nacional

Potenza Dal Masetto MF (2012) "La implementación del Plan Nacer en ámbitos subnacionales". Documento de trabajo 82. CIPPEC. 2012 https://www.cippec.org/wp-content/uploads/2017/03/2450.pdf

Sabignoso M., et. al (2014) "Lecciones aprendidas y desafíos futuros bajo nuevos esquemas de gestión de la salud en la Argentina", 2014. http://www.msal.gob.ar/sumar/images/stories/pdf/lecciones-aprendidas-desafios-futuros.pdf 


\section{ANEXO. CANASTAS DE ALIMENTOS COMO ELEMENTO PARA LA TOMA DECISIONES EN POLÍTICAS RELACIONADAS CON LA SEGURIDAD ALIMENTARIA: EL DILEMA DE LA CANASTA BÁSICA Y LOS MODELOS SALUDABLES}

La Canasta Básica de Alimentos (CBA) es un instrumento de uso extendido en varios países de América Latina y que, con algunas variantes metodológicas, mantiene los lineamientos definidos hace unas tres décadas por la Comisión Económica para América Latina (CEPAL) y el Instituto de Nutrición de Centroamérica y Panamá (INCAP). En nuestro país, la primera CBA fue desarrollada por el INDEC en 1988 sobre la base de los consumos registrados en la encuesta de gasto de hogares de 1985/86 y solo fue modificada una vez, en 2016, actualizando su base de referencia de consumos con la encuesta de gasto de hogares de 1996/97, a la vez que regionalizando las canastas (seis versiones).

En forma sintética, la CBA es un conjunto de alimentos y bebidas que refleja el patrón de consumo del segmento de la población más próximo a la línea de pobreza (habitualmente entre el 2do y 3er decil de ingresos de la población), ajustado a valores normativos de requerimientos y recomendaciones de energía y macronutrientes y -en la medida de lo posible dependiendo del criterio relativo al patrón de consumo- de micronutrientes esenciales; definida la conformación por grupos y subgrupos de alimentos, la selección final de los artículos (alimentos y bebidas) prioriza las variedades más económicas y disponibles en el mercado.

Dada esa definición, la CBA representa el valor más económico de la alimentación de un individuo o una familia para mantener una alimentación básica cubriendo el criterio normativo nutricional descripto en el párrafo anterior. Una vez definido su valor, el mismo se utiliza como trazador de la línea de indigencia y su proyección a un valor de canasta básica total (CBT) define la línea de pobreza.

La composición actual de la CBA (en sus seis variantes regionales) se puede observar en el siguiente cuadro (1). 
Cuadro A-1. Composición de las canastas básicas regionales INDEC 2016 ( $\mathrm{g} \circ \mathrm{ml}$ por mes por adulto equivalente $=2750 \mathrm{kcal}$ )

\begin{tabular}{|c|c|c|c|c|c|c|}
\hline Producto & $\begin{array}{c}\text { Gran Buenos } \\
\text { Aires }\end{array}$ & Pampeana & Noroeste & Noreste & Cuyo & Patagonia \\
\hline Pan Francés & 6.75 & 7.02 & 7.35 & 7.02 & 7.62 & 6.72 \\
\hline Galletitas dulces & 210 & 180 & 90 & 120 & 120 & 180 \\
\hline Galletitas de agua & 420 & 390 & 360 & 180 & 210 & 180 \\
\hline Harina de trigo & 1.08 & 1.35 & 2.19 & 2.07 & 1.65 & 2.85 \\
\hline Harina de maíz & 210 & 180 & 210 & 150 & 150 & 150 \\
\hline Arroz & 1.2 & 1.08 & 1.05 & 1.5 & 870 & 810 \\
\hline Fideos secos & 1.74 & 1.68 & 1.05 & 1.05 & 1.68 & 810 \\
\hline Asado & 1.23 & 1.5 & 1.05 & 1.38 & 1.41 & 1.2 \\
\hline Carnaza común & 510 & 450 & 630 & 630 & - & 690 \\
\hline Hueso con carne & 390 & 450 & 1.05 & 870 & 630 & - \\
\hline Paleta & 780 & - & - & - & 330 & 270 \\
\hline Carne picada & 900 & 810 & 480 & 660 & 1.2 & 1.5 \\
\hline Nalga & 630 & 1.02 & 1.26 & 1.29 & 660 & 630 \\
\hline Hígado & 270 & 270 & 270 & 270 & 270 & 180 \\
\hline Pechito de cerdo & - & - & 60 & - & - & 240 \\
\hline Pollo & 1.65 & 1.89 & 1.8 & 1.23 & 1.65 & 1.8 \\
\hline Carne de pescado & 180 & 330 & 120 & 210 & 330 & 210 \\
\hline Mortadela & - & 60 & - & 60 & - & 30 \\
\hline Paleta cocida & 30 & 30 & - & 30 & 60 & 30 \\
\hline Salchichón & - & - & - & - & 120 & - \\
\hline Salame & 30 & - & - & - & - & - \\
\hline Aceite de girasol & 1.2 & 1.02 & 1.05 & 1.14 & 990 & 1.02 \\
\hline Margarina para cocinar & - & 90 & - & 60 & 150 & 90 \\
\hline Leche fluida & 9.27 & 8.1 & 6.9 & 4.56 & 5.07 & 4.05 \\
\hline Leche en polvo entera & - & 330 & 390 & 750 & 570 & 750 \\
\hline Queso crema & 80 & 50 & 60 & 40 & 70 & 70 \\
\hline Queso cuartirolo & 170 & 110 & 120 & 80 & 140 & 140 \\
\hline Queso de rallar & 80 & 50 & 60 & 30 & 60 & 60 \\
\hline Manteca & 60 & 60 & 60 & - & - & 90 \\
\hline Yogur & 570 & 570 & 510 & 360 & 480 & 510 \\
\hline Dulce de leche & 110 & 70 & 70 & 30 & 40 & 30 \\
\hline Huevo & 600 & 480 & 390 & 480 & 540 & 450 \\
\hline Manzana & 1.38 & 1.83 & 997 & 1.147 & 1.433 & 1.89 \\
\hline Mandarina & 1.14 & 1.32 & 1.23 & 1.23 & 1.32 & 1.59 \\
\hline Naranja & 1.35 & 1.29 & 1.71 & 1.65 & 1.26 & 1.47 \\
\hline Banana & 810 & 960 & 1.41 & 1.47 & 1.164 & 1.17 \\
\hline Pera & 270 & 480 & 137 & 137 & 159 & - \\
\hline Batata & 510 & 270 & - & - & 240 & - \\
\hline Papa & 6.51 & 6.87 & 6.87 & 6.93 & 6.87 & 7.23 \\
\hline Acelga & 750 & 750 & 360 & 300 & 660 & 570 \\
\hline Cebolla & 1.38 & 1.32 & 1.53 & 1.98 & 1.08 & 2.1 \\
\hline Choclo & - & - & 300 & - & - & - \\
\hline Lechuga & 660 & 660 & 420 & 540 & 660 & 660 \\
\hline Tomate perita & 1.44 & 2.07 & 2.16 & 1.68 & 2.01 & 1.35 \\
\hline Zanahoria & 540 & 810 & 840 & 750 & 780 & 780 \\
\hline Zapallo & 720 & 870 & 1.05 & 810 & 990 & 840 \\
\hline Tomate envasado & 240 & 210 & 180 & 240 & 180 & 240 \\
\hline Arvejas en lata & 120 & 240 & 120 & 150 & 120 & 180 \\
\hline Lentejas secas & 120 & - & 120 & 150 & 120 & 60 \\
\hline Azúcar & 1.23 & 1.29 & 1.29 & 1.35 & 1.38 & 1.38 \\
\hline Dulce de batata & 110 & 70 & - & - & - & 30 \\
\hline Mermelada & 110 & 70 & 70 & 30 & 40 & 30 \\
\hline Sal fina & 120 & 150 & 120 & 150 & 150 & 180 \\
\hline Mayonesa & 60 & 60 & 60 & 90 & 90 & 90 \\
\hline Vinagre & 60 & 90 & 60 & 30 & 60 & 60 \\
\hline Caldo concentrado & 60 & 30 & 30 & 30 & 30 & 30 \\
\hline Gaseosas & 750 & 630 & 1.5 & 930 & 600 & 1.11 \\
\hline Jugos Concentrados & 1.5 & 960 & 900 & 870 & 870 & 810 \\
\hline Soda & 1.2 & 2.1 & 2.4 & 1.5 & 2.55 & 900 \\
\hline Cerveza & 510 & 630 & 300 & 600 & 300 & 600 \\
\hline Vino & 570 & 660 & 510 & 600 & 1.02 & 600 \\
\hline Café & 30 & 30 & 30 & 30 & 60 & 30 \\
\hline Yerba & 510 & 600 & 360 & 750 & 360 & 450 \\
\hline Té en saquitos & - & 30 & 30 & 30 & 30 & 30 \\
\hline
\end{tabular}

Fuente: INDEC, 2016 
Según la Organización Mundial de la Salud (OMS), una alimentación saludable o sana es protectora de la malnutrición en todas sus formas y de las enfermedades crónicas; y las bases de una alimentación sana reconocen la importancia de la variedad de alimentos, el equilibrio de la dieta y una ingesta prudente en nutrientes críticos como azúcares, sodio y ácidos grasos saturados.

En nuestro país las Guías Alimentarias para la población argentina (GAPA) son la referencia sobre la conformación de una alimentación saludable. Las GAPA recomiendan cinco grupos de alimentos de consumo diario: verduras y frutas; leche, yogur y queso; legumbres, cereales, papa, pan y pastas; carnes y huevos; y aceites, frutas secas y semillas; también se sugiere el consumo diario de agua. Un sexto grupo, denominado alimentos de consumo opcional es recomendado como su propio nombre lo indica. Entre los mensajes de las guías se establecen, aunque de manera algo difusa ciertos criterios de preferencia al interior de los grupos de recomendación de consumo diario: a manera de ejemplo: cereales integrales, legumbres, variedades no enteras de carnes o lácteos.

Las GAPA también orientan la conformación de un plan o patrón alimentario (cantidades de alimentos) consistente con sus recomendaciones. De tal forma que las guías proporcionan los lineamientos para establecer cuáles alimentos, en qué proporción, con cual frecuencia y en qué grado de variedad integran una dieta saludable, normativa, preventiva y protectora de todas las formas de malnutrición y enfermedades crónicas.

Más allá de las GAPA, la literatura científica en nutrición viene aportando nuevas y más consistentes evidencias sobre el rol de los alimentos y los patrones de consumo en la prevención de la morbilidad más prevalente en el mundo, de estrecha vinculación con dietas poco saludables (Mozaffarian 2016; Mozaffarian 2018; Cena 2019).

La segunda Encuesta Nacional de Nutrición y Salud (ENNyS 2018), aun cuando aún no se ha terminado de difundir en forma completa, consolida un cuerpo de antecedentes sobre la situación alimentario-nutricional que complementa los resultados ya conocidos de las cuatro encuestas nacionales de factores de riesgo (ENFR 2005, 2009, 2013 y 208). Fuera del ámbito de las encuestas nacionales, el proyecto ELANS (Estudio Latinoamericano de Nutrición y Salud) también proporciona información consistente con la ENNyS y las ENFR y un reciente estudio de nuestro equipo (CEPEA) en proceso de publicación aborda la cuestión de la calidad de dieta en nuestra población (estudio ABCDieta).

No es objeto de este anexo realizar una descripción detallada de la situación alimentaria y nutricional de la población argentina, pero los hallazgos de al menos los estudios citados permiten algunas pocas conclusiones relevantes:

1. la principal manifestación de malnutrición es el exceso de peso (sobrepeso y obesidad), de instalación temprana y tendencia creciente en el ciclo de vida y en los últimos años.

2. los estudios también informan prevalencias de enfermedades crónicas (diabetes, hipertensión) que encuentran en la calidad de dieta uno de sus factores determinantes principales.

3. las brechas por bajos consumos son altas en alimentos de buena calidad nutricional: legumbres, cereales integrales, verduras, frutas y lácteos.

4. las brechas por altos consumos son altas en alimentos de baja calidad nutricional, en particular fuentes de azúcares y sodio.

5. las brechas por altos consumos son también altas en alimentos fuente de almidones y bajo contenido de fibra (harinas muy refinadas y panificados).

La extensión de la malnutrición por sobrepeso, su combinación con altas prevalencias de inseguridad alimentaria y la caracterización muy poco saludable de la dieta de amplios sectores de la población en especial los de alta vulnerabilidad social configuran un paradigma muy diferente en 2020 en relación con el existente en los años en que se consolidó la metodología de la CBA. 
La comparación entre la estructura de consumo de la CBA y una dieta que refleje las recomendaciones de las GAPA y las de la literatura científica más reciente resulta en que la CBA tiene graves distorsiones en relación con:

1. la proporcionalidad y variedad de verduras y frutas.

2. la virtual ausencia de legumbres y cereales integrales.

3. la baja cantidad de leche, yogur y queso.

4. el exceso de cereales, harinas muy refinadas y panificados.

5. el exceso de alimentos de consumo opcional y fuente de azúcares y sodio.

Estas distorsiones tienen su origen en la propia metodología de la CBA, la que refleja paradigmas y conocimientos acerca de las recomendaciones nutricionales propios de la década de los ' 80 pero distantes de los actuales.

En momentos (en particular epidemiológicos) en que es muy extendida la recomendación y abogacía por una dieta más saludable, utilizar la CBA como un estándar para definir o monitorear políticas públicas es una grave paradoja.

La CBA efectivamente suele ser considerada como un parámetro contra cuyo valor e incluso conformación se referencian políticas o estrategias sociales-alimentarias, cuyo diseño por lo tanto termina siendo divergente de otras referencias como las propias GAPA.

Nuestro equipo (CEPEA) ha publicado (Britos et. al., 2018) una propuesta metodológica de diseño de una canasta saludable de alimentos (CSA) cuya composición refleja de manera normativa las recomendaciones de las GAPA y de la literatura científica; y a través de un ejercicio académico en la Escuela de Nutrición de la Universidad de Buenos Aires, se determina su valor económico tres veces por año. La última medición (febrero 2020) registra una diferencia de $62 \%$ (más cara) entre la CSA y la CBA para la misma unidad familiar de referencia.

\section{Cuadro A-2. Composición de la canasta saludable de alimentos (CSA) propuesta por CEPEA}

\begin{tabular}{|lccc|}
\hline \multicolumn{1}{|c}{ Alimentos } & $\begin{array}{c}\text { Cant. diaria referen- } \\
\text { cia 2000 kcal (g o ml) }\end{array}$ & $\begin{array}{c}\text { Cant. diaria mismo } \\
\text { adulto equivalente CBA } \\
\text { (2750 kcal) (g o ml) }\end{array}$ & $\begin{array}{c}\text { Cant. mes adulto } \\
\text { equivalente 2750 } \\
\text { kcal (kg o l) }\end{array}$ \\
\hline Hortalizas no feculentas & 350 & 480 & 14,4 \\
\hline Frutas & 350 & 480 & 14,4 \\
\hline Leche y yogur y quesos & 400 & 500 & 15 \\
\hline Quesos & 30 & 40 & 1,2 \\
\hline Legumbres, cereales integrales y granos & 90 & 120 & 3,6 \\
\hline Carnes y huevos & 175 & 240 & 7,2 \\
\hline Aceites & 30 & 40 & 1,2 \\
\hline $\begin{array}{l}\text { Panificados, harinas, arroz común, pastas, } \\
\text { hortalizas feculentas y galletitas saladas }\end{array}$ & 100 & 130 & 3,9 \\
\hline \begin{tabular}{l} 
Alimentos opcionales \\
\hline
\end{tabular} & No más de $300 \mathrm{kcal}$ & No más de $400 \mathrm{kcal}$ & \\
\hline
\end{tabular}

Fuente: elaboración propia

Tampoco es objetivo de este anexo desarrollar de manera muchos más detallada (puede consultarse el artículo mencionado en el párrafo anterior), pero sí se pretende incidir en la discusión acerca de la necesidad de considerar un modelo más saludable de canasta en los procesos de definición de políticas públicas, en especial aquellas que refieren a la problemática alimentario-nutricional. 
Una CSA como la que se presenta en el artículo mencionado refleja un criterio absolutamente normativo (muy estricto y de alto impacto económico y socio-cultural). El mismo admite al menos dos posibles escenarios alternativos y quizá de mayor asequibilidad:

a. Una canasta asequible bajo criterios de dieta saludable que refleje una progresividad y priorización en la disminución de las brechas de consumo informadas por distintas investigaciones (cambios saludables progresivos con impacto económico razonable).

b. Una canasta más estricta en sus criterios de dieta saludable (pero sostenible en términos socio-culturales) que refleje cambios más acelerados en la disminución de brechas de consumo y permita establecer escenarios presupuestarios que acompañen los cambios propuestos.

La reciente implementación del Plan Argentina contra el Hambre y su mención a la necesidad de mejorar el consumo de alimentos de la población infantil pero haciéndolo bajo un paradigma de salud marca una oportunidad para discutir un cambio necesario de paradigma hacia modelos de canastas de alimentos más consistentes con las recomendaciones de guías alimentarias.

\section{BIBLIOGRAFÍA ANEXO}

Andueza E. (1988) Canasta Básica de Alimentos del Gran Buenos Aires. Documento de trabajo nro 3, Proyecto IPA, INDEC.

Britos S., Borg A., Guiraldes C., Simonetti C., Oliveri E., Chichizola N. (2018). Diseño de una canasta saludable de alimentos y criterios para una evaluación comparativa de precios y densidad de nutrientes; DIAETA; 2018; 36(164):20-29

Cena H.; Calder P. (2020). Defining a Healthy Diet: Evidence for The Role of Contemporary Dietary

Patterns in Health and Disease; Nutrients 2020, 12, 334

CEPAL, (2018). Medición de la pobreza por ingresos. Actualización metodológica y resultados. (https://repositorio.cepal.org/bitstream/handle/11362/44314/1/S1800852 es.pdf)

Fisberg M., Kovalskys I., et.al. (2018); Total and Added Sugar Intake: Assessment in Eight Latin American Countries; Nutrients 2018, 10, 389

INDEC, (2016). La medición de la pobreza y la indigencia en la Argentina. (https://www.indec.gob.ar/ftp/cuadros/sociedad/EPH metodologia 22 pobreza.pdf)

Kovalskys I.; Rigotti A., et.al. (2019); Latin American consumption of major food groups: Results from the ELANS study; PLoS ONE 14(12): e0225101

Menchú MT.; Osegueda O. (2002). La canasta básica de alimentos en Centroamérica. Revisión de la metodología. INCAP.

Ministerio de Salud, (2019a). Segunda Encuesta Nacional de Nutrición y Salud. Indicadores priorizados. http://msal.gob.ar/images/stories/bes/graficos/0000001602cnt-2019-10 encuestanacional-de-nutricion-y-salud.pdf

(2019b). Cuarta Encuesta Nacional de Factores de Riesgo. Principales resultados. http://www.msal.gob.ar/images/stories/bes/graficos/0000001444cnt-4ta-encuesta-nacionalfactores-riesgo 2019 principales-resultados.pdf

Mozaffarian D. (2016). Dietary and Policy Priorities for Cardiovascular Disease, Diabetes, and Obesity: a comprehensive review; Circulation. 2016;133:187-225

Mozaffarian D., et.al. (2018). History of modern nutrition science implications for current research, dietary guidelines, and food policy; BMJ 2018;361:k2392. 


\section{CAPÍTULO IV. POLÍTICAS DE ASISTENCIA ALIMENTARIA Y PROGRAMAS RELACIONADOS, ANTES DE LA PANDEMIA}

María Eugenia Herrera Vegas

\section{PRESENTACIÓN}

Este capítulo examina los principales programas alimentarios vigentes en la Argentina, hasta antes de la pandemia relacionada con el COVID-19, dirigidos a la lucha contra la inseguridad alimentaria infantil. El tratamiento de tres políticas nacionales de asistencia alimentaria, cuatro políticas nacionales de producción de alimentos, y cerca de noventa políticas y acciones provinciales, permiten caracterizar y proponer discusiones en dos dimensiones: (a) el marco institucional de sectores y niveles de gobierno involucrados en la instrumentación, incluyendo sus niveles de coordinación e interacción, y (b) los detalles que hacen a la práctica concreta de las políticas de asistencia y producción alimentaria (año de creación, normas, presupuestos, operación y evaluaciones disponibles), incluyendo sus niveles de cohesión e integralidad.

Al respecto, cabe preguntarse: ¿por qué persisten, aumentan y se complejizan en el tiempo la inseguridad alimentaria, la pobreza infantil, y la malnutrición en niños y niñas de sectores vulnerables en la Argentina? La puesta en diálogo las dos dimensiones de análisis propuestas, ensaya algunas respuestas posibles.

Como perspectiva de análisis, la medición de Inseguridad Alimentaria ${ }^{18}$ entiende que una sola dimensión no alcanza para contemplar todos los aspectos relacionados con las privaciones en la alimentación, y configura un indicador con distintas facetas (disponibilidad, acceso, utilización de alimentos y vulnerabilidades en el acceso) (Moncada-Ortega, 2007). En Argentina el indicador equivale a un 14,1\% (ODSA-UCA, 2019) de Inseguridad Alimentaria Severa en niños, niñas y adolescentes de hasta 17 años, cuyo abordaje esperado es el de políticas holísticas e integrales.

Las tres políticas nacionales de asistencia alimentaria incluyen el Programa Nacional de Seguridad Alimentaria (en adelante, PNSA); la Asignación Universal por Hijo (en adelante, AUH) ${ }^{19}$ y el Plan Nacional de Primera Infancia (en adelante, PNPI). En estas políticas, la principal modalidad es la transferencia económica directa o a través de las provincias, a los titulares. Las cuatro políticas nacionales de producción alimentaria incluyen el programa ProHuerta y programa Proyectos Especiales (ambos en articulación con el PNSA), el programa de Agroalimentos y el programa de Desarrollo e Innovación en Tecnologías Alimentarias, donde las modalidades son el apoyo técnico, y dotaciones materiales. El gráfico 1 ofrece una síntesis las políticas tratadas, con un enfoque de Sistemas Alimentarios y Nutricionales (Producción, Acceso y Comportamiento Alimentario).

\footnotetext{
${ }^{18}$ Nota: la Inseguridad Alimentaria comenzó a ser medida por la USDA en 1995 junto a especialistas de la Universidad de Cornell. Tras una serie de validaciones fue incorporada a la EPH de Estados Unidos, y en 2002 el Consejo de Expertos de la FAO Roma evaluó su pertinencia de medición. Hoy forma parte de EPH de México y Brasil, entre otros países (Moncada, G., Ortega, J., 2007)

${ }^{19}$ Nota: la AUH es tratada con relación a aspectos de asistencia alimentaria, sin perjuicio de su tratamiento particular en el Capítulo I
} 
Gráfico 1. Políticas Alimentarias y Sistemas Alimentarios y Nutricionales.

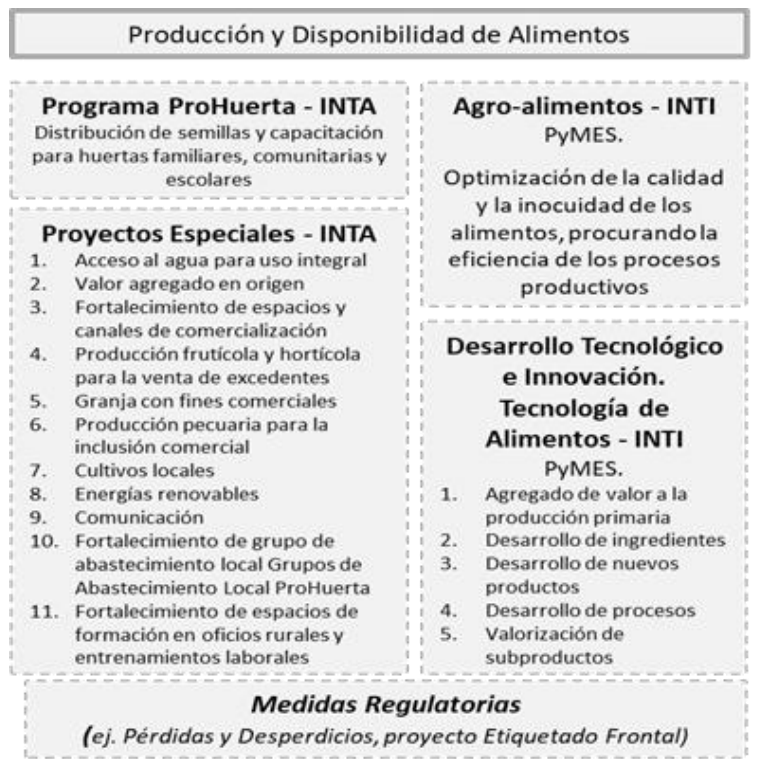

\begin{tabular}{|c|}
\hline Acceso a Alimentos \\
AUH - ANSES \\
(Transferencias Directas) \\
PNSA - MDSN \\
(Tarjetas Alimentarias, \\
Comedores Escolares y \\
Comunitarios, Merenderos, \\
Módulos, ProHuerta) \\
PNPI - MDSN \\
(prestaciones alimentarias en EPI; \\
buenos hábitos nutricionales). \\
Políticas Provinciales - \\
DS/E/S \\
(Tarjetas, Comedores, Celiacos, \\
Abordajes Nutricionales, etc.) \\
\hline Politicas Municipales DS/E/S \\
(Tarjetas, Comedores, \\
Celiacos, Abordajes \\
Nutricionales, etc.)
\end{tabular}

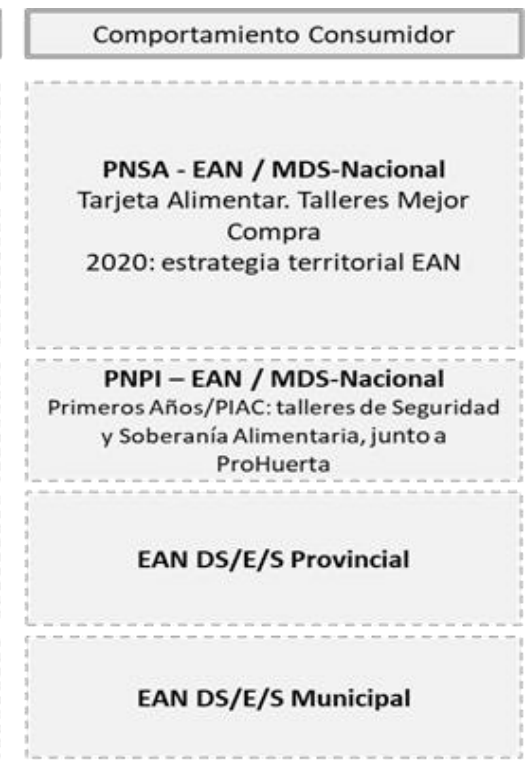

Fuente: Elaboración Propia en base a normativas y documentos oficiales. MDSN o MDS es Ministerio de Desarrollo Social nacional. $\mathrm{DS} / \mathrm{E} / \mathrm{S}$ se refiere a los ministerios provinciales de desarrollo social, educación y salud. EAN es educación alimentaria y nutricional.

Las políticas de asistencia alimentaria, a cargo de 24 provincias y 2165 municipios, parten de 44 normas y el relevamiento de un estimado de 88 programas y acciones de seguridad alimentaria (ver detalle en anexo al final del capítulo) cuyas líneas más homogéneas son las tarjetas alimentarias y los comedores escolares, acompañadas por una oferta complementaria local de propuestas. Las políticas provinciales de producción de alimentos no cuentan con fuentes suficientes que sistematicen programas o acciones. En algunos presupuestos provinciales, se incorporan acciones junto al INTA y a organismos internacionales, a través del Ministerio de Agricultura, Ganadería y Pesca. A continuación, el Gráfico 2 permite ilustrar los ministerios, secretarías, subsecretarías y organismos descentralizados, e instancias según niveles de gobierno alcanzados por el trabajo. 

mentaria

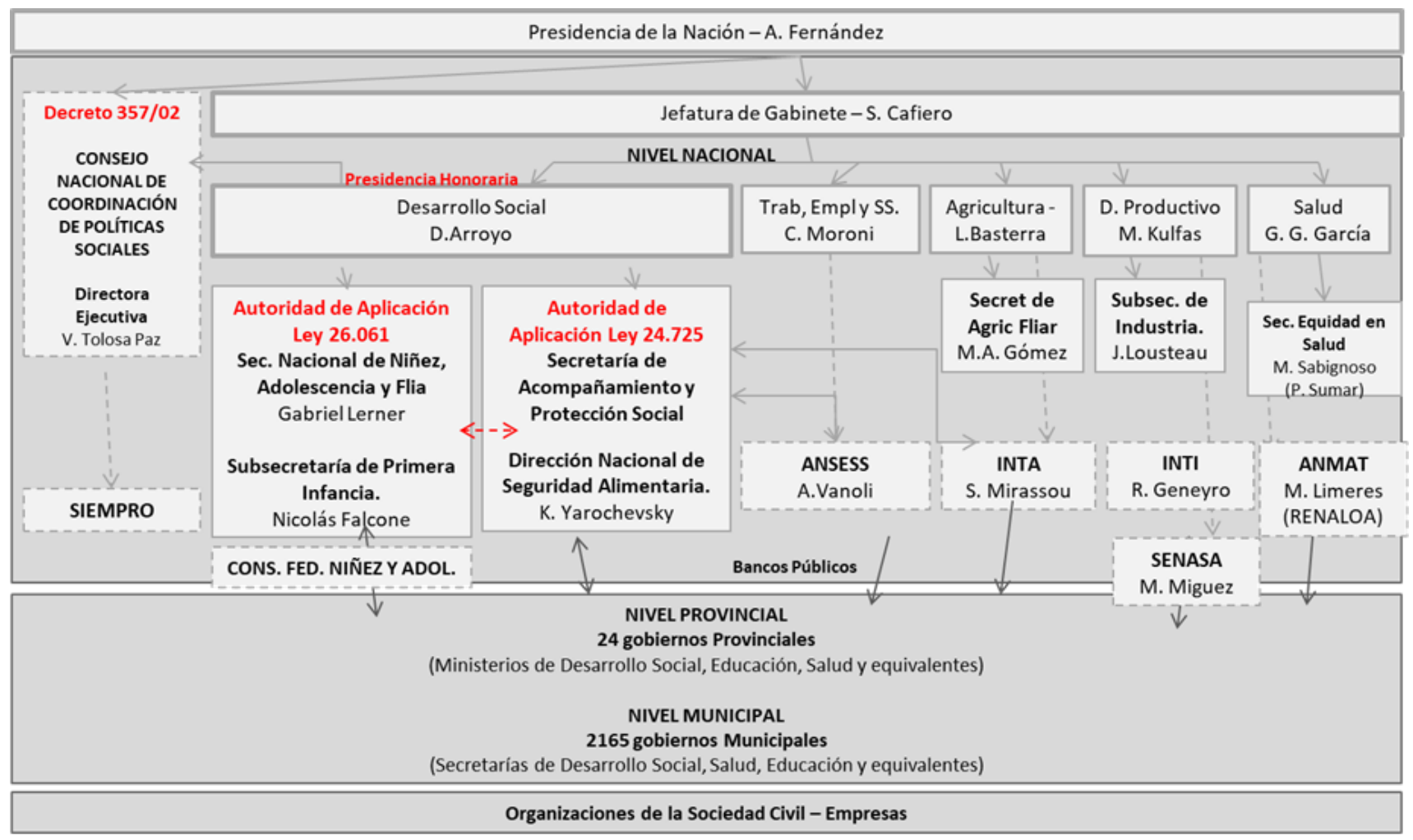

Fuente: Elaboración propia en base a Organigramas Oficiales.

Cabe señalar que las dependencias comprendidas en el gráfico incluyen aquellas alcanzadas por las políticas bajo análisis. Es decir, se trata de una representación recortada del organigrama general y total de dependencias en cada caso, que busca facilitar el análisis. El gráfico ilustra un marco institucional compuesto de (a) Sectores (Desarrollo Social, Salud, Educación, Producción, Agricultura, Consejo Nacional de Coordinación de Políticas Sociales, Trabajo, Agricultura, Producción, Salud, y con corresponsabilidad de organizaciones y empresas), o plano de 'integración horizontal' y (b) Niveles de gobierno (nacional, provincial y municipal) o plano de 'integración vertical' en los cuales los sectores se distribuyen.

Dentro de estas combinaciones, los sectores de asistencia alimentaria y políticas para la infancia del nivel nacional cuentan con facultades, atribuciones, responsabilidades y presupuestos, que presentan al Ministerio de Desarrollo Social de la Nación (representado como "MDS-N" en el gráfico) con un rol rector dentro de la estructura (ver atribuciones en rojo).

En materia de sectores de producción y disponibilidad física de alimentos del nivel nacional, las políticas presentadas, se encuentran a cargo del Instituto Nacional de Tecnología Agropecuaria (INTA) y el Instituto Nacional de Tecnología Industrial (INTI). Estas instituciones son las que exponen mayor proximidad con las políticas de asistencia alimentaria. En el caso del INTA, se encuentran relaciones con el Ministerio de Desarrollo Social de la Nación a través del PNSA y el PNPI, e interacciones con las provincias de casi dos décadas.

Por su parte, los sectores de asistencia alimentaria de gobiernos provinciales delimitan su propia oferta de políticas y distribuyen atribuciones entre distintos ministerios, y con distintos niveles de descentralización, entre Gobiernos y Secretarías Municipales (Desarrollo Social, Salud y Educación o equivalentes, en adelante $D / S / E$ ), para gestionar políticas co-financiadas entre fondos nacio- 
nales y provinciales. En cuanto a los sectores de producción y disponibilidad física de alimentos del nivel provincial, los gobiernos también interactúan, en mayor o menor medida, con las 52 bases experimentales del INTA y la red de centros y profesionales del INTI en distintas iniciativas.

Por último, la corresponsabilidad de organizaciones de la sociedad civil y empresas presenta asimetrías territoriales en presencia y accionar, heterogeneidad de perfiles y financiamiento de fondos públicos y privados. Por su parte, también con heterogeneidad territorial y de acción alcanza a las empresas que acompañan acciones alimentarias y de transferencia de tecnologías. Ambos sectores acompañan niveles nacionales, provinciales y municipales.

Ante las políticas, sectores y niveles de gobierno presentados hasta aquí, cabe retomar la pregunta inicial: ¿por qué persisten, aumentan y se complejizan en el tiempo la inseguridad alimentaria, la pobreza infantil, y la malnutrición en niños y niñas de sectores vulnerables? Entre las múltiples respuestas, ¿es óptima la disponibilidad de alimentos y la instrumentación de políticas de asistencia alimentaria?

Una primera discusión, expone vacíos en la coordinación del abordaje de las políticas citadas, tanto entre los sectores que las proponen, como entre los niveles de gobierno que las instrumentan. Esta mirada coincide, actualiza y amplía antecedentes de otros autores que han tratado las políticas de seguridad alimentaria (Repetto, F., Alonso, G., 2004; Maceira, D., Stechina, M., 2008; Maceira, D., Lignelli, B., 2009; Repetto, F., Fernández, J., 2012; Aulicino, C., 2012; Díaz Langou y Aulicino, 2012; Abeyá Gilardón, E., 2016; F. Alimentaris, 2019). Las lecturas más convergentes, describen efectos en las desigualdades territoriales del gasto en la niñez, y en la fragmentación y superposición de políticas y acciones de asistencia. En el presente estudio, por ejemplo, la falta de distribución de responsabilidades y alcances hacen que programas provinciales como "Chaco Familia" (Desarrollo Social y Salud, Provincia de Chaco) o "Pai.Cor" (Desarrollo Social, Provincia de Córdoba), no presenten fuentes que indiquen en qué se complementan o qué sustituyen frente a políticas nacionales presentes en sus territorios.

La creación del Consejo Federal de Desarrollo Social ${ }^{20}$ en diciembre de 2019, podría saldar los vacíos en la formalización de espacios de coordinación, como las comisiones provinciales previstas en la Ley 25.724 de 2003 (art. $4^{\circ}$ ) que crea el PNSA (desarrollado más adelante), o el fortalecimiento de objetivos de funcionamiento del Consejo Nacional de Coordinación de Políticas Sociales creado por Decreto 357 de 2002. La resolución № 8/2020 del Ministerio de Desarrollo Social que crea el plan "Argentina contra el Hambre", establece que el diseño e implementación se basa en "un enfoque interdisciplinario garantizando la coordinación interjurisdiccional e intersectorial de diversos organismos y niveles del Estado nacional, provincial, y municipal, y actores de la sociedad civil para el logro de los objetivos planteados". No obstante, la norma no enuncia los órganos que formalizan dichos enfoques junto al Ministerio de Desarrollo Social, ni distribuye responsabilidades entre los distintos actores pre-existentes (Secretarías y Subsecretarías, Consejo Nacional de Coordinación de Políticas Sociales, otros Ministerios) o creadas para él (Consejo Federal de Desarrollo Social, Mesa intersectorial, Observatorio de políticas alimentarias).

Una segunda discusión, expone vacíos en la integralidad de las políticas alimentarias, con la cual también coinciden los autores citados. Desde esta perspectiva, puede decirse que la integralidad comprende la cohesión conceptual de todos los sectores y niveles de gobierno sobre los problemas abordados; la intencionalidad en el combate a la inseguridad alimentaria infantil; los abordajes holísticos; y la integración administrativa y evaluativa. A lo cual se suma particularmente un

${ }^{20}$ Como antecedentes de este tipo de órgano, se encuentra el Consejo Federal de Educación (creado en 1979 por Ley № 22.047 y Dec. 943/84); el Consejo Federal de Salud (creado en 1981 por Ley № 22.373) y el Consejo Federal de Niñez, Adolescencia y Familia (creado por Ley $\mathrm{N}^{\circ} 26.061$ y Dec. 1293/05). 
déficit de integración entre las políticas orientadas a la producción de alimentos y las orientadas a la asistencia alimentaria. ${ }^{21}$

A nivel de sectores nacionales, por ejemplo, las huertas familiares del PNSA/ProHuerta (DesarroIlo Social e INTA), no están conectadas intencionalmente con Espacios de Primera Infancia (Desarrollo Social), la AUH (Trabajo y Seguridad Social / ANSES), la tarjeta social del PNSA (Desarrollo Social), la asistencia a un Comedor Comunitario (Organización Civil), estrategias de Educación Alimentaria y Nutricional en la escuela (Educación) o a controles antropométricos del Plan Sumar (Salud). Ni en edades, ni en acciones, ni en intencionalidades. La fragmentación y el aislamiento no son fenómenos ajenos a los niveles provinciales o a las organizaciones sociales: en un mismo municipio hay "entidades que trabajan en problemas parecidos o complementarios" y están "desconectadas entre si" (Tercer Sector, 2017). Puede tratarse del/a mismo/a niño/a en un mismo territorio, visto desde distintas áreas de desarrollo humano, de modo excluyente. Cada sector y nivel observa al niño, sólo desde su propio abordaje.

Como síntesis de esta introducción, se puede inferir que los bajos niveles de coordinación e integralidad producen un desfasaje entre la institucionalidad y la práctica concreta de la asistencia alimentaria, que "bloquea nuevas propuestas o tornan difícil su implementación" (CISI-UCA, 2016), y debilitan la capacidad óptima de impacto de las políticas de producción y asistencia alimentaria.

A continuación, se presentan seis apartados que sustentan estas consideraciones introductorias:

- El apartado 2 presenta y caracteriza las institucionalidades nacionales, incluyendo las normas, atribuciones, antecedentes y marco general de las políticas de cada una de ellas, como contexto del cual se extraen las políticas alimentarias tratadas en este trabajo.

- El apartado 3 presenta dimensiones, características operacionales y evaluaciones de las políticas nacionales de asistencia alimentaria y producción de alimentos instrumentadas por las entidades caracterizadas en el apartado 2.

- El apartado 4 presenta las institucionalidades jurisdiccionales (24 provincias y 2165 municipios), incluyendo heterogeneidades y procesos políticos en común en materia de asistencia alimentaria, sin perjuicio de la soberanía e individualidades de cada jurisdicción.

- El apartado 5 caracteriza algunos aspectos convergentes y divergentes de las políticas jurisdiccionales en materia de seguridad alimentaria. El anexo incluye una enumeración y descripción (realizada a los fines de este trabajo), incluyendo (a) modalidades (88 acciones incluyendo tarjetas alimentarias, comedores escolares, ofertas complementarias por jurisdicción); (b) niveles de descentralización de fondos en municipios. Con el PNSA como principal interacción entre el gobierno nacional y las provincias, el anexo también incluye (c) coberturas de beneficiarios por modalidad, según provincia; (d) aportes económicos nacionales por modalidad y provincia.

- El Apartado 7, por último, resume las principales consideraciones finales del trabajo.

${ }^{21}$ Pero "por lo general, las instituciones tradicionales no responden a enfoques integrales (...) Hay una vieja institucionalidad que precede a las nuevas visiones y procesos emergentes" (INDA-FAO-UDELAR, 2015). 


\section{INSTITUCIONALIDADES SECTORIALES DEL ESTADO NACIONAL.}

Desde la vuelta a la democracia en 1983, la asistencia alimentaria a cargo del gobierno nacional pasó por la órbita del Sector Salud en los '80, a la convivencia del Sector Salud con la órbita de Acción Social durante principios de la década de los '90, hasta llegar a la escisión de ambos sectores, en un Ministerio de Salud por un lado, y el Ministerio de Desarrollo Social por el otro, en $1999^{22}$ (Abeyá Gilardón, E., 2016:593). La mayor parte de las políticas de erradicación de la pobreza infantil han estado bajo la órbita del Ministerio de Desarrollo Social desde entonces. En 2018, Desarrollo Social absorbió el Ministerio de Salud como Secretaría de Gobierno, por decreto. La experiencia duró poco más de un año, con la recuperación de la condición de Ministerio del sector Salud, en 2020.

Desde el Ministerio de Desarrollo Social, emana el diseño, instrumentación, monitoreo y evaluación de políticas de asistencia alimentaria (PNSA, incluyendo la nueva Tarjeta AlimentAR) y de protección social de la niñez y la adolescencia. El Ministerio vehiculiza la mayor parte de sus decisiones y acciones alimentarias a través de la Administración Nacional de Seguridad Social (ANSES), el Banco de la Nación y Gobiernos Provinciales (Desarrollo Social, Salud y Educación, o "D/S/E"). Dentro de este rol rector del Ministerio de Desarrollo Social, se destacan tres de sus principales atribuciones:

-En primer lugar, como Unidad Ejecutora del Programa Nacional de Seguridad Alimentaria (PNSA). La creación del PNSA surge en el contexto de crisis del 2001-02, y se concreta con la sanción de la ley nacional 25.724 del 2003. Esta ley, se reglamenta con el Decreto 1018/03 y la Resolución 2040/03, que le confieren atribuciones de instrumentación al Ministerio. La ley contaba con objetivos de construcción multiactoral e integral. El artículo 4 de la ley proponía una "Comisión Nacional de Nutrición y Alimentación" con 8 ministerios y organizaciones sociales, y "Comisiones Provinciales con similares integrantes" (art.4). Pero las comisiones no se constituyeron, y la reglamentación facultó al Ministerio para centralizar la instrumentación. En una primera etapa y como apoyo a la instrumentación, en su lugar se creó el apoyo del CNCPS que comenzó con el PNSA como su primera política. El mandato de actuar junto al Ministerio de Salud que preveía el Decreto 1018/03, la articulación "no sucedió" (Aulicino, C., Díaz Langou, 2012). Actualmente, el PNSA amplía magnitudes y alcances con la instrumentación de la Tarjeta AlimentAR.

-En segundo lugar, la presidencia honoraria del Consejo Nacional de Coordinación de Políticas Sociales (CNCPS). Según Hilda "Chiche" Duhalde (primera Presidenta Honoraria), el órgano fue pensado y creado durante su gestión, como un espacio de optimización de recursos en un momento de crisis, a través de presencia territorial y articulación interministerial (Maya, F., 2019). Creado en 2002 por decreto №357, y dependiente de Presidencia de la Nación, el CNCPS tiene el fin de "articular las áreas del Estado nacional que implementan políticas sociales para alcanzar una correcta y más eficaz administración de los recursos". Los decretos 880/16 y 292/18 suman amplias facultades para cumplir un rol integrador con 11 objetivos en materia de diseño, coordinación, monitoreo y evaluación de políticas sociales. Tiene responsabilidad, incluso un Plan

22 Nota: Abeyá Gilardón (2016), página 593. Posterior a denuncias y eventos surgidos durante la política "Bono Solidario" gestionada desde el Ministerio de Salud y Acción Social, el autor afirma: "Las dificultades políticas y operativas de la asistencia social y del desarroIlo humano, sumadas al convencimiento de la sociedad sobre la corrupción ministerial vinculada a la asistencia social llevaron, en 1999, a su escisión en dos ministerios, Salud por un lado y Desarrollo Social por el otro, que aún se mantiene”. 
Nacional de Monitoreo y Evaluación, aún no instrumentado. Como espacio privilegiado de coordinación, el funcionamiento del CNCPS no ha estado libre de tensiones ${ }^{23}$.

Desde 2020, la Dirección Ejecutiva del CNCPS ${ }^{24}$ cobra un rol activo e incorpora la actuación de otros sectores en presentaciones de la nueva "política integral AlimentAR" como parte del plan "Argentina contra el hambre":

\section{Gráfico 3. Descripción de Sectores y Prestaciones de la Política AlimentAR}

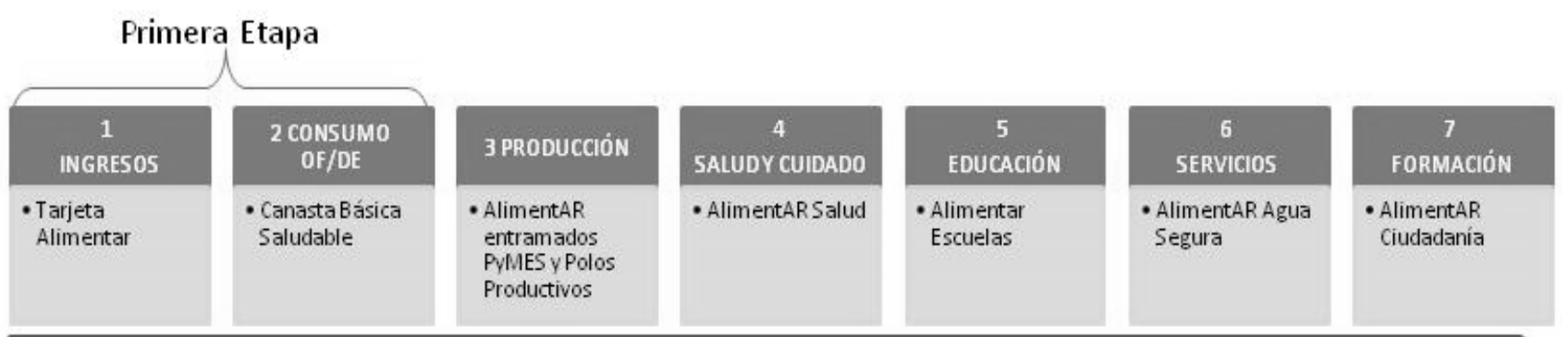

AlimentAR: política integral coordinación entre políticas intervinientes, niveles, sectores, jurisdicciones

Fuente: Tolosa Paz, CNCPS, 2020

La confluencia de estos sectores en la etapa inicial de la política AlimentAR comprende declaraciones públicas, que exponen convergencias sobre los precios de los alimentos ${ }^{25}$, poblaciones alcanzadas, algunos términos de la matriz de producción de alimentos (Tolosa Paz, V., 2020), aspectos sanitarios y de acceso al agua, reinserción escolar, entre otros ${ }^{26}$. También presenta algunas tensiones entre sectores en las medidas dirigidas a transformar comportamientos alimentarios (por ejemplo, respecto de si el principal problema es la obesidad, que parece la posición del Ministerio de Salud, o el hambre y la desnutrición, que están más enfatizadas por el Ministerio de Desarrollo Social) ${ }^{27}{ }^{28}$ y el modo de establecer una línea de base para monitorear su evolución, en un momento clave como es la distribución de la tarjeta alimentaria durante la etapa inicial (lo que requiere clarificar el punto anterior sobre los problemas que se desean resolver). ${ }^{29}$

- En tercer lugar, el Ministerio de Desarrollo Social cumple con el rol de autoridad de aplicación en la protección de derechos de niños y adolescentes en situación de vulnerabilidad, a través de la Secretaría Nacional de Niñez, Adolescencia y Familia (SENNAF) desde el año 2006. Esto implica velar por los derechos de esta población, con especial énfasis en aquellos más vulnerables. La Ley 26.061 de Protección Integral establece, "una serie de derechos vinculados a la salud, la educación, el desarrollo, la protección, la alimentación saludable, la identidad, el cuidado y la

\footnotetext{
${ }^{23}$ Gabriela Agosto (Directora Ejecutiva, período 2016-19), opta por definir que "este consejo tiene una presidencia honoraria que es necesario definir políticamente de manera clara para no confundir la institucionalidad cuando quién la ocupa también cumple otro rol". (Maya, F., 2019). En palabras de Duhalde: "si todos son ministros de igual rango y se elige un coordinador de políticas sociales que no esté envestido de autoridad, no funciona." (Maya, F., 2019:55). Agosto coincide con Duhalde, y entiende que la institucionalidad del CNCPS consiste en el tratamiento de transversalidades, entendiendo que la individualidad y estructura específica de 'ministerio' "ya no sirve para la gestión administrativa del Estado", e invitando a redefinir y repensar los espacios de coordinación y el poder que se les otorga (Maya, F., 2019:59). Además de un espacio de coordinación para el PNSA en un momento inicial y de crisis, el único programa de gestión interministerial con asignaciones presupuestarias y gestión a cargo del CNCPS desde 2002, fue el programa "Primeros Años", que desde 2018 se encuentra bajo la órbita de la Secretaría Nacional de Niñez, Adolescencia y Familia (SENNAF) del Ministerio.

${ }^{24}$ Fuente: presentación oficial realizada por V. Tolosa Paz, Directora Ejecutiva del Consejo Nacional de Coordinación de Políticas Sociales (CNCPS), al Grupo de Fundaciones y Empresas (GDFE) el viernes 10/1/2020. Se cita como Tolosa Paz, V., CNCPS, 2020.

${ }^{25}$ Fuente: recup. 23/1/2020 https://www.lanacion.com.ar/comunidad/daniel-arroyo-para-parar-hambre-hay-resolver-nid2315790

${ }^{26}$ Ibídem.

${ }^{27}$ Fuente: recup. 16/1/2020: https://www.pagina12.com.ar/240694-por-que-se-incluyo-alcohol-y-coca-cola-en-precios-cuidados

${ }^{28}$ Fuente: recup. 15/1/2020 https://www.lanacion.com.ar/economia/gines-gonzalez-garcia-nadie-se-va-a-quedar-sin-medicamentos-poruna-decision-economica-nid2323052

${ }^{29}$ Fuente: entrevista 9/1/2020 con la Dirección Nacional de Seguridad Alimentaria (DNSA) del Ministerio de Desarrollo Social de la Nación. Responsable de instrumentación del PNSA y de la Tarjeta Alimentar.
} 
vivienda de los NNyA. Estipula el rol central de las familias como responsables prioritarias de asegurar a los niños el disfrute pleno y efectivo de sus derechos y garantías, siendo el Estado el garante último de su cumplimiento" (UNICEF, 2016). Si bien su papel prioriza y concentra mayores esfuerzos en el tratamiento de vulnerabilidades severas (cuidados no parentales, violencia y maltrato infantil, embarazo no intencional adolescente, responsabilidad penal juvenil, entre otras), la SENNAF comprende también la coordinación e interacción con otros sectores (salud, educación, justicia y sociedad civil, especialmente) y un papel de abordaje territorial, que debe garantizar el cumplimiento de las "las provincias que adhirieron a esta ley nacional" (2016). En este sentido, el Consejo Federal de Niñez y Adolescencia propone un ámbito de discusión territorial sobre los problemas prioritarios de esta población. La SENNAF también actúa como promotor de políticas, y financiador de transferencias a las jurisdicciones. El Plan Nacional de Primera Infancia se instrumenta desde la Subsecretaría de Primera Infancia, bajo su órbita.

Además del Ministerio de Desarrollo Social y sus atribuciones, la ANSES se incorpora al combate por la inseguridad alimentaria infantil, al ser nombrado órgano de instrumentación de la Asignación Universal por Hijo (AUH), por decreto nacional 1602, del 2009 (ver también Capítulo II). La norma integra la AUH a la implementación de la Ley 24.714 de asignaciones familiares del año 1996, que alcanza también asignaciones de trabajadores activos, del sector público, monotributistas y pasivos. La red territorial de ANSES presenta $\mathbf{4 3 4}$ oficinas y unidades de atención inmediata (UDAI) en todo el país, para prestaciones previsionales, asistenciales, y de identidad junto al Registro Nacional de las Personas (Re.Na.Per). Normas, presupuesto y red territorial ubican a ANSES como principal vehiculizador de transferencias directas a individuos del gobierno nacional.

En materia de Producción de Alimentos, desde el Ministerio de Agricultura, Ganadería y Pesca, se destacan tres dependencias con distintos niveles de integración y contribución a la asistencia alimentaria. Por su contribución directa, las políticas analizadas en este trabajo incluyen aquellas vinculadas al Instituto Nacional de Tecnología Agropecuaria (INTA) como organismo descentralizado bajo la órbita de este ministerio. El INTA fue creado por Decreto Ley 21.680 en 1956 para "impulsar, vigorizar y coordinar el desarrollo de la investigación y extensión agropecuaria y acelerar, con los beneficios de estas funciones fundamentales, la tecnificación y el mejoramiento de la empresa agraria y de la vida rural". Cuenta con 52 bases experimentales, 15 Centros Regionales en todo el país, y 6 Centros de Investigación e Institutos (Agroindustria; Ciencias Políticas, Económicas y Sociales; Ciencias Veterinarias y Agronómicas; Desarrollo Tecnológico para la Agricultura Familiar CIPAF; Investigaciones Agropecuarias; Recursos Naturales). El organismo ha hecho contribuciones significativas a la tecnología agrícola, con un presupuesto para investigación y desarrollo que se incrementó sustancialmente en los últimos años. En la actualidad, la agenda investigación y el desarrollo para al sector agropecuario, agroalimentario y agroindustrial toman forma en el Plan Estratégico Institucional (PEI), con una visión de largo plazo para todas las regiones del país ${ }^{30}$. EI INTA ha mantenido desde 2003 una articulación con el Ministerio de Desarrollo Social, dado que su programa ProHuerta se integró al PNSA ese año. Podría decirse que esta articulación es la proximidad más sostenida entre la producción de alimentos y la asistencia alimentaria. También ha tenido acciones conjuntas con el Programa Primeros Años del CNCPS.

En segunda medida, la Secretaría de Agricultura Familiar, Campesina e Indígena (SAFCI), plantea contribuciones indirectas a las políticas de asistencia alimentaria. La tradición, de larga data, de producción de alimentos desde la familia es abordada por la Ley № 27.118 de Reparación Histórica de la Agricultura Familiar, sancionada en 2014. Pero la norma aún no ha sido reglamentada y no cuenta con presupuesto propio, dejando a la SAF en un lugar de menor integración con la asisten-

\footnotetext{
${ }^{30}$ Fuente: https://inta.gob.ar/paginas/historia-del-inta
} 
cia que el INTA. Según algunas posiciones, en los últimos años presentó "cierta ambigüedad e indefinición en el tipo de productor al que se orientan las acciones vinculadas con el desarrollo rural y la agricultura familiar", considerando sectores "campesinistas" y "emprendedoristas" con visiones encontradas, y mayor estabilidad de acciones con financiamiento administrado y coordinado por la Unidad para el Cambio Rural (UCAR) (Nogueira y Urcola, RELAER, 2017).

Por último, la Dirección Nacional de Alimentos y Bebidas también se encuentra menos integrada y con contribuciones indirectas a la asistencia, mediante el apoyo a pequeñas y medianas empresas (PyMES) de alimentos y bebidas. En los últimos años, la Dirección se abocó al posicionamiento de la industria en materia de exportaciones, facilitar líneas de financiamiento, producir información técnica y comercial, y promover y fiscalizar medidas regulatorias como la Comisión Nacional de Alimentos. Dependiente de la Secretaría de Alimentos y Bioeconomía, el área continúa hoy con muchas de estas líneas, y se propone "contribuir al posicionamiento de la producción de alimentos y bebidas en la sociedad como un sector estratégico y necesario para el desarrollo de la Argentina" en el marco de lograr diversificación de la matriz exportadora. Muchas de la PyMES apoyadas se encuentran representadas por la Coordinadora de las Industrias de Productos Alimenticios (COPAL), que ha interactuado como agrupación con esta Secretaría, y también con el Ministerio de Producción en relación a la política de Precios Cuidados.

Desde el sector de la Producción, el Ministerio de Desarrollo Productivo también plantea, a través de las PyMES, y la política Precios Cuidados como aspectos integrables y contribuciones a la asistencia alimentaria. Bajo su órbita, como organismo descentralizado, se encuentra el Instituto Nacional de Tecnología Industrial (INTI), creado por el Decreto Ley 17.138 de 1957. El INTI cuenta con centros regionales y multipropósito, y una "red de laboratorios y profesionales especializados" con una oferta de "más de 1200 servicios para todos los sectores de la industria". Al igual que el INTA, hace contribuciones en materia de transferencia de tecnologías. Hasta 2018, su "Red de Apoyo al Trabajo Popular" reunía organizaciones sociales sin fines de lucro y organismos gubernamentales que llevan adelante proyectos productivos, con la finalidad de generar fuentes de trabajo para los sectores más vulnerables con diversas acciones. Esta red se disolvió en el medio de un conflicto gremial en 2018, ya que el titular de ese entonces consideró que el ministerio de Trabajo y el ministerio de Desarrollo Social estaban "trabajando estas áreas con calidad y conocimiento"31. Si bien el conflicto podría haber derivado en la distribución de responsabilidades superpuestas entre el área de Economía Social (Desarrollo Social), Empleo Joven (Trabajo) y el INTI, y coordinar actuaciones conjuntas y complementarias, esta línea social del organismo dejó un mayor énfasis de actuación frente al fortalecimiento de pequeñas y medianas empresas (PyMES), Cooperativas, Cámaras, Empresas del Estado provincial y nacional, Universidades, entre otras para las cuales cuenta con presencia territorial y apoyo en la producción de alimentos y bebidas como principal contribución directa incluida en este trabajo.

Entre las dependencias del Ministerio de Desarrollo productivo, también se incluyen a la Secretaría de la Pequeña y Mediana Empresa y los Emprendedores y la Subsecretaría de Industria, cuyas líneas estratégicas de trabajo se encuentran en revisión ${ }^{32}$, y de las cuales se infieren algunas convergencias con funciones de la Dirección Nacional de Alimentos y Bebidas del Ministerio de Agricultura. Como política vigente y con continuidad, el Ministerio es responsable de Precios Cuidados, basada en acuerdos comerciales para combatir la inflación en alimentos prioritarios. Si bien esta podría ser una política integrable y con contribución directa a la asistencia alimentaria, las

\footnotetext{
${ }^{31}$ Ver: https://www.baenegocios.com/politica/El-presidente-del-INTI-defendio-los-258-despidos-20180225-0001.html

${ }^{32}$ El sitio web del Ministerio, comunica estar adecuando sus contenidos oficiales al Decreto $N^{\circ} 7$ de 2020 en función de la Ley de Ministerios. Ver: https://www.argentina.gob.ar/produccion
} 
fuentes relevadas no muestran relaciones entre Precios Cuidados y aquellos productos alimenticios a adquirir con la tarjeta AlimentAR.

Por último, durante y después de la producción, y antes de la disponibilidad física, la sanidad, inocuidad y calidad de los alimentos, se incluye intervenciones de otros dos organismos descentralizados bajo orbitas sectoriales. El Servicio Nacional de Sanidad y Calidad Agroalimentaria (SENASA) también bajo la órbita del Ministerio de Agricultura, Ganadería y Pesca, y de la Administración Nacional de Medicamentos, Alimentos y Tecnología Médica (ANMAT), bajo la órbita de Salud.

\section{PRINCIPALES POLÍTICAS ALIMENTARIAS NACIONALES.}

Desde el punto de vista presupuestario, el gobierno nacional tiene una responsabilidad sobre aproximadamente el $55 \%{ }^{33}$ del presupuesto del gasto social consolidado argentino (1980-2017). Las principales asignaciones para la asistencia alimentaria en 2019 son parte del presupuesto de $\$ 30$ mil millones de dólares a la Administración Nacional de Seguridad Social (ANSES), y $\$ 9.891$ millones de dólares al Ministerio de Desarrollo Social de la Nación. ${ }^{34}$ En el caso de ANSES, el 82\% consta de aportes previsionales (jubilaciones y pensiones) como principal partida. En el caso del Ministerio de Desarrollo Social, las "contribuciones figurativas" incluyen pensiones no contributivas (madres con más de 7 hijos, por ejemplo) y de la economía social, que en 2019 representaron \$8.502 millones de dólares (86\%), y se operacionalizaron a través de ANSES.

La asignación a asistencia alimentaria de ambas instituciones es \$2.416 millones de dólares, equivalente al $6 \%$ de los dos presupuestos sumados, con los detalles que se presentan a continuación. En 2020, a este "piso mínimo" se sumará una asignación estimada en \$952 millones de dólares para la tarjeta AlimentAR.

\section{PROGRAMA NACIONAL DE SEGURIDAD ALIMENTARIA y ASIGNACIÓN UNIVERSAL POR HIJO.}

Si bien el PNSA y la AUH parten de normativas, propósitos e institucionalidades distintas, ambas constituyen las principales políticas de asistencia alimentaria desde los sectores de Desarrollo Social y la Seguridad Social del nivel nacional, dado que el acceso económico a alimentos, y la mayor focalización en la niñez y la adolescencia, resultan aspectos convergentes entre ambas. Las características y dimensiones pueden resumirse en el siguiente cuadro.

El Cuadro 1 muestra por un lado la AUH a cargo de ANSES, con transferencias directas que llegan a 2 millones de titulares con alcance a 4 millones de niños y adolescentes (SIEMPRO, 2019). En 2019, el presupuesto fue de $\$ 2.037$ millones de dólares ${ }^{35}$, dando lugar a que las transferencias directas a titulares de derechos representen $84 \%$ de la asistencia nacional destinada a aliviar la inseguridad alimentaria con apoyo al acceso económico a alimentos.

\footnotetext{
${ }^{33}$ Fuente: Análisis del Gasto Público Nacional 2017 sobre el gasto consolidado. También se tuvo en cuenta promedio de serie histórica 1980-2017, dando \% similares, con distintas composiciones. Según Secretaría de Política Económica, del Ministerio de Economía de la Nación. Más información en anexo.

${ }^{34}$ Nota: ver anexo con presupuestos nacionales iniciales y ejecutados 2019

${ }^{35}$ https://www.presupuestoabierto.gob.ar/sici/destacado-explorador-programas\#. Se valorizan cifras al dólar oficial valor de venta al 24/1/2020 - \$AR 63 por U\$1, Ejecución del presupuesto al 26/12/2019: AUH: \$128.339 millones de pesos; PNSA: \$23.435 millones de pesos.
} 


\section{Cuadro 1. Síntesis de Políticas Alimentarias Nacionales. Dependencias, Normas, Cobertura y Presupuesto.}

\begin{tabular}{|c|c|c|c|c|c|c|c|c|}
\hline \multirow{2}{*}{ Organismo } & \multirow{2}{*}{$\begin{array}{l}\text { Marco Norma- } \\
\text { tivo }\end{array}$} & \multirow{2}{*}{$\begin{array}{l}\text { Perfil y Edad de los Des- } \\
\text { tinatarios }\end{array}$} & \multirow{2}{*}{ Políticas y Programas } & \multirow{2}{*}{ Modalidad } & \multirow{2}{*}{$\mathbf{N}^{\circ}$ de Destinatarios } & \multirow{2}{*}{$\begin{array}{l}\text { Presup. } \\
\text { (mil.\$AR) }\end{array}$} & \multicolumn{2}{|c|}{ Ejecución Presupuestaria } \\
\hline & & & & & & & En mill. \$AR & En mill. \$US \\
\hline ANSES & $\begin{array}{l}\text { Res. } 1602 / 09 \\
\text { Año } 2009\end{array}$ & $\begin{array}{l}\text { Embarazadas (AUE) - } \\
0 \text { a } 18 \text { años (AUH) } \\
\text { Niñas, Niños, Adol. y Adul- } \\
\text { tos con discapacidad } \\
\text { (AUHD) }\end{array}$ & $\begin{array}{l}\text { Asignación Universal para Prot. } \\
\text { Social }(A \cup H)\end{array}$ & Transferencia Directa & $\begin{array}{l}\text { AUE: } 75.160 \\
\text { AUH:3.888.989 } \\
\text { AUHD:35.745 } \\
\text { Titulares de cobro: } \\
2.262 .539\end{array}$ & $\$ 109.752,4$ & $\$ 128.339,2$ & $\$ 2.037,1$ \\
\hline \multirow{8}{*}{$\begin{array}{l}\text { Ministerio de Desa- } \\
\text { rrollo Social }\end{array}$} & \multirow{8}{*}{$\begin{array}{l}\text { Ley 25.724; De- } \\
\text { creto 1018; Res. } \\
\text { 2040. Año } 2003\end{array}$} & \multirow{7}{*}{$\begin{array}{l}\text { Prioridad sobre embaraza- } \\
\text { das, niños, niñas y adoles- } \\
\text { centes de } 0 \text { a } 14 \text { años. } \\
\text { También personas mayores }\end{array}$} & $\begin{array}{l}\text { Secretaría de Acomp. y Prot. } \\
\text { Social - PNSA }\end{array}$ & $\begin{array}{l}\text { Combinación de } \\
\text { prestaciones }\end{array}$ & & $\$ 12.582,2$ & $\$ 23.475,3$ & $\$ 372,6$ \\
\hline & & & PNSA, Tarjetas Alimentarias. & Convenio N-Prov. & 1.088.428 titulares & $\$ 4.384,0$ & $\$ 12.851,4$ & $\$ 204,0$ \\
\hline & & & $\begin{array}{l}\text { PNSA, Complemento Alimenta- } \\
\text { rio. }\end{array}$ & $\begin{array}{l}\text { Transferencias a } \\
\text { OSC }\end{array}$ & $\begin{array}{l}\text { Merenderos de OSC. } \\
\text { Para reforzar el } \\
\text { aporte nutritivo antes } \\
\text { de recibir la cena. s/d } \\
\text { cobertura. }\end{array}$ & $\$ 3.545,0$ & $\$ 3.832,3$ & $\$ 60,8$ \\
\hline & & & PNSA, Comedores Escolares. & Convenio N-Prov. & $\begin{array}{l}18.704 \text { comedores } \\
\text { Estimado: } 4.5 \text { mill. de } \\
\text { niños, niñas y adol. }\end{array}$ & $\$ 1.828,0$ & $\$ 2.739,4$ & $\$ 43,5$ \\
\hline & & & $\begin{array}{l}\text { PNSA, Comedores Comunita- } \\
\text { rios }\end{array}$ & Convenio c/OSC & 1.165 comedores & $\$ 1.065,0$ & $\$ 1.384,0$ & $\$ 22,0$ \\
\hline & & & PNSA, Asistencia al ProHuerta & $\begin{array}{l}\text { Distrib. de insumos, } \\
\text { capacitación y A. } \\
\text { Técnico a huertas y } \\
\text { granjas. }\end{array}$ & $\begin{array}{l}588.749 \text { huertas flia- } \\
\text { res. } \\
13.000 \text { huertas esco- } \\
\text { lares } \\
6.545 \text { huertas comu- } \\
\text { nitarias. }\end{array}$ & $\$ 80,2$ & $\$ 120,2$ & $\$ 1,9$ \\
\hline & & & $\begin{array}{l}\text { Políticas Alimentarias. Accio- } \\
\text { nes de Nutrición }\end{array}$ & S/D & S/D de cobertura & $\$ 1.680,0$ & $\$ 2.548,1$ & $\$ 40,4$ \\
\hline & & $\begin{array}{l}\text { Familias bajo extrema po- } \\
\text { breza e ins. Alim. de } 32 \text { mu- } \\
\text { nic. GBA, en San Luis y } \\
\text { CABA. }\end{array}$ & $\begin{array}{l}\text { Secretaría de Acomp. y Prot. } \\
\text { Social. Plan Nacional de Pro- } \\
\text { tección Social }\end{array}$ & $\begin{array}{l}\text { Transferencia Directa } \\
\text { al titular }\end{array}$ & $\begin{array}{l}204.020 \text { titulares tar- } \\
\text { jeta con acompaña- } \\
\text { miento de ONGs. }\end{array}$ & $\$ 440,0$ & $\$ 360,0$ & $\$ 5,7$ \\
\hline & & & & & & $\$ 122.774,6$ & $\$ 152.175,4$ & $\$ 2.415,5$ \\
\hline
\end{tabular}

Fuente: Elaboración propia en base a Presupuesto Abierto, Ministerio de Economía y SIEMPRO Reportes AUH1T-2019 PNSA2T -2019. Partida 26 del Presupuesto Nacional 2019. 
Por otra parte, el PNSA, a cargo del Ministerio de Desarrollo Social y Provincias, comprende una combinación de prestaciones co-financiadas entre el gobierno nacional y las 24 provincias argentinas que alcanzan, como mínimo, a 1,3 millones de familias (tarjetas), y a 4,5 millones de niños, niñas y adolescentes en edad escolar (18.469 comedores escolares) (SIEMPRO, 2019; CIPPEC, 2014). El aporte nacional en 2019 fue de $\$ 372,6$ millones de dólares ${ }^{36}$ (Ministerio de Economía, 2019).

En 2003, el PNSA surgió de la unificación de programas de los ministerios nacionales de Educación, Salud y Agricultura y Desarrollo Social. Este proceso comprendió la integración de: (a) Programa Alimentario Nutricional Complementario (Asistencia Nutricional Directa), el Fondo Participativo de Inversión Social - FOPAR, (Desarrollo Social); (b) Acciones Compensatorias para Escuelas Críticas (Educación); (c) algunas acciones del Plan Materno Infantil (Salud); y (d) Programa Pro-Huerta (INTA-Agricultura) (Aulicino, C., Díaz Langou, 2012). Esta unificación muestra un "consenso entre ciertos sectores" sobre sus resultados: "el PNSA no supuso una reestructuración de los programas vigentes sino tan sólo la confluencia de ellos bajo un mismo paraguas" (2012:16). Las evaluaciones describen la disparidad territorial de operación del PNSA, y escaso monitoreo y seguimiento, (Maceira, D., CEDES, 2009; Aulicino, C., CIPPEC, 2012; Díaz Langou, G. y Aulicino, C., CIPPEC, 2012; Abeyá Gilardón, E. 2016; Maya, F., 2019). Se logra relevar informes de monitoreo bajo el formato de sistematizaciones de coberturas y acciones del PNSA (SIEMPRO, 2019), pero desde el origen de la política, no se relevan evaluaciones de impacto del plan o sus componentes.

En 2020, el PNSA y la AUH se articulan con la distribución de 1.455.517 Tarjetas AlimentAR, con un alcance estimado en 2.004.471 embarazadas, bebés, niños y niñas de 0 a 6 años (Tolosa Paz, CNCPS, 2020). Como ampliación del PNSA, y una nueva partida estimada en $\$ 60.000$ millones de pesos ${ }^{37}$ (aproximadamente $\$ 952$ millones de dólares). La tarjeta incrementa el PNSA de $\$ 23.475$ millones a un mínimo de 84 mil millones de pesos en 2020 (+256\%).

Dentro de este esquema, el Ministerio de Desarrollo Social informa que la tarjeta AlimentAR, lanzada como parte del PNSA, busca (a) alcanzar cerca del 40\% de los niños y niñas menores de 6 años y mujeres embarazadas alcanzados por la $\mathrm{AUH}^{38}$, (b) darle cobertura a poblaciones no alcanzadas por la tarjeta AlimentAR (niños y adolescentes de 7 a 18 años, adultos mayores, poblaciones vulnerables como personas celíacas y adultos que no llegan a edad jubilatoria, pero requieren asistencia) a través de la tarjeta social en co-financiación junto a las provincias, (c) incrementar el número de huertas familiares del ProHuerta junto al INTA y (d) disponer territorialmente acciones de Educación Alimentaria Nutricional (EAN) desde el equipo de nutricionistas de la DNSA.

A partir de la tarjeta AlimentAR, el PNSA pasaría a un universo de casi 2.5 millones de tarjetas:

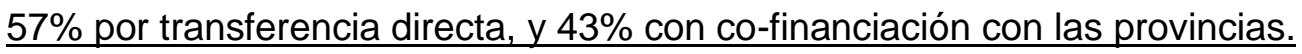

\section{POLÍTICAS ALIMENTARIAS PARA LA PRIMERA INFANCIA}

Como focalización de las políticas alimentarias en la niñez, vale detenerse en la Primera Infancia. Una robusta evidencia argumenta la potencialidad de inversiones en esta etapa de la vida, dirigida a reducir la reproducción de la pobreza y la malnutrición. Las políticas dirigidas a bebés, niñas y ni-

\footnotetext{
${ }^{36}$ Fuente: Montos oficiales recuperados el 23/1/19 en https://www.presupuestoabierto.gob.ar/sici/destacado-explorador-programas\#. ${ }^{37}$ Ver: https://www.infobae.com/politica/2019/12/19/el-gobierno-destinara-60000-millones-al-programa-de-la-tarjeta-alimentaria-que-yaempezo-a-distribuir-en-concordia/

${ }^{38}$ Nota: también validado por Tolosa Paz, V., CNCPS el 13/1/2020.
} 
ños de hasta 5 años, representan una focalización estratégica dentro de la infancia y la adolescencia, como parte de la lucha contra la inseguridad alimentaria y la promoción del desarrollo infantil temprano, dada la multiplicidad de procesos de esta etapa. En este sentido, el Ministerio de Desarrollo Social, a través de la SENNAF, su Subsecretaría de Primera Infancia y el Programa Primeros Años, representan al Plan Nacional de Primera Infancia que se sintetiza a continuación en el cuadro 2.

\section{Cuadro 2. Síntesis de Políticas del Plan Nacional de Primera Infancia.}

\begin{tabular}{|c|c|c|c|c|c|c|}
\hline \multirow{2}{*}{ Organismo } & \multirow{2}{*}{ Marco Normativo } & \multirow{2}{*}{$\begin{array}{c}\text { Unidades Ejecutoras. Políticas y } \\
\text { Programas }\end{array}$} & \multirow{2}{*}{ Modalidad } & \multirow{2}{*}{$\begin{array}{l}\text { Presu- } \\
\text { puesto }\end{array}$} & \multicolumn{2}{|c|}{$\begin{array}{l}\text { Ejecución Presu- } \\
\text { puestaria }\end{array}$} \\
\hline & & & & & $\begin{array}{l}\text { En mil. } \\
\text { \$AR }\end{array}$ & $\begin{array}{l}\text { En Mill. } \\
\text { \$US }\end{array}$ \\
\hline \multirow{10}{*}{$\begin{array}{l}\text { Ministerio de } \\
\text { Desarrollo Social }\end{array}$} & \multirow{10}{*}{ Decreto $874 / 16$} & $\begin{array}{l}\text { Subsecretaría de Primera Infancia - } \\
\text { PNPI }\end{array}$ & & $\$ 510,1$ & $\$ 1.021,8$ & $\$ 16,2$ \\
\hline & & PNPI, Acciones Federales & Cuidados, EPI & $\$ 256,8$ & $\$ 698,5$ & $\$ 11,1$ \\
\hline & & PNPI, Dirección Superior & Administración & $\$ 195,1$ & $\$ 235,6$ & $\$ 3,7$ \\
\hline & & $\begin{array}{l}\text { PNPI, Centros de Prev. y Recup. de } \\
\text { Desnutrición Infantil }\end{array}$ & Cuidados, CPR & $\$ 50,0$ & $\$ 76,3$ & $\$ 1,2$ \\
\hline & & $\begin{array}{l}\text { PNPI, capacitación y asistencia téc- } \\
\text { nica }\end{array}$ & Para Efectores & $\$ 8,2$ & $\$ 11,4$ & $\$ 0,2$ \\
\hline & & Secretaría de Coord. Apoyo al PNPI & & $\$ 107,9$ & $\$ 125,4$ & $\$ 2,0$ \\
\hline & & $\begin{array}{l}\text { Remodelación y construcción de } \\
\text { EPIs. BID }\end{array}$ & Cuidados, EPI & $\$ 89,4$ & $\$ 61,0$ & $\$ 1,0$ \\
\hline & & $\begin{array}{l}\text { Fort. EPIs e Intervenciones Domicilia- } \\
\text { rias }\end{array}$ & Cuidados, PIAC & $\$ 18,5$ & $\$ 64,4$ & $\$ 1,0$ \\
\hline & & SENNAF - Programa Primeros Años & Cuidados, PIAC & $\$ 169,0$ & $\$ 169,0$ & $\$ 2,7$ \\
\hline & & \multicolumn{2}{|c|}{ Políticas de Atención de Cuidado y Crianza } & $\$ 787,0$ & $\$ 1.316,2$ & $\$ 20,9$ \\
\hline
\end{tabular}

Fuente: Elaboración propia en base a Presupuesto Abierto, Ministerio de Economía.

EI PNPI tiene dos componentes. Los "Espacios de Primera Infancia" (EPIs) cuyo origen es la ley 26.233 de "Centros de Desarrollo Infantil" (CDI) del año 2006, con cobertura a 105 mil niños y niñas menores de 4 años. Y el plan Primeros Años (ahora "Primera Infancia, Acompañamos la Crianza", o "PIAC"), creado en 2005 como el único plan interministerial operado por el CNPS. A raíz del decreto 874/16, el PIAC pasó a depender de la SENNAF en 2018. Con aportes de siete ministerios, y operación de 1750 facilitadores, el PIAC incorporó visitas domiciliarias a 64 familias anuales desde 2018, que suman a esfuerzos de 1.643 EPIs, según el detalle a continuación.

\section{Cuadro 3. Cobertura del Plan Nacional de Primera Infancia. Alcances.}

\begin{tabular}{|l|l|r|r|}
\hline \multirow{2}{*}{ Región } & PROVINCIAS (según distribución regional del PIAC) & \multicolumn{1}{|c|}{ PIAC } & \multicolumn{1}{c|}{ EPI } \\
\cline { 3 - 4 } & familias visitadas & Niñas/os, 0- 4 años \\
\hline NOA & $\begin{array}{l}\text { Jujuy, Catamarca, La Rioja, Salta, Santiago del Estero y Tu- } \\
\text { cumán }\end{array}$ & 14.942 & 10.420 \\
\hline NEA & $\begin{array}{l}\text { Formosa, Chaco, Corrientes, Misiones, Santa Fe, Córdoba y } \\
\text { E. Ríos }\end{array}$ & 14.959 & 28.506 \\
\hline BUENOS AIRES & Gran Buenos Aires e Interior. & 22.857 & 40.952 \\
\hline CUYO & Mendoza, San Luis y San Juan & 7.781 & 3.796 \\
\hline PATAGONIA & Río Negro y La Pampa & 2.004 & 4.454 \\
\hline Otras Patagonia & Santa Cruz, Chubut, Tierra del Fuego, Neuquén & -- & 5.456 \\
\hline CABA & CABA & -- & 11.467 \\
\hline & Totales & $\mathbf{6 2 . 5 4 3}$ & $\mathbf{1 0 5 . 0 5 1}$ \\
\hline
\end{tabular}

Fuente: Elaboración propia en base a Informe de Gestión 2018 del PIAC y de la base de datos EPIs del Minist. de Modernización (dataset) 
EI PNPI, como parte de la gestión de la SENNAF, se inserta dentro de una oferta, tan fragmentada y superpuesta como la asistencia alimentaria, entre sectores y niveles de gobierno. La atención de la Primera Infancia está comprendida dentro de la descentralización de tres sistemas, entre las distintas provincias: (a) Espacios de cuidado, nutrición y acompañamiento familiar para niños de 0 a 4 años, promovidos por el sector de Desarrollo Social público (nacional, provincial y municipal) y civil (organizaciones comunitarias); el PNPI forma parte de este sistema; (b) Jardines Maternales (3.221) y de Infantes (18.493) de gestión estatal oficial provincial dependiente del sector Educación, con alcance a 1.175 .768 de niños de 45 días a 5 años en aquellas instituciones de gestión estatal oficial (CIPPEC, 2019), que brindan servicios de pre-escolar y cuidado obligatorios (4 y 5 años) y universales (45 días a 3 años); y (c) más de 5.000 Centros de Atención Primaria de la Salud (CAPS), hospitales y maternidades provinciales del sistema de Salud para atención maternoinfantil, a las cuales se suman programas nacionales que fortalecen esta red (Plan Sumar, PROTEGER, etc).

La efectividad de funcionamiento de los EPIs en el marco del PNPI, forma parte del estudio "Calidad de procesos y desarrollo infantil en los Espacios de Primera Infancia del Gran Buenos Aires"39 (López Boo y Paz Ferro Benegas, BID, 2019), basado en una muestra de 95 EPIs (5,8\% del universo total). La observación de prestaciones alimentarias incluyó mayor frecuencia de almuerzos ( $81 \%$ de los casos), si bien la evaluación de infraestructura detecta falta de comedores en una alta proporción de EPIs de jornada completa que deben prestar este servicio (74\%). También, se observaron artefactos para cocinar en mal estado (39\%) (2019:20). Lamentablemente, este estudio no incorpora datos antropométricos asociados a estos servicios, como parte de la evaluación. Desde los procesos de cuidado y educación, se resaltan las fortalezas de atención según pruebas estandarizadas, que dan a las áreas de "Apoyo emocional y conductual y de Interacciones" resultados superiores en comparación con otros programas de América Latina; las debilidades se observaron en rangos bajos de "Modelaje Lingüístico" de los niños y en la producción de situaciones de enseñanza y aprendizaje.

Desde niveles jurisdiccionales, se encuentra otro estudio realizado sobre una muestra de 456 niños menores de 4 años (sobre 7743 niños/as), que asisten a 13 Centros de Primera Infancia (CPI) de la Ciudad de Buenos Aires (sobre un total de 72) (UNICEF, 2019). Los resultados destacan efectos más favorables en niños con una permanencia mayor a 1 año al programa CPI y sus prestaciones. Entre múltiples impactos presentados, se destacan datos antropométricos preocupantes: un $41 \%$ de sobrepeso (13,8\% de ellos con obesidad), y baja talla del 23,2\% (2019:20). "Este perfil de malnutrición y de problemas de desarrollo infantil temprano requiere una especial atención que implica intervenciones con las familias (estilos de crianza y pautas de alimentación saludable) y fortalecimiento de las potencialidades de que dispone el Programa (cambios en los menús, mayor actividad física, estimulación verbal a través de la promoción de actividades comunicacionales)".

\section{POLÍTICAS DE PRODUCCIÓN, DISPONIBILIDAD FÍSICA, INOCUIDAD Y CALIDAD DE ALIMENTOS.}

Las políticas de producción de alimentos y aquellas que cuidan su salubridad, suelen encontrarse en un sistema de funcionamiento previo a las políticas de asistencia expresadas hasta aquí.

Varios autores describen la disponibilidad física de alimentos en Argentina como "excedentaria", identificando la accesibilidad económica como única causalidad de inseguridad alimentaria (Abeyá

\footnotetext{
${ }^{39}$ Fuente: recuperado el 27/1/2020, https://publications.iadb.org/publications/spanish/document/Calidad_de_procesos_y_desarrollo_infantil_en_los_Espacios_de_Primera_Infancia_del_Gran_Buenos_Aires_Validaci\%C3\%B3n_de_una_lista_corta_de_monitoreo_de_centros_infantiles_es.pdf
} 
Gilardón, E., 2016). Un caso práctico, permite problematizar esa afirmación. En 1952, el acceso a la producción láctea se encontraba concentrada en un 70\%, en las provincias productoras de Buenos Aires, Santa Fe y Entre Ríos (Biernat C, Ramacciotti K., 2008 en Abeyá Gilardón, E. 2016:591).

Según el Informe de Cadena de Valor № 22 del Ministerio de Agroindustria ${ }^{40}$ (2016), la producción láctea incorporó solo una provincia con desarrollo lácteo desde ese entonces: con Buenos Aires (25\%), Santa Fe (25\%), Entre Ríos (4\%), se suma Córdoba (33\%), incrementando la concentración al $\mathbf{9 7 \%}$. Más allá de la persistencia de la concentración, este dato permite observar vacancias en la transferencia de tecnologías de producción láctea de escala en 20 provincias argentinas a lo largo de 67 años. Este dato permite inferir no solo la debilidad de la seguridad alimentaria de las mismas, sino que lleva aún hoy a la continuidad de distribución de leche a través del Estado a familias vulnerables, a través del Plan Materno Infantil y el PNSA, en un contexto de reducción del consumo.

Si bien la eficiencia logística de la industria de alimentos y bebidas permite llegar hoy a 2950 bocas de supermercados e hipermercados (INDEC, 2019), y a más de 300 mil negocios tradicionales, los circuitos logísticos y otras operaciones intermedias de distribución, permiten pensar si la configuración de precios y los obstáculos de abastecimiento de alimentos suficientes y nutritivos, no se habrían optimizado favoreciendo desarrollos regionales o apoyando otras tecnologías. El cuadro 4 a continuación, sintetiza las políticas, que presentan mayores relaciones con la asistencia alimentaria y potencialidades de desarrollo bajo esta discusión. 
Cuadro 4. Síntesis de las principales políticas de producción, calidad e inocuidad de Alimentos

\begin{tabular}{|c|c|c|c|c|}
\hline $\begin{array}{l}\text { Ministerio / Organismo } \\
\text { Descentralizado }\end{array}$ & Tipo de Política & Programa & $\begin{array}{l}\text { Monto Ejec } \\
\text { (en mil. \$AR) }\end{array}$ & $\begin{array}{c}\text { SUBT } \\
\text { (en mil \$AR.) }\end{array}$ \\
\hline \multirow{15}{*}{$\begin{array}{l}\text { Secretaría de Agroindustria } \\
\text { (actual Ministerio de } \\
\text { Agricultura, Ganadería y } \\
\text { Pesca) }\end{array}$} & \multirow{8}{*}{$\begin{array}{l}\text { Políticas para la Agricultura Familiar. } \\
\text { Secretaría de Agricultura Familiar } \\
\text { (SAF) }\end{array}$} & Conducción y Dirección Superior & $\$ 736,6$ & \multirow{8}{*}{$\$ 1.270,6$} \\
\hline & & PRODERI-FIDA, Desarrollo Social Incluyente & $\$ 230,4$ & \\
\hline & & Inclusión Socioeconómica áreas rurales. PISEAR & $\$ 108,2$ & \\
\hline & & Formulación de políticas para cadenas agroindustriales & $\$ 98,5$ & \\
\hline & & BID - Desarrollo Rural y Agricultura Familiar & $\$ 58,2$ & \\
\hline & & Form. de políticas para desarrollo territorial y agricultura familiar & $\$ 22,9$ & \\
\hline & & FIDA - Inserción de pequeños. prod. norte a cadenas de valor & $\$ 11,1$ & \\
\hline & & FIDA - Desarrollo de cadenas caprinas. PRODECCA & $\$ 4,7$ & \\
\hline & $\begin{array}{l}\text { Aumento de producción y productivi- } \\
\text { dad de cadenas agroindustriales }\end{array}$ & $\begin{array}{l}\text { Bosques cultivados, sector pesquero, lechero, algodonero, forestal, } \\
\text { ganaderia ovina. Sist. de riego, reconversión PYME Agropecuarias }\end{array}$ & $\$ 2.384,9$ & \multirow{7}{*}{$\$ 4.782,5$} \\
\hline & Valor Agregado en Cadenas Agroind. & Sector Azucarero, Bioindustrias & $\$ 276,3$ & \\
\hline & Gestión del Riesgo Agropecuario & Sistema Nacional & $\$ 394,5$ & \\
\hline & \multicolumn{2}{|l|}{ Desarrollo de Mercados } & $\$ 219,1$ & \\
\hline & \multicolumn{2}{|c|}{ Servicios Agrícolas Provinciales } & $\$ 331,6$ & \\
\hline & \multicolumn{2}{|c|}{ Administración. y Control Comercial Agropecuario } & $\$ 203,7$ & \\
\hline & \multicolumn{2}{|l|}{ Actividades Centrales } & $\$ 972,4$ & \\
\hline \multicolumn{4}{|c|}{ SUBTOTAL SECRETARÍA DE AGROINDUSTRIA } & $\$ 6.053,1$ \\
\hline
\end{tabular}




\begin{tabular}{|c|c|c|c|c|}
\hline $\begin{array}{l}\text { Ministerio / Organismo Des- } \\
\text { centralizado }\end{array}$ & Tipo de Política & Programa & $\begin{array}{l}\text { Monto Ejec } \\
\text { (en mil. \$AR) }\end{array}$ & $\begin{array}{c}\text { SUBT } \\
\text { (en mil \$AR.) }\end{array}$ \\
\hline \multirow{9}{*}{ INTA } & \multicolumn{2}{|c|}{ Investigación aplicada, innovación, transf. de tecnologías, Extensión y apoyo al desarrollo rural } & $\$ 5.861,3$ & \multirow{9}{*}{$\$ 7.857,2$} \\
\hline & \multirow{5}{*}{$\begin{array}{l}\text { Investigación Fundamental e } \\
\text { Innovaciones Tecnológicas }\end{array}$} & Ciencias Agropecuarias y Veterinarias & $\$ 543,2$ & \\
\hline & & Agroindustrias & $\$ 293,2$ & \\
\hline & & Recursos Naturales & $\$ 257,5$ & \\
\hline & & Agricultura Familiar & $\$ 120,0$ & \\
\hline & & Estudios Políticos, Económicos y Sociales & $\$ 54,9$ & \\
\hline & \multicolumn{2}{|c|}{ Fortalecimiento estratégico y articulación institucional } & $\$ 213,3$ & \\
\hline & \multicolumn{2}{|l|}{ Actividades Centrales } & $\$ 429,7$ & \\
\hline & \multicolumn{2}{|c|}{ Construcciones y ampliaciones INTA Castelar y Unidades Interior } & $\$ 84,1$ & \\
\hline \multirow{6}{*}{ INTI } & \multirow{4}{*}{$\begin{array}{l}\text { Fomento de la competitividad } \\
\text { industrial }\end{array}$} & Desarrollo y Asistencia a la Industria Alimenticia & $\$ 349,8$ & \multirow{6}{*}{$\$ 2.704,3$} \\
\hline & & Desarrollo y Asistencia a la Industria & $\$ 535,3$ & \\
\hline & & Recursos Naturales y Medio Ambiente & $\$ 385,8$ & \\
\hline & & Medición y Calibración para industrias reguladas & $\$ 182,9$ & \\
\hline & Extensionismo Ind. Fed & Promoción y Fortalecimiento de Industrias Regionales & $\$ 515,5$ & \\
\hline & \multicolumn{2}{|l|}{ Actividades Centrales } & $\$ 735,0$ & \\
\hline \multirow{5}{*}{$\begin{array}{l}\text { SENASA - Producción y } \\
\text { Trabajo }\end{array}$} & $\begin{array}{l}\text { Inocuidad y Calidad Agroali- } \\
\text { mentaria }\end{array}$ & $\begin{array}{l}\text { Origen animal, tráfico internacional, Vegetal y Piensos, agroalimenta- } \\
\text { ria, pesca y acuicultura, residuos contaminantes. Fiscalización }\end{array}$ & $\$ 1.536,6$ & \multirow{5}{*}{$\$ 6.179,4$} \\
\hline & \multicolumn{2}{|l|}{ Sanidad Animal } & $\$ 932,9$ & \\
\hline & \multicolumn{2}{|l|}{ Protección Vegetal } & $\$ 834,0$ & \\
\hline & \multicolumn{2}{|l|}{ Aplicaciones Financieras } & $\$ 95,8$ & \\
\hline & \multicolumn{2}{|l|}{ Actividades Centrales } & $\$ 2.780,1$ & \\
\hline \multirow{4}{*}{ ANMAT - Salud } & \multicolumn{2}{|c|}{ Fiscalización de medicamentos, alimentos, productos médicos y de consumo doméstico } & $\$ 1.218,0$ & \multirow{4}{*}{$\$ 1.273,8$} \\
\hline & \multicolumn{2}{|c|}{ Control y Fiscalización de productos médicos y de diagnóstico } & $\$ 26,7$ & \\
\hline & \multicolumn{2}{|c|}{ Control y Fiscalización de alimentos } & $\$ 21,9$ & \\
\hline & \multicolumn{2}{|c|}{ Control y Fiscalización de productos cosméticos, médicos y de uso doméstico } & $\$ 7,2$ & \\
\hline \multicolumn{3}{|c|}{ Secretaría de Gobierno de Ambiente y Desarrollo Sustentable } & $\$ 1.903,9$ & $\$ 1.903,9$ \\
\hline & & TOTAL & & $\$ 18.644,8$ \\
\hline
\end{tabular}

Fuente: Elaboración propia en base a Presupuesto Abierto, Ministerio de Economía. 
Dentro de las líneas de trabajo del INTA, el ProHuerta se presenta como la política más 'social' del organismo, con una articulación con el PNSA del Ministerio de Desarrollo Social desde 2003. Su cobertura se estima en casi 600 mil huertas familiares, 13.000 huertas escolares y 6.500 huertas comunitarias (Presupuesto Nacional 2019, partida 26). Adicionalmente, los Proyectos Especiales son también una iniciativa del Ministerio de Desarrollo Social de la Nación y el INTA. Tienen como objetivo el desarrollo de actividades, la ejecución de obras y adquisición de equipamiento para mejorar la calidad de vida y garantizar derechos de comunidades rurales y periurbanas de todo el país. En los proyectos participan grupos, organizaciones e instituciones locales en asociación con las unidades del INTA ${ }^{41}$. Están orientados a pequeños productores, minifundistas, campesinos, colonos, inmigrantes, pueblos originarios indígenas, puesteros, crianceros, banquineros, feriantes, pescadores artesanales, artesanos rurales y agricultores familiares de las distintas regiones argentinas. En los años 2016 y 2017 se desarrollaron más de $\mathbf{6 0 0}$ proyectos que alcanzaron a 50 mil familias. Los proyectos especiales convocan al financiamiento de iniciativas de Acceso al agua para uso integral; Valor agregado en origen; Fortalecimiento de espacios y canales de comercialización; Producción frutícola y hortícola para venta de excedentes ; Granja con fines comerciales ; Producción pecuaria inclusión comercial ; Cultivos locales; Energías renovables; Comunicación; Fortalecimiento de grupo de abastecimiento local; Fortalecimiento de espacios de formación en oficios rurales y entrenamientos laborales. Los Proyectos Especiales, no presentan evaluaciones de impactos o resultados.

Tanto las transferencias de tecnologías, como las huertas y proyectos especiales cuentan con escasas sistematizaciones o evaluaciones que conduzcan a conocer los distintos niveles de efectividad de las acciones. Con relación a las transferencias de tecnología agropecuaria, "hace falta evidencia documentada acerca del impacto del sistema oficial" que produce el INTA (INTA-BID, 2018), así como el análisis detallado sobre el impacto de algunos programas actuales. Una aproximación a impactos posibles, se encuentra un proyecto de la cátedra libre de Soberanía Alimentaria de la Facultad de Agronomía de la UBA (Carballo González, C. et al, 2014), que comprendió la promoción de producción de maíces criollos en la provincia de Misiones junto a 4200 pequeños productores. Entre los impactos se describe cómo la superposición de programas públicos y la falta de coordinación repercutía en una baja cobertura inicial y en discontinuidades. Esto llevó a formalizar coordinaciones desde el equipo de la UBA, incluyendo, entre múltiples actores, al INTA y a una "abarcativa Coordinación de los Programas de Extensión y Transferencia de Tecnología que procuraba sumar a la orientación de un Sistema de Extensión debilitado, el accionar de los Programas de la Unidad de Minifundio, 'Cambio Rural', PROFAM y ProHuerta” (UBA, 2014).

Con relación a las huertas, el ProHuerta no presenta sistematizaciones y evaluaciones de impacto sobre la población asistida, su estado nutricional o los efectos de su funcionamiento. Se relevan algunos estudios de casos que permiten inferir el valor nutricional de las huertas familiares, pero no se presentan como representativos del programa o de la sustentabilidad de impactos en las familias. El programa Primeros Años (PIAC), presenta algunos aportes en materia de huertas comunitarias y familiares donde el PNSA y el PNPI-PIAC, se cruzan. Una evaluación ${ }^{42}$ del período 2012-16 incluyó encuestas entre 1250 familias, que mencionan que la Seguridad y Soberanía Alimentaria es el principal contenido de los espacios para las familias en el $100 \%$ de los casos, junto al interés de la comunidad por "la recuperación de alimentos y plantas tradicionales y a la valorización de saberes ancestrales sobre la preparación”; el aprovechamiento de los cultivos y frutas autóctonas, el acceso a pescados y animales de monte, y la incorporación de hábitos saludables de higiene tanto en la preparación y conservación de alimentos, como en la potabilización del agua (2016:46). En 2018, frente a la preocupación por la calidad del agua en los barrios, el PIAC y el ProHuerta realizaron

\footnotetext{
${ }^{41}$ Fuente: https://www.infocampo.com.ar/abren-la-convocatoria-a-proyectos-especiales-de-prohuerta/

${ }^{42}$ Ver https://www.argentina.gob.ar/sites/default/files/politicassociales-publicaciones-primerosanios-informe-evaluacion 2016.pdf
} 
capacitaciones sobre "Agua Segura y potabilización" o "Agua versus bebidas azucaradas". Pero estas evaluaciones, no forman parte de un diseño que permita ver el impacto y aplicación sustentable de los intereses relevados en una población pequeña (sólo 1250 familias, bajo una cobertura estimada en 600.000).

En 2020, la DNSA del Ministerio de Desarrollo Social, informa que el cumplimiento de las metas del programa ProHuerta 2019 contabiliza menos huertas que el promedio anual histórico, producto del desplazamiento de acciones hacia "proyectos especiales". Sin evaluaciones que argumenten la mayor o menor efectividad de una $u$ otra modalidad, se menciona las huertas como una fuente de autoconsumo a promover desde la política AlimentAR. Del intercambio con el sector Agricultura/INTA, ya existe un acuerdo de incrementar la escala en 2020.

En cuanto al INTI, entre las líneas estratégicas a la fecha, se encuentran el programa de Agroalimentos y el programa de Desarrollo e Innovación en Tecnologías Alimentarias. En el primer caso, se busca transferir tecnologías que permitan la adecuación de las empresas PyMES "a las exigencias de los mercados, para su inserción local e internacional, priorizando la ampliación de la cadena de valor de los productos alimenticios ${ }^{\prime 43}$ donde se describen emprendimientos como Equipos de "medición de rancidez en alimentos" o Planta de panificación, galletitas y pastas. En esta línea se encuentra el Centro de Investigación en Tecnologías de Industrialización de Alimentos con diversos aportes tecnológicos.

En cuanto al Desarrollo de Tecnología de Alimentos, se encuentran líneas de Agregado de valor a la producción primaria, Desarrollo de ingredientes, Desarrollo de nuevos productos, Desarrollo de procesos y Valorización de subproductos, con diversos emprendimientos en diversos territorios. No se encuentran evidencias documentadas sobre la efectividad de estas políticas con relación a las Cooperativas o emprendedores a las que van dirigidas, particularmente a niveles territoriales, 0 como parte de contenidos potenciales para las capacitaciones gratuitas brindadas por el organismo. Otra característica importante es que el INTI se constituye "como Instituto Nacional de Metrología, de acuerdo con la Ley 19511 (Decreto 788/03) (...)”, por el cual realiza, reproduce y mantiene "patrones nacionales de medida" que difunden y promueven exactitud como valor. Estos patrones se dirigen a "asegurar la calidad en mediciones relacionadas con el cuidado del ambiente, la salud, los alimentos, la seguridad pública, la equidad en el comercio y la calidad de la producción industrial"44.

Como efectores de cuidado a la población en materia de salubridad e inocuidad de alimentos, encontramos al Servicio Nacional de Sanidad y Calidad Agroalimentaria (SENASA) y a la Administración Nacional de Medicamentos, Alimentos y Tecnología Médica (ANMAT). Por su parte, SENASA es un organismo sanitario rector de la República Argentina, cuyo objetivo principal es la "fiscalización y certificación de los productos y subproductos de origen animal y vegetal, sus insumos y residuos agroquímicos, así como la prevención, erradicación y control de enfermedades animales, incluyendo las transmisibles al hombre, $y$ de las plagas vegetales que afectan a la producción agropecuaria del país"45. Una de sus facultades más relevantes es la de registrar, habilitar clausurar y fiscalizar "plantas de procesamiento, acondicionamiento, transporte y comercialización de productos del área de su competencia". Con relación a la ANMAT, su objetivo es fortalecer las capacida-

\footnotetext{
${ }^{43}$ Ver: https://www.inti.gob.ar/areas/servicios-industriales/alimentos/agroalimentos

${ }^{44}$ Ver: https://fundacionsabercomo.org.ar/elinti-esp/

${ }^{45}$ Ver: http://www.produccion-animal.com.ar/sanidad intoxicaciones metabolicos/infecciosas/comun varias especies/58-que es senasa.pdf
} 
des de regulación, fiscalización y vigilancia a nivel nacional y provincial en productos para la salud $^{46}$. Vale destacar su conducción del Programa Federal de Control de Alimentos y la Red Nacional de Laboratorios Oficiales de Alimentos (RENALOA) ${ }^{47}$. En 2019, el Sistema de Vigilancia Epidemiológica reportó que el $\mathbf{4 0 \%}$ de los brotes de Enfermedades Transmitidas por Alimentos en Argentina, ocurren en el hogar ${ }^{48}$.

\section{INSTITUCIONALIDADES SECTORIALES DEL ESTADO PROVINCIAL Y MUNICIPAL.}

La asistencia alimentaria forma parte de las gestiones provinciales, desde la descentralización y desregulación de los servicios de educación, salud, nutrición, vivienda y obras sociales en las 24 jurisdicciones, dispuesta tras la reforma constitucional de 1994. El proceso "formalizó los cambios en las relaciones intergubernamentales", con reformas jurídicas, administrativas y económicas de efectivización heterogénea (Repetto-Fernández, 2012). Algunos posicionamientos infieren que este proceso contó con "escasa voluntad" y un uso de recursos en materia social "para negociar apoyos políticos de corto plazo" (Repetto, F., Alonso, G., 2004:6-7). El resultado de estas prácticas deja desafíos en cuanto a "nuevas expresiones del federalismo en materia de responsabilidades de gestión social" (Repetto, F., Alonso, G., 2004:7).

Al analizar los 24 presupuestos provinciales y fuentes oficiales, puede observarse la diversidad de sectores y articulaciones que administran la asistencia alimentaria en cada jurisdicción:

\footnotetext{
${ }^{46}$ Ver: https://federal.anmat.gov.ar/page/Objetivos.php\#: :text=\%2D\%20Conformar\%20una\%20red\%20integrada\%20(estructura,con\%20referentes\%20en\%20cada\%20jurisdicci\%C3\%B3n.

${ }^{47}$ Ver: https://federal.anmat.gov.ar/page/docs/Programa_Federal_de_Control_de_los_Alimentos_2011.pdf

http://www.anmat.gov.ar/webanmat/renaloa/renaloa.asp

${ }^{48}$ Ver: https://www.grupolaprovincia.com/economia/la-inocuidad-de-los-alimentos-tambien-prioridad-argentina-314115
} 


\section{Cuadro 5. Instituciones Sectoriales a cargo de Asistencia Alimentaria, por Provincia}

\begin{tabular}{|c|c|}
\hline PROVINCIA & INSTITUCIÓN PROVINCIAL RESPONSABLE \\
\hline Buenos Aires & Ministerio de Desarrollo Social, Subsecretaria de Fortalecimiento Familiar y Comunitario \\
\hline Catamarca & Ministerio de Desarrollo Social, Dirección de Políticas Alimentarias \\
\hline $\begin{array}{l}\text { Ciudad de Bs } \\
\text { As }\end{array}$ & $\begin{array}{l}\text { Ministerio de Desarrollo Social, Sec. de Fort. Fliar. y Com. (Tarjetas y Com. Comunit.). Min. de Educ. } \\
\text { (Comedores Escolares) }\end{array}$ \\
\hline Chaco & Interministerial. Desarrollo Social y Salud (red de gestión junto a organizaciones, corresponsabilidad) \\
\hline Chubut & Ministerio de Familia y Promoción Social \\
\hline Córdoba & $\begin{array}{l}\text { Secretaría General de la Gobernación - Dirección General del PAICor. Ministerio de Desarrollo Social } \\
\text { (Tarjeta Social) }\end{array}$ \\
\hline Corrientes & Ministerio de Desarrollo Social, Dirección de Seguridad Alimentaria \\
\hline Entre Rios & Ministerio de Desarrollo Social \\
\hline Formosa & Ministerio de Cultura y Educación (Nutrición Escolar) y Ministerio de Desarrollo Humano (Plan Nutrir) \\
\hline Jujuy & Ministerio de Desarrollo Humano \\
\hline La Pampa & $\begin{array}{l}\text { Ministerio de Cultura y Educ. (Com. Esc.). Ministerio de Desarrollo Social, SS de Descent. Territ. Dir. } \\
\text { Gral de Planif. y Ev. de PS. (Tarjeta) }\end{array}$ \\
\hline La Rioja & Ministerio de Desarrollo Social e Inclusión Social. Dirección de Planificación de Políticas Alimentarias \\
\hline Mendoza & $\begin{array}{l}\text { Ministerio de Salud, Desarrollo Social y Deportes (PNSA general). Dirección General de Educación } \\
\text { (Comedores Escolares) }\end{array}$ \\
\hline Misiones & Ministerio de Derechos Humanos \\
\hline Neuquen & $\begin{array}{l}\text { Ministerio de Salud y Desarrollo Social. Area Gobierno y Educación MDS y Secretaría de Educación } \\
\text { (Comedores Escolares). }\end{array}$ \\
\hline Río Negro & $\begin{array}{l}\text { Ministerio de Desarrollo Humano. Subsec. de Políticas Activas de Inclusión Social (Tarjetas). Minist. } \\
\text { de Educación y DDHH (Com. Esc.) }\end{array}$ \\
\hline Salta & $\begin{array}{l}\text { Ministerio de Desarrollo Social, Subsecret. de Programas Descent. (tarjetas). Ministerio de Educación } \\
\text { CyT (comedores escolares) }\end{array}$ \\
\hline San Juan & Ministerio de Desarrollo Humano y Promoción Social. Dirección de Políticas Alimentarias. \\
\hline San Luis & Ministerio de Desarrollo Social \\
\hline Santa Cruz & Ministerio de la Familia \\
\hline Santa Fe & $\begin{array}{l}\text { Ministerio de Educación (Comedores Escolares y copa de leche). Ministerio de Desarrollo Social (Tar- } \\
\text { jeta Única de Ciud.) }\end{array}$ \\
\hline $\begin{array}{l}\text { Santiago Del } \\
\text { Estero }\end{array}$ & Ministerio de Salud (PAS) \\
\hline $\begin{array}{l}\text { Tierra Del } \\
\text { Fuego }\end{array}$ & $\begin{array}{l}\text { Ministerio de Desarrollo Social (tarjetas). Ministerio de Educación (Comedores Escolares, fondos pro- } \\
\text { vinciales) }\end{array}$ \\
\hline Tucumán & $\begin{array}{l}\text { Ministerio de Desarrollo Social, Dirección de Políticas Alimentarias. Ministerio de Salud (Abordaje en } \\
\text { Desnutrición) }\end{array}$ \\
\hline
\end{tabular}

Fuente: Elaboración Propia en base a Sitios Oficiales Provinciales 2019/20 - Presupuestos Provinciales de los diversos Ministerios de Hacienda - SIEMPRO, 2019

Sin Comisiones Provinciales previstas por la ley 25.724, o espacios formales de coordinación e integración, la diversidad de implementaciones de la asistencia alimentaria de las últimas casi dos décadas, parecen carecer de cohesión. Más aún, entre las asignaturas pendientes de las provin- 
cias, el déficit en la conformación de información clara y consolidable con los datos nacionales, sigue siendo una deuda. Por citar un ejemplo, la Ley 25.917 de transparencia fiscal, es analizada y medida en el "Índice de transparencia presupuestaria provincial" (ITPP) de CIPPEC, desde 2013. ${ }^{49}$

Según una evaluación, "en la Administración Pública Provincial aún prevalece el modelo administrativo tradicional, donde el gasto se ejecuta y cuantifica principalmente según el clasificador por objeto, y el control es de tipo financiero y legal. En consecuencia, las rendiciones de cuentas de las instituciones hoy se focalizan en el cumplimiento de las normas, dejando de lado el análisis de los resultados obtenidos con los recursos aplicados" (Pesaresi, N., UBA, 2016). Esta 'legalidad' se refleja en que si bien todas las provincias (menos San Luis, en 2019) cumplen con la ley de transparencia fiscal, son pocas las que permiten reconocer los programas en los cuales se aplican los recursos, y en el déficit de evaluaciones que comuniquen resultados e impactos.

En materia de producción de alimentos, las constituciones provinciales juegan un rol importante en el modo en que las políticas se gestan y desarrollan en los niveles locales: "a pesar de estar entre las tareas más demandadas al municipio, las constituciones provinciales asumen al desarrollo regional y al desarrollo económico y social como atribuciones provinciales." (Iturburu, M., Instituto Nacional de la Administración Pública, INAP, 2000). Los municipios, tienen como atribución tradicional el desarrollo urbanístico sin definiciones de una perspectiva integradora (2000). Los presupuestos provinciales y documentos oficiales relevados, lamentablemente no brindan sistematizaciones que describan las relaciones entre la política de producción de alimentos, la asistencia alimentaria y los niveles de inseguridad alimentaria, y las principales líneas sostenidas en el tiempo.

\section{POLÍTICAS ALIMENTARIAS PROVINCIALES Y MUNICIPALES}

Los gobiernos provinciales y municipales cuentan con el $\mathbf{4 5 \%}$ del gasto social consolidado argentino, que se divide entre un $37 \%$ a cargo de la administración provincial central, y un $8 \%$ a cargo de la administración municipal ${ }^{50}$ (Ministerio de Economía, 1980-2017). En la composición de este gasto, las fuentes permiten ver el peso de la descentralización a las provincias en un mayor gasto social en Educación, Salud, y Promoción Social. Sumando todos los presupuestos provinciales aprobados por las legislaturas en el año 2019, se obtiene un total de \$48.589 millones de dólares, incluyendo gastos corrientes y de capital. Los documentos y sus planillas anexas no permiten desglosar la totalidad de la Asistencia Alimentaria provista por los tesoros provinciales, como contraparte de los \$372,6 millones de dólares transferidos por el PNSA del Ministerio de Desarrollo Social (ver Cuadro 1), a los cuales se sumarán en 2020 las transferencias de la tarjeta AlimentAR.

Las Políticas Alimentarias de las 24 Provincias y 2165 Municipios (ver detalles en anexo), presentan las entro de los presupuestos provinciales, un rasgo común de oferta alimentaria. Y es el lugar que ocupan las tarjetas sociales y los comedores escolares, que desde la campaña "el

\footnotetext{
49 El ITPP muestra mejoras considerables entre 2013 y 2019, pero aún muestra brechas que van desde 3,7 puntos de Chubut (menor puntaje) a 10 puntos en Entre Ríos (mayor puntaje) (CIPPEC, 2019). Esto repercute, por ejemplo, en la capacidad de obtener información homogénea sobre la contraparte económica de presupuestos provinciales a las transferencias nacionales del PNSA, y a las dimensiones en que se combinan las modalidades brindadas. Los presupuestos, en buena parte de las provincias, no desagregan información por programas.

${ }^{50}$ Fuente: https://www.argentina.gob.ar/economia/politicaeconomica/macroeconomica/gastopublicoconsolidado
} 
Hambre más urgente" ${ }^{51}$ y la creación del PNSA en 2003 se apoyó en la descentralización provincial. Ambas prestaciones son el rasgo más homogéneo de la oferta, si bien el modo de implementación varía según jurisdicción.

Con nombres apropiados por varias jurisdicciones, las 22 tarjetas provinciales (Más Vida, Sapukay, Crecer, Familia, Única de Ciudadanía, Peñi Social, etc.) son el 55\% de los aportes nacionales del PNSA. A través de fuentes nacionales, las tarjetas permiten identificar un $38,8 \%$ de beneficiarios en la Provincia de Buenos Aires (501 mil titulares - SIEMPRO, 2019; ver anexo), entre aportes para la tarjeta Más Vida y transferencias directas de la tarjeta descentralizada (directa a titulares desde el PNSA), seguido por asimetrías en las coberturas de otras jurisdicciones. Pero no se exponen las edades de niños/as y adolescentes, distribución territorial, entre otros datos.

Las variabilidades territoriales, también incluyen a los 18.469 comedores escolares y 1165 comunitarios contabilizados por el Estado Nacional (SIEMPRO, 2019). En cuanto a esquemas de abastecimiento, las compras y cocinas centralizadas con alimentos que se distribuyen entre comedores y centros de distribución, conviven con transferencias directas a municipios, consejos escolares, escuelas y comedores para compras autónomas. Una evaluación del período 2016-18 sobre comedores del "Servicio Alimentario Escolar" de la provincia de Buenos Aires, concluye que los estándares de calidad nutricional del menú sugerido por el programa, cuenta con mejores probabilidades en aquellos comedores escolares de escuelas primarias de gestión municipal (CESNI-CEPEA, 2019). La evaluación es representativa del $44 \%$ de los comedores escolares del país. No se incluyen datos antropométricos ex post de alumnos en el estudio.

EI PNSA brinda también aportes a Merenderos (como tercera línea de prioridad), y módulos alimentarios en tres provincias. En cuanto a la oferta complementaria, las provincias no permiten dimensionar coberturas o la combinación de modalidades que brindan (módulos alimentarios, prestaciones para celíacos, suplementos nutricionales como "Nutri-Sopa" producida por una planta industrial pública en Formosa, abordajes de salud de niños desnutridos, entre otras). La oferta de programas provinciales presenta, en el mejor de los casos, objetivos y descripciones generales, y comunicaciones oficiales programáticas, sin datos actualizados. Algunos programas articulan acciones entre Desarrollo Social y Salud como el Programa de Abordaje Nutricional (PAN) de Tucumán, o el Programa Chaco Familia. En cuanto a la descentralización, las políticas pasan del extremo de compras centralizadas por el Estado Provincial y distribuidas en centros específicos (sin transferir fondos a los municipios), como, por ejemplo, las provincias de Corrientes y Formosa; a esquemas de alta descentralización, como las provincias de Buenos Aires, Neuquén o Salta.

${ }^{51}$ Nota: algunos presupuestos provinciales y documentos oficiales siguen comunicando el PNSA bajo este término creado en $2002-03$. 


\section{CORRESPONSABILIDAD DE ORGANIZACIONES SOCIALES Y EMPRESAS}

Para completar una mirada intersectorial de las políticas de Asistencia Alimentaria, es relevante describir el rol y aportes de las organizaciones de la sociedad civil y las empresas argentinas.

Con dependencia del CNCPS, el Centro Nacional de Organizaciones de la Comunidad -CENOCfue creado en el año 1995. En 2019, su Registro cuenta con un total de 19.016 organizaciones inscriptas ${ }^{52}$, donde el $42 \%$ se dedica a acciones "social/humana" y "salud", que incluyen asistencia alimentaria. Este Registro Obligatorio y Oficial, tiene por mandato: "Promover la participación de las Organizaciones de la Sociedad Civil (OSC) en la gestión de las políticas públicas". Los antecedentes del organismo describen asimetrías territoriales que muestran una presencia dispar en cada municipio y provincia (Ikei, V., Iñiguez, E., López Burgos, F., Mayer, G., Sola Álvarez, M.A., 2003). En general, estas organizaciones se articulan con dependencias del sector Desarrollo Social.

A la hora de analizar las transformaciones más recientes, en "Diagnóstico del Tercer Sector"53 (2017), varias agrupaciones y referentes evalúan distintos posicionamientos. Uno de ellos se detiene en la heterogeneidad y múltiples identidades, que se pluralizan en distintas 'sociedades civiles', en tipos de organizaciones y posturas frente a la asistencia social. Se observa una tendencia a la fragmentación y al aislamiento, que se ejemplifica con casos donde en un mismo municipio hay "entidades que trabajan en problemas parecidos o complementarios" y están "desconectadas entre sí" (2017). La fragmentación y superposición de acciones observada en políticas públicas no parecen ser ajenas al accionar al interior de este sector, o en "la relación entre ONG y Gobierno, que aún falla en la coordinación" (2017). Organizaciones de base comunitaria que cuentan con apoyos nacionales, provinciales y municipales para asistencia alimentaria, conviven con aquellas que no cuentan con apoyo alguno. Barrios con una presencia concentrada de organizaciones y comedores, conviven con barrios sin presencia comunitaria alguna.

Además de una heterogénea configuración de organizaciones de base comunitaria, las organizaciones confesionales, también tienen presencia en el tema, como la Iglesia Católica, distribuidas en 66 diócesis y más de 3500 parroquias y capillas en todo el país ${ }^{54}$ desde la estructura de Cáritas. A través del área de "Ayuda Inmediata", una de sus principales funciones es la asistencia alimentaria. La Iglesia Evangelista y sus congregaciones también actúan en una escala que ha ido ganando espacio territorial.

Con relación a empresas, las acciones directas o de Responsabilidad Social (RSE) incluyen aportes económicos destinados al inversiones sociales e innovaciones, muchas veces, en articulación con el sector público nacional, provincial o municipal. Un relevamiento da cuenta de una muestra de estas acciones, con 184 prácticas relevadas entre 64 áreas de RSE de empresas privadas por el Consejo Empresario Argentino para el Desarrollo Sostenible (CEADS), en el marco de acciones empresarias dirigidas a los Objetivos del Desarrollo Sostenible (ODS) ${ }^{55}$ (2019). En cuanto al ODS2 ("Hambre Cero"), el relevamiento incluye empresas con iniciativas de transferencias de tecnología agrícola, educación alimentaria, donaciones a bancos de alimentos, entre otras. Otras inversiones sociales encuentran alianzas como Sed Cero, liderada por Fundación Avina junto a empresas y universidades, con tecnologías de acceso al agua para zonas rurales.

\footnotetext{
52 Fuente: base CENOC actualizada al 19/10/2020 https://www.argentina.gob.ar/desarrollosocial/cenoc/datosdelasoscs

${ }^{53}$ Fuente: recuperado el 24/1/2020 https://tercersector.org.ar/diagnostico-del-sector-social-en-argentina/

${ }^{54}$ Fuente: https://www.caritas.org.ar/ayuda-inmediata/

${ }^{55}$ Fuente: recuperado 24/1/2020 http://www.ods.ceads.org.ar/
} 
Entre las agrupaciones del sector, más de 50 empresas y fundaciones privadas se nuclean en el Grupo de Fundaciones y Empresas (GDFE). En 2020, la presentación del Plan AlimentAR a cargo del CNCPS, permitió acordar la realización de "un mapa que identifique acciones -en curso o proyectadas en materia de seguridad alimentaria", en sus distintas modalidades, y de "fortalecimiento de la agricultura familiar e impulso de investigaciones, y acciones que contribuyan de manera directa e indirecta con la erradicación del hambre en la Argentina." 56

En general, muchas de estas experiencias son de escala pequeña y con escasas evaluaciones sobre las transformaciones que producen.

\section{CONSIDERACIONES FINALES}

A continuación, se retoman las discusiones presentadas en la introducción, y se presenta una consideración particular producto del análisis.

\section{Discusión sobre la integralidad de Políticas Alimentarias.}

"El proceso de construcción de acciones integrales es muy complejo; no sólo implica el intercambio y la construcción colectiva de saberes, lenguajes y prácticas entre los diversos sectores involucrados, sino la variedad de intereses políticos y de las maneras de concebir la política social y al "otro" que cada actor tiene. Sin embargo, ello hace que se vuelva posible generar acciones innovadoras."

(Informe de Evaluación 2016. Programa Primeros Años, CNCPS)

El repaso que realiza este trabajo deja una agenda que propone actualizar el modo de comprender qué es la inseguridad alimentaria infantil, y qué aportes realiza cada sector y nivel de gobierno al niño y niña que la sufren. Si el concepto de inseguridad alimentaria reúne privaciones relacionadas con la disponibilidad, acceso físico y económico, y con el consumo de alimentos suficientes y nutricionales, cada sector y nivel convocado debería poder reconocer sus capacidades y aportes a cada una de esas dimensiones. Esta comprensión toma reiteradas y visibles menciones a la disparidad territorial del gasto público en la niñez (Unicef, 2016; Unicef y Ministerio de Hacienda, 2018). También, los niveles territoriales críticos de inseguridad alimentaria (Márquez, A., ODSA-UCA, 2017; ODSA-UCA, 2019), las prevalencias de malnutrición de cada región (ENNyS, 2018-19; Plan Sumar, 2018), las capacidades de abastecimiento de alimentos nutricionales (Censo Nacional Agropecuario, 2019), los comportamientos de consumo (ENNyS, 2018-19; Encuesta Nacional de Gasto en el Hogar, 2018), la situación económica de las familias (EPH, 2020; próx. Censo 2020), las realidades locales de las dinámicas familiares (próx. Encuesta Nacional de Condiciones de Vida de Niños, Niñas y Adolescentes, 2020), entre otros. De no abordar de modo holístico los problemas, se sostendrá la inercia de 16 años del PNSA: se continuará instrumentando un conjunto de políticas públicas "bajo un mismo paraguas" (Díaz Langou-Aulicino, 2012) sin objetivos comunes, con la incorporación de una tarjeta y más recursos económicos.

${ }^{56}$ Fuente: comunicación del Grupo de Fundaciones y Empresas, 14/1/2020 


\section{Discusión sobre la coordinación entre sectores y niveles de gobierno.}

"La superposición de programas e iniciativas de distinta índole o su discontinuidad a través del tiempo, hizo que el accionar del sector público alcanzara como máximo al 18\% de la población ob-

jetivo, dejando totalmente abandonada a las consecuencias de las políticas macroeconómicas aquellos productores o grupos menos organizados o más alejados de las vías de comunicación."

(Carballo González, C. et al, 2014)

El análisis presentado, expone que los espacios formales para despejar percepciones incompletas o excluyentes, reconocer los recursos disponibles, y distribuir responsabilidades para su óptima utilización, son una deuda que, a dos meses de iniciada la política integral AlimentAR, parece reconocida pero no saldada. Las declaraciones públicas de distintos ministerios nacionales omiten el nivel de acuerdos obtenidos. La relación con las provincias, como el caso de Salta y las situaciones trascendidas recientemente, expone situaciones de asimetrías territoriales graves y de larga data, que demandan una coordinación de abordaje que solamente puede surgir de la planificación, más que de la reacción. Sea desde la postergada conformación de las Comisiones de la Ley 25.724, desde el CNCPS, el Consejo Federal de Niñez y Adolescencia, o de nuevos espacios convoquen a funcionarios con capacidad de toma de decisiones, puede inferirse que la puesta en común y organización de políticas alimentarias sectoriales y jurisdiccionales, junto a la distribución de responsabilidades de implementación, resultan una agenda impostergable. En esta discusión, también se corre el riesgo de prorrogar lo que ya ocurrió y ocurre con el PNSA y las demás políticas presentadas. Cada sector y nivel continuará operando bajo su propia órbita, fragmentando y superponiendo políticas.

\section{Sobre Vacancias de Monitoreo y Evaluación de Políticas Alimentarias.}

"Una falencia generalizada de los programas sociales en general, y los alimentarios en particular, es la ausencia de monitoreo y evaluación"

(Abeyá Gilardón, E., 2016)

Las políticas alimentarias presentadas, plantean procesos de sistematización, monitoreo y evaluación como prácticas, generalmente, poco apropiadas por todos los sectores (público, privado y civil) y niveles de gobierno (nacional, provincial y municipal). Cuando existen, sus diseños no son pensados para ponerse en diálogo con otras prestaciones y resultados. Por ejemplo, se mide el valor nutricional de un menú escolar, pero no se considera la antropometría de los niños alcanzados por los comedores. La escasa orientación, valor dado y socialización de resultados y evidencias, obstaculiza el desarrollo de capacidades compartidas, con el objetivo de identificar si se están produciendo, o no, cambios sustentables en la población infantil con las políticas vigentes. Y es que "la mera existencia de múltiples organismos con una amplia oferta de políticas públicas no es garantía de que éstas sean efectivas si las mismas no son debidamente diseñadas, implementadas y evaluadas" (Maya, F., 2019:5). Las nuevas ideas sobre 'accountability', basadas en los valores de 'desempeño' y 'efectividad' o premisas de 'análisis de la gestión por resultados' (CISI-UCA, 2016), suelen estar impregnadas de connotaciones eficientistas, a veces divorciadas de prácticas procesuales de las ciencias sociales. No obstante, una postura intermedia debería encontrar en la evaluación un modo de ampliar la observación de efectos, ya que los productos por sí solos no son resultados. También, lleva al establecimiento de metas, y a la responsabilización por las acciones. 
En este caso, el riesgo de persistir en la línea actual es la imposibilidad de realizar ajustes a las políticas alimentarias que lleven a la consecución de metas y a cambios favorables. En esta postura, persiste la continuidad de depender de mediciones ajenas a las políticas, como Encuestas Nacionales y relevamientos estadísticos, que muestran datos que no pueden vincularse directamente a las prestaciones de asistencia alimentaria o producción y a sus resultados.

\section{BIBLIOGRAFÍA}

Abeyá Gilardón, E. (2016) “Una evaluación crítica de los programas alimentarios en Argentina”. SALUD COLECTIVA. 2016;12(4):589-604. doi:

10.18294/sc.2016.935.https://www.scielosp.org/pdf/scol/2016.v12n4/589-604

Arakaki, Agustín (2011), “La Pobreza en Argentina 1974-2006. Construcción Y Análisis De La Información". Centro de Estudios sobre Población, Empleo y Desarrollo (CEPED). Documento de Trabajo N 15. Facultad de Ciencias Económicas de la UBA. Recuperado 15/1/20: http://bibliotecadigital.econ.uba.ar/download/docin/docin ceped d 015

Aulicino, C., Díaz Langou, G. (2012) "La implementación del Plan Nacional de Seguridad Alimentaria en ámbitos subnacionales” DOCUMENTO DE TRABAJO N88 ABRIL DE 2012. Programa de Protección Social, CIPPEC. https://www.cippec.org/wp-content/uploads/2017/03/2454.pdf

Aulicino, C. (2012) "Una primera aproximación a las políticas de Educación Nutricional en las provincias argentinas”. DOCUMENTO DE TRABAJO N`90, MAYO DE 2012. Programa de Protección Social, CIPPEC.http://municipios.unq.edu.ar/modules/mislibros/archivos/201205nutricion.pdf

Carballo González, C. et al (2014) "Evaluación del impacto del programa sostenimiento del empleo y seguridad alimentaria en la pequeña agricultura familiar" de la Provincia de Misiones. Cátedra Libre de Soberanía Alimentaria -CaLiSA. Facultad de Agronomía UBA. Convenio Secretaria de Empleo - Ministerio de Trabajo, Empleo y Seguridad Social de la Nación- Facultad de Agronomía de la Universidad de Buenos Aires. http://www.trabajo.gob.ar/downloads/promoempleo/evaluacion del impacto del programa sesapaf misiones.pdf

De Martini, S.L., Carpintero, K.G., Donzelli, B.E., García Rossi, M.I., Aras, F., Bohl, F. (2016) “Análisis crítico de la implementación de políticas públicas alimentarias en la Argentina". Centro de Investigación del Sistema Interamericano de Derechos Humanos de la Pontificia Universidad Católica de Argentina (“CISI"-UCA), V Convocatoria de Investigaciones del Observatorio del Derecho a la Alimentación de América Latina y el Caribe.http://www.fao.org/3//8961ES/i8961es.pdf

Gasparini, L., Gluzmann, Tornarolli, L., (2019) "Pobreza Crónica en Datos de Corte Transversal: Estimaciones para Argentina” Documentos de Trabajo del CEDLAS № 252, Octubre, 2019, CEDLAS-Universidad Nacional de La Plata.Recuperado 17/1/20: http://www.cedlas.econo.unlp.edu.ar/wp/no-252/

Fernández, V, Arciet, J., Bove, I., Rodríguez S., Bach, Camacho, S., Curutchet, M.R., Magnani, D., Sampayo, V. (2015) "Derecho a la Seguridad Alimentaria. Logros y Desafíos de Uruguay". Departamento de Geografía de la Facultad de Ciencias de la Universidad de la República y Obser- 
vatorio de Seguridad Alimentaria y Nutricional, INDA. http://dspace.mi-

des.gub.uy:8080/xmlui/bitstream/handle/123456789/683/1674 In-

forme\%20SAN.pdf?sequence $=1$ \&isAllowed $=y$

Iturburu, Mónica (2000) "Potestades y Restricciones Constitucionales para un Nuevo Modelo de Gestión Local" - Instituto Nacional de la Administración Pública, INAP. https://www.academia.edu/41705622/MUNICIPIOS ARGENTINOS Potestades y Restricciones Constitucionales para un Nuevo Modelo de Gesti\%C3\%B3n Local

Maceira, Daniel - Lignelli, Bárbara (2009) "Componente de Apoyo al Programa Nacional de Seguridad Alimentaria. Programa de Apoyo al Sistema de Protección e Inclusión Social de Argentina. Estudio de Casos: BERAZATEGUI, FLORENCIO VARELA, SAN JUAN, TUCUMÁN". Banco Interamericano de Desarrollo (BID) y el Centro de Estudios de Estado y Sociedad (CEDES). Diciembre, 2009. https://www.danielmaceira.com.ar/wp-content/uploads/2014/07/MaceiraLignelliPNSA-BID-26dic09-final.pdf

Márquez, Agustina - Salvia, Agustín (2017) “Estimación y Georreferenciación de la probabilidad de padecer Inseguridad Alimentaria. Metodología y resultados para el total país". Observatorio de la Deuda Social. Pontificia Universidad Católica Argentina. Recuperado 20/1/20: http://wadmin.uca.edu.ar/public/ckeditor/Observatorio\%20Deuda\%20Social/Presentaciones/2019/CARTOGRAFIA-INSEGURIDAD-ALIMENTARIA/2019-OBSERVATORIOGEORREFERENCIACION-INSEGURIDAD-ALIMENTARIA-VF-1.pdf

Maya, Florencia (2019) "Evaluación y Monitoreo de las políticas públicas en una posible reforma del Consejo Nacional de Coordinación de Políticas Sociales en Argentina”. Tesis de Maestría en Políticas Públicas, Universidad Austral. Diciembre 2019. Tutora: Dra. Patricia Rodríguez Aguirre. Ministerio de Salud (2019) Segunda Encuesta Nacional de Nutrición y Salud 2018-19 (ENNyS2). http://www.msal.gob.ar/images/stories/bes/graficos/0000001602cnt-2019-10 encuesta-nacional-de-nutricion-y-salud.pdf

Moncada, G., Ortega, J. (2007) "Medición de la Inseguridad Alimentaria en Encuestas De Hogares: Un Método Cualitativo factible de aplicar en América Latina y el Caribe". FAO-RLC en IX Reunión de Expertos Gubernamentales en Encuestas a Hogares. VI Reunión de Expertos Gubernamentales en Encuestas A Hogares Del Proyecto Andestad - 21 Y 22 Febrero De 2007 Quito - Ecuador. Recuperado 2/2/2020 http://intranet.comunidadandina.org/Documentos/Reuniones/DTrabajo/SG REG EH SIEH IX dt\%204.doc

Nogueira, M.E., Urcola, M., Lattuada, M. (2017) “La Gestión Estatal del Desarrollo Rural y la Agricultura Familiar en Argentina: Estilos de Gestión y Análisis de Coyuntura 2004-2014 Y 20152017". Revista Latinomericana de Estudios Rurales (RELAER). Vol 2, No 4 (2017) http://www.ceil-conicet.gov.ar/ojs/index.php/revistaalasru/article/view/273

Pesaresi, Noelia Mercedes (2016) "Auditoría de gestión del programa Sumar en la provincia de Tierra del Fuego. Proyecto de implementación de una nueva visión de control orientado a resultados y a la eficacia del gasto público". Trabajo Final de Posgrado. Facultad de Ciencias Económicas, Escuela de Estudios de Posgrado Asociación Argentina de Presupuesto y Administración Financiera Pública. Especialización en Gestión Pública por Resultados, UBA. Recuperado de http://bibliotecadigital.econ.uba.ar/download/tpos/1502-1032 PesaresiNM.pdf 
Programa Primeros Años - Acompañamos la Crianza (2016). Informe de Evaluación. Consejo Nacional de Coordinación de Políticas Sociales.Recuperado 20/2/20: https://www.argen-

tina.gob.ar/sites/default/files/politicassociales-publicaciones-primerosanios-informe-evalua-

cion 2016.pdf

Repetto, F., Fernández, J.P. (2012) "Coordinación de políticas, programas y proyectos sociales". Programa de Protección Social de CIPPEC y área Monitoreo y Evaluación de UNICEF Argentina.

Salvia, Agustín et al (2019) "Incidencia de la inseguridad alimentaria severa y total para los Hogares y la Población en la Argentina urbana 2010-2019". Observatorio de la Deuda Social. Pontificia Universidad Católica Argentina. Recuperado 20/1/20: http://wadmin.uca.edu.ar/public/ckeditor/Observatorio\%20Deuda\%20Social/Presentaciones/2019/2019-OBSERVATORIOINSEGURIDAD-ALIMENTARIA-SEVERA-Y-TOTAL-VF.pdf

Thurow, R. (2019) "The Looming Global Obesity Threat”. The Chicago Council on Global Affairs, "https://www.thechicagocouncil.org/publication/looming-global-obesity-threat

Waisgrais, S., Aulicino, C. et al (2019) "Informe sobre evaluación de efectos del Programa CPI: un estudio muestral". Fondo de las Naciones Unidas para la Infancia (UNICEF) https://www.unicef.org/argentina/media/5701/file/Evaluaci\%C3\%B3n\%20de\%20efectos\%20del\%20Programa\%20CPI.pdf 


\section{ANEXO. DETALLE DE PROGRAMAS POR PROVINCIA}

\section{Cuadro A-1. Programas Provinciales de Tarjetas Alimentarias}

\begin{tabular}{|c|c|c|c|c|}
\hline Provincia & Unidad/es Ejecutora/s & $\begin{array}{c}\text { Nombre Tarjeta } \\
\text { Provincial }\end{array}$ & Nombre del SAE & Otros Programas. Observaciones sobre el PPSA. \\
\hline BUENOS AIRES & $\begin{array}{c}\text { Ministerio de Desarrollo } \\
\text { Social, Subsecretaria de } \\
\text { Fortalecimiento Familiar } \\
\text { y Comunitario }\end{array}$ & Plan Más Vida & $\begin{array}{l}\text { Servicio Alimentario Escolar } \\
\qquad \text { (SAE) }\end{array}$ & $\begin{array}{l}\text { Programa Espacios Comunitarios. Programa Servicio Alimentario Fa- } \\
\text { miliar y Programa Tarjeta Plus Alimentaria. Menor escala que Mas } \\
\text { Vida y SAE. }\end{array}$ \\
\hline CATAMARCA & $\begin{array}{l}\text { Ministerio de Desarrollo } \\
\text { Social, Dirección de Po- } \\
\text { líticas Alimentarias }\end{array}$ & Tarjeta Familia & $\begin{array}{l}\text { Programa "Pío" de apoyo a co- } \\
\text { medores escolares }\end{array}$ & $\begin{array}{l}\text { Comedores "Emergentes". asistencia } 4.500 \text { personas, con } 23 \text { sedes } \\
\text { distribuidas en San Fernando del Valle de Catamarca y Valle Viejo }\end{array}$ \\
\hline CIUDAD DE BUENOS AIRES & $\begin{array}{c}\text { Ministerio de Desarrollo } \\
\text { Social, Secretaria de } \\
\text { Fortalecimiento Familiar } \\
\text { y Comunitario (Tarjetas } \\
\text { y Comedores Comunita- } \\
\text { rios). Ministerio de Edu- } \\
\text { cación (Comedores Es- } \\
\text { colares) }\end{array}$ & Ticket Social & $\begin{array}{l}\text { Programa de Alimentación } \\
\text { Escolar }\end{array}$ & $\begin{array}{l}\text { Ciudadanía Porteña (transferencias directas para adquisición de ali- } \\
\text { mentos, productos de limpieza e higiene personal, combustible para } \\
\text { cocinar y útiles escolares, en la Red de Comercios del Programa) y } \\
\text { Otras intervenciones que dependen de distintos ministerios: Desarro- } \\
\text { llo Social, Salud y Educación }\end{array}$ \\
\hline $\mathrm{CHACO}$ & $\begin{array}{l}\text { Interministerial. Desa- } \\
\text { rrollo Social y Salud } \\
\text { (tiende a la conforma- } \\
\text { ción de una nueva red } \\
\text { de gestión junto a orga- } \\
\text { nizaciones de la socie- } \\
\text { dad civil, cumpliendo } \\
\text { con el principio básico } \\
\text { de corresponsabilidad) }\end{array}$ & Tarjeta Social & \begin{tabular}{c|} 
\\
Chaco Familia (vigilancia y \\
supervisión nutricional de los \\
comedores Unidad Provincial \\
de Seguimiento Nutricional)
\end{tabular} & $\begin{array}{l}\text { La Unidad Provincial de Seguimiento Nutricional brinda contención a } \\
4.500 \text { individuos de forma mensual con acciones en territorio y mó- } \\
\text { dulos alimentarios específicos. } \\
\text { Subsecretaría de Abordaje Territorial del Ministerio de Desarrollo So- } \\
\text { cial, se complementa la entrega de módulos con "charlas participati- } \\
\text { vas relacionadas a la buena alimentación, cuidado del medio am- } \\
\text { biente, higiene y seguridad en los alimentos, talleres de antropome- } \\
\text { tría y capacitaciones que tienen como fin concienciar, fomentar la in- } \\
\text { clusión y generar espacios de contención y acompañamiento perma- } \\
\text { nente". También, Programa Movida Saludable en espacios públicos } \\
\text { (incluye atención a celíacos). } \\
\text { PROGRAMA DE ALIMENTACIÓN Y HÁBITOS SALUDABLES. Sub- } \\
\text { secretaría Promoción y Prevención de la Salud. Sólo en Resistencia. } \\
\text { Talleres. } \\
\text { PROGRAMA DE KIOSCOS SALUDABLES. Subsecretaría Promo- } \\
\text { ción y Prevención de la Salud. }\end{array}$ \\
\hline
\end{tabular}




\begin{tabular}{|c|c|c|c|c|}
\hline Provincia & Unidad/es Ejecutora/s & $\begin{array}{c}\text { Nombre Tarjeta } \\
\text { Provincial }\end{array}$ & Nombre del SAE & Otros Programas. Observaciones sobre el PPSA. \\
\hline & & & & $\begin{array}{l}\text { PROGRAMA “PROYECTO PROTEGER”, MINISTERIO DE SALUD } \\
\text { PÚBLICA EDUCACION PARA LA SALUD Y PROCREACION } \\
\text { HUMANA RESPONSABLE DE LA PROVINCIA DEL CHACO. } \\
\text { MINISTERIO DE HACIENDA FORTALECIMIENTO DE LA } \\
\text { ECONOMÍA REGIONAL (FER). } \\
\text { PROGRAMA NACIONAL DE SALUD ESCOLAR -PROSANE. Salud } \\
\text { Integral. Prevención de la Salud. } \\
\text { Región del Impenetrable: Dirección Nacional de Maternidad e Infan- } \\
\text { cia, la provincia impulsa un proyecto de "Proyecto de Atención Co- } \\
\text { munitaria de la Desnutrición Aguda y Moderada". el Estado provincial } \\
\text { tendrá a su cargo la provisión de alimentos de rápido uso; en tanto } \\
\text { que Nación aportará los equipos necesarios para las capacitaciones } \\
\text { y las mediciones del Perímetro Braquial, que es la medida antropo- } \\
\text { métrica con mayor predicción de mortalidad y de fácil aplicación (mé- } \\
\text { todo de medición, primera vez que se lo usará en Argentina; y en- } \\
\text { trega de alimentos de rápido uso -de origen francés). Recuperación } \\
\text { de } 100 \text { a } 150 \text { niños }\end{array}$ \\
\hline CHUBUT & $\begin{array}{l}\text { Ministerio de Familia y } \\
\text { Promoción Social }\end{array}$ & Tarjeta Social & $\begin{array}{l}\text { Servicio Alimentario Escolar } \\
\text { (SAE) }\end{array}$ & $\begin{array}{l}\text { SAE: fondos provinciales para alimentos, compra de utensilios de co- } \\
\text { cina, equipamiento (cocina, heladera, freezer, etc), y personal auxi- } \\
\text { liar para la elaboración de los mismos. Control antropométrico, Capa- } \\
\text { citación para Auxiliares de la Educación en "Alimentación Saludable } \\
\text { y Manipulación de Alimentos". Capacitación a docentes de primaria: } \\
\text { "Aprender a Vivir con Salud", estuvo a cargo del "Nutriendo Chubut", } \\
\text { Dirección General de Educación Física y Deportes del Ministerio de } \\
\text { Educación y del Departamento de Nutrición del Ministerio de Salud. } \\
\text { Kioscos Saludables. Ley Provincial 2019: “crea un programa de se- } \\
\text { guridad alimentaria que ya existe dentro del presupuesto provincial» } \\
\text { (plan El hambre más urgente). }\end{array}$ \\
\hline CORDOBA & $\begin{array}{c}\text { Secretaría General de la } \\
\text { Gobernación - Dirección } \\
\text { General del PAICor. Mi- } \\
\text { nisterio de Desarrollo } \\
\text { Social (Tarjeta Social) }\end{array}$ & Tarjeta Social & $\begin{array}{l}\text { PROGRAMA DE ASISTENCIA } \\
\text { INTEGRAL DE CÓRDOBA } \\
\text { (PAICOr) }\end{array}$ & $\begin{array}{l}\text { PROGRAMA DE ASISTENCIA INTEGRAL DE CÓRDOBA (PAICor). } \\
\text { EI PAICor inició su implementación en enero de 1984, cuenta con } 35 \\
\text { años de servicio y asistencia a la comunidad. Tarjeta Social: Permite } \\
\text { a familias cordobesas que se encuentran por debajo de la línea de } \\
\text { indigencia adquirir alimentos que ayuden a cubrir sus necesidades } \\
\text { nutricionales básicas. Es una asistencia económica canalizada a tra- } \\
\text { vés de una tarjeta con la cual se pueden comprar alimentos en co- } \\
\text { mercios adheridos al programa. Para esto, es necesario que los co- } \\
\text { mercios tengan sistema de posnet o pago electrónico adherido a } \\
\text { Bancor. }\end{array}$ \\
\hline
\end{tabular}




\begin{tabular}{|c|c|c|c|c|}
\hline Provincia & Unidad/es Ejecutora/s & $\begin{array}{l}\text { Nombre Tarjeta } \\
\text { Provincial }\end{array}$ & Nombre del SAE & Otros Programas. Observaciones sobre el PPSA. \\
\hline CORRIENTES & $\begin{array}{l}\text { Ministerio de Desarrollo } \\
\text { Social, Dirección de Se- } \\
\text { guridad Alimentaria }\end{array}$ & Tarjeta Sapucay & Programa Alimentario Escolar & $\begin{array}{l}\text { Con Salud, OPERATIVOS de antropometría en los comedores. } \\
\text { JÓVENES, junto a Nación: programa Empleo y programas deporti- } \\
\text { vos (base en comedores) Plan } 1000 \text { días, asistencia a través de } \\
\text { CAPS. Asistencia a personas con Celiaquía. PROGRMA } \\
\text { ALIMENTARIO CORRIENTES (PAC) Emergencia Alimentaria } 2019 .\end{array}$ \\
\hline ENTRE RIOS & $\begin{array}{l}\text { Ministerio de Desarrollo } \\
\text { Social }\end{array}$ & Tarjeta Social & $\begin{array}{l}\text { Comedores y Copa de Leche } \\
\text { Reforzada (RAN) }\end{array}$ & $\begin{array}{l}\text { Plan de Emergencia Alimentaria 2019. El Programa Provincial de Se- } \\
\text { guridad Alimentaria nace en 2008. "A la mesa, entre todos" (Ministe- } \\
\text { rio de Salud y Acción Social entrerriano en ese entonces) }\end{array}$ \\
\hline FORMOSA & $\begin{array}{l}\text { Ministerio de Cultura y } \\
\text { Educación (Nutrición } \\
\text { Escolar) y Miniserio de } \\
\text { Desarrollo Humano } \\
\quad \text { (Plan Nutrir) }\end{array}$ & Tarjeta Plan Nutrir & $\begin{array}{l}\text { Programa de Alimentación y } \\
\text { Nutrición Escolar }\end{array}$ & $\begin{array}{l}\text { 1. Plan Nutrir: Huertas familiares y comunitarias. } 2 \text {. Plan de Seguri- } \\
\text { dad Alimentaria: } 12.000 \text { cajas mensuales según } 3 \text { grupos etarios, y } \\
\text { como refuerzo para casos detectados de desnutrición. 3. Compras } \\
\text { del plan Nutrir: } 100 \% \text { productores locales. } 4 \text {. Planta industrial de } \\
\text { "NUTRIR" ALIMENTOS produce la Nutrisopa y otros alimentos pre - } \\
\text { elaborados que refuerzan la dieta diaria de miles de formoseños. } \\
\text { Tarjeta plan nutrir: (familias aborígenes prioritarias de la ciudad capi- } \\
\text { tal, para luego avanzar al interior de la provincia. Permite retirar cada } \\
15 \text { días canasta saludable de } 8 \text { centros de distribución ubicados en } \\
\text { puntos estratégicos de la ciudad) }\end{array}$ \\
\hline JUJUY & $\begin{array}{c}\text { Ministerio de Desarrollo } \\
\text { Humano }\end{array}$ & & Programa de Nutrición Escolar & $\begin{array}{l}\text { 1. Plan Jujuy Asiste y Reactiva. Comedores infantiles comunitarios. } \\
\text { "Programa Comer en Casa" (modulos alimentarios, y granjas y huer- } \\
\text { tas comunitarias y familiares para el autoabastecimiento con asisten- } \\
\text { cia técnica). Habilitación de los Centros de Acción Familiar, CAF. } \\
\text { Programa Puente: raciones para personas en situación de calle. } 2 \text {. } \\
\text { Plan Social Nutricional: en comedores escolares }\end{array}$ \\
\hline LA PAMPA & $\begin{array}{l}\text { Ministerio de Cultura y } \\
\text { Educación de la Provin- } \\
\text { cia (Comedores Escola- } \\
\text { res). Ministerio de Desa- } \\
\text { rrollo Social, Subsecre- } \\
\text { taria de Descentraliza- } \\
\text { ción Territorial. Direc- } \\
\text { ción General de Planifi- } \\
\text { cación y Evaluación de } \\
\text { Políticas Sociales. (Tar- } \\
\text { jeta) }\end{array}$ & \begin{tabular}{|l} 
Tarjeta Alimentaria \\
o Social. Sistema \\
Pilquen
\end{tabular} & $\begin{array}{l}\text { "MEJORAMIENTO DE LA } \\
\text { CALIDAD DE LOS SERVICIOS } \\
\text { ALIMENTARIOS DE LAS } \\
\text { ESCUELAS EN SITUACIÓN } \\
\text { DE MAYOR } \\
\text { VULNERABILIDAD } \\
\text { SOCIOEDUCATIVA" (Escuela } \\
\text { Hogares y las Escuelas de } \\
\text { Jornada Completa) }\end{array}$ & $\begin{array}{l}\text { Proyecto de educación alimentaria nutricional y valoración antropo- } \\
\text { métrica en las escuelas hogares y escuelas de jornada completa de } \\
\text { la provincia de La Pampa (parte de los objetivos del proyecto con el } \\
\text { PNSA) }\end{array}$ \\
\hline LA RIOJA & $\begin{array}{l}\text { Ministerio de Desarrollo } \\
\text { Social e Inclusión So- }\end{array}$ & Tarjeta Social & $\begin{array}{c}\text { Comedores Escolares } \\
\text { prioritarios (290 escuelas rura- } \\
\text { les) }\end{array}$ & \\
\hline
\end{tabular}




\begin{tabular}{|c|c|c|c|c|}
\hline Provincia & Unidad/es Ejecutora/s & $\begin{array}{c}\text { Nombre Tarjeta } \\
\text { Provincial }\end{array}$ & Nombre del SAE & Otros Programas. Observaciones sobre el PPSA. \\
\hline & $\begin{array}{l}\text { cial. Dirección de Plani- } \\
\text { ficación de Políticas Ali- } \\
\text { mentarias }\end{array}$ & & & \\
\hline MENDOZA & $\begin{array}{l}\text { Ministerio de Salud, } \\
\text { Desarrollo Social y De- } \\
\text { portes (PNSA general). } \\
\text { Dirección General de } \\
\text { Educación (Comedores } \\
\text { Escolares) }\end{array}$ & Tarjeta Ticket & Comedores Escolares & $\begin{array}{l}\text { En el presupuesto provincial, figuran el PROSOCO, Nutrifamil y Di- } \\
\text { rección de Contingencia por } \$ 348 \text { millones. El PNSA, comprende, } \\
\text { según medios oficiales, } 4 \text { programas que con fondos nacionales y } \\
\text { provinciales ejecuta la Dirección de Derecho a la Alimentación, } 245 \\
\text { millones (total, octubre } 2019 \text { ): "Comer juntos en familia", "Nutrifami- } \\
\text { lia", "Tarjeta Tickets" y "Módulos Alimentarios". "Comer juntos en fa- } \\
\text { milia" entrega alimentos secos y frescos y se realizan capacitacio- } \\
\text { nes. El programa tiene } 1.800 \text { inscriptos y cuenta con una inversión } \\
\text { de } 13 \text { millones de pesos. "Nutrifamilia" tarjeta electrónica, para la } \\
\text { compra de alimentos en comercios y supermercados adheridos al } \\
\text { sistema. Son } 700 \text { personas las beneficiarias. "Tarjeta Tickets" com- } \\
\text { pra de alimentos en comercios y supermercados adheridos al sis- } \\
\text { tema electrónico en la provincia. Cuenta con } 10 \text { mil beneficiarios. } \\
\text { "Módulos Alimentarios" entrega alimentos frescos y secos a } 1.000 \text { ti- } \\
\text { tulares de derecho. DGE. Comedores Escolares (745 millones total, } \\
\text { octubre 2019). }\end{array}$ \\
\hline MISIONES & $\begin{array}{c}\text { Ministerio de Derechos } \\
\text { Humanos }\end{array}$ & $\begin{array}{l}\text { Tarjetas sociales } \\
\text { de los programas } \\
\text { Provinciales "Pue- } \\
\text { blos Originarios", } \\
\text { "Recuperación Nu- } \\
\text { tricional Hambre } \\
\text { Cero" y "Seguridad } \\
\text { Alimentaria - Ciu- } \\
\text { dad de Posadas": }\end{array}$ & $\begin{array}{l}\text { Programa de Asistencia } \\
\text { Alimentaria Escolar }\end{array}$ & $\begin{array}{l}\text { Programa Provincial de Seguridad Alimentaria y Nutricional. Norma- } \\
\text { tiva: en el ámbito del Ministerio de Desarrollo Social, del Ministerio de } \\
\text { Salud Pública, del Ministerio de Cultura y Educación y de la Secreta- } \\
\text { ría de Estado de Agricultura Familiar. Nutrición Escolar (Educación). } \\
\text { A partir de octubre de } 2010 \text { la coordinación del Programa pasó a es- } \\
\text { tar bajo la órbita del Ministerio de Derechos Humanos. }\end{array}$ \\
\hline NEUQUEN & $\begin{array}{l}\text { Ministerio de Salud y } \\
\text { Desarrollo Social. Area } \\
\text { Gobierno y Educación } \\
\text { MDS y Secretaría de } \\
\text { Educación (Comedores } \\
\text { Escolares). }\end{array}$ & Tarjeta Crecer & $\begin{array}{l}\text { Comedores Escolares } \\
\text { (refuerzo a } 257 \text { escuelas) }\end{array}$ & \\
\hline RÍO NEGRO & $\begin{array}{l}\text { Ministerio de Desarrollo } \\
\text { Humano y Articulación } \\
\text { Solidaria. Subsecreta- } \\
\text { ría de Políticas Activas }\end{array}$ & $\begin{array}{l}\text { Tarjetas sociales } \\
\text { Rionegrinas: Peñi, } \\
\text { Pasar y Celíacos }\end{array}$ & $\begin{array}{c}\text { Comedores Escolares } \\
\text { prioritarios }\end{array}$ & $\begin{array}{l}\text { Dos convenios PNSA. Tarjetas según sitio oficial: Se pueden adquirir } \\
\text { alimentos tales como carnes, huevos, frutas, verduras, lácteos, le- } \\
\text { gumbres y cereales. En el caso de los pacientes celíacos alimentos } \\
\text { SIN TACC que se encuentren en el listado de ANMAT. Educación: El }\end{array}$ \\
\hline
\end{tabular}




\begin{tabular}{|c|c|c|c|c|}
\hline Provincia & Unidad/es Ejecutora/s & $\begin{array}{l}\text { Nombre Tarjeta } \\
\text { Provincial }\end{array}$ & Nombre del SAE & Otros Programas. Observaciones sobre el PPSA. \\
\hline & $\begin{array}{c}\text { de Inclusión Social (Tar- } \\
\text { jetas). Ministerio de } \\
\text { Educación y Derechos } \\
\text { Humanos (Comedores } \\
\text { Escolares) }\end{array}$ & & & $\begin{array}{l}\text { objetivo del convenio es mantener y mejorar la calidad de los servi- } \\
\text { cios alimentarios que brindan los comedores, sosteniendo la calidad } \\
\text { nutricional de las prestaciones en todas las escuelas públicas de Río } \\
\text { Negro. }\end{array}$ \\
\hline SALTA & $\begin{array}{l}\text { Ministerio de Desarrollo } \\
\text { Social, subsecretaria de } \\
\text { Programas Descentrali- } \\
\text { zado (tarjetas). Ministe- } \\
\text { rio de Educación Cien- } \\
\text { cia y Tecnologia (come- } \\
\text { dores escolares) }\end{array}$ & $\begin{array}{l}\text { Tarjeta Abordaje } \\
\text { Integral de las Polí- } \\
\text { ticas Alimentarias } \\
\text { Salta (AIPAS) (ex } \\
\text { tarjeta social) }\end{array}$ & Plan Nutricional del Escolar & $\begin{array}{l}\text { Plan Nutri-Vida: } 70.000 \text { módulos alimentarios + "Plan Alimentario } \\
\text { Salteño" (2019), apoyo de emergencia en escuelas y CPI los fines de } \\
\text { semana. Ministerio de Primera Infancia y acciones focalizadas } \\
\text { (Crianza, Nutrición, Estimulación Temprana). Líneas con del PNPI. }\end{array}$ \\
\hline SAN JUAN & $\begin{array}{l}\text { Ministerio de Desarrollo } \\
\text { Humano y Promoción } \\
\text { Social. Dirección de Po- } \\
\text { líticas Alimentarias. }\end{array}$ & Tarjeta Social & Comedores Escolares & $\begin{array}{l}\text { Sitio oficial: La Dirección de Políticas Alimentarias del Ministerio de } \\
\text { Desarrollo Humano tiene a cargo el diseño y gestión de los progra- } \\
\text { mas de Colonias de Verano, Tarjeta Social, Asistencia alimentaria al } \\
\text { celiaco, desayunos y meriendas fortificadas y comedores escolares. }\end{array}$ \\
\hline SAN LUIS & $\begin{array}{c}\text { Ministerio de Desarrollo } \\
\text { Social }\end{array}$ & -- & $\begin{array}{l}\text { Copa de Leche y refuerzo } \\
\text { alimentario a comedores esco- } \\
\text { lares }\end{array}$ & $\begin{array}{l}\text { Plan Inclusión Social y el Plan Solidario. Hay tarjetas directas a titula- } \\
\text { res. "La provincia de San Luis y Catamarca no poseían, hasta el año } \\
\text { 2009, bancarizada su política alimentaria" (Betsabé Policastro, 2012; } \\
\text { UBA/Margen 71). MInistro de Desarrollo Social (Berardo), diciembre } \\
\text { 2019: Berardo dijo que "una vez que se hagan los cruces de datos } \\
\text { en la Anses, se informará a cada ministerio provincial para que vea- } \\
\text { mos si están incluidas todas las familias y quiénes se quedan afuera. } \\
\text { "Sabemos que hay madres en la provincia que no están cobrando la } \\
\text { AUH y nos corresponde a nosotros trabajar para que comiencen a } \\
\text { percibir la asignación universal y que inmediatamente accedan a la } \\
\text { Tarjeta Alimentaria". }\end{array}$ \\
\hline SANTA CRUZ & Ministerio de la Familia & Tarjeta Social & $\begin{array}{l}\text { Comedores Escolares, } \\
\text { Hogares de Adultos Mayores, } \\
\text { Escuelas Albergue, Escuelas } \\
\text { Especiales y Centros de } \\
\text { Desarrollo Infantil }\end{array}$ & $\begin{array}{l}\text { Las tarjetas incluyen un plus para personas con celiaquía. Programa } \\
\text { Provincial de Seguridad Alimentaria. Octubre 2019: Con la participa- } \\
\text { ción del Consejo Provincial de Educación, el Ministerio de Salud y } \\
\text { Ambiente y el Consejo Agrario Provincial, el Gobierno Provincial lle- } \\
\text { vará adelante diferentes acciones de seguridad alimentaria en el } \\
\text { marco del Día Mundial de la Alimentación Saludable. Estas reunio- } \\
\text { nes se realizan con el objetivo de determinar y generar acciones de } \\
\text { concientización y sensibilización sobre hábitos y costumbres saluda- } \\
\text { bles. }\end{array}$ \\
\hline SANTA FE & $\begin{array}{l}\text { Ministerio de Educación } \\
\text { (Comedores Escolares }\end{array}$ & $\begin{array}{l}\text { Tarjeta Única de } \\
\text { Ciudadanía }\end{array}$ & $\begin{array}{l}\text { Servicio Alimentario en las } \\
\text { Escuelas (SAE) }\end{array}$ & $\begin{array}{l}\text { Programa Familias y Nutrición (nacional) y el Programa Único Inte- } \\
\text { gral para la Obesidad (provincial). Fondo para Atención de Necesida- }\end{array}$ \\
\hline
\end{tabular}




\begin{tabular}{|c|c|c|c|c|}
\hline Provincia & Unidad/es Ejecutora/s & $\begin{array}{l}\text { Nombre Tarjeta } \\
\text { Provincial }\end{array}$ & Nombre del SAE & Otros Programas. Observaciones sobre el PPSA. \\
\hline & $\begin{array}{l}\text { y copa de leche). Minis- } \\
\text { terio de Desarrollo So- } \\
\text { cial (Tarjeta Única de } \\
\text { Ciudadanía) }\end{array}$ & & & $\begin{array}{l}\text { des Inmediatas (FANI): fondos para comedores escolares. remodela- } \\
\text { ciones, adecuaciones de cocinas y comedores, y compra de equipa- } \\
\text { miento para mejorar la prestación de los servicios alimentarios. }\end{array}$ \\
\hline SANTIAGO DEL ESTERO & $\begin{array}{l}\text { Ministerio de Salud } \\
\text { (PAS) }\end{array}$ & Tarjeta Social & $\begin{array}{l}\text { Programa de Asistencia } \\
\text { Alimentaria a Escolares }\end{array}$ & Sin otros datos. \\
\hline TIERRA DEL FUEGO & $\begin{array}{l}\text { Ministerio de Desarrollo } \\
\text { Social (tarjetas). Minis- } \\
\text { terio de Educación (Co- } \\
\text { medores Escolares, fon- } \\
\text { dos provinciales) }\end{array}$ & $\begin{array}{l}\text { Tarjetas de Presta- } \\
\text { ción Social }\end{array}$ & $\begin{array}{c}\text { Comedores escolares (fondos } \\
\text { provinciales) }\end{array}$ & Programa Alimentario Provincial "Cuidemos la mesa fueguina" \\
\hline TUCUMAN & $\begin{array}{l}\text { Ministerio de Desarrollo } \\
\text { Social, Dirección de Po- } \\
\quad \text { líticas Alimentarias }\end{array}$ & Tarjeta Cabal & $\begin{array}{l}\text { Comedores escolares } \\
\text { (Escuelas Primarias) }\end{array}$ & $\begin{array}{l}\text { 1. Integral de Nutrición: ARTICULACIÓN DS + SALUD (Programa de } \\
\text { Abordaje en Nutrición): Transferencias directas y módulos alimenta- } \\
\text { rios para } 58.000 \text { familias críticas y } 9.000 \text { titulares en rehabilitación } \\
\text { nutricional detectados por el Ministerio de Salud. 2. Fortalecimiento } \\
\text { de espacios comunitarios vinculados a la nutrición infantil: reconver- } \\
\text { sión de los comedores infantiles, el fortalecimiento a cocinas comuni- } \\
\text { tarias, y Formación de centros de cuidado y nutrición infantil. }\end{array}$ \\
\hline
\end{tabular}

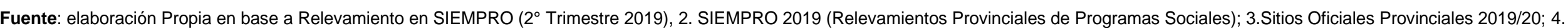
Aulicino, C., CIPPEC 2012; 5.Aulicino, C., Díaz Langou, G., CIPPEC, 2012; 6. Maceira, D. CEDES (2009) 
Cuadro A-2. Descentralización Municipal de Programas Alimentarios

\begin{tabular}{|c|c|c|}
\hline Provincia & $\begin{array}{l}\text { Municipios y Departa- } \\
\text { mentos }\end{array}$ & Descentralización en municipios \\
\hline BUENOS AIRES & 135 & $\begin{array}{l}\text { Alta descentralización. EI PNSA también tiene convenios directos con los municipios (no sólo nivel provincial). Ma- } \\
\text { yormente, del Gran Buenos Aires. Casos de estudio disponibles: Florencio Varela y Berazategui (CEDES, 2009) }\end{array}$ \\
\hline CATAMARCA & 34 & En San Fernando del Valle de Cat.: sedes municipales, comedores emergentes. \\
\hline CIUDAD DE BUENOS AIRES & 15 comunas & $s / d$ \\
\hline $\mathrm{CHACO}$ & 68 & $s / d$ \\
\hline CHUBUT & 45 & $s / d$ \\
\hline CORDOBA & 428 & Programa PAICoR. Comprende transferencias a Municipios y Entes comunales \\
\hline CORRIENTES & 66 & $\begin{array}{l}\text { Baja descentralización: la provincia distribuye los fondos hacia los municipios que solo deben hacer la rendición } \\
\text { (CIPPEC 2012). PROGRAMA PROVINCIAL DE SEGURIDAD ALIMENTARIA: Tarjeta Sapukay y Comedores Co- } \\
\text { munitarios y Merenderos dependientes del Ministerio de Desarrollo Social (200 centros en zonas urbanas y } 60 \text { en } \\
\text { interior, alimentos frescos y deshidratados). }\end{array}$ \\
\hline ENTRE RIOS & 259 & $s / d$ \\
\hline FORMOSA & 37 & Baja. En ciudad de Formosa, plan para familias aborígenes (2018). \\
\hline JUJUY & 60 & $\mathrm{~s} / \mathrm{d}$ \\
\hline LA PAMPA & 79 & Cuenta con la Subsecretaría de Desarrollo Territorial y partida de transferencias. \\
\hline LA RIOJA & 18 & $\mathrm{~s} / \mathrm{d}$ \\
\hline MENDOZA & 18 & $\begin{array}{l}\text { Descentralización Nivel Medio, CIPPEC 2012: la provincia distribuye los fondos hacia pero los municipios que verifi- } \\
\text { can el cumplimiento de los requisitos para acceder al programa al evaluar a los titulares y completar una ficha } \\
\text { APROS }\end{array}$ \\
\hline MISIONES & 75 & $\begin{array}{l}\text { Descentralización a municipios de nivel medio, CIPPEC 2012: "El gobierno provincial realiza transferencias mensua- } \\
\text { les a los grupos familiares y los municipios llevan los contactos con los titulares y realizan las inscripciones y el se- } \\
\text { guimiento de titulares (Aulicino, 2012): En muchos casos, las autoridades municipales no reconocen como válidos } \\
\text { los criterios utilizados por los agentes de salud para definir si un niño presenta o no problemas de desnutrición, lo } \\
\text { que genera que haya niños/as que forman parte de la población objetivo pero no están incluidos en el "Hambre } \\
\text { Cero". Otro problema crítico es el período que transcurre entre que un niño es detectado por el sistema de salud con } \\
\text { un diagnóstico de desnutrición, hasta que es incorporado efectivamente al Programa. Esa brecha generalmente su- } \\
\text { pera el mes y en ocasiones llega a los sesenta días. Además, las prestaciones asignadas a los hogares numerosos } \\
\text { en los que hay un niño con diagnóstico de desnutrición son insuficientes: la prestación no incide de manera ade- } \\
\text { cuada en la recuperación del titular" }\end{array}$ \\
\hline NEUQUEN & 57 & $\begin{array}{l}\text { Alta descentralización. Tarjeta Crecer, según sitio oficial: El ministerio de Salud y Desarrollo Social cuenta con áreas } \\
\text { desentralizadas para la atención al público. Puede dirigirse a los Centros de Promoción Comunitaria, presentes en } \\
47 \text { de los barrios de la capital neuquina, o a las Delegaciones y Unidades de Gestión en el interior. Allí se coordinará }\end{array}$ \\
\hline
\end{tabular}




\begin{tabular}{|c|c|c|}
\hline Provincia & $\begin{array}{l}\text { Municipios y Departa- } \\
\text { mentos }\end{array}$ & Descentralización en municipios \\
\hline & & $\begin{array}{l}\text { una visita del asistente social al domicilio donde se completará o se actualizará el Formulario Único de Identificación } \\
\text { Familiar. Coincide en } 2012 \text { con CIPPEC: Alta descentralización municipal. "los efectores son los encargados de la } \\
\text { implementación del programa" }\end{array}$ \\
\hline RÍO NEGRO & 75 & $s / d$ \\
\hline SALTA & 59 & $\begin{array}{l}\text { Alta descentralización. la implementación de los programas es canalizada a través de las } 6 \text { regiones administrativas } \\
\text { provincia (CIPPEC 2012) }\end{array}$ \\
\hline SAN JUAN & 19 & $s / d$ \\
\hline SAN LUIS & 64 & $\begin{array}{l}\text { Alta descentralización municipal: "las Cooperadoras Escolares gestionan la Copa de Leche y los refuerzos"; "ambos } \\
\text { programas están dirigidos a niñas/os y adolescentes que asisten a establecimientos escolares y/o comedores comu- } \\
\text { nitarios" (CIPPEC, 2012). "- }\end{array}$ \\
\hline SANTA CRUZ & 20 & $s / d$ \\
\hline SANTA FE & 363 & $s / d$ \\
\hline SANTIAGO DEL ESTERO & 71 & $\begin{array}{l}\text { En Ciudad de Santiago del Estero: Programa de Asistencia Social (PAS), que tiene por objetivo "atender a los niños } \\
\text { de hasta cinco años de edad y a las mamás en estado de embarazo, lactancia", y el Programa Copa de Leche, para } \\
\text { jardines de Infantes Municipales. }\end{array}$ \\
\hline TIERRA DEL FUEGO & 3 & $s / d$ \\
\hline TUCUMAN & 112 & $s / d$ \\
\hline TOTAL & 2165 & \\
\hline
\end{tabular}

Fuente: elaboración propia en base a sitios oficiales y estudio Aulicino, C. y Díaz Langou, G., CIPPEC, 2012 
Cuadro A-3. Cobertura de los Principales Programas Alimentarios Nacionales, según Provincia.

\begin{tabular}{|c|c|c|c|c|c|c|}
\hline \multirow[b]{2}{*}{ PROVINCIA } & \multirow{2}{*}{$\begin{array}{c}\text { AUH - ANSES } \\
\text { (SIEMPRO, 1T- } \\
\text { 2019) }\end{array}$} & \multicolumn{5}{|c|}{ PNSA - MINISTERIO DE DESARROLLO SOCIAL (SIEMPRO, 2T-2019). En co-financiación con provincias. } \\
\hline & & $\begin{array}{l}\text { Tarjeta Federal } \\
\text { Descentralizada } \\
\text { (convenio Prov.) }\end{array}$ & $\begin{array}{c}\text { Tarjeta Federal Centrali- } \\
\text { zada } \\
\text { (directa tit. PNSA) }\end{array}$ & $\begin{array}{l}\text { COMEDORES } \\
\text { ESCOLARES } \\
\text { (conv. Prov) }\end{array}$ & $\begin{array}{l}\text { MODULOS ALIMENTARIOS } \\
\text { (FEDERAL DESCENTRALIZADO) } \\
\text { (conv. Prov.) }\end{array}$ & $\begin{array}{l}\text { COMEDORES } \\
\text { COMUNITARIOS (PNUD - } \\
\text { conv. OSC) }\end{array}$ \\
\hline BUENOS AIRES & 1.484 .557 & 300.000 & 201.634 & 8.125 & -- & 429 \\
\hline CATAMARCA & 39.512 & 6.930 & -- & 480 & -- & 17 \\
\hline CIUDAD DE BUENOS AIRES & 98.547 & -- & -- & -- & -- & 64 \\
\hline $\mathrm{CHACO}$ & 174.037 & 100.000 & 1.117 & 1.948 & -- & 48 \\
\hline CHUBUT & 28.883 & 10.493 & -- & 46 & -- & - \\
\hline CÓRDOBA & 291.940 & 69.000 & -- & 307 & -- & 25 \\
\hline CORRIENTES & 133.492 & 60.300 & -- & 1.159 & -- & 51 \\
\hline ENTRE RÍOS & 113.674 & 49.000 & -- & 1.346 & -- & 60 \\
\hline FORMOSA & 79.488 & 21.139 & -- & 1.076 & 14.578 & 69 \\
\hline JUJUY & 75.634 & 50.000 & -- & 105 & 35.000 & 67 \\
\hline LA PAMPA & 25.877 & 16.769 & -- & 26 & -- & 1 \\
\hline LA RIOJA & 35.444 & 21.250 & -- & 290 & -- & 5 \\
\hline MENDOZA & 179.276 & 15.000 & -- & 122 & -- & 34 \\
\hline MISIONES & 16.287 & 22.000 & -- & 200 & -- & 76 \\
\hline NEUQUÉN & 38.204 & 13.900 & -- & 267 & -- & 3 \\
\hline RIO NEGRO & 46.955 & & -- & 160 & -- & 32 \\
\hline SALTA & 164.395 & 49.436 & -- & 192 & -- & 23 \\
\hline SAN JUAN & 85.320 & 17.527 & -- & 196 & -- & 14 \\
\hline SAN LUIS & 27.153 & -- & 1.269 & -- & 19.171 & 4 \\
\hline SANTA CRUZ & 14.309 & 5.484 & -- & -- & -- & -- \\
\hline SANTA FE & 271.798 & 172.500 & -- & 2.033 & -- & 96 \\
\hline SANTIAGO DEL ESTERO & 129.010 & 50.000 & -- & 51 & -- & 16 \\
\hline TIERRA DEL FUEGO & 6.354 & 1.200 & -- & -- & -- & -- \\
\hline TUCUMÁN & 176.652 & 36.500 & $\begin{array}{ll}- \\
\end{array}$ & 340 & -- & 31 \\
\hline AUH 80\% & 3.736 .798 & 1.088 .428 & 204.020 & 18.469 & 68.749 & 1.165 \\
\hline AUH 20\% & 252.587 & & & & & \\
\hline Total AUH & 3.989 .385 & & & & & \\
\hline AUE & 75.160 & & & & & \\
\hline AUHD & 35.745 & & & & & \\
\hline
\end{tabular}


Cuadro A-4. Transferencias de la Administración Nacional a las Provincias 2019 - en Millones de Pesos

\begin{tabular}{|c|c|c|c|c|c|c|c|c|c|c|c|c|c|c|}
\hline & \multicolumn{5}{|c|}{$\begin{array}{c}\text { Gastos totales por Ubicación Geográfica. Administración } \\
\text { Nacional. Presupuesto } 2019\end{array}$} & \multicolumn{6}{|c|}{ Políticas Alimentarias. Presupuesto Inicial 2019} & \multirow{2}{*}{$\begin{array}{c}\text { Subtotal } \\
\text { PNSA }\end{array}$} & \multirow{2}{*}{$\begin{array}{l}\text { AU para Pro- } \\
\text { tección So- } \\
\text { cial. Presu- } \\
\text { puesto Ini- } \\
\text { cial } 2019\end{array}$} & \multirow{2}{*}{$\begin{array}{c}\text { TOTAL } \\
\text { Políticas } \\
\text { Alimenta- } \\
\text { rias y AUH }\end{array}$} \\
\hline & $\begin{array}{l}\text { Presu- } \\
\text { puesto Ini- } \\
\quad \text { cial }\end{array}$ & $\begin{array}{l}\text { Presu- } \\
\text { puesto Vi- } \\
\text { gente }\end{array}$ & $\begin{array}{l}\text { Compro- } \\
\text { metido }\end{array}$ & $\begin{array}{l}\text { Deven- } \\
\text { gado }\end{array}$ & Pagado & $\begin{array}{l}\text { Comedores } \\
\text { Escolares }\end{array}$ & $\begin{array}{c}\text { Tarjetas Ali- } \\
\text { mentarias }\end{array}$ & $\begin{array}{l}\text { Comedores } \\
\text { Comunitarios. }\end{array}$ & $\begin{array}{c}\text { Complemento } \\
\text { Alimentario }\end{array}$ & $\begin{array}{c}\text { Acciones } \\
\text { De Nutri- } \\
\text { ción }\end{array}$ & $\begin{array}{l}\text { Asisten- } \\
\text { cia } \\
\text { Pro- } \\
\text { Huerta }\end{array}$ & & & \\
\hline Buenos Aires & 915.857 & 987.920 & 961.705 & 915.791 & 835.151 & 240 & 1.643 & & & & & 1.883 & 40.297 & 42.179 \\
\hline $\begin{array}{l}\text { Ciudad de Bue- } \\
\text { nos Aires }\end{array}$ & 806.136 & 971.576 & 1.092 .657 & 1.059 .460 & 971.310 & 688 & 1.662 & 1.065 & 3.545 & 1.680 & 80 & 8.720 & 2.951 & 11.671 \\
\hline Córdoba & 178.410 & 200.622 & 190.161 & 178.837 & 168.873 & 49 & 92 & & & & & 141 & 8.170 & 8.311 \\
\hline Santa Fe & 165.291 & 176.364 & 168.000 & 158.989 & 147.448 & 197 & 98 & & & & & 294 & 7.547 & 7.841 \\
\hline Mendoza & 108.015 & 116.990 & 106.315 & 100.438 & 94.484 & 89 & 61 & & & & & 150 & 5.099 & 5.249 \\
\hline Tucumán & 88.701 & 96.924 & 90.130 & 85.590 & 80.184 & 98 & 66 & & & & & 164 & 4.794 & 4.958 \\
\hline Salta & 71.934 & 77.297 & 75.841 & 72.230 & 67.339 & 45 & 61 & & & & & 105 & 4.631 & 4.737 \\
\hline Entre Ríos & 64.317 & 67.936 & 66.296 & 63.290 & 58.926 & 98 & 65 & & & & & 163 & 3.215 & 3.378 \\
\hline Río Negro & 61.380 & 64.475 & 63.272 & 60.087 & 55.111 & 27 & 38 & & & & & 65 & 1.866 & 1.931 \\
\hline Misiones & 54.236 & 58.675 & 54.374 & 52.329 & 49.027 & 40 & 63 & & & & & 103 & 4.312 & 4.415 \\
\hline $\begin{array}{l}\text { Provincia del } \\
\text { Chaco }\end{array}$ & 51.993 & 56.808 & 56.445 & 54.230 & 51.681 & 49 & 50 & & & & & 99 & 4.595 & 4.694 \\
\hline S. del Estero & 51.088 & 55.632 & 54.448 & 52.127 & 49.304 & 4 & 58 & & & & & 62 & 3.636 & 3.698 \\
\hline Corrientes & 53.302 & 55.512 & 53.371 & 51.127 & 48.191 & 13 & 100 & & & & & 113 & 3.664 & 3.778 \\
\hline San Juan & 48.188 & 52.487 & 48.884 & 46.608 & 43.341 & 14 & 48 & & & & & 62 & 2.473 & 2.535 \\
\hline $\begin{array}{l}\text { Provincia del } \\
\text { Chubut }\end{array}$ & 43.948 & 46.651 & 43.394 & 41.444 & 38.038 & 11 & 25 & & & & & 36 & 1.208 & 1.244 \\
\hline Jujuy & 40.365 & 42.574 & 41.886 & 40.000 & 37.269 & 40 & 42 & & & & & 82 & 2.226 & 2.308 \\
\hline \begin{tabular}{|l|} 
Provincia del \\
Neuquén
\end{tabular} & 39.407 & 42.215 & 61.530 & 59.691 & 55.357 & 22 & 0,0 & & & & & 22 & 1.580 & 1.602 \\
\hline Santa Cruz & 21.813 & 29.826 & 34.055 & 33.235 & 30.033 & 0,4 & 28 & & & & & 28 & 680 & 708 \\
\hline San Luis & 27.036 & 29.602 & 28.217 & 26.911 & 24.955 & 45 & 33 & & & & & 77 & 880 & 958 \\
\hline La Rioja & 26.894 & 29.531 & 28.870 & 27.875 & 25.696 & 1 & 32 & & & & & 33 & 1.109 & 1.142 \\
\hline Formosa & 25.534 & 28.879 & 25.784 & 24.958 & 23.579 & 33 & 43 & & & & & 76 & 2.216 & 2.293 \\
\hline La Pampa & 26.353 & 27.622 & 27.677 & 26.373 & 24.564 & 9 & 30 & & & & & 39 & 1.053 & 1.092 \\
\hline Catamarca & 24.010 & 25.657 & 26.849 & 25.516 & 23.627 & 13 & 25 & & & & & 38 & 1.194 & 1.232 \\
\hline T. del Fuego & 13.656 & 14.347 & 14.005 & 13.256 & 12.077 & 1 & 23 & & & & & 24 & 356 & 380 \\
\hline Binacional & 3.443 & 3.432 & 3.397 & 3.397 & 3.394 & & & & & & & 0 & & 0 \\
\hline Nacional & 587.115 & 748.629 & 625.485 & 608.347 & 559.065 & & & & & & & 0 & & 0 \\
\hline No Clasificado & 480.607 & 614.560 & 597.189 & 574.588 & 494.054 & & & & & & & 0 & & 0 \\
\hline Interprovincial & 93.282 & 200.917 & 79.414 & 78.873 & 73.053 & & & & & & & 0 & & 0 \\
\hline
\end{tabular}




\begin{tabular}{|c|c|c|c|c|c|c|c|c|c|c|c|c|c|c|}
\hline & \multicolumn{5}{|c|}{$\begin{array}{c}\text { Gastos totales por Ubicación Geográfica. Administración } \\
\text { Nacional. Presupuesto } 2019\end{array}$} & \multicolumn{6}{|c|}{ Políticas Alimentarias. Presupuesto Inicial 2019} & \multirow{2}{*}{$\begin{array}{c}\text { Subtotal } \\
\text { PNSA }\end{array}$} & \multirow{2}{*}{$\begin{array}{l}\text { AU para Pro- } \\
\text { tección So- } \\
\text { cial. Presu- } \\
\text { puesto Ini- } \\
\text { cial } 2019\end{array}$} & \multirow{2}{*}{$\begin{array}{c}\text { TOTAL } \\
\text { Políticas } \\
\text { Alimenta- } \\
\text { rias y AUH }\end{array}$} \\
\hline & $\begin{array}{l}\text { Presu- } \\
\text { puesto Ini- } \\
\text { cial }\end{array}$ & $\begin{array}{l}\text { Presu- } \\
\text { puesto Vi- } \\
\text { gente }\end{array}$ & $\begin{array}{l}\text { Compro- } \\
\text { metido }\end{array}$ & $\begin{array}{l}\text { Deven- } \\
\text { gado }\end{array}$ & Pagado & $\begin{array}{l}\text { Comedores } \\
\text { Escolares }\end{array}$ & $\begin{array}{l}\text { Tarjetas Ali- } \\
\text { mentarias }\end{array}$ & $\begin{array}{l}\text { Comedores } \\
\text { Comunitarios. }\end{array}$ & $\begin{array}{c}\text { Complemento } \\
\text { Alimentario }\end{array}$ & $\begin{array}{l}\text { Acciones } \\
\text { De Nutri- } \\
\text { ción }\end{array}$ & $\begin{array}{c}\text { Asisten- } \\
\text { cia } \\
\text { Pro- } \\
\text { Huerta }\end{array}$ & & & \\
\hline $\begin{array}{l}\text { TOTAL } \\
\text { GASTOS } \\
\text { CTES. Y DE } \\
\text { CAPITAL }\end{array}$ & 4.172.312 & 4.923 .661 & 4.719 .651 & 4.535 .599 & 4.145 .131 & 1.828 & 4.384 & 1.065 & 3.545 & 1.680 & 80 & 12.582 & 109.752 & 122.335 \\
\hline & & & & & & & & & & & & & & \\
\hline $\begin{array}{l}\text { Presupuesto to- } \\
\text { tal Inicial } 2019 \\
\end{array}$ & 4.172.312 & & & & & 1.828 & 4.384 & 1.065 & 3.545 & 1.680 & 80 & 12.582 & 109.752 & 122.335 \\
\hline $\begin{array}{l}\text { Presupuesto to- } \\
\text { tal Ejecutado } \\
2019\end{array}$ & & & & 4.535 .599 & & 2.739 & 12.851 & 1.384 & 3.832 & 2.548 & 120 & 23.475 & 128.339 & 151.815 \\
\hline & & & & & & $49,9 \%$ & $193,1 \%$ & $30,0 \%$ & $8,1 \%$ & $51,7 \%$ & $49,9 \%$ & $86,6 \%$ & $16,9 \%$ & $24,1 \%$ \\
\hline
\end{tabular}

Fuente: Elaboración propia en base a

a. Planillas por ubicación geográfica, Oficina Nacional de Presupuesto, Ministerio de Hacienda. Datos 2019. https://www.minhacienda.gob.ar/onp/presupuestos/2019

b. Ejecución presupuestaria, plataforma Presupuesto Abierto, Ministerio de Economía. Datos 2019. https://www.presupuestoabierto.gob.ar/sici/donde-se-gasta

Ejecución. Actualizaciones al 26/12/2019 
Cuadro A-5. Presupuestos Provinciales. Publicación según Ley de Transparencia Fiscal № 25.917 y Leyes de Adhesión Provinciales

\begin{tabular}{|c|c|c|c|c|c|c|}
\hline Provincia & $\begin{array}{l}\text { No Ley Pro- } \\
\text { vincial del } \\
\text { Presupuesto } \\
\text { Anual }\end{array}$ & $\begin{array}{l}\text { Presupuesto } \\
\text { Total Provincia } \\
\text { (en \$AR) }\end{array}$ & $\begin{array}{l}\text { Presupuesto } \\
\text { Total Provincia } \\
\text { (En Us\$) }\end{array}$ & Sitio Web & $\begin{array}{l}\text { Unidad Ejecu- } \\
\text { tora de Políti- } \\
\text { cas Alimenta- } \\
\text { rias y Afines }\end{array}$ & $\begin{array}{l}\text { Valores Por Política Social/Alimentario Identificables En EI } \\
\text { Texto De Ley Y Anexos }\end{array}$ \\
\hline \multirow{15}{*}{ Buenos Aires } & \multirow{15}{*}{ L15.078 } & \multirow{15}{*}{$\$ 929.466 .529 .764$} & \multirow{15}{*}{$\$ 14.753 .436 .980$} & \multirow{15}{*}{$\begin{array}{l}\frac{\text { https://www.gba.gob.a }}{\text { r/hacienda y finan- }} \\
\text { zas/direccion provin- } \\
\text { cial de presu- } \\
\text { puesto publico/presu- } \\
\text { puesto } 2019 \\
\end{array}$} & \multirow{15}{*}{\begin{tabular}{|l|} 
\\
Ministerio de \\
Desarrollo So- \\
cial. Subsecre- \\
taría de Fortale- \\
cimiento Fami- \\
liar y Comunita- \\
rio.
\end{tabular}} & $\begin{array}{l}\text { Sitio oficial. Ministerio de Hacienda. Presupuesto 2019, Ministe- } \\
\text { rio de Desarrollo Social: } 22.315 .786 .000\end{array}$ \\
\hline & & & & & & $\begin{array}{l}\text { Presupuesto 2019, Programa 7, políticas alimentarias: } \$ 9.984 \\
\text { millones, Hacienda. (sin detalle) }\end{array}$ \\
\hline & & & & & & Presupuesto 2018. Desglose \\
\hline & & & & & & SAE PRIMARIA 2018: $\$ 4.865 .000 .000$ \\
\hline & & & & & & SAE POSPRIMARIA DIRECCION 2018: \$1.085.000.000 \\
\hline & & & & & & SAE Equipamiento e infraestructura 2018: $\$ 95.000 .000$ \\
\hline & & & & & & SAE MONITOREO Y AUDITORIA 2018: \$25.000.000 \\
\hline & & & & & & SAE: 2.010 .000 beneficiarios. \\
\hline & & & & & & $\begin{array}{l}\text { ASISTENCIA ALIMENTARIA A POBLACION VULNERABLE A } \\
\text { TRAVES DE TRANSF DIRECTAS (Más Vida): } 210.000 \text { beneficia- } \\
\text { rios. }\end{array}$ \\
\hline & & & & & & MAS VIDA MENORES DE 0 A 5 AÑOS: $\$ 2.538 .000 .000$ \\
\hline & & & & & & MÁS VIDA Celíacos e inmunosuprimidos:\$ 45.136 .000 \\
\hline & & & & & & Un vaso de Leche por día: 360.000 beneficiarios \\
\hline & & & & & & "UN VASO DE LECHE POR DIA" 0 a 5: $\$ 350.000 .000$ \\
\hline & & & & & & ALIMENTOS: $\$ 250.000 .000$ \\
\hline & & & & & & Logística y distribución: $\$ 31.100 .000$ \\
\hline Catamarca & L5586 & $\$ 49.792 .701 .561$ & $\$ 790.360 .342$ & $\begin{array}{l}\frac{\text { http://www.ha- }}{\text { cienda.cata- }} \\
\text { marca.gov.ar/pdf/ley } \\
\text { presupuesto 2019.pdf }\end{array}$ & $\begin{array}{l}\text { Ministerio de } \\
\text { Desarrollo So- } \\
\text { cial. Dirección } \\
\text { de Seguridad } \\
\text { Alimentaria Pro- } \\
\text { vinicial }\end{array}$ & $\begin{array}{l}\text { Presupuesto 2019. Seguridad Social. Gastos Corrientes } \\
\$ 45.008 .787 .559 \text {. Gastos de Capital: } 4.783 .914 .002 \text {. Sin planillas } \\
\text { analíticas }\end{array}$ \\
\hline \multirow{4}{*}{$\begin{array}{l}\text { Ciudad de } \\
\text { Buenos Aires }\end{array}$} & \multirow{4}{*}{ L6068 } & \multirow{4}{*}{$\$ 327.083 .586 .716$} & \multirow{4}{*}{$\$ 5.191 .802 .964$} & \multirow{4}{*}{$\begin{array}{l}\frac{\text { https://www.buenosai- }}{\text { res.gob.ar/econo- }} \\
\frac{\text { miayfinanzas/presu- }}{\text { puesto-2019 }}\end{array}$} & \multirow{4}{*}{$\begin{array}{l}\text { Ministerio de } \\
\text { Desarrollo So- } \\
\text { cial y Hábitat, } \\
\text { Secretaria de } \\
\text { Fortalecimiento }\end{array}$} & Presupuesto CABA 2019 \\
\hline & & & & & & Promoción y Acción Social: $\$ 31.483 .443 .420$ Total \\
\hline & & & & & & \$13.793.355.514 Ministerio de Hábitat y Desarrollo \\
\hline & & & & & & Tesoro de la Ciudad: $\$ 13.213 .690 .521$ \\
\hline
\end{tabular}




\begin{tabular}{|c|c|c|c|c|c|c|}
\hline Provincia & $\begin{array}{c}\mathrm{N}^{\circ} \text { Ley Pro- } \\
\text { vincial del } \\
\text { Presupuesto } \\
\text { Anual }\end{array}$ & $\begin{array}{l}\text { Presupuesto } \\
\text { Total Provincia } \\
\text { (en \$AR) }\end{array}$ & $\begin{array}{l}\text { Presupuesto } \\
\text { Total Provincia } \\
\text { (En Us\$) }\end{array}$ & Sitio Web & $\begin{array}{l}\text { Unidad Ejecu- } \\
\text { tora de Políti- } \\
\text { cas Alimenta- } \\
\text { rias y Afines }\end{array}$ & $\begin{array}{l}\text { Valores Por Política Social/Alimentario Identificables En EI } \\
\text { Texto De Ley Y Anexos }\end{array}$ \\
\hline & & & & & \begin{tabular}{|l|} 
Familiar y Co- \\
munitario (Tar- \\
jetas y Comedo- \\
res Comunita- \\
rios). Ministerio \\
de Educación \\
(Comedores Es- \\
colares)
\end{tabular} & \\
\hline \multirow{7}{*}{ Chaco } & \multirow{7}{*}{ L2962-F } & \multirow{7}{*}{$\$ 81.963 .106 .000$} & \multirow{7}{*}{$\$ 1.301 .001 .683$} & \multirow{7}{*}{$\begin{array}{l}\text { http://haciendayfinan- } \\
\text { zas.chaco.gov.ar/uplo } \\
\text { ads/archi- } \\
\text { vos/L.2962.F\%20Pre- } \\
\text { su- } \\
\text { puesto\%202019\%20( } \\
\text { 1).pdf }\end{array}$} & \multirow{7}{*}{$\begin{array}{l}\text { Ministerio de } \\
\text { Desarrollo So- } \\
\text { cial }\end{array}$} & Presupuesto Provincial 2019. Ley 2962. Planillas Anexas. Foja 20 \\
\hline & & & & & & PNSA - Abordaje Federal: $\$ 158.000 .000$ \\
\hline & & & & & & El Hambre Más Urgente: \\
\hline & & & & & & $\$ 226.800 .000$ \\
\hline & & & & & & Plan Nacer \\
\hline & & & & & & $\$ 60.405 .000$ \\
\hline & & & & & & Instituto de Desarrollo Rural y Agricultura Familiar, \$2.000.000 \\
\hline Chubut & $\begin{array}{l}\text { Ley II - De- } \\
\text { creto I de Re- } \\
\text { conducción } \\
\text { del presu- } \\
\text { puesto } 2018\end{array}$ & $\$ 86.140 .104 .731$ & $\$ 1.367 .303 .250$ & $\begin{array}{l}\frac{\text { http://www.chu- }}{\text { but.gov.ar/portal/wp- }} \\
\text { organismos/sgp/ }\end{array}$ & $\begin{array}{l}\text { Ministerio de } \\
\text { Familia y Pro- } \\
\text { moción Social }\end{array}$ & $\begin{array}{l}\text { Prestaciones de la Seguridad Social, III trimestre, Devengado: } \\
\text { 191.400.521. Presupuesto inicial: } \$ 11.590 .633 .733\end{array}$ \\
\hline Córdoba & L10.592 & $\$ 221.003 .530 .000$ & $\$ 3.507 .992 .540$ & $\frac{\frac{\text { https://www.cba.gov.a }}{\text { r/proyecto-presu- }}}{\frac{\text { puesto-provincial-ano- }}{\underline{2019 /}}}$ & $\begin{array}{l}\text { Ministerio de } \\
\text { Desarrollo So- } \\
\text { cial }\end{array}$ & $\begin{array}{l}\text { Presupuesto Provincial 2019. Presupuesto por Programas. } \\
\text { Programa: } 213 \text { (P.A.I.COR.) PROGRAMA ASISTENCIA INTEGRAL } \\
\text { CÓRDOBA. Total } \$ 4.018 .685 .000 \text {. Principales rubros. Alimentos } \\
\text { para personas: } 247.760 .000 \text {. Transferencias Municipios y Entes } \\
\text { Comunales: } 787.000 .000 \text {. Programa: } 682 \text { PROGRAMAS } \\
\text { SOCIALES FINANCIADOS CON RECURSOS NACIONALES. Mi- } \\
\text { nisterio De Desarrollo Social. SubProg.: } 1 \text { Plan Nacional De Seguri- } \\
\text { dad Alimentaria: } 124.200 .000\end{array}$ \\
\hline Corrientes & L6492 & $\$ 68.477 .522 .172$ & $\$ 1.086 .944 .796$ & $\begin{array}{l}\text { http://www.cgpcorrien- } \\
\text { tes.gov.ar/lis- } \\
\text { tas.php?r=4\&s=1\&t=1 } \\
\end{array}$ & $\begin{array}{l}\text { Instituto de Pre- } \\
\text { visión Social y } \\
\text { Ministerio de } \\
\text { Hacienda }\end{array}$ & $\begin{array}{l}\text { Presupuesto Provincial 2019. Ley 6492. Sin planillas o cuadros ana- } \\
\text { líticos. Artículo 26: Instituto de Previsión Social } \$ 14.196 .276 .416\end{array}$ \\
\hline Entre Ríos & L10.660 & $\$ 129.343 .647 .000$ & $\$ 2.053 .073 .762$ & $\begin{array}{l}\frac{\text { https://www.entre- }}{\text { rios.gov.ar/presu- }} \\
\text { puesto/leypres/2019/ }\end{array}$ & $\begin{array}{l}\text { Ministerio de } \\
\text { Desarrollo So- } \\
\text { cial }\end{array}$ & $\begin{array}{l}\text { Presupuesto Provincial 2019. Anexo art. } 1 \text { de la Ley. Tesoro Provin- } \\
\text { cial: Promoción y Asistencia Social } 2.368 .898 .000 \text {. Seguridad So- } \\
\text { cial. 8.184.600.000. Presupuesto del Ministerio de Desarrollo Social: } \\
2.468 .571 .000 \text {. Las planillas analíticas no desglosan por programa. }\end{array}$ \\
\hline
\end{tabular}




\begin{tabular}{|c|c|c|c|c|c|c|}
\hline Provincia & $\begin{array}{l}\mathrm{N}^{\circ} \text { Ley Pro- } \\
\text { vincial del } \\
\text { Presupuesto } \\
\text { Anual }\end{array}$ & $\begin{array}{l}\text { Presupuesto } \\
\text { Total Provincia } \\
\quad \text { (en \$AR) }\end{array}$ & $\begin{array}{l}\text { Presupuesto } \\
\text { Total Provincia } \\
\text { (En Us\$) }\end{array}$ & Sitio Web & $\begin{array}{l}\text { Unidad Ejecu- } \\
\text { tora de Políti- } \\
\text { cas Alimenta- } \\
\text { rias y Afines }\end{array}$ & $\begin{array}{l}\text { Valores Por Política Social/Alimentario Identificables En EI } \\
\text { Texto De Ley Y Anexos }\end{array}$ \\
\hline Formosa & L1486 & $\$ 1.566 .665 .764$ & $\$ 24.867 .711$ & $\begin{array}{l}\frac{\text { https://www.for- }}{\text { mosa.gob.ar/hacien- }} \\
\text { dayfinanzas/presu- } \\
\text { puesto/2019 }\end{array}$ & \begin{tabular}{|l|} 
Ministerio de \\
Desarrollo So- \\
cial. Instituto de \\
Previsión Social
\end{tabular} & $\begin{array}{l}\text { Prestaciones de la Seguridad Social, III trimestre, Pagado. Transfe- } \\
\text { rencias corrientes } \$ 2.788 .485 .368 \text {. Prestaciones de Seguridad So- } \\
\text { cial: } \$ 8.847 .483 .163 \text {. El Ministerio de Hacienda no publica el presu- } \\
\text { puesto inicial. Las planillas analíticas no desglosan por programa. }\end{array}$ \\
\hline Jujuy & L6113 & $\$ 11.235 .411 .082$ & $\$ 178.339 .858$ & $\begin{array}{l}\text { http://hacienda.ju- } \\
\text { uy.gob.ar/presu- } \\
\text { puesto-2019/\# }\end{array}$ & \begin{tabular}{|l|} 
Ministerio de \\
Desarrollo So- \\
cial
\end{tabular} & $\begin{array}{l}\text { Presupuesto Provincial 2019. Planilla Analítica. Promoción y Asis- } \\
\text { tencia Social } \$ 1,069,838,205 \text {. Seguridad Social } 277,557,450 \text {. Las } \\
\text { planillas analíticas no desglosan por programa. }\end{array}$ \\
\hline La Pampa & L3144 & $\$ 42.105 .870 .292$ & $\$ 668.347 .147$ & $\begin{array}{l}\text { https://www.la- } \\
\text { pampa.gob.ar/ima- } \\
\text { ges/Archivos/Nor- } \\
\text { mas/Ley de Presu- } \\
\text { puesto/Presu- } \\
\text { puesto 2019.pdf }\end{array}$ & $\begin{array}{l}\text { Ministerio de } \\
\text { Desarrollo So- } \\
\text { cial }\end{array}$ & $\begin{array}{l}\text { Concepto 7. Plan Nacional de Seguridad Alimentaria } \$ 23.543 .676 . \\
\text { SECRETARIA DESARROLLO SOCIAL - Programa Nacer-Sumar } \\
\text { 23.221.170 (RECURSOS NACIONALES). Ministerio de Desarrollo } \\
\text { Social: } \$ 1.211 .650 .346 \text {. Comer en familia y Pilquen: } 540.125 \text {. Sub- } \\
\text { secretaría de Desarrollo Territorial, Asistencia Alimentaria: } \\
\text { 174.194.222 }\end{array}$ \\
\hline La Rioja & L10.148 & $\$ 37.802 .165 .894$ & $\$ 600.034 .379$ & $\begin{array}{l}\frac{\text { https://la- }}{\text { rioja.gob.ar/institucio- }} \\
\frac{\text { nal/transparencia fis- }}{\text { cal.php }}\end{array}$ & $\begin{array}{l}\text { Ministerio de } \\
\text { Desarrollo So- } \\
\text { cial, Instituto de } \\
\text { Seguridad So- } \\
\text { cial y Organis- } \\
\text { mos Descentra- } \\
\text { lizados }\end{array}$ & $\begin{array}{l}\text { Presupuesto 2019. Servicios Sociales } \$ 17.912 \text { millones. Instituto de } \\
\text { Seguridad Social, } \$ 2.020 \text { millones, } \$ 15.057 \text { millones Administración } \\
\text { Central. Saldo en Organismos Descentralizados. Ejecución Presu- } \\
\text { puestaria, acumulado a septiembre } 2019 \text {, devengado: seguridad so- } \\
\text { cial } \$ 59 \text { millones. Promoción y Asistencia Social (Transferencias) } \\
\$ 996 \text { millones. Transferencias "Relaciones Interiores" } \$ 5.146 \text { millo- } \\
\text { nes. Sin analítico programático. }\end{array}$ \\
\hline Mendoza & L9122 & $\$ 141.532 .424 .828$ & $\$ 2.246 .546 .426$ & $\begin{array}{l}\frac{\text { http://www.ha- }}{\text { cienda.men- }} \\
\frac{\text { doza.gov.ar/presu- }}{\text { puesto-2019/ }}\end{array}$ & \begin{tabular}{|l|} 
\\
Ministerio de \\
Salud, Desarro- \\
Ilo Social y De- \\
portes
\end{tabular} & $\begin{array}{l}\text { Presupuesto 2019. Jurisdicción, Ministerio de Desarrollo Social: } \\
\$ 23.701 .374 .769 \text {. Transferencias y erogaciones corrientes: } \\
\$ 185.751 .446 \text {. Apertura: Programa Social Nutricional (PRO.SO.NU) } \\
\$ 4.000 .000 \text {. Programa Alimentario Infantil: \$29.700.000. } \\
\text { PROGRAMA DERECHO ALIMENTARIO Y NUTRI FAMIL: } \\
\$ 29.700 .000 \text {. PO.SO.CO-POLÍTICAS SOCIALES COMUNITARIAS: } \\
\$ 1.445 .362 \text {. DIRECCIÓN DE CONTINGENCIA (incluye transferen- } \\
\text { cias): \$312.946.172. En el Presupuesto por Programas gráfico el } \\
\text { total de los tres programas como "Grupos Vulnerables por emergen- } \\
\text { cia socioeconómica" \$348.091.534. }\end{array}$ \\
\hline Misiones & LEY VII N 86 & $\$ 68.629 .802 .000$ & $\$ 1.089 .361 .937$ & 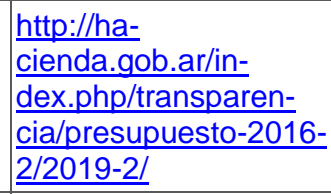 & $\begin{array}{l}\text { Ministerio de } \\
\text { Desarrollo So- } \\
\text { cial }\end{array}$ & $\begin{array}{l}\text { BIENESTAR SOCIAL: } \$ 8.831 .616 .000 \text {. Asistencia Social: } \\
\text { 689.338.000. BIENESTAR SOCIAL - VARIOS } \$ 1.876 .363 .000 \text {. } \\
\text { VIVIENDA Y URBANISMO: 4.891.304.000. Incluye al Plan Nacional } \\
\text { de Seguridad Alimentaria } \$ 92 \text { millones. Ejecución 2Trimestre, Pro- } \\
\text { moción y Asistencia Social: } 784.778 .000\end{array}$ \\
\hline Neuquén & L3169 & $\$ 81.781 .567 .775$ & $\$ 1.298 .120 .123$ & $\begin{array}{l}\text { https://www.legislatu- } \\
\text { raneu- } \\
\text { quen.gob.ar/SVRFILE }\end{array}$ & $\begin{array}{l}\text { Ministerio de } \\
\text { Trabajo, Desa- } \\
\text { rrollo Social y }\end{array}$ & $\begin{array}{l}\text { SERVICIOS SOCIALES: } \$ 50.720 .907 .428 \text {. Promoción y Asistencia } \\
\text { Social: } \$ 3.523 .356 .055 \text {. Plan Provincial De Seguridad Alimentaria: }\end{array}$ \\
\hline
\end{tabular}




\begin{tabular}{|c|c|c|c|c|c|c|}
\hline Provincia & $\begin{array}{l}\mathrm{N}^{\circ} \text { Ley Pro- } \\
\text { vincial del } \\
\text { Presupuesto } \\
\text { Anual }\end{array}$ & $\begin{array}{l}\text { Presupuesto } \\
\text { Total Provincia } \\
\text { (en \$AR) }\end{array}$ & $\begin{array}{l}\text { Presupuesto } \\
\text { Total Provincia } \\
\text { (En Us\$) }\end{array}$ & Sitio Web & $\begin{array}{l}\text { Unidad Ejecu- } \\
\text { tora de Políti- } \\
\text { cas Alimenta- } \\
\text { rias y Afines }\end{array}$ & $\begin{array}{l}\text { Valores Por Política Social/Alimentario Identificables En El } \\
\text { Texto De Ley Y Anexos }\end{array}$ \\
\hline & & & & $\begin{array}{l}\text { S/hln/documen- } \\
\text { tos/VerTa- } \\
\frac{\text { qui/XLVII/ApendiceRe }}{\text { union24/Pro- }} \\
\text { yecto12272.pdf }\end{array}$ & $\begin{array}{l}\text { de Familia. } \\
\text { SUBSECRETA } \\
\text { RÍA DE } \\
\text { DESARROLLO } \\
\text { SOCIAL Y } \\
\text { FAMILIA }\end{array}$ & $\begin{array}{l}\text { \$114.416.775. PLAN PROVINCIAL DE ASISTENCIA } \\
\text { COMUNITARIA: } 112.114 .686\end{array}$ \\
\hline Rio Negro & L5334 & $\$ 71.816 .237 .517$ & $\$ 1.139 .940 .278$ & $\begin{array}{l}\text { https://www.rione- } \\
\text { gro.gov.ar/?con- } \\
\underline{\mathrm{tID}=8101}\end{array}$ & $\begin{array}{l}\text { Ministerio de } \\
\text { Desarrollo So- } \\
\text { cial. }\end{array}$ & $\begin{array}{l}\text { SERVICIOS SOCIALES: } \$ 34,739,735,904 \text {. Ministerio de Desarrollo } \\
\text { Social: } \$ 957,601,955 \text {. Transferencias del MDS: } \$ 186,464,000 \text {. EI } \\
\text { PPSA es el programa 15, ASISTENCIA A POBLACION CON } \\
\text { VULNERABILIDAD ALIMENTARIA. No se muestran valores o me- } \\
\text { tas físicas en el detalle. }\end{array}$ \\
\hline Salta & L8127 & $\$ 76.487 .867 .165$ & $\$ 1.214 .093 .130$ & $\begin{array}{l}\frac{\text { http://presu- }}{\text { puesto.salta.gov.ar/Le }} \\
\text { yes/Textos.htm }\end{array}$ & $\begin{array}{l}\text { Ministerio de } \\
\text { Educación, } \\
\text { Ciencia y Tec- } \\
\text { nología (partida } \\
\text { Política Alimen- } \\
\text { taria). Ministerio } \\
\text { de la Primera } \\
\text { Infancia }\end{array}$ & $\begin{array}{l}\text { Ministerio de la Primera Infancia } \$ 420.005 .826 \text {. Cód S1407, } \\
\text { Transferencias por Políticas Alimentarias. Ministerio de Educación, } \\
\text { Ciencia y Tecnología. 44.877.664. No se presenta información por } \\
\text { programas. }\end{array}$ \\
\hline San Juan & L1869-I & $\$ 65.163 .860 .000$ & $\$ 1.034 .346 .984$ & $\frac{\text { https://minha- }}{\text { cienda.san- }}$ & $\begin{array}{l}\text { Ministerio de } \\
\text { Desarrollo Hu- } \\
\text { mano y Promo- } \\
\text { ción Social }\end{array}$ & $\begin{array}{l}\text { PROMOCIÓN Y ASISTENCIA SOCIAL: } 2.610 .518 .000 . \\
\text { MINISTERIO DE DESARROLLO HUMANO Y PROMOCIÓN } \\
\text { SOCIAL: \$ 2.086.371.000 }\end{array}$ \\
\hline San Luis & $\begin{array}{c}\text { No se publicó } \\
\text { Ley } 2019\end{array}$ & $\$ 39.102 .620 .285$ & $\$ 620.676 .512$ & $\begin{array}{l}\text { https://www.minha- } \\
\text { cienda.gob.ar/dnap/ej } \\
\text { ecuciones.html }\end{array}$ & $\begin{array}{l}\text { SIN } \\
\text { INFORMACIÓN } \\
\text { 2019. FALTA } \\
\text { PUBLICACIÓN } \\
\text { DE LA LEY }\end{array}$ & $\begin{array}{l}\text { No se publica la Ley de Presupuesto en sitios del Ministerio de Ha- } \\
\text { cienda. DATOS EN MEDIOS DE PRENSA Y EN OFICINA } \\
\text { NACIONAL DE PRESUPUESTO, DIFIEREN. Ver: http://agencia- } \\
\text { sanluis.com/notas/2018/10/02/zabala-chacur-el-presupuesto-provin- } \\
\text { cial-es-real-y-mas-prolijo-que-el-presentado-por-el-gobierno-nacio- } \\
\text { nal/ La oficina nacional de presupuesto, solo cuenta con el valor } \\
\text { 2018. https://www.minhacienda.gob.ar/dnap/ejecuciones.html }\end{array}$ \\
\hline Santa Cruz & L3633 & $\$ 58.045 .226 .364$ & $\$ 921.352 .799$ & $\begin{array}{l}\text { https://www.santa- } \\
\text { cruz.gob.ar/nuestros- } \\
\text { numeros/presupues- } \\
\text { tos/\#prettyPhoto/4/ }\end{array}$ & $\begin{array}{l}\text { Ministerio de } \\
\text { Desarrollo So- } \\
\text { cial. }\end{array}$ & $\begin{array}{l}\text { Ministerio de Desarrollo Social: } \$ 583.126 .768 \text {. Planilla Anexa } N^{\circ} 17 \text {. } \\
\text { Comedores escolares, copa de leche: } \$ 96.000 .000 \text {. Comedores es- } \\
\text { colares, plan nacional: } \$ 446,778 \text {. Plan Nacional, Tarjeta: } \\
\$ 27.629 .320\end{array}$ \\
\hline Santa Fe & L13.871 & $\$ 277.182 .629 .000$ & $\$ 4.399 .724 .270$ & $\begin{array}{l}\text { https://www.san- } \\
\text { tafe.gob.ar/norma- } \\
\text { tiva/get- } \\
\text { File.php?id }=1347920 \\
\end{array}$ & $\begin{array}{l}\text { Ministerio de } \\
\text { Desarrollo So- } \\
\text { cial. Ministerio }\end{array}$ & $\begin{array}{l}\text { ORIGEN PROVINCIAL: } \$ 129.082 .280 .000 \text {. INCLUYE LAS } \\
\text { TRANSFERENCIAS POR MUNICIPIO. Ministerio de Desarrollo So- } \\
\text { cial: } \$ 3.902 .891 .000 \text {. Servicios Sociales del MDS: } \$ 2.565 .639 .000 . \\
\text { Recursos del Tesoro Provincial MDS: } \$ 3.610 .878 .000 \text {. Anexo por }\end{array}$ \\
\hline
\end{tabular}




\begin{tabular}{|c|c|c|c|c|c|c|}
\hline Provincia & $\begin{array}{l}N^{\circ} \text { Ley Pro- } \\
\text { vincial del } \\
\text { Presupuesto } \\
\text { Anual }\end{array}$ & $\begin{array}{l}\text { Presupuesto } \\
\text { Total Provincia } \\
\text { (en \$AR) }\end{array}$ & $\begin{array}{l}\text { Presupuesto } \\
\text { Total Provincia } \\
\text { (En Us\$) }\end{array}$ & Sitio Web & $\begin{array}{l}\text { Unidad Ejecu- } \\
\text { tora de Políti- } \\
\text { cas Alimenta- } \\
\text { rias y Afines }\end{array}$ & $\begin{array}{l}\text { Valores Por Política Social/Alimentario Identificables En EI } \\
\text { Texto De Ley Y Anexos }\end{array}$ \\
\hline & & & & $\frac{\frac{\& i t e m=189699 \& \operatorname{cod}=f}{85 f 23 b 4 b 50094 c 687 b}}{\underline{6 b a 2 d 5756926 a}}$ & $\begin{array}{l}\text { de Salud (Agen- } \\
\text { cia Santafecina } \\
\text { de Seguridad } \\
\text { Alimentaria. Or- } \\
\text { ganismo Des- } \\
\text { centralizado) }\end{array}$ & $\begin{array}{l}\text { programas: Secretaría de Políticas Sociales: } \$ 1.354 .994 .000 \text {. Anexo } \\
\text { III. Ministerio de Salud. Agencia Santafesina de Seguridad Alimenta- } \\
\text { ria. } \$ 112.282 .000 \text { (organismos descentralizados) }\end{array}$ \\
\hline $\begin{array}{l}\text { Santiago del } \\
\text { Estero }\end{array}$ & L7272 & $\$ 59.373 .650 .242$ & $\$ 942.438 .893$ & $\begin{array}{l}\frac{\text { http://me- }}{\text { conse.gov.ar/presu- }} \\
\text { puesto-2019/ }\end{array}$ & \begin{tabular}{|l|} 
Ministerio de \\
Desarrollo So- \\
cial, Promoción \\
Humana y RRII \\
con la Comuni- \\
dad
\end{tabular} & MDS-PH-RRII/COM: $\$ 74.965 .607$ \\
\hline $\begin{array}{l}\text { Tierra del } \\
\text { Fuego }\end{array}$ & $\begin{array}{l}\text { Presupuesto } \\
\text { Reconducido } \\
\text { Decreto } 21 / 19\end{array}$ & $\$ 39.662 .198 .452$ & $\$ 629.558 .706$ & $\begin{array}{l}\frac{\text { https://economia.tie- }}{\text { rradel- }} \\
\text { fuego.gob.ar/presu- } \\
\text { puesto-2019-2/ }\end{array}$ & $\begin{array}{l}\text { Ministerio de } \\
\text { Desarrollo So- } \\
\text { cial }\end{array}$ & $\begin{array}{l}\text { Ministerio de Desarrollo Social, Transferencias de la Administración } \\
\text { Central Nacional: } 2.548 .800 \text {. Resolución } 23 \text { y } 59 \text { posteriores y sin } \\
\text { más detalles. No hay desglose por Jurisdicción o Programas. }\end{array}$ \\
\hline Tucumán & L9138 & $\$ 96.362 .819 .900$ & $\$ 1.529 .568 .570$ & \begin{tabular}{|l|} 
http://www.mecon- \\
tuc.gov.ar/presu- \\
puesto/archivos va- \\
rios/carga 2019/Ley \\
$\begin{array}{l}\text { i138 PG \%202019.p } \\
\text { df }\end{array}$ \\
\end{tabular} & $\begin{array}{l}\text { Ministerio de } \\
\text { Desarrollo So- } \\
\text { cial }\end{array}$ & No hay desglose por Jurisdicción o Programas. \\
\hline TOTAL & & $\$ 3.061 .121 .744 .504$ & $\$ 48.589 .234 .040$ & & & \\
\hline
\end{tabular}

Fuente: Elaboración propia en base a sitios oficiales provinciales de Ministerios de Hacienda y Legislaturas. 


\title{
CAPITULO V. SITUACIÓN SOCIOECONÓMICA Y ALIMENTARIA Y POLÍTICAS PÚBLICAS EN CONTEXTO DE PANDEMIIA COVID-19 EN LA ARGENTINA
}

\author{
Agustín Salvia y Sergio Britos ${ }^{57}$
}

En los capítulos anteriores se analizaron aspectos críticos de la situación alimentaria y de la pobreza en la Argentina, así como una serie de políticas orientadas a abordar estas cuestiones hasta antes de la llegada al país del COVID-19. En este capítulo se continúa este análisis examinando los principales efectos socioeconómicos provocados por las políticas sanitarias y las medidas adoptadas por el nuevo gobierno, especialmente aquellas destinadas a paliar sus consecuencias regresivas en materia de pobreza e inseguridad alimentaria y nutricional.

La crisis social generada por el COVID-19 ha requerido una actualización de los análisis realizados en los capítulos anteriores, realizados durante los primeros meses del año, en los momentos previos a la aparición del virus en la Argentina. Para tal efecto se ha compilado la mayor cantidad posible de información disponible hasta la fecha con el fin de evaluar el impacto que ha tenido el nuevo escenario socioeconómico sobre la seguridad alimentaria y nutricional de la población, así como las principales medidas adoptadas para atender las nuevas realidades que impone la pandemia. ${ }^{58}$

En función de este objetivo, el documento ofrece una primera parte en donde se realiza una actualización de datos sobre nivel de actividad, empleo, consumo, pobreza, (in)seguridad alimentaria y malnutrición durante el primer semestre del presente año. En este marco, se incluyen dos apartados en donde se presentan los principales resultados de estudios recientes. El primero de ellos, realizado por el Observatorio de la Deuda Social de la Universidad Católica Argentina (ODSA-UCA), examina de manera diacrónica el efecto de la crisis sobre la inseguridad alimentaria en un panel de hogares residentes en el Área Metropolitana de Buenos Aires, así como el impacto de los programas sociales y las medidas de alivio adoptadas. El segundo de ellos, elaborado por el CEPEA, aporta datos sobre el consumo de alimentos en el contexto del COVID-19. El objetivo de este estudio fue la caracterización de la frecuencia de consumo de grupos de alimentos característicos del patrón alimentario local.

En la segunda parte del documento, se describe el alcance social y el impacto fiscal de las diferentes políticas de protección social reforzadas y/o introducidas por el actual gobierno en el contexto de la política de aislamiento social, preventivo y obligatorio (ASPO), en procura de aliviar la caída del consumo, el empleo y los ingresos de los sectores más pobres (refuerzos y ampliación a los programas existentes). Entre los nuevos programas introducidos destacan el Ingreso Familiar de Emergencia (IFE) y el Programa de Asistencia al Trabajo y la Producción (ATP). De manera particular, se detallan los cambios que han experimentado el Plan Argentina Contra el Hambre (PACH), la política de asistencia alimentaria a comedores escolares y comedores comunitarios, los programas sobre malnutrición, espe-

\footnotetext{
${ }^{57}$ Los autores agradecen la colaboración del Dr. Santiago Poy Piñeiro, el Lic. Enzo Rave, la Lic. Ayelén Borg y la pasante de investigación Cristina Mirabelli para la elaboración del presente capítulo.

${ }^{58}$ La mayor parte corresponde a datos hasta junio, aunque en algunos casos se ha podido incluir información posterior. Los autores reconocen que la situación es cambiante y con muchas incertidumbres, pero consideramos útil poder consolidar la información existente hasta el momento de escribir este capítulo.
} 
cialmente relacionados con la obesidad y el sobrepeso, y otros programas vinculados con la producción de alimentos con pequeños productores. Hasta donde existe información disponible, se incluye un análisis sobre las medidas adoptas en cadenas productivas específicas de manera de asegurar el funcionamiento y abastecimiento seguro de alimentos. Se incluye también información sobre dos iniciativas desarrolladas por la sociedad civil en materia de asistencia alimentaria y nutricional.

Por último, el documento cierra con una reflexión sobre las acciones adoptadas, la necesidad de articulación en su diseño e implementación para evitar la descoordinación que parece existir, así como algunas reflexiones sobre qué cabría hacer y/o cómo tendrían que ajustarse los programas existentes para el período posterior a la pandemia.

\section{BALANCE SOCIO ECONÓMICO Y ALIMENTARIO DE LA CRISIS SANITARIA EN CONTEXTO DE ASPO-COVID-19.}

El avance del COVID-19 ha obligado a la Argentina a emprender políticas preventivas de aislamiento social, preventivo y obligatorio (ASPO), con efectos regresivos -como en gran parte del mundo- en materia socioeconómica todavía impredecibles para el mediano y largo plazo. ${ }^{59}$ Pero en el caso argentino, los efectos de esta pandemia y de las medidas sanitarias adoptadas tuvieron lugar bajo un particular escenario previo de estanflación, crisis de deuda y parálisis económica estructural. La situación social ya era crítica ya a finales de 2019 (ver Capítulos I y II); ahora el panorama es todavía más grave, y nada indica que las cosas mejoren en los próximos meses.

Las primeras estimaciones señalan que el escenario de pandemia profundizará la recesión en la que ya está sumida la economía argentina. Contra una caída esperada del 1,5\% del PIB para este año, se estima actualmente una caída entre 8-10\% según la Organización para la Cooperación y el Desarrollo Económicos (OCDE). Las diversas estimaciones coinciden en que la contracción será profunda, debido a los efectos globales y domésticos del brote del COVID-19. El cierre de actividad socava la oferta agregada, mientras que la demanda se ve afectada por un mayor desempleo, menores ingresos y una creciente incertidumbre, lo que impulsa una disminución del consumo privado. La inversión también se ve afectada por la volatilidad financiera y una perspectiva económica incierta, por lo que la economía queda atrapada en un círculo vicioso de disminución del consumo y menor empleo e ingresos.

En relación al empleo, en el cuarto trimestre de 2019, el desempleo fue según el INDEC de 8,9\% y el subempleo de 13,1\%. De acuerdo con las proyecciones de la OIT realizadas sobre la base de distintos escenarios, bajo una caída del PIB del 8,25\%, se perderían entre 750.000 y 850.500 empleos en 2020. Para el Observatorio de la Deuda Social de la Universidad Católica Argentina (UCA), durante el segundo trimestre del año se habrían perdido 300 mil empleos formales y más de 650 mil informales. En cuanto a la situación de la pobreza, según datos oficiales del INDEC correspondientes al $4^{\circ}$ trimestre de 2019 , la tasa de indigencia urbana ya afectaba al 8,7\% de la población y el porcentaje de personas

\footnotetext{
${ }^{59}$ La Organización de las Naciones Unidas, a través de su Programa de Naciones Unidas para el Desarrollo (PNUD) cataloga la nueva situación como una "crisis sistémica del desarrollo humano" (PNUD, 2020). El nuevo escenario saca a la luz los déficits persistentes de protección social en numerosos países que, como los latinoamericanos, registran una informalidad muy extendida (OIT, 2020). A la vez, pone de relieve inequidades socioculturales menos evidentes: las medidas de aislamiento reestructuran las tareas y los tiempos de cuidados en las familias -con consecuencias sobre las desigualdades de género y generación-, potencia las desigualdades de acceso a recursos tecnológicos y amplifica las brechas digitales preexistentes. En síntesis, la pandemia pone en crisis las distintas dimensiones de la reproducción social.
} 
por debajo de la línea de pobreza era de 38,4\%. Según estimaciones del Observatorio de la Deuda Social, la pobreza en Argentina -con base en datos del INDEC- habría llegado al $45 \%$ en el segundo trimestre de 2020, mientras que la indigencia habría llegado al 12\%. Para esta fuente, el año pasado la pobreza alcanzó al 38\% del total de la población, lo cual representaría 17 millones de habitantes. En este marco, también para esta fuente, la inseguridad alimentaria severa habría pasado de 7,5\% a 14\% (ODSA-UCA, 2020b). Esto incluso, a pesar de las importantes medidas de asistencia social y alimentaria que puso en marcha el gobierno.

Al respecto, cabe tener en cuenta que antes de la crisis sanitaria COVID-19, el 33\% de los hogares de la Argentina percibía una asistencia monetaria directa a cargo del Estado, sin contar las prestaciones de la seguridad social formal (ver Capítulo II). Se calcula que en mayo de 2020 esta proporción podría haber alcanzado al 45\% de los hogares del país. Sin duda, el conjunto de medidas adoptadas fue importante pero no suficiente para evitar la propagación de la crisis social. Es cierto también que el contexto económico argentino pre-COVID-19, degradado por la estanflación, la crisis de deuda y la caída de reservas, no constituía un escenario favorable para emprender programas de mayor alcance.

De esta manera, el nuevo escenario, lejos de abrir una nueva normalidad social, multiplica los dramas estructurales que viene atravesando el sistema social argentino. La medida de aislamiento se ha fundado en supuestos sobre la velocidad e intensidad de la pandemia y de su letalidad, así como de sus eventuales impactos económicos y sociales. Al igual que cualquier otra decisión de política pública, les corresponde a las ciencias sociales preguntarse sobre la pertinencia de las medidas, los alcances e impactos de estas, los costos presentes y futuros de las decisiones adoptadas. Esta tarea tiene como finalidad, no la crítica en un contexto de comprensible incertidumbre, sino contribuir a mejorar los diagnósticos y las políticas que permitan organizar tanto el presente como el futuro de nuestra sociedad, así como también a extraer enseñanzas de más largo aliento de esta crisis pandémica.

\subsection{EMERGENCIA SOCIOECONÓMICA EN CONTEXTO DE ASPO-COVID-19: ALGUNAS CLAVES PARA SU EVALUACIÓN.}

La expansión global de la enfermedad del coronavirus (COVID-19) a partir de diciembre de 2019 instaló una crisis social y económica de consecuencias aún imprevisibles. En la Argentina, distintos organismos pronostican un severo impacto de la pandemia sobre la actividad económica; pero ello, tal como se ha mencionado, en un contexto de fuerte y creciente deterioro previo vinculado a una década de estancamiento, inflación, inestabilidad financiera y crisis de deuda, con efectos sobre la pobreza y la calidad de vida de la población. ${ }^{60}$

En este marco, el primer trimestre de 2020 será recordado como uno de los más críticos de la historia económica argentina. El momento más dramático parece haber sido abril-mayo, con caídas sin precedentes en una multiplicidad de países. En la Argentina, la actividad económica cayó 26,4\% interanual, es decir, muy por encima del peor momento de la crisis de 2001-2002 (cuando llegó a 16,7\%). Sin embargo, desde que comenzó el aislamiento social, preventivo y obligatorio (ASPO), el 20 de marzo, el país se ha movido a dos velocidades. Por un lado, las zonas que hoy continúan en emergencia sanitaria debido a sus mayores contagios (el Área Metropolitana de Buenos Aires es la más destacada en este sentido, por su peso demográfico y económico) fueron las más afectadas tanto a fines de marzo y

\footnotetext{
${ }^{60}$ Según datos oficiales del INDEC correspondientes al $4^{\circ}$ trimestre de 2019, la tasa de indigencia urbana afecta al 8,7\% de la población urbana, y el porcentaje de personas por debajo de la línea de pobreza alcanzaba al 38,4\%. En ese marco, según el Observatorio de la Deuda Social Argentina (ODSA-UCA, 2020a), para el mismo período, el 7,4\% de los hogares urbanos $(9,2 \%$ de la población) experimentaban inseguridad alimentaria severa, al mismo tiempo que la inseguridad alimentaria total habría alcanzado al $18,6 \%$ de los hogares ( $23,5 \%$ de la población).
} 
mediados de abril -cuando regía la cuarentena estricta a nivel nacional-como desde entonces. Por otro lado, las zonas que han pasado intermitentemente al distanciamiento social, preventivo y obligatorio (DISPO) -por haber registrado menores contagios- el impacto de la crisis es menor. Sin embargo, el balance es en cualquier caso altamente regresivo, tanto en lo económico como en lo socio-alimentario.

Al respecto, todas las proyecciones muestran caídas importantes en todos los indicadores socioeconómicos. El Relevamiento de Expectativas de Mercado del Banco Central de la República Argentina (BCRA) proyecta una caída de 9,5\% (BCRA, 2020a); la Organización para la Cooperación y el Desarrollo Económico (OCDE) ha pronosticado una reducción del PBI de 8,3\% y el FMI del 9,9\%. De materializarse una caída de 9,5\% en el PBI, el PBI per cápita sería 16,2\% menor que en 2017. Algunos especialistas proyectan una caída del PBI superior al 9\% (ver Cuadro 1). ${ }^{61}$

\section{Cuadro 1: Argentina Escenarios ex Ante - Durante Covid-19: Proyecciones de Indicado- res Socioeconómicos para una cuarentena de seis meses*}

\begin{tabular}{|l|r|r|}
\hline & $\begin{array}{c}\text { 2020-Pre } \\
\text { COVID19 }\end{array}$ & $\begin{array}{c}\text { 2020 - COVID-19 } \\
\text { dic. 2020 }\end{array}$ \\
\hline PBI (1) & $-1,6 \%$ & $-9,5 \%$ \\
\hline Consumo Privado (1) & $-0,3 \%$ & $-10,0 \%$ \\
\hline Tipo De Cambio (1) & 78,0 & 91,5 \\
\hline Brecha Cambiaria (1) & $-50 \%$ & $50-100 \%$ \\
\hline Empleo Registrado (2) & $-1,2 \%$ & $-2,5 \%$ \\
\hline Empleo Total (2) & $-1,5 \%$ & $-6.5 \%$ \\
\hline Pobreza EPH-INDEC (2) & $35-38 \%$ & $44-47 \%$ \\
\hline Pobreza ODSA-UCA (2) & $38-40 \%$ & $47-49 \%$ \\
\hline
\end{tabular}

Fuente: Observatorio de la Deuda Social Argentina. Informe Especial, septiembre 2020.

Según el último informe del EMAE (INDEC, 2020a), todos los sectores de actividad presentaron una caída interanual, pero entre las que presentaron mayor retracción se destacan la Construcción ($86,4 \%)$, Hoteles y restaurantes (-85,6\%) y Otras Actividades y Servicios Comunitarios (72,1\%). Por otra parte, los que más incidieron en la retracción del nivel general de la actividad fueron la Industria manufacturera $(-34,4 \%)$ y Comercio (-27,0\%). De acuerdo con la Unión Industrial Argentina, el $75 \%$ de las empresas presenta una disminución en su nivel de ventas, y por ello, el $40 \%$ de estas y el $51 \%$ de las empresas de consumo masivo, considera que será necesario reducir su cantidad de empleados. Al mismo tiempo que la Confederación Argentina de la Mediana Empresa (CAME) ha informado que la producción de las Pymes industriales cayó 34,9\% en mayo 2020 frente a igual mes del año anterior y que en los primeros cinco meses de 2020 se acumula una baja de 23,6\%. En el mes de mayo de 2020, si se considera solo a los rubros definidos como no esenciales en la cuarentena, esta disminución fue

\footnotetext{
${ }^{61}$ La consultora Ecolatina (2020) había proyectado, con anterioridad a la irrupción de la COVID-19, una evolución del PBI de -1,3\%. El recalculo de esta evolución, en función del tiempo de cuarentena y del resultado de la negociación de la deuda del Estado con acreedores privados, generó dos escenarios: el optimista ubica a la evolución del PBI en $-9,5 \%$ y el pesimista en $-13,5 \%$. Estas proyecciones son coherentes con la fuerte caída interanual registrada por el nivel de actividad económica que, según el Estimador Mensual de Actividad Económica (EMAE) reportó el INDEC (2020a) en los meses de marzo $(-11,5 \%)$ y abril $(-26,4 \%)$.
} 
del $45,8 \%$. Esto se da con el uso de capacidad instalada de solo el $47,4 \%$ y logrando rentabilidad positiva solamente el 15,3\% de las empresas (CAME, 2020). ${ }^{62}$

En un mercado de trabajo que ya experimentaba estancamiento, caída del empleo y precarización creciente, la tasa de desocupación fue en 2017 de 8,4\%, subiendo a 9,8\% en 2019, en ambos casos con tasas de informalidad laboral superiores al 35\% de los asalariados y del $66 \%$ de los trabajadores no asalariados. Según el INDEC, para el primer trimestre del año 2020 el desempleo abierto ya afectaba al 10,4\% de la PEA. Según información del Ministerio de Trabajo, el número de trabajadores registrados se redujo 1,2\% en el primer trimestre de 2020 frente al mismo período de 2019 y 2,8\% en comparación con 2018. Estas cifras resultan de una destrucción de empleo asalariado privado registrado ($2,9 \%$ y $-4,9 \%$, respectivamente), sólo parcialmente compensado por puestos no asalariados o en casas particulares. También se retrajo el número de trabajadores independientes registrados (con monotributo o autónomos), lo que pondría indicar un aumento de la informalidad. De acuerdo con la Encuesta de Indicadores Laborales (EIL) del Ministerio de Trabajo, la caída habría continuado en abril ( $0,6 \%$ frente a marzo y $3,1 \%$ interanual). De acuerdo con la oficina local de la OIT, las actividades más afectadas por la cuarentena ocupan al 70,1\% de la fuerza laboral urbana del país (Ernst y López-Mourelo, 2020).

En cuanto a la producción y a los servicios, se estiman que 800.000 trabajadores mercantiles están sin tareas, suspendidos por 60 días y que no recibirán la totalidad de su salario neto. Por otro lado, cayó un $0,5 \%$ el empleo privado registrado en empresas de más de 10 trabajadores y la mayoría de los dirigentes de las empresas argentinas creen que demorarán entre 6 y 18 meses en salir de la crisis que se está generando por la pandemia del coronavirus. En el mismo sentido, la actual coyuntura obliga al sector informal a no poder seguir funcionando y que muchísimas personas se vean imposibilitadas de percibir ingresos diarios para su hogar. Según estimaciones del Observatorio de la Deuda Social Argentina (ODSA-UCA, 2020c), a fines de mayo se estima que la pérdida de puestos de trabajo habría afectado a no menos del $8 \%$ de lo ocupados. Entre el sector formal e informal se estima para mayojunio una pérdida de más de 900 mil puestos de trabajo. Según el mismo estudio, no sólo el 8,3\% de los ocupados habían perdido el empleo, sino que el 39,3\% estaban suspendidos o debieron dejar de trabajar, el 4,2\% estaba de licencia por ser grupo de riesgo y el 22\% estaba trabajando menos horas. Sólo el $26,4 \%$ seguía trabajando como siempre o más horas.

En este contexto, destaca como información que el 19,8\% de los ocupados no cobró ni tuvo ingresos durante la cuarentena, el $44,2 \%$ vio reducidos sus ingresos y solo el $36 \%$ pudo disponer de los mismos o más ingresos; y más allá de que los programas sociales de transferencia de ingresos aumentaron cobertura, alcanzando a más del $50 \%$ de los hogares, la pobreza por ingresos aumentó. Según primeras estimaciones del CEDLAS (2020), la tasa de pobreza habría ascendido $41-42 \%$ a principios del mes de abril; pero al mes de mayo, las estimaciones del ODSA-UCA (2020b) dan cuenta de una pobreza que superaría al 45\% de la población. Esto habría ocurrido a nivel general, pero destaca el aumento de la pobreza y de la indigencia en el Área Metropolitana de Buenos Aires.

Según el estudio del ODSA-UCA, la cuarentena habría provocado una caída significativa de los ingresos de los hogares. En el AMBA, el 38,8\% de los hogares declaran que los ingresos durante del mes de abril se redujeron hasta un $50 \%$, mientras que para un 18,8\% la reducción habría sido mayor al

\footnotetext{
${ }^{62}$ El Ministerio de Desarrollo Productivo (CEP XXI, 2020b, 2020b) estima que las tendencias recesivas habrían empezado a revertirse desde mayo pues más del $80 \%$ del empleo privado en 15 provincias ya se encuentra habilitado y la demanda de energía eléctrica muestra una reactivación en la mayoría de las actividades industriales. Sin embargo, aún no se retornó a niveles previos a la cuarentena y el Área Metropolitana de Buenos Aires, que genera casi la mitad del PBI, continúa muy afectada por la evolución de la epidemia.
} 
$50 \%$. Sólo el 37,1\% declaró que los ingresos no habrían variado, a la vez que el 5,1\% afirmó un incremento durante la cuarentena. Asimismo, el 38,2\% de los hogares declararon que los recursos monetarios corrientes recibidos durante la cuarentena no les alcanzaron para cubrir sus gastos básicos. En el otro extremo, un $11,4 \%$ de los hogares pudieron incluso ahorrar y un $50,5 \%$, declaró que los ingresos percibidos -aunque menores a los habituales- les alcanzaron para cubrir sus gastos básicos.

En este contexto, al menos el $35 \%$ del total de hogares urbanos habrían recibido alguna transferencia de ingresos: son 3,1 millones de hogares que representan más de 10 millones de personas. El $25 \%$ de los hogares encuestados por el ODSA-UCA afirmaron haber accedido al IFE, el $29 \%$ al bono extraordinario por la $\mathrm{AUH}$, el $2 \%$ recibió el bono de jubilados y el $22 \%$ accedió a la tarjeta Alimentar u otros mecanismos de apoyo alimentario. De todos ellos, el $84 \%$ reportó no haber tenido inconvenientes para acceder a la transferencia. Al indagar sobre la tarjeta Alimentar, el $93 \%$ no ha tenido problemas para su utilización. Entre quienes reportaron inconvenientes, se relacionan con el rechazo de la tarjeta en comercios o la falta de terminales electrónicas de cobro. En cualquier caso, a pesar de esto, tal como ser analiza en el siguiente apartado, la situación tuvo impacto social diferencial en cuanto a caer en la pobreza extrema y padecer inseguridad alimentaria.

Dada la situación de recesión, el Estado ha visto reducida su capacidad de recaudación tanto por el Impuesto a las Ganancias, como así también por el Impuesto al Valor Agregado (IVA). La caída de la recaudación del IVA cayó un 27\% en abril en términos reales, mientras que Ganancias lo hizo en $31 \%$ real interanual. Ambos tributos son esenciales para el Estado, dado que proveen alrededor del $70 \%$ de lo recaudado en todo el país. La caída de los ingresos fiscales, sumado al creciente gasto público financiado por simple emisión, hace que el déficit fiscal corriente ascienda a más del $5 \%$ del PBI al final de año. La situación de las cuentas públicas alerta sobre el potencial impacto del sobrante monetario acumulado sobre el sistema de precios, especulándose un nuevo proceso inflacionaria pos-ASPOCOVID-19 (Manzanelli, et al, 2020).

En mayo de 2020, en un contexto de fuerte crisis de oferta y demanda, los precios aumentaron 1,5\%, mismo ritmo de aumento que el mes anterior. Estos niveles inflacionarios son los más bajos desde noviembre de 2017, cuando se registró 1,4\%. Sin embargo, en junio la inflación alcanzó 2,2\% y un 42,8\% interanual. Los bienes estacionales fueron los que más se incrementaron. Los alimentos y bebidas crecieron $1 \%$ en ese mes, en particular en los rubros de pan y cereales (3,3\%), verduras, tubérculos y legumbres tomate $11,1 \%$, zapallo $5 \%$ y cebolla $3,7 \%$ ) y bebidas no alcohólicas (entre $1,6 \%$ y $2,5 \%$ ).

Cabe recordar que, en 2019, la inflación acumulada superó el 50\%, y que para 2020, aunque con índice a la baja en abril, mayo y junio, el Banco Central prevé una inflación interanual de 37,8\% (BCRA, 2020b); aunque otras fuentes estiman $44,5 \%$ (Ecolatina, 2020). Este nivel de inflación tiene lugar bajo un tipo de tipo cambio oficial relativamente retrasado, aunque con estricto control y "cepo cambiario". Este particular desequilibrio, que tiende agravarse con el correr de los meses, atenta contra la reactivación económica y el necesario aumento que se requiere de las exportaciones, como principal fuente genuina de financiamiento, tanto público como privado. En este contexto, las expectativas de shock devaluatorio van en alza. 
Gráfico 1. Impacto del Escenario COVID-19 sobre los Ingresos de los Hogares para cubrir 1, 203 Canastas Básicas Alimentarias. Julio-octubre 2019 versus mayo 2020. Panel de 500 hogares del Área Metropolitana de Buenos Aires* - EDSA-UCA. En porcentaje de hogares y personas.

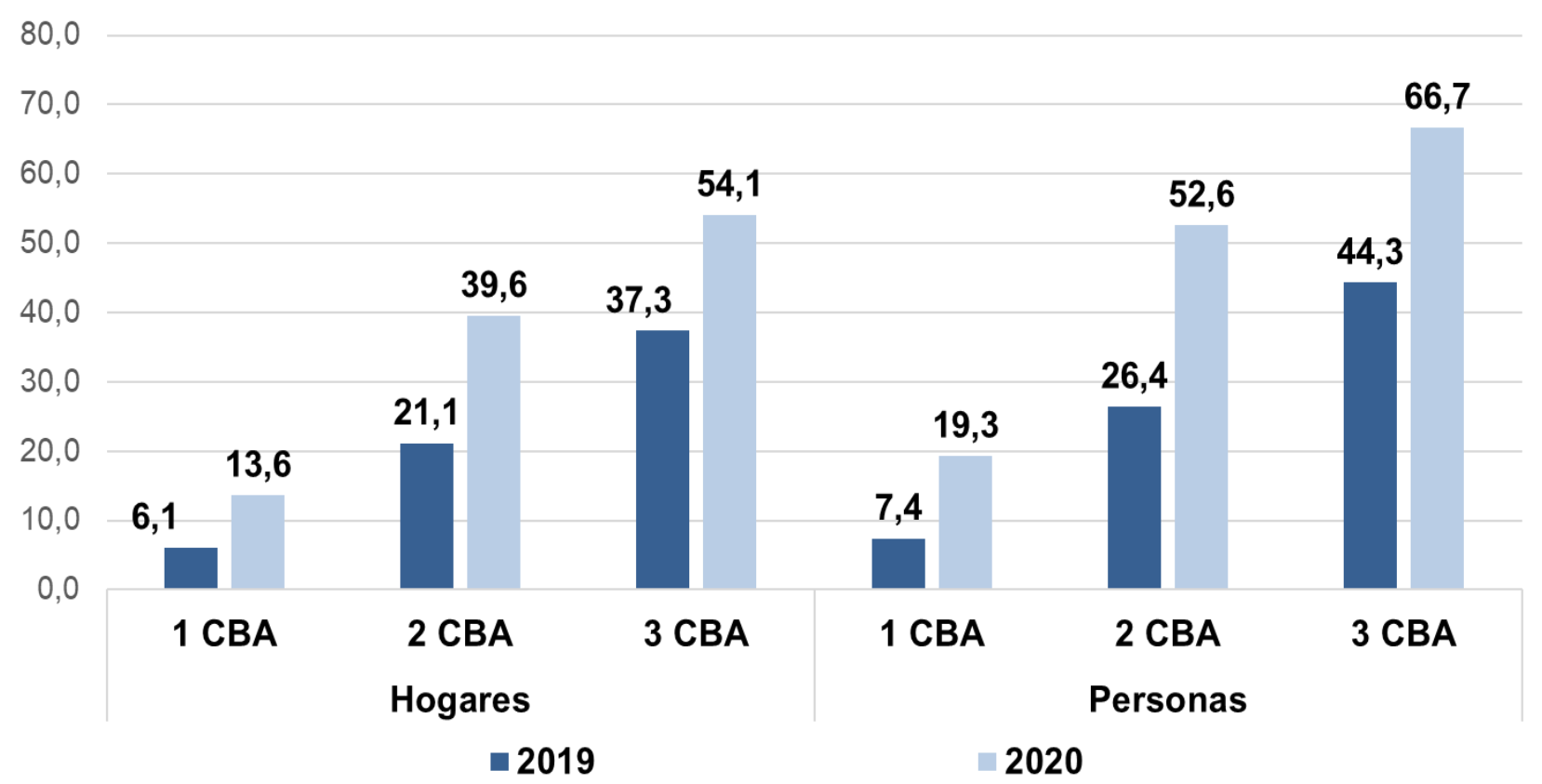

Fuente: EDSA COVID-19, mayo 2020; empalme EDSA Agenda para la Equidad (julio-octubre), Observatorio de la Deuda Social Argentina (UCA).

*Área Metropolitana de Buenos Aires: Ciudad de Buenos Aires y 30 Partidos del Conurbano Bonaerense.

Por último, más allá de tener lugar una crisis tanto de oferta como de demanda, el valor de la Canasta Básica Alimentaria -con el cual se mide la pobreza extrema- no ha dejado de crecer. Según el INDEC (2020b), si bien la misma no aumentó entre abril y mayo, en este último mes el índice acumuló un aumento de $14,7 \%$ con respecto a diciembre pasado, es decir, superior al registrado por el índice general de precios. Así como también una variación interanual de $47 \%$. El problema fue que, al mismo tiempo, tal como se mencionó más arriba, los ingresos de los hogares cayeron en forma abrupta. Una aproximación a este impacto se presenta en informe ya citado del ODSA-UCA (2020b), cuyos datos principales se presentan en el Gráfico 1.

\subsection{AUMENTO DE LA INSEGURIDAD ALIMENTARIA Y ASISTENCIA SOCIAL EN CONTEXTO DE ASPO-COVID-19.}

La inseguridad alimentaria constituye una medida directa de privación económica de los hogares que da cuenta de la falta de alimentos por motivos económicos. Se puede manifestar a partir de distintos aspectos y presenta distintas intensidades; en este trabajo se consideró la disminución de porciones 
de los alimentos, el salteo de comidas y la experiencia de hambre como elementos característicos ${ }^{63}$. Este aspecto es considerado dentro de la agenda de los Objetivos de Desarrollo Sostenible 2030 bajo el objetivo "Hambre Cero" (ONU, 2015, 2020) y su análisis resulta relevante para dar cuenta del impacto de la pandemia y la política de aislamiento preventivo obligatorio sobre las condiciones de vida de la población. Estudios previos revelan una marcada tendencia ascendente de la inseguridad alimentaria desde 2018 (ODSA, 2020b).$^{64}$

En este contexto cabe preguntarse: ¿cuáles fueron los hogares del Área Metropolitana de Buenos Aires más afectados en materia de inseguridad alimentaria por el deterioro de la situación económicoocupacional generada por el ASPO? ¿Tuvieron las políticas de transferencia de ingresos y asistencia alimentaria directa algún efecto en cuanto a reducir los riesgos alimentarios de estos hogares? En función de dar respuesta a estas preguntas, este apartado analiza la variación 2019 (julio-octubre) - 2020 (mayo) que tuvo lugar en los niveles de inseguridad alimentaria -severa y total- experimentados por un panel de 500 hogares del AMBA objeto de estudio. En el anexo I de este capítulo se ofrece información complementaria del nivel de cobertura alcanzado por los programas de protección social y asistencia alimentaria en el contexto del APSO-COVID19 para el Área Metropolitana de Buenos Aires.

A partir de esta estrategia es posible identificar en primer lugar los cambios en los diferentes niveles de inseguridad alimentaria, así como los distintos riesgos sociales asociados a los mismos. En segundo lugar, se examinan -dado el carácter panel de la muestra de hogares- la matriz de transiciones subyacente a estos cambios y los principales perfiles sociales asociadas a los mismos. Los cambios de estado no solamente expresan en qué medida para la población estudiada el fenómeno es persistente, sino que constituye un elemento de análisis valioso para dar cuenta de la forma en la que impacta una situación sobre distintos grupos o perfiles sociales (Maletta, 2012; Arnau y Bono, 2008).

\footnotetext{
${ }^{63}$ La definición de seguridad alimentaria contempla el acceso físico y económico a alimento suficiente, seguro y nutritivo para poder llevar una vida activa y saludable (FAO, 2009), a su vez en la Cumbre Mundial de la Alimentación se reconoce en la Declaración de Roma (FAO, 1996) "el derecho de toda persona a tener acceso a alimentos sanos y nutritivos, en consonancia con el derecho a una alimentación apropiada y con el derecho de toda persona a no padecer hambre".

${ }^{64}$ El análisis de la situación, los determinantes y la evolución de la inseguridad alimentaria es abordado por distintos estudios del Observatorio de la Deuda Social Argentina dentro de la dimensión condiciones de subsistencia de los hogares, también forma parte de los indicadores que componen el índice multidimensional de pobreza que el observatorio elabora desde 2016, ver Bonfiglio, J.I y Vera, J; Salvia (2019) y ODSA-UCA (2020a).
} 
Gráfico 2. Impacto del Escenario COVID19 sobre la Inseguridad Alimentaria Moderada, Severa y Total. Julio-octubre 2019 - Mayo 2020. Panel de 500 hogares del Área Metropolitana de Buenos Aires* - EDSA-UCA. En porcentaje de hogares.

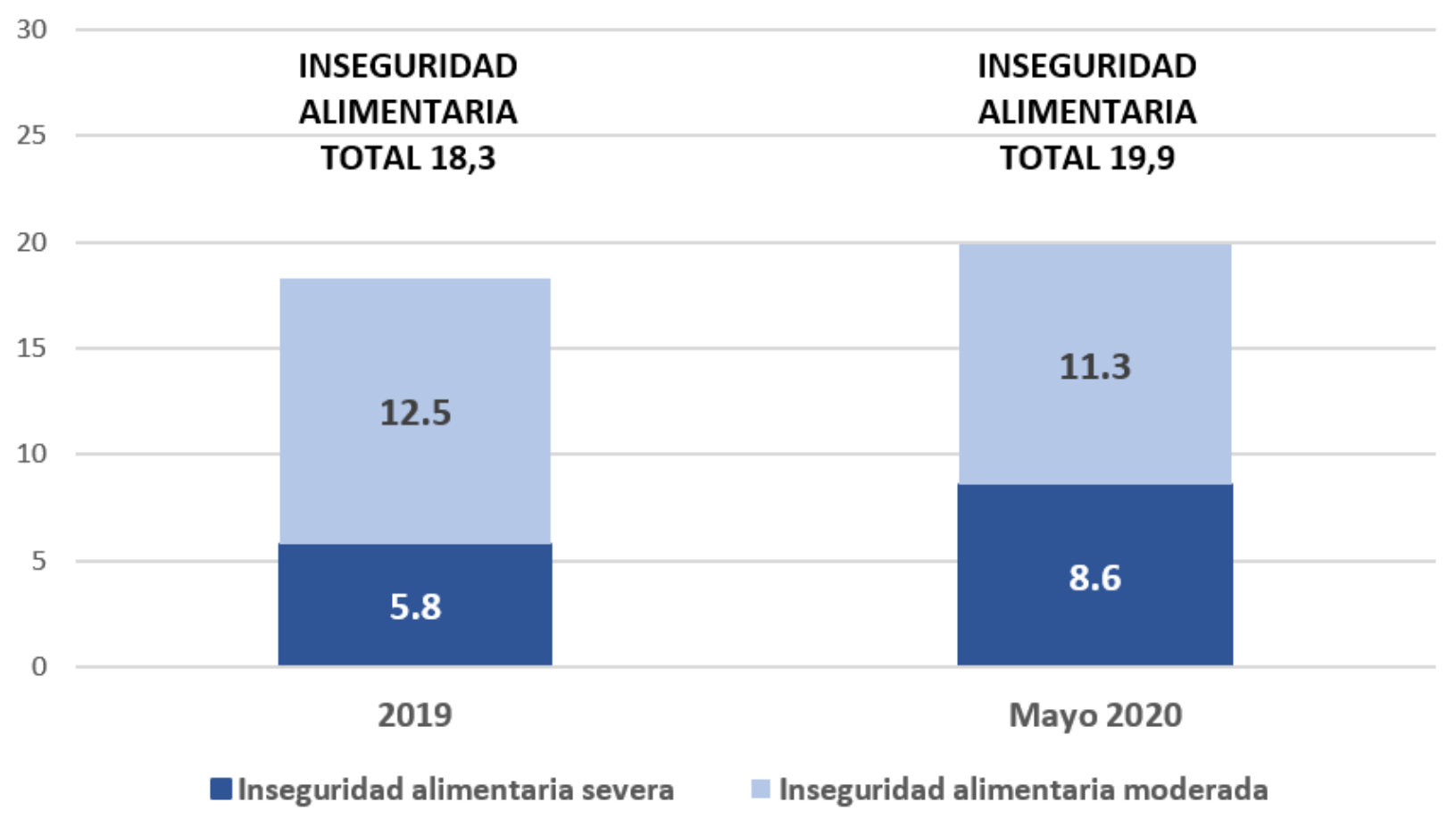

Fuente: EDSA COVID-19, mayo 2020; empalme EDSA Agenda para la Equidad (2017-2025), Observatorio de la Deuda Social Argentina (UCA)

*Área Metropolitana de Buenos Aires: Ciudad de Buenos Aires y 30 partidos del conurbano bonaerense.

Para estos análisis se definieron dos situaciones: la inseguridad alimentaria total (que incluye la inseguridad alimentaria moderada y la severa) y la inseguridad alimentaria severa. La inseguridad alimentaria moderada expresa la reducción involuntaria de la porción de comida. Mientras que la inseguridad alimentaria severa se refiere a la percepción frecuente de experiencias de hambre (en situaciones severas) por problemas económicos durante el período de referencia. ${ }^{65}$

- La inseguridad alimentaria total (inseguridad alimentaria severa + inseguridad alimentaria moderada) alcanzó para mayo de 2020 al $20 \%$ de los hogares del AMBA, mientras que las situaciones de mayor privación afectaron al $9 \%$ de los hogares. Para ambos casos se registra un deterioro respecto de la situación del año 2019, dónde los niveles alcanzaban al 18\% y al 6\% respectivamente (Gráfico 2).

- La inseguridad alimentaria se incrementó especialmente entre los hogares del Conurbano Bonaerense, impactando en mayor medida sobre hogares en condiciones de vulnerabilidad asociadas a la falta de afiliación al sistema de seguridad social producto del débil vínculo con el mercado de trabajo formal (Gráfico 3).

- Un aspecto destacable en este sentido es que el aumento de la incidencia en estos indicadores tuvo también lugar entre hogares que no eran pobres por ingresos en 2019, así como en hogares de

\footnotetext{
${ }^{65} \mathrm{Si}$ bien la encuesta EDSA-ODSA que se aplica regularmente considera como período de referencia 12 meses, el caso de la encuesta EDSACOFID-19 se tomó ventana de análisis el periodo de cuarentena previo al relevamiento: entre el 20 de marzo y el 5-10 de mayo de 2020.
} 
estratos socio-ocupacionales de "trabajadores integrados", tanto como segmentos de hogares marginales pobres (Gráfico 4 y 5 ). ${ }^{66}$

En mayo de 2020, en un contexto donde casi el $73 \%$ de los hogares se mantuvo sin déficit alimentario en el indicador de inseguridad total, y 7\% dejó de experimentarlo, casi 9\% cayó en esta privación y $11 \%$ se mantuvo en situación deficitaria. En cuanto al indicador de inseguridad severa, mientras que el $89 \%$ se mantuvo sin déficit y casi 3\% salió del mismo, 6\% cayó en esa situación y 3\% nunca dejó estarlo (Gráfico 5).

Gráfico 3. Impacto del Escenario COVID19 sobre la Inseguridad Alimentaria Moderada, Severa y Total, según Región y Condición de Pobreza. Julio-octubre 2019 - mayo 2020. Panel de 500 hogares del Área Metropolitana de Buenos Aires* - EDSA-UCA. En porcentaje de hogares.

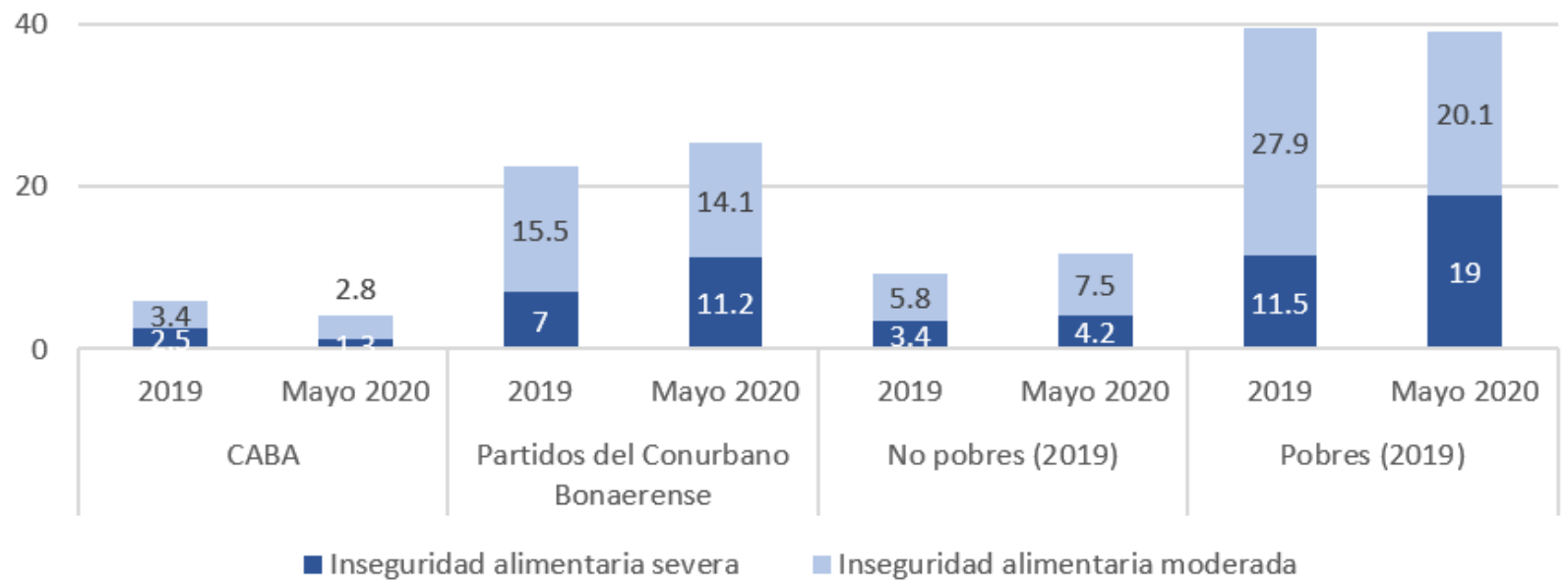

Fuente: EDSA COVID-19, mayo 2020; empalme EDSA Agenda para la Equidad (2017-2025), Observatorio de la Deuda Social Argentina (UCA)

*Área Metropolitana de Buenos Aires (Ciudad de Buenos Aires y 30 partidos del conurbano bonaerense).

\footnotetext{
${ }^{66}$ El estrato socio-ocupacional mide en la EDSA-ODSA la inserción económico-laboral de los hogares a través de un algoritmo que toma en cuenta la calificación ocupacional, las fuentes de ingresos, la jerarquía laboral y el nivel de protección social del principal sostén económico del grupo familiar. Las categorías resultantes se agrupan en este caso en cuatro estratos: medio profesional, medio no profesional, trabajador integrado y trabajador marginal (ODSA-UCA, 2020a)
} 
Gráfico 4. Impacto del Escenario COVID19 sobre la Inseguridad Alimentaria Moderada, Severa y Total, según Estrato Socio-Ocupacional. Julio-octubre 2019 - mayo 2020. Panel de 500 hogares del Área Metropolitana de Buenos Aires* - EDSA-UCA. En porcentaje de hogares.

40

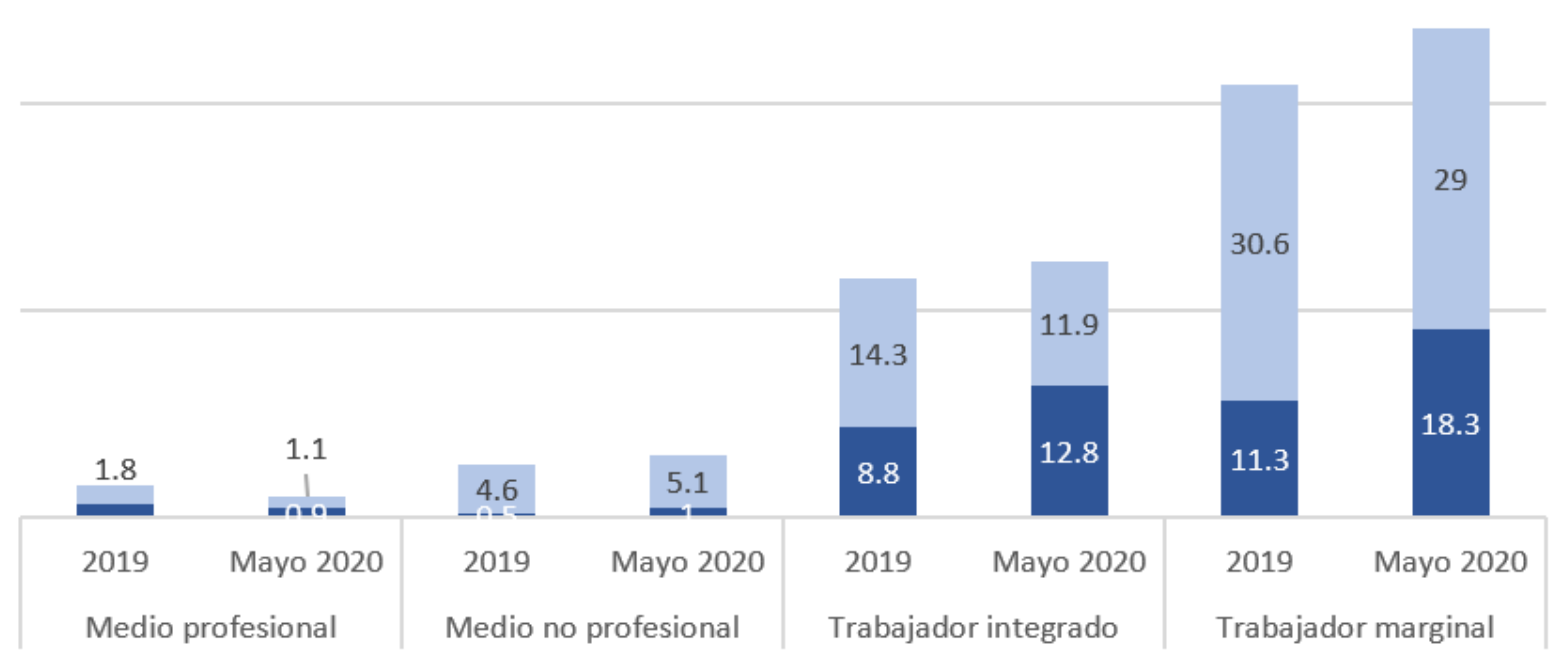

E Inseguridad alimentaria severa Inseguridad alimentaria moderada

Fuente: EDSA COVID-19, mayo 2020; empalme EDSA Agenda para la Equidad (2017-2025), Observatorio de la Deuda Social Argentina (UCA)

*Área Metropolitana de Buenos Aires (Ciudad de Buenos Aires y 30 partidos del conurbano bonaerense).

Gráfico 5. Cambios y Permanencias de los Hogares en la Inseguridad Alimentaria Total y Severa durante el Escenario COVID-19. Julio-octubre 2019 - mayo 2020. Panel de 500 hogares del Área Metropolitana de Buenos Aires* - EDSA-UCA. En porcentaje de hogares.

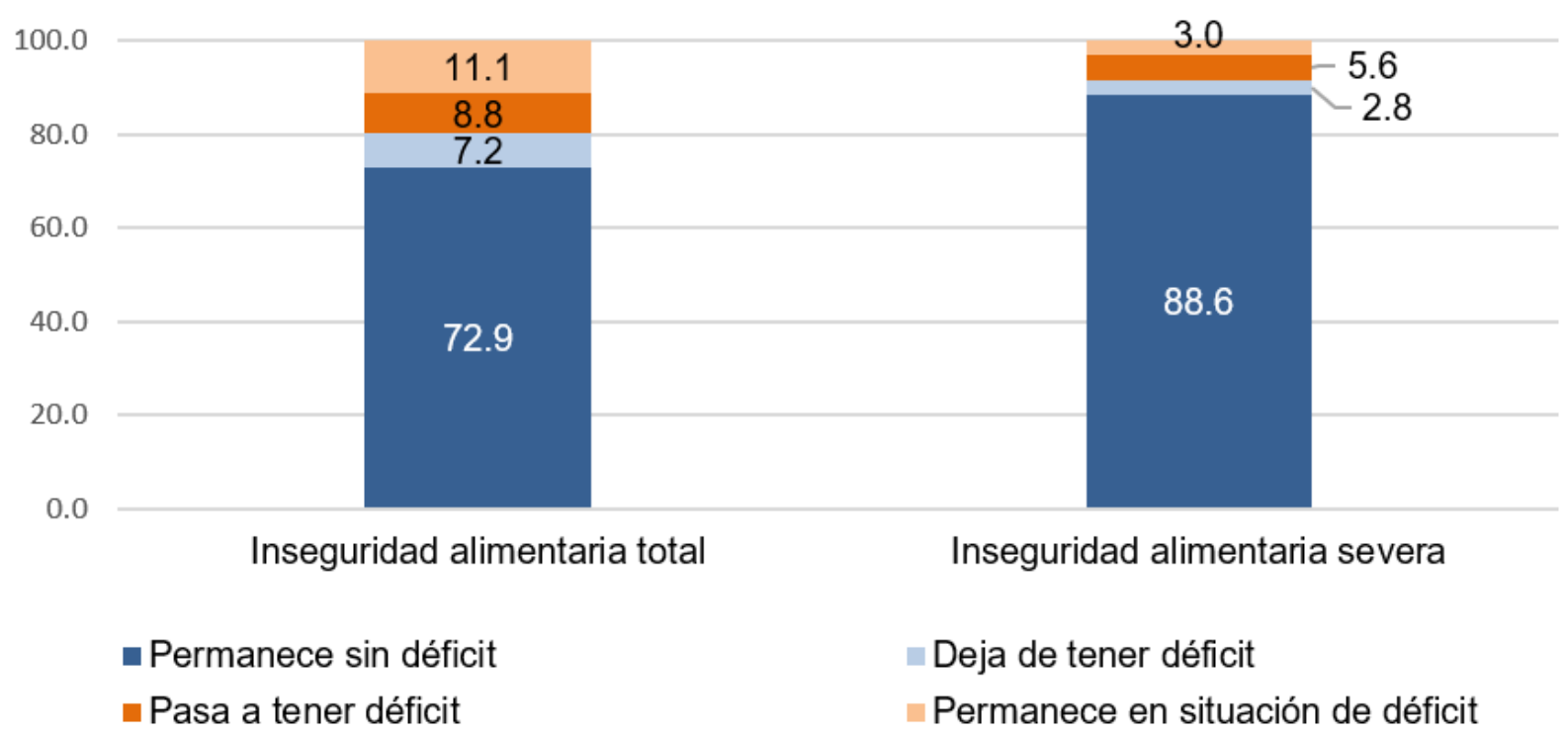

Fuente: EDSA COVID-19, mayo 2020; empalme EDSA Agenda para la Equidad (2017-2025), Observatorio de la Deuda Social Argentina (UCA)

*Área Metropolitana de Buenos Aires: Ciudad de Buenos Aires y 30 partidos del conurbano bonaerense. 
Entre dinámicas, destaca el hecho de que los que caen a situación de inseguridad alimentaria total son principalmente no pobres de estratos medios bajos o de trabajadores pobres, pero con niveles débiles de integración; mientras que los que pasan a situación de inseguridad alimentaria severa son principalmente los estratos más vulnerables. Por otra parte, resulta llamativo el elevado nivel de salidas del déficit alimentario, tanto de la situación de inseguridad alimentaria severa como total. Esto tuvo lugar tanto entre los hogares más vulnerables, como entre los que están mejor posicionados en términos sociales (ver Cuadros 1 y 2 ).

Este fenómeno podría explicarse como consecuencia del efecto de la política asistencial-alimentaria puesta en juego antes y durante el ASPO-COVID-19. En efecto, al examinar las transiciones de los hogares con y sin AUH-Tarjeta Alimentar se observa que la caída en inseguridad alimentaria severa es más importante entre los hogares pobres en 2019 que no son beneficiarios, con respecto de los que sí son beneficiarios. Sin embargo, este tipo de inferencia descriptiva requiere de pruebas estadísticas más sofisticadas para su validación, lo que se discute en la sección siguiente.

Con el fin de evaluar con mayor precisión los factores asociados a la probabilidad de caer en déficit alimentario total o severo en 2020 (mayo), en comparación con la situación de no déficit alimentario registrada 2019 (julio-octubre), se probaron modelos de regresión logística binaria. Los modelos se construyeron sobre la base de las variables analizadas previamente, las cuales presentan esquemas analíticos plausibles.

Con este fin se ha ajustó un modelo de regresión en el cual la variable dependiente toma los valores 1 y 0 , siendo 1 la situación de haber pasado a experimentar inseguridad alimentaria total o inseguridad alimentaria severa en mayo de 2020 sin haber estado en esa situación en 2019. Si los coeficientes $\operatorname{EXP}(\beta i)$ son mayores a 1 (uno) esto implica que la probabilidad de pasar a experimentar una situación de inseguridad alimentaria total o severa aumenta frente a la condición referenciada en la variable independiente. De manera contraria, si los coeficientes $\operatorname{EXP}(\beta i)$ son menores a 1 (uno) el factor bajo análisis hace descender las chances de pérdida de ingresos familiares corrientes ${ }^{67}$. En el anexo II de este documento se presentan completos los resultados de los modelos de regresión ajustados.

Los resultados generados por estos modelos se presentan en el Gráfico 6, siendo los principales hallazgos, los siguientes:

- Se observan principalmente dos factores que determinaron las posibilidades de haber pasado a la condición de inseguridad alimentaria total o a la de inseguridad alimentaria severa en mayo de 2020. Estos son el estrato socio ocupacional y los cambios en la actividad laboral que tuvieron lugar como consecuencia del impacto de la pandemia y las medidas de aislamiento social preventivo y obligatorio.

- Los hogares de estrato socio-ocupacional de "trabajador marginal" tuvieron entre 5 y 6 veces más posibilidades de pasar a la condición de inseguridad alimentaria severa o a inseguridad alimentaria total que los hogares de estrato medio profesional, a su vez la categoría de trabajador integrado asumió un valor predictivo relevante al ubicarse multiplicando por 4 o 5 las chances de pasar a experimentar inseguridad alimentaria respecto a los hogares de estratos medios profesionales.

- Por otra parte, el hecho de haber pasado a trabajar menos horas, ser despedido, suspendido o no poder desarrollar sus actividades laborales constituye otro factor relevante, siendo entre 2 y

\footnotetext{
${ }^{67}$ Véase López-Roldán, P y Fachelli, S (2015), Chitarroni, H (2002) y Salas Velasco, M (1996), entre otros.
} 
3 veces mayores las posibilidades en este caso de pasar a la situación de inseguridad alimentaria severa o total, respecto a haber seguido trabajando la misma cantidad de horas que antes de la cuarentena.

- La afiliación al sistema de seguridad social pesó solamente a la hora de explicar el cambio hacia la inseguridad alimentaria total, pero resultó no significativo para la inseguridad alimentaria severa. La condición de pobreza resultó un factor relevante para explicar la caída en la situación de inseguridad alimentaria severa, aunque sin efecto neto sobre la inseguridad alimentaria total.

- El acceso a ayuda social, diferente de la tarjeta alimentaria, resulta no significativo en términos estadísticos y su peso neto sobre las chances de pasar a una de las situaciones consideradas es bajo. Sin embargo, si se evalúa el peso de los beneficiarios de AUH-Tarjeta Alimentar, se destaca que percibirla, reduce las chances de pasar a la situación de inseguridad alimentaria severa en un $60 \%$.

- Residir en el Conurbano Bonaerense resulta un factor predictivo relevante para dar cuenta de la caída o no en la inseguridad alimentaria total y la inseguridad alimentaria severa, los hogares residentes en los partidos del Conurbano Bonaerense presentan entre 2 y 3 veces más de posibilidades de experimentar un deterioro de su situación en estos aspectos. 
Gráfico 6. Factores Asociados al Riesgo pasar a Experimentar Inseguridad Alimentaria Total e Inseguridad Alimentaria Severa. Coeficientes EXP(b) -Odds Ratio- de la Regresión Logística. Julio-octubre 2019 - mayo 2020. Panel de 500 hogares del Área Metropolitana de Buenos Aires*

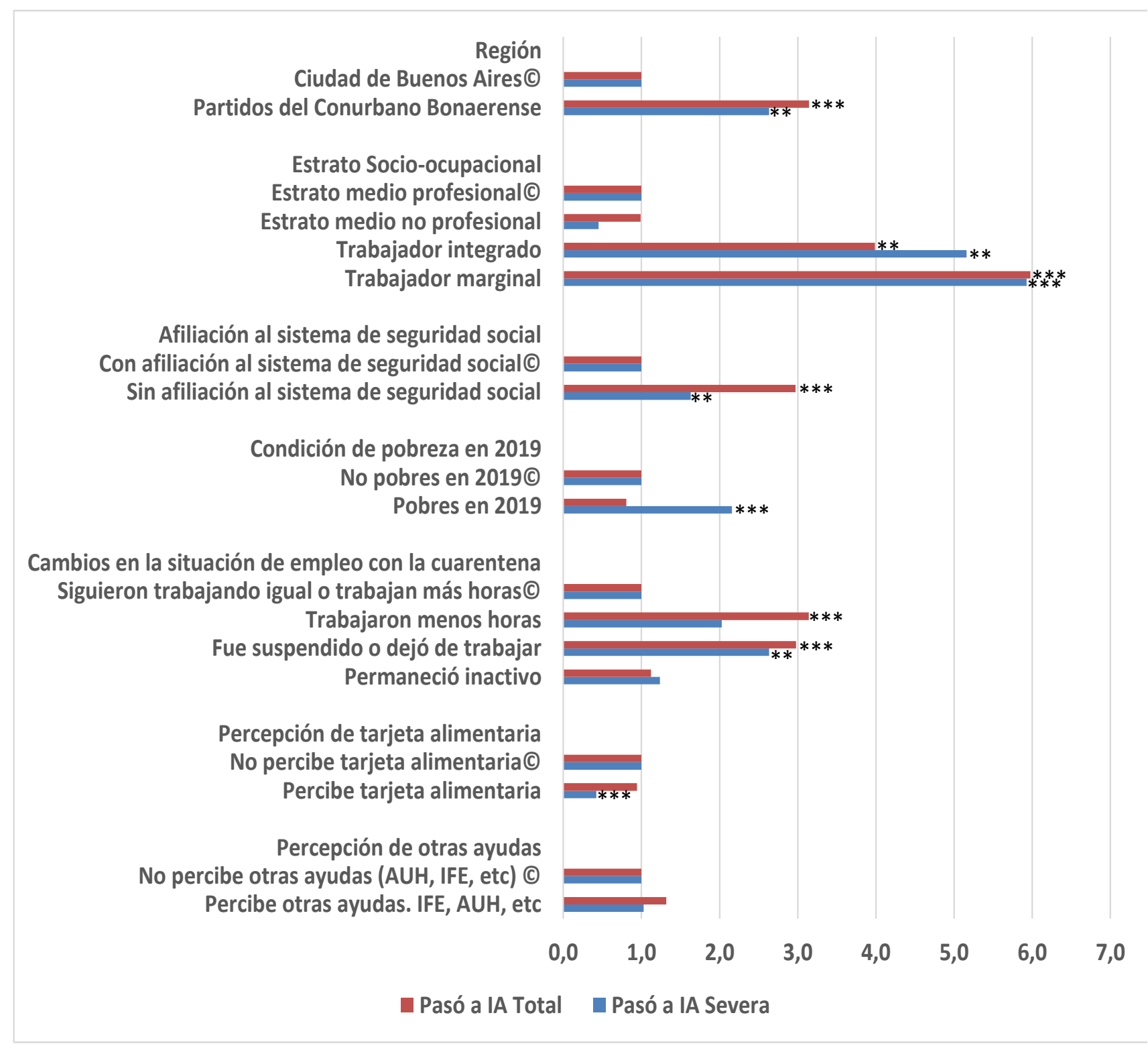

Categoría de referencia

** Coeficientes betas estandarizados significativos ( $p$-value $<0,05)$

*** Coeficientes betas estandarizados significativos ( $p$-value $<0,01$ )

*Área Metropolitana de Buenos Aires (Ciudad de Buenos Aires y 30 partidos del conurbano bonaerense).

Fuente: EDSA COVID-19, mayo 2020; empalme EDSA Agenda para la Equidad (2017-2025), Observatorio de la Deuda Social Argentina (UCA) 
Cuadro 2. Cambios en Inseguridad Alimentaria Total. Julio-octubre 2019 - Mayo 2020. Panel de 500 hogares del Área Metropolitana de Buenos Aires*. En porcentaje de hogares.

\begin{tabular}{|c|c|c|c|c|}
\hline & $\begin{array}{c}\text { Permanece sin } \\
\text { déficit }\end{array}$ & Deja de tener déficit & Pasa a tener déficit & $\begin{array}{c}\text { Permanece en } \\
\text { situación de } \\
\text { déficit }\end{array}$ \\
\hline \multicolumn{5}{|l|}{ TOTAL } \\
\hline Estadístico & 72,9 & 7,2 & 8,9 & 11,1 \\
\hline
\end{tabular}

\begin{tabular}{|c|c|c|c|c|}
\hline \multicolumn{5}{|l|}{ CARACTERÍSTICAS ESTRUCTURALES } \\
\hline \multicolumn{5}{|l|}{ REGIONES URBANAS } \\
\hline CABA & 91,7 & 4,1 & 2,5 & 1,8 \\
\hline Conurbano Bonaerense & 66,4 & 8,3 & 11,1 & 14,3 \\
\hline \multicolumn{5}{|l|}{ ESTRATO SOCIO-OCUPACIONAL (2019) } \\
\hline Medio profesional & 94,6 & 3,3 & 2,1 & 0,0 \\
\hline Medio no profesional & 91,4 & 2,5 & 3,6 & 2,5 \\
\hline Trabajador integrado & 64,0 & 11,3 & 12,9 & 11,8 \\
\hline Trabajador marginal & 44,0 & 8,7 & 14,1 & 33,3 \\
\hline \multicolumn{5}{|l|}{ NIVEL SOCIOECONÓMICO (2019) } \\
\hline Medio alto & 93,0 & 5,2 & 1,8 & 0,0 \\
\hline Medio bajo & 86,7 & 5,2 & 5,3 & 2,7 \\
\hline Bajo & 54,4 & 13,7 & 19,3 & 12,5 \\
\hline Muy Bajo & 46,6 & 6,9 & 13,1 & 33,3 \\
\hline \multicolumn{5}{|l|}{ POBREZA POR INGRESOS (2019) } \\
\hline No pobre & 83,8 & 4,6 & 7,1 & 4,6 \\
\hline Pobre & 47,6 & 13,4 & 13,1 & 26,0 \\
\hline \multicolumn{5}{|l|}{ CARACTERÍSTICAS HOGAR } \\
\hline \multicolumn{5}{|l|}{ EMPLEO DEL JEFE (2019) } \\
\hline Empleo pleno & 85,2 & 5,0 & 5,8 & 4,0 \\
\hline Empleo precario & 63,5 & 7,9 & 14,5 & 14,0 \\
\hline Subempleo/ Desempleo & 50,5 & 4,6 & 11,8 & 33,1 \\
\hline Inactivo & 71,0 & 11,2 & 7,1 & 10,7 \\
\hline \multicolumn{5}{|l|}{ SEXO DEL JEFE } \\
\hline Varón & 73,3 & 6,9 & 9,1 & 10,6 \\
\hline Mujer & 71,8 & 7,9 & 8,3 & 12,0 \\
\hline \multicolumn{5}{|l|}{ NIÑOS EN EL HOGAR } \\
\hline Sin niños & 85,8 & 3,8 & 4,7 & 5,8 \\
\hline Con niños & 59,1 & 10,9 & 13,3 & 16,7 \\
\hline \multicolumn{5}{|c|}{ SEGURIDAD Y ASISTENCIA SOCIAL EN EL HOGAR } \\
\hline \multicolumn{5}{|c|}{ EMPLEO REGISTRADO Y SEGURIDAD SOCIAL (2019) } \\
\hline Con empleo registrado y seguridad social & 83,9 & 5,3 & 5,9 & 4,9 \\
\hline Sin empleo registrado y seguridad social & 47,4 & 11,5 & 15,7 & 25,3 \\
\hline \multicolumn{5}{|l|}{ AYUDAS SOCIALES (2020) } \\
\hline No recibe ayudas sociales & 85,6 & 4,8 & 6,1 & 3,4 \\
\hline Recibe ayudas sociales & 42,1 & 13,0 & 15,5 & 29,4 \\
\hline \multicolumn{5}{|l|}{ TARJETA ALIMENTAR (2020) } \\
\hline No recibe Tarjeta Alimentar & 76,9 & 6,6 & 7,9 & 8,6 \\
\hline Recibe Tarjeta Alimentar & 49,6 & 10,5 & 14,7 & 25,2 \\
\hline
\end{tabular}

Fuente: EDSA, COVID19, mayo 2020, empalme EDSA Agenda para la Equidad (2017-2025), Observatorio de la Deuda Social Argentina (UCA).

*Área Metropolitana de Buenos Aires (Ciudad de Buenos Aires y 30 partidos del conurbano bonaerense). 
Cuadro 3. Cambios en Inseguridad Alimentaria Severa. Julio-octubre 2019 - mayo 2020. Panel de 500 hogares del Área Metropolitana de Buenos Aires*. En porcentaje de hogares.

\begin{tabular}{|c|c|c|c|c|}
\hline & $\begin{array}{c}\text { Permanece sin } \\
\text { déficit }\end{array}$ & Deja de tener déficit & Pasa a tener déficit & $\begin{array}{c}\text { Permanece en } \\
\text { situación de } \\
\text { déficit }\end{array}$ \\
\hline \multicolumn{5}{|l|}{ TOTAL } \\
\hline Estadístico & 88,6 & 2,8 & 5,6 & 3,0 \\
\hline
\end{tabular}

\begin{tabular}{|c|c|c|c|c|}
\hline \multicolumn{5}{|l|}{ CARACTERÍSTICAS ESTRUCTURALES } \\
\hline \multicolumn{5}{|l|}{ REGIONES URBANAS } \\
\hline CABA & 96,3 & 2,5 & 1,2 & 0,0 \\
\hline Conurbano Bonaerense & 85,9 & 2,9 & 7,1 & 4,1 \\
\hline \multicolumn{5}{|l|}{ ESTRATO SOCIO-OCUPACIONAL (2019) } \\
\hline Medio profesional & 97,9 & 1,3 & 0,8 & 0,0 \\
\hline Medio no profesional & 99,0 & 0,0 & 0,5 & 0,5 \\
\hline Trabajador integrado & 82,5 & 4,7 & 8,6 & 4,2 \\
\hline Trabajador marginal & 77,6 & 4,1 & 11,1 & 7,2 \\
\hline \multicolumn{5}{|l|}{ NIVEL SOCIOECONÓMICO (2019) } \\
\hline Medio alto & 98,2 & 0,8 & 1,0 & 0,0 \\
\hline Medio bajo & 95,2 & 2,6 & 2,3 & 0,0 \\
\hline Bajo & 81,0 & 3,7 & 12,2 & 3,1 \\
\hline Muy Bajo & 73,4 & 3,1 & 10,5 & 13,0 \\
\hline \multicolumn{5}{|l|}{ POBREZA POR INGRESOS (2019) } \\
\hline No pobre & 94,0 & 1,8 & 2,6 & 1,5 \\
\hline Pobre & 76,0 & 5,0 & 12,5 & 6,5 \\
\hline \multicolumn{5}{|l|}{ CARACTERÍSTICAS HOGAR } \\
\hline \multicolumn{5}{|l|}{ EMPLEO DEL JEFE (2019) } \\
\hline Empleo pleno & 93,7 & 0,9 & 4,5 & 0,9 \\
\hline Empleo precario & 88,6 & 2,4 & 5,1 & 3,8 \\
\hline Subempleo/Desempleo & 74,8 & 4,8 & 10,5 & 9,9 \\
\hline Inactivo & 85,8 & 5,3 & 5,9 & 3,0 \\
\hline \multicolumn{5}{|l|}{ SEXO DEL JEFE } \\
\hline Varón & 89,2 & 3,0 & 5,3 & 2,5 \\
\hline Mujer & 87,2 & 2,3 & 6,2 & 4,3 \\
\hline \multicolumn{5}{|l|}{ NIÑOS EN EL HOGAR } \\
\hline Sin niños & 94,1 & 3,3 & 1,2 & 1,4 \\
\hline Con niños & 82,7 & 2,2 & 10,3 & 4,8 \\
\hline \multicolumn{5}{|c|}{ SEGURIDAD Y ASISTENCIA SOCIAL EN EL HOGAR } \\
\hline \multicolumn{5}{|c|}{ EMPLEO REGISTRADO Y SEGURIDAD SOCIAL (2019) } \\
\hline Con empleo registrado y seguridad social & 93,2 & 1,4 & 3,4 & 2,0 \\
\hline Sin empleo registrado y seguridad social & 78,1 & 5,9 & 10,6 & 5,4 \\
\hline \multicolumn{5}{|l|}{ AYUDAS SOCIALES (2020) } \\
\hline No recibe ayudas sociales & 94,5 & 1,2 & 3,8 & 0,5 \\
\hline Recibe ayudas sociales & 74,3 & 6,6 & 9,9 & 9,2 \\
\hline \multicolumn{5}{|l|}{ TARJETA ALIMENTAR (2020) } \\
\hline No recibe Tarjeta Alimentar & 89,5 & 2,4 & 5,5 & 2,6 \\
\hline Recibe Tarjeta Alimentar & 83,0 & 5,0 & 6,4 & 5,6 \\
\hline
\end{tabular}

Fuente: EDSA, COVID19, mayo 2020, empalme EDSA Agenda para la Equidad (2017-2025), Observatorio de la Deuda Social Argentina (UCA).

*Área Metropolitana de Buenos Aires (Ciudad de Buenos Aires y 30 partidos del conurbano bonaerense). 


\subsection{HÁBITOS ALIMENTARIOS DURANTE EL AISLAMIENTO SOCIAL, PREVENTIVO Y OBLIGATORIO.}

Con el propósito de aportar datos sobre el consumo de alimentos en el contexto del COVID-19, se llevó a cabo un estudio exploratorio sobre hábitos alimentarios entre el 7 y 12 de mayo de 2020 (CEPEA, 2020). El objetivo del estudio fue la caracterización de la frecuencia de consumo de grupos de alimentos característicos del patrón alimentario local.

El trabajo no refleja qué cambios ocurrieron como consecuencia del aislamiento o sus efectos sobre el ingreso de los hogares o sus patrones de abastecimiento, pero informa un panorama acerca de la calidad de un conjunto de consumos trazadores de lo que se considera saludable y poco saludable en la población. La encuesta no indagó cantidades consumidas de alimentos sino solo sus ocasiones de

consumo. Sus resultados (que no pretenden tener una representatividad estadística ya que se trata de una muestra de conveniencia) pueden aportar una aproximación acerca del desafío que la salida del ASPO-COVID-19 impondrá a las políticas alimentarias.

El estudio se basó en un formulario online que indagó la frecuencia de consumo de 14 grupos, categorías o subcategorías de alimentos. Los primeros cinco grupos coinciden con los que las Guías Alimentarias (GAPA) recomiendan como de consumo regular (diario). A ellos se sumaron otras agregaciones que refieren a alimentos de alta densidad calórica o fuente de nutrientes en exceso en la dieta. El formulario también registró información sobre variables de categorización de la muestra (edad, género, provincia, condición laboral, presencia de niños o recepción de planes sociales).

Las preguntas sobre hábitos alimentarios consistieron en opciones de respuestas predeterminadas referidas a cuatro posibles frecuencias de consumo: diario (todos los días), frecuente (6, 5, 4 veces/semana), poco frecuente $(3,2,1$ vez/semana) y rara vez (menos que una vez por semana / no consumo). La encuesta se distribuyó a través de aplicaciones del sitio Nutrinfo.com y CEPEA; sus receptores de origen fueron mayoritariamente profesionales de nutrición a quienes se solicitó que reenvíen el formulario a por lo menos tres personas de su conocimiento bajo la instrucción de que preferentemente no fueran profesionales afines.

La muestra total fue de 3.539 sujetos, de los cuales el 80,8\% no correspondió a profesionales de salud. La distribución de la muestra fue manipulada para estimar ponderadores por edad, género, provincia de residencia y presencia de niños; los ponderadores fueron necesarios para balancear las respuestas obtenidas en la muestra de individuos y mejorar su representatividad.

Los Cuadros 4 y 5 resumen los criterios adoptados para la construcción de dos indicadores ad-hoc: uno sobre consumo saludable (alimentos de alta densidad de nutrientes) y otro de puntaje global de la dieta. Los resultados que se exponen abajo se refieren a las muestras respectivas ponderadas por edad, género, condición laboral y presencia de niños. Ambos indicadores son construcciones ad-hoc de este estudio, propuestos como una manera rápida de aproximar una valoración de la adecuación de la dieta a recomendaciones de las GAPA. 


\section{Cuadro 4. Criterios para el Tratamiento de las Respuestas sobre el Consumo Semanal de Alimentos}

\begin{tabular}{|c|c|c|}
\hline & $\begin{array}{l}\text { Criterio de consumo deseable (mínimo) o } \\
\text { adecuado de alimentos de alta densidad } \\
\text { de nutrientes }\left({ }^{\star}\right)\end{array}$ & $\begin{array}{l}\text { Criterio de consumo en exceso de ali- } \\
\text { mentos de baja densidad de nutrientes }\end{array}$ \\
\hline Hortalizas no feculentas & Diario o frecuente (4, 5 o 6 veces/semana) & \\
\hline Frutas & Diario o frecuente & \\
\hline Carnes frescas & $\begin{array}{l}\text { Poco frecuente (hasta } 3 \text { veces/semana) o } \\
\text { más }\end{array}$ & \\
\hline Lácteos & Diario o frecuente & \\
\hline $\begin{array}{l}\text { Legumbres / cereales /pas- } \\
\text { tas / harinas / hortalizas fe- } \\
\text { culentas }\end{array}$ & $\begin{array}{l}\text { Diario o frecuente en cereales/pastas/hari- } \\
\text { nas/hortalizas feculentas con al menos poco } \\
\text { frecuente en legumbres }\end{array}$ & \\
\hline $\begin{array}{l}\text { Alimentos fuente de hari- } \\
\text { nas muy refinadas }\end{array}$ & & $\begin{array}{l}\text { Consumo frecuente o diario en al menos } \\
\text { dos grupos de alimentos fuente }\left({ }^{* \star}\right)\end{array}$ \\
\hline $\begin{array}{l}\text { Alimentos fuente de azúca- } \\
\text { res }\end{array}$ & & $\begin{array}{l}\text { Consumo frecuente o diario en al menos } \\
\text { dos grupos de alimentos fuente de azúca- } \\
\text { res }\left(^{\star \star \star}\right)\end{array}$ \\
\hline Comidas rápidas & & $\begin{array}{l}\text { Consumo frecuente o diario en al menos } \\
\text { dos grupos de comidas rápidas }\left(^{* * *}\right)\end{array}$ \\
\hline
\end{tabular}

Fuente: CEPEA 2020

$\left({ }^{*}\right)$ Las GAPA recomiendan consumir diariamente los cinco primeros grupos alimentarios, de alta densidad de nutrientes; solo a los efectos del estudio, se consideró como adecuado un consumo diario o al menos frecuente; en carnes, el criterio se modificó hasta un mínimo de poco frecuente y en legumbres y cereales el consumo diario o frecuente se ajustó por una frecuencia como mínimo de poco frecuente de legumbres.

$\left({ }^{* *}\right)$ Alimentos fuente de harinas muy refinadas: pan, galletitas saladas / harinas, pastas, hortalizas feculentas / pizza

${ }^{(* * *)}$ Alimentos fuente de azúcares: bebidas azucaradas / galletitas dulces, facturas o repostería / mate o infusiones con azúcar

$\left({ }^{* * \star}\right)$ Alimentos fuente de comidas rápidas: fiambres, embutidos / tartas, empanadas /pizza

Los resultados que se presentan en el Cuadro 6 y Gráficos 5 y 6 informan los porcentajes de tres agregaciones de la población (todos o población general, desocupados + trabajadores inestables y hogares con presencia de niños) para dos indicadores:

a) Consumo saludable: \% de sujetos según diferentes niveles de adecuación a los criterios de consumo deseable o mínimo de alimentos de alta densidad de nutrientes.

b) Puntaje global de la dieta: \% de sujetos según diferentes niveles de adecuación a los criterios de consumo deseable de alimentos de alta densidad de nutrientes (más saludables) ajustado por la frecuencia de consumo de los de baja densidad (poco saludables).

\section{Cuadro 5. Definición de Indicadores de Consumo Saludable y Puntaje Global de la Dieta en base a Criterios de Tratamiento de Consumo Semanal}

\begin{tabular}{|l|l|l|}
\hline & $\begin{array}{l}\text { Consumo saludable (según ocasiones de con- } \\
\text { sumo semanal de alimentos de alta densidad } \\
\text { de nutrientes) }\end{array}$ & $\begin{array}{l}\text { Puntaje global de la dieta (ocasiones de con- } \\
\text { sumo semanal de alimentos de alta densidad } \\
\text { de nutrientes ajustado por frecuencia de con- } \\
\text { sumo de alimentos de baja densidad) }\left(^{*}\right)\end{array}$ \\
\hline Bueno/a & 5 grupos con consumo adecuado & 4 o 5 puntos \\
\hline Aceptable & 4 grupos con consumo adecuado & 3 puntos \\
\hline Regular & 3 grupos con consumo adecuado & 2 puntos \\
\hline Bajo/a & Menos de 3 grupos con consumo adecuado & Menos de 2 puntos \\
\hline
\end{tabular}

$\left({ }^{*}\right)$ Cada criterio de alimentos saludables suma un punto y cada criterio de alimentos poco saludables resta un punto.

Fuente: CEPEA, 2020. 
Cuadro 6. Porcentaje de la Muestra según Indicador de Consumo Saludable y Calidad de Dieta en Diferentes Agregados de la Población

\begin{tabular}{|l|c|c|c|c|c|c|}
\hline \multirow{2}{*}{$\begin{array}{l}\text { Niveles de } \\
\text { adecuación }\end{array}$} & \multicolumn{2}{|c|}{ Población general } & \multicolumn{2}{c|}{ Desocupados/informales } & \multicolumn{2}{c|}{ Presencia de niños } \\
\cline { 2 - 7 } & $\begin{array}{c}\text { Consumo } \\
\text { saludable }\end{array}$ & $\begin{array}{c}\text { Puntaje global } \\
\text { de dieta }\end{array}$ & $\begin{array}{c}\text { Consumo } \\
\text { saludable }\end{array}$ & $\begin{array}{c}\text { Puntaje global } \\
\text { de dieta }\end{array}$ & $\begin{array}{c}\text { Consumo } \\
\text { saludable }\end{array}$ & $\begin{array}{c}\text { Puntaje global } \\
\text { de dieta }\end{array}$ \\
\hline Bueno/a & 12,7 & 8,6 & 11,9 & 6,3 & 14,9 & 8,8 \\
\hline Aceptable & 32,6 & 19,9 & 24,5 & 17 & 31,8 & 17,8 \\
\hline Regular & 27,9 & 24,2 & 26,9 & 21,5 & 27,4 & 24,6 \\
\hline Bajo/a & 26,6 & 47,2 & 36,3 & 54,9 & 25,7 & 48,6 \\
\hline
\end{tabular}

Fuente: CEPEA, 2020

Se trata por lo tanto de indicadores más cualitativos que cuantitativos que aproximan una valoración sobre la calidad de dieta y probablemente sobreestimen los porcentajes de población con consumos saludables y puntajes globales de la dieta adecuados (si se hubiera preguntado cantidad los porcentajes de "bueno/a" probablemente serían menores a los que se presentan). ${ }^{68}$

Solo el $12,7 \%$ de la población general (11,9\% entre quienes son desocupados o trabajadores informales y $14,9 \%$ en hogares con niños) manifiesta consumir los cinco grupos alimentarios de mejor calidad nutricional en las frecuencias más próximas a las recomendaciones de las guías alimentarias. Por el contrario, algo más de la mitad de la muestra reportó consumos entre regulares y bajos $(63,2 \%$ entre quienes se encuentran desocupados o con trabajo informal).

De la combinación entre los consumos saludables y los de alimentos de más baja calidad nutricional (fuentes de harinas, azúcares y comidas rápidas) resulta que, en términos de puntaje global, no más del $8,6 \%$ de la población general (6,3\% entre desocupados y trabajadores informales) logra el mejor resultado (buen puntaje), mientras que algo más del $70 \%$ (76,4\% entre desocupados y trabajadores informales) registra un puntaje global de la dieta entre regular y bajo.

Las mayores brechas de adecuación de consumos saludables ocurren en legumbres, frutas, hortalizas no feculentas, lácteos (en especial yogur) y carnes frescas (en ese orden). En cuanto a los productos de baja densidad de nutrientes, las brechas de exceso en ocasiones de consumo son casi idénticas entre alimentos fuente de harinas muy refinadas y alimentos fuente de azúcares (en este último grupo debido, en particular, a infusiones y mate azucarados).

\footnotetext{
${ }^{68}$ Las frecuencias de personas informadas en la Tabla 3 no se basan en las cantidades consumidas de cada tipo de alimento sino a las ocasiones en que ellos fueron consumidos, independientemente de la cantidad.
} 


\section{POLÍTICAS PÚBLICAS EN RESPUESTA A LA CRISIS SOCIOECÓNOMICA Y ALIMENTARIA EN EL CONTEXTO DE EMERGENCIA SANITARIA COVID- 19.}

En los primeros meses del año, previo a la crisis generada por el COVID-19, el nuevo gobierno -asumido el 10 de diciembre de 2019- ya había puesto en marcha una serie de medidas de emergencia para atender la crisis social y alimentaria acumulada luego de dos años de recesión económica. Entre las medidas adoptadas destacaban el Plan Argentina contra el Hambre (PACH) y una serie de complementos o ampliaciones en los programas de transferencia de ingresos (ver Capítulos II, III, y IV).

Con el temprano avance de la pandemia COVID-19, casi todos los gobiernos del mundo desplegaron esfuerzos presupuestarios significativos para morigerar el impacto recesivo sobre la economía generado por medidas sanitarias. El Estado argentino fue uno de los primeros en la región en decretar frente al avance del COVID-19- medidas de prevención y aislamiento obligatorio para toda la población. A partir de lo cual logró implementar una serie de medidas oportunas, transparentes y basadas en las evidencias disponibles, a fin de mitigar la propagación de la pandemia y su impacto en el sistema sanitario, según lo establecido en el decreto 297/2020.

En particular, cabe destacar aquellas medidas orientadas a cuidar el ingreso de las familias, proteger la producción y el empleo y garantizar el abastecimiento. Según nuestras estimaciones, las transferencias de ingresos -sin considerar subsidios sectoriales y ayudas a los gobiernos provinciales- habrían representado más del $20 \%$ del gasto público primario durante el primer semestre del año ( $8 \%$ del PBI semestral): 975.000 millones de pesos entre enero y junio de 2020. En este marco, se destacan las iniciativas del Ingreso Familiar de Emergencia (IFE) y el Programa de Asistencia de Emergencia al Trabajo (ATP). A lo que se sumaron políticas de asistencia a la producción, políticas de precios y una serie de refuerzos para asistir a necesidades alimentarias urgentes. ${ }^{69}$

El objetivo central de estas acciones fue garantizar un piso mínimo de protección en materia de trabajo, ingresos y seguridad alimentaria, buscando aliviar el impacto regresivo de la cuarentena sobre el consumo, el empleo y los ingresos de las familias, la oferta de bienes y servicios básicos, el abastecimiento y los precios de alimentos y otros bienes esenciales. Entre los programas existentes y las nuevas acciones emprendidas en materia de protección social implicaron para el Estado transferencias alrededor de los 978 mil millones de pesos (Cuadro 7). Todo lo cual tuvo un impacto fiscal considerable en un presupuesto ya deficitario.

Si bien no hay cifras definitivas, el gasto primario del sector público no financiero durante el primer semestre del año (enero-junio) habría sido de 4.254 .580 millones de pesos (Ministerio de Economía, 2020). En tal caso, el gasto público habría crecido $90,4 \%$ en términos nominales con respecto al mismo período del año anterior. Según Ecolatina (2020) el déficit primario del sector público para el primer semestre habría alcanzado los 889.805 millones de pesos, lo que ya representaba un $3,3 \%$ del $\mathrm{PBI}$. Sin embargo, hay razones para sospechar que el mayor problema que han presentado las políticas de emergencia social emprendidas, en este caso en clave a objetivos de seguridad alimentaria -

\footnotetext{
${ }^{69}$ Según el Ministro de Desarrollo Social aseguró ante la Comisión de Salud y Acción Social de la Cámara de Diputados que a partir de la pandemia estima que son más de "11 millones los argentinos que acceden a una asistencia alimentaria a partir de distintos mecanismos brindados por el Gobierno nacional y federalizados en distintas partes del país". https://www.pagina12.com.ar/285128-daniel-arroyo-11-millonesde-argentinos-reciben-asistencia-a (consulta 6/09/2020).
} 
aunque también extensibles a la seguridad sanitaria-, no ha estado tanto en los déficits asociados, sino en la calidad de los diseños y la escasa coordinación nacional y federal de las acciones ejecutadas.

El presente apartado describe las principales políticas de transferencia de ingresos -con impacto socioalimentario- emprendidas por el gobierno argentino durante el primer semestre del año, en el contexto de aislamiento social, preventivo y obligado (ASPO) bajo el marco de la crisis sanitaria. Las mismas se clasifican según su origen o finalidad en términos de: protección social, producción y consumo, seguridad alimentaria y otras medidas de promoción productiva.

\subsection{POLÍTICAS DE PROTECCIÓN SOCIAL EN RESPUESTA A LA CRISIS SOCIOECONÓMICA EN EL CONTEXTO DEL COVID-19.}

Tal como analizado en capítulos anteriores, el escenario socioeconómico crítico presente a finales de 2019, el nuevo gobierno que asumió el 5 de diciembre no sólo mantuvo los programas de protección social existentes, sino que amplió el sistema de asistencia pública (Capítulo III y IV). En ese marco, con el fin de contener la caída del ingreso real y sus efectos sobre la inseguridad alimentaria en los sectores más vulnerables, el gobierno lanzó el denominado Plan Argentina Contra el Hambre (PACH) e introdujo una serie de refuerzos en forma de bonos monetarios en los programas sociales, las pensiones y las jubilaciones mínimas (MDS, 2020a).

A partir de la irrupción de la pandemia COVID-19 y la política sanitaria de implementar férreas acciones de aislamiento social obligatorio, el gobierno procuró ampliar y/o reforzar los programas de protección social. De esta manera, además de la Asignación Universal por Hijo, el PACH, las pensiones no contributivas, la asistencia a comedores escolares y comunitarios, el programa Potencia Trabajo (ex Salario Social Complementario y Hacemos Futuro) -preexistentes al inicio de la nueva administración-, se le sumaron -entre los meses de marzo y junio de 2020- una serie de refuerzos a esas transferencias y nuevos programas e incentivos: el Ingreso Familiar de Emergencia (IFE), el Programa de Asistencia de Emergencia al Trabajo (ATP) y bonos no remunerativos para los trabajadores de la salud.

En cuanto a los objetivos instrumentales asociados a las políticas de protección social aplicadas durante la pandemia, cabe diferenciar aquellas medidas que apuntaron a compensar la pérdida de ingresos de los sectores informales, de aquellos que tuvieron como estrategia evitar despidos de trabajadores formales, asistir a las empresas y cubrir parte de las remuneraciones laborales.

Entre las nuevas medidas orientadas a impactar en el ingreso corriente de los sectores informales destaca el Ingreso Familiar de Emergencia (IFE) dirigido a personas de 18 a 65 años desocupadas, inactivas o con trabajo en la economía informal, o incluso monotributistas o de las categorías más bajas (A y B), en cuyo núcleo familiar proveedor no hubiera nadie con un empleo, pensión o jubilación formal. En su primera ronda, el IFE alcanzó a cerca de 8,9 millones de personas, con transferencia de $\$ 10.000$ a cada beneficiario (ANSES, 2020). Este programa ya acumuló 3 pagos a beneficiarios en los últimos 56 meses.

Por otra parte, una serie de medidas estuvieron dirigidas a asistir a las empresas y a sus trabajadores con el fin de evitar la pérdida de puestos de trabajo y la caída de sueldos. Al respecto, cabe destacar: a) el derecho a tomar licencias para poblaciones de riesgo o trabajadores con responsabilidad familiar, b) la habilitación del trabajo remoto, c) la prohibición de despidos y/o suspensiones, y d) la habilitación de prórrogas al vencimiento de deudas (entre otras facilidades fiscales instrumentadas a través de la 
AFIP). Pero en términos de transferencia directa, destaca como una innovación en la política de empleo para la Argentina, el Programa de Asistencia de Emergencia al Trabajo y la Producción (ATP).

EI ATP se constituyó como la principal herramienta de subsidio o transferencia para aliviar la caída de las remuneraciones de trabajadores formales y el riesgo de cierre de empresas. En este marco se adoptaron las siguientes medidas: a) pago de una parte del salario a cargo del Estado a trabajadores formales de empresas privadas con caída en el nivel de actividad ${ }^{70}$; b) postergación de la obligación del pago de contribuciones patronales; c) apertura de créditos a tasas cero para monotributistas y empresas en situación crítica; y d) ampliación del beneficio del Seguro del Desempleo (de alcance limitado en la Argentina). A estas medidas, cabe sumar el refuerzo que recibieron los trabajos formales de la salud y de la seguridad, como un reconocimiento a su labor en contexto de la emergencia sanitaria.

\section{CUADRO 7. Programas de Protección Social en el Contexto COVID-19. Período enero-} junio de 2020 y comparación con PBI 20201. En millones de pesos corrientes

\begin{tabular}{|c|c|c|c|c|}
\hline & $\begin{array}{l}\text { Beneficiarios } \\
\text { (miles) }\end{array}$ & $\begin{array}{l}\text { Gasto Total } \\
\text { (millones } \\
\text { de pesos) }\end{array}$ & $\begin{array}{c}\% \mathrm{PBI} \\
1^{\circ} \text { sem. } \\
2020\end{array}$ & $\begin{array}{c}\% \text { PBI } \\
\text { Anual } \\
2020 \\
\end{array}$ \\
\hline \multicolumn{5}{|c|}{ PROGRAMAS DE PROTECCIÓN SOCIAL PRE COVID-19 } \\
\hline Asignación Universal por Hijo - AU Embarazo (enero-junio) & \multirow{2}{*}{$\begin{array}{l}2.400 \text { titulares } \\
\text { ( } 3.300 \text { benef.) }\end{array}$} & 192.565 & 1,60 & 0,73 \\
\hline Bono Asignación Universal por Hijo - AU por Embarazo (abril) & & 11.175 & 0,09 & 0,04 \\
\hline Plan Alimentar / Tarjeta Alimentar (enero-junio) & \multirow{2}{*}{$\begin{array}{l}1.500 \text { titulares } \\
\text { ( } 2.800 \text { benef.) }\end{array}$} & 44.694 & 0,37 & 0,17 \\
\hline Bono Tarjeta Alimentar (mayo) & & 7.771 & 0,06 & 0,03 \\
\hline Asistencia a Comedores Escolares y Sociales (convenios) & \multirow{2}{*}{$\begin{array}{l}24,5 \text { comedores } \\
(2.500 \text { benef. })\end{array}$} & 7.300 & 0,06 & 0,03 \\
\hline Refuerzo a Comedores y Ayuda Alimentaria Directa & & 2.320 & 0,02 & 0,01 \\
\hline $\begin{array}{l}\text { Potenciar Trabajo (Salario Social Complementario + Hacemos } \\
\text { Futuro) (enero-junio) }\end{array}$ & \multirow{2}{*}{570 titulares } & 28.854 & 0,24 & 0,11 \\
\hline Bono Programas Sociales / Potenciar Trabajo (mayo) & & 2.073 & 0,02 & 0,01 \\
\hline $\begin{array}{l}\text { Pensiones no Contributivas / Pensión a la Vejez - Invalidez- } \\
\text { otras (enero-junio) }\end{array}$ & \multirow[t]{2}{*}{1.545 titulares } & 114.456 & 0,95 & 0,43 \\
\hline Bono Jubilaciones y Pensiones no Contributivas (abril) & & 10.451 & 0,09 & 0,04 \\
\hline \multicolumn{5}{|c|}{ PROGRAMAS DE PROTECCIÓN SOCIAL COVID-19 } \\
\hline IFE - Ingreso Familiar de Emergencia (abril-junio-agosto) & $\begin{array}{l}8.900 \text { titulares } \\
\text { (11.000 benef.) }\end{array}$ & 268.543 & 2,24 & 1,01 \\
\hline $\begin{array}{l}\text { ATP - Salario Complementario + Créditos a tasas cero para mo- } \\
\text { notributistas y empresas (abril-mayo-junio) }\end{array}$ & \multirow{2}{*}{$\begin{array}{l}2.300 \text { titulares } \\
350 \text { empresas }\end{array}$} & 266.333 & 2,22 & 1,01 \\
\hline ATP - Seguro de Desempleo (enero-junio) & & 1.368 & 0,01 & 0,01 \\
\hline $\begin{array}{l}\text { Bono trabajadores de la salud y personal de seguridad (abril- } \\
\text { mayo-junio) }\end{array}$ & \multirow[t]{2}{*}{420 titulares } & 13.000 & 0,11 & 0,05 \\
\hline Refuerzo al Ministerio de Salud para transferencias a provincias & & 6.800 & 0,06 & 0,03 \\
\hline Total & & 977.703 & 8,00 & 3,69 \\
\hline
\end{tabular}

${ }^{1}$ Según cálculos del Observatorio Fiscal Federal, el PBI a precios corrientes para el período de enero a junio de 2020 es de 12.218 .795 millones de pesos. Dicha entidad estima un PBI total a precios corrientes para 2020 de 26.465 .696 millones de pesos. Ver http://www.observatoriofiscal.org.ar/

Fuente: Observatorio de la Deuda Social Argentina con base en información del Ministerio de Desarrollo Social, Ministerio de Desarrollo Productivo, Ministerio de Economía y ANSES.

\footnotetext{
${ }^{70} \mathrm{~A}$ través de este programa se dispuso el pago directo a través del Estado de hasta el $50 \%$ de las remuneraciones a trabajadores registrados del sector privado. Los montos por depositar no pueden ser inferiores a un Salario Mínimo Vital y Móvil (\$16.875) ni superar el doble de esa referencia $(\$ 33.750)$.
} 
Según estimaciones del Observatorio de la Deuda Social Argentina, el total de transferencias generadas por el conjunto de las políticas de protección social ejecutadas entre enero y junio de 2020 (978.000 millones de pesos), representaron alrededor de 3,6\% del PBI de 2020 (estimado en 26.465.696 millones de pesos), o de 8\% correspondiente al PBI semestral (estimado en cerca de 12.218.795 millones de pesos corrientes). ${ }^{71} \mathrm{Si}$ de este gasto se descuentan las transferencias destinadas a los segmentos formales (ATP, seguro de desempleo y bono a los trabajadores de la salud), el monto de transferencias monetario-alimentarias directas e indirectas a poblaciones pobres o informales habría representado al menos 5,6\% del PBI semestral (2,5\% del PBI 2020 estimado). El gasto presupuestario y la población beneficiaria estimada de cada uno de los programas de protección social se detallan en el Cuadro 7.

Cabe destacar que, en términos de transferencias, los esfuerzos realizados para la política social habrían representado durante este el primer semestre 2020 casi un $23 \%$ del gasto público primario, estimado en 4.254.580 millones de pesos. Al mismo tiempo que este gasto registró, tan sólo para este período, un déficit primario que se estima en 889.805 millones de pesos (3,36\% del PBI 2020). Sin duda, el financiamiento de estos recursos constituye una cuestión medular para en definiciones que habrá de adoptar la política económica post-COVID-19. Mucho más si se tiene en cuenta un pronóstico de caída anual del PBI de alrededor del $10 \%$.

\subsection{POLÍTICAS DE APOYO A LA PRODUCCIÓN, ABASTECIMIENTO Y CONSUMO DE ALIMENTOS EN EL CONTEXTO DEL COVID-19.}

A diferencia de crisis anteriores, la oferta de alimentos se ha mantenido estable. Por lo tanto, no existen razones que justifiquen aumentos importantes en los precios de los alimentos. No obstante, si la pandemia se extiende en el tiempo, las cadenas de abastecimiento de alimentos pueden estar sometidas a mayor presión. En este sentido, cabe esforzarse para mantener funcionando las cadenas locales, nacionales, regionales y globales de abastecimiento, para lograr asegurar los alimentos de forma sostenible para toda la población. La pandemia ha causado una espiral hacia abajo de ambos lados: una crisis de demanda y de oferta a la misma vez, que se va potenciando. La estimación es que la crisis de la oferta se podrá superar mucho antes que la crisis de la demanda.

Con el fin de mantener en funcionamiento las diferentes cadenas productivas y reducir los efectos críticos del ASPO-COVID-19, el Ministerio de Desarrollo Productivo lanzó una línea de créditos a tasa subsidiada (24\%). A principios de junio se habían asistido a 136.000 empresas (mayormente PyMEs), por un monto de $\$ 231.000$ millones. Los tres sectores que más beneficiados por este programa fueron el comercio (32\%), la industria (29\%) y el sector agropecuario (13\%).

\section{PRODUCCIÓN, CONSUMO Y COMERCIALIZACIÓN DE ALIMENTOS}

Una de las principales preocupaciones de la sociedad durante la actual pandemia de COVID-19 es la cadena de suministro de alimentos. Las imágenes iniciales de supermercados con estanterías vacías generaron temores sobre el desabastecimiento de productos necesarios para el cuidado de todos durante el aislamiento social. En este marco, las industrias de alimentos y bebidas deben garantizar su

\footnotetext{
${ }^{71}$ Las estimaciones y proyecciones sobre los valores mensuales de PBI de 2020 a precios corrientes corresponden al Observatorio Fiscal Federal http://www.observatoriofiscal.org.ar/.
} 
producción, muchas veces operando en su máxima capacidad, al mismo tiempo que priorizan la seguridad alimentaria y sanitaria del público y de todo su personal. A estos fines, la FAO y otros organismos desarrollaron una serie de medidas prácticas que sirven como una guía para todos los países de la región, incluida Argentina. Estas medidas aseguran que estos mercados sigan cumpliendo su papel estratégico en el suministro de alimentos de las ciudades, reduciendo al mínimo los riesgos de contagio entre sus operadores, proveedores y quienes acuden a ellos a comprar alimentos.

En el caso argentino, si bien la industria alimentaria fue la menos afectada por la crisis generada por el ASPO-COVID-19, la misma no quedó al margen de la crisis de oferta y demanda generalizada de bienes y servicios. En el comparativo anual, el sector registró una variación negativa del 1\%. A su interior, el rubro con mayor incidencia contractiva fue el de bebidas, debido a la baja de la demanda en sus cadenas habituales de distribución (restaurantes, bares, kioscos, etc.). En dirección contraria, las principales incidencias positivas provinieron de los productos lácteos, yerba mate, te y café, vinos, carnes aviar y carne vacuna. En general, el consumo creció en supermercados durante la cuarentena, pero cayó en los pequeños comercios. Aunque los distintos relevamientos muestran resultados dispares dependiendo del tipo de comercio y productos vendidos. De acuerdo con CAME, las ventas minoristas en comercios chicos acentuaron su caída en abril y mayo.

Al arranque del ASPO-COVID-19, los controles sobre la circulación por rutas y caminos dificultaron la logística de traslado de alimentos desde sus lugares de producción hasta acopios o centros de distribución y comercialización. El sector frutihortícola fue probablemente el más afectado por estos acontecimientos, a los que se sumó el hecho de que los camiones que transportaban alimentos a los mercados concentradores debían volver vacíos a sus ciudades de origen (a causa de la interrupción de cualquier otra actividad no esencial) impactando de esa manera en el precio de verduras y frutas. Con el correr de las semanas el suministro de alimentos se fue normalizando. Sin embargo, comienzan a aparecer los desafíos en términos de cuellos de botella logísticos y en términos productivos, que afectan a los productos frescos y de estación. Asimismo, la escasez de fertilizantes, medicamentos veterinarios y otros insumos podría afectar a la producción agrícola. El cierre de restaurantes, hoteles y la menor frecuencia de compras en tiendas de comestibles reducen la demanda de productos frescos y pesqueros, lo que afecta a productores y proveedores (ONU, 2020).

En el primer mes completo de aislamiento (abril), este conjunto de factores se tradujo en que las frutas duplicaron el crecimiento del índice de precios al consumidor (IPC) y las verduras más que lo triplicaron. En mayo las primeras tuvieron un leve descenso en sus precios mientras que las verduras mantuvieron un aumento por encima del IPC mensual. En junio y por quinto mes consecutivo (desde febrero), las verduras constituyeron la categoría de alimentos de mayor crecimiento según el IPC (INDEC, 2020c). En los grandes centros urbanos y en especial en el ámbito del Área Metropolitana de Buenos Aires (AMBA), las estimaciones no oficiales dan cuenta de que al menos dos tercios (algunos mencionan más del 70\%) de las verdulerías trabajan en la informalidad. Esta situación impide a estos sectores a tramitar permisos de circulación y es común observar verdulerías cerradas a causa de que sus titulares veían limitada la posibilidad de transitar para abastecerse de mercadería. El aislamiento impacta en la discontinuidad de las diferentes ferias barriales y mercados populares, cuyo crecimiento en los últimos años implicó una progresiva, aunque aún marginal, incidencia en la competitividad del sector. ${ }^{72}$

\footnotetext{
72 Solo en la ciudad de Buenos Aires existen regularmente 39 ferias en 186 emplazamientos y la cantidad de vecinos que compraban (antes del ASPO) en ellas llegó a unos 250 mil en los últimos cuatro años (aumentó más de 12 veces en ese período). En las últimas semanas de
} 
En términos de demanda, según las mediciones de consultoras privadas, el comportamiento en compras de alimentos tuvo dos momentos: uno inicial caracterizado por compras impulsivas traccionadas por la incertidumbre por desabastecimiento: ese momento se tradujo en asegurar stocks de alimentos en particular secos y rendidores (harina de maíz, otras harinas, premezclas, azúcar, tomates y otros vegetales envasados). En un segundo momento, aproximadamente a fines de abril, el consumo empieza una lógica de reposición más que de formación de stocks. Ese momento coincide con cierta seguridad de que el abastecimiento estaba asegurado y los comercios empezaron a organizarse de mejor manera en la atención al público y el resguardo de los necesarios protocolos. Se empezó a verificar también un ritmo de compras más frecuentes de cantidades más pequeñas.

Por otra parte, desde el Ministerio de Agricultura, Ganadería y Pesca se desarrollaron un conjunto de dieciséis lineamientos sobre buenas prácticas para diferentes producciones agropecuarias. Los mismos varían entre las distintas cadenas productivas, aunque la generalidad remiten a las precauciones para detección de síntomas de COVID-19, la higiene personal, el escalonamiento seguro de turnos de trabajo, distanciamiento, previsiones de elementos desinfectantes, limpieza de elementos y vehículos, prevenciones en relación a la circulación por rutas y caminos, limpieza de áreas de contacto entre compradores y vendedores, precauciones en relación con aglomeraciones, entre los principales (Ministerio de Agricultura, Ganadería y Pesca, 2020). En igual sentido, el mismo Ministerio de Agricultura, junto con la Bolsa de Comercio de Rosario, puso en funcionamiento una herramienta digital destinada a transportistas y trabajadores de cadenas productivas para la provisión de información esencial sobre prácticas sanitarias y otras relacionadas con el buen funcionamiento logístico para el movimiento de alimentos (Ministerio de Agricultura, Ganadería y Pesca, 2020).

Actualmente, la cadena alimentaria ha logrado estabilizarse, manteniéndose una oferta constante bajo un relativo control de precios. De todas maneras, aunque el sector alimentario es el menos afectado por la crisis del ASPO-COVID-19, dada la caída generalizada del consumo, se calcula -según CAME (2020)- una caída en el nivel de producción industrial en PyMES (cantidades) de 16\%, para el segundo trimestre del año, con respecto al mismo período del año anterior.

\section{POLÍTICA DE PRECIOS}

En el contexto de crisis del ASPO.COVID-19, la inflación de alimentos tendió primero a crecer en marzo-abril, para luego a desacelerarse en mayo. Si bien en mayo la inflación volvió a ser del 1,5\% mensual, los determinantes fueron distintos. Mientras que en abril la inflación había estado traccionada por los alimentos (+3,2\% mensual, debido a subas en frescos en tiendas de proximidad), en mayo y junio ocurrió lo contrario: los alimentos aumentaron $0,7 \%$ y 1\%, con una menor dispersión entre canales de comercialización.

En este contexto, una de las mayores preocupaciones del Gobierno fue controlar que no se produzcan abusos de precios que perjudicaran a los consumidores en un contexto de vulnerabilidad social. Para eso, reguló una Ley de Abastecimiento y presentó una aplicación móvil para que los compradores puedan verificar y denunciar a todos aquellos locales que no tuvieran precios retrotraídos al 6 de marzo,

mayo se inició un proceso progresivo de reapertura, bajo estrictos protocolos de higiene y distanciamiento. Actualmente se han reabierto 127 de los 186 emplazamientos preexistentes (Gobierno de la Ciudad de Buenos Aires, 2020) 
según lo dispuso la resolución 100/2020 de la Secretaria de Comercio. En este marco, se ha mantenido vigente una normativa específica de Precios Máximos. ${ }^{73}$

Estas medidas, obligaron a los comercios a retrotraer los precios de diversos productos de consumo masivo al 6 de marzo, logrando un alto acatamiento en las grandes cadenas. En efecto, en la semana previa a la cuarentena los precios de los alimentos superaron una tasa de aumento de $3,5 \%$ mensual, de acuerdo a la media móvil 30 días. Tras el 20 de marzo, se registró una menor velocidad de suba en los precios, de modo que la suba acumulada hasta el 31 de mayo fue del 0,9\%. También hubo medidas dirigidas a mantener el consumo como la extensión del Programa Ahora 12.

Entre otras iniciativas acordadas por los agentes económicos y que acompañaron estas medidas destaca el plan "Compromiso Social de Abastecimiento" desarrollado por el Mercado Central de Buenos Aires (el MCBA suministra alimentos a 13 millones de personas distribuidas entre Capital y el Gran Buenos Aires). El mismo busca garantizar el pleno abastecimiento de alimentos frescos a "precio justo". Para ello el MCBA convocó a los operadores a regular los aumentos estacionales de precios de los productos frutihortícolas de manera acordada. El objetivo es evitar aumentos desmedidos en frutas y verduras durante la pandemia, siendo los valores publicados como precios de referencia para aportar transparencia en la comercialización.

En el Ministerio de Desarrollo Productivo, la Dirección de Análisis y Evaluación de Mercados utiliza un registro de precios (Programa "Precios Claros") para monitorear los precios diarios de unos 900 productos de consumo masivo en los supermercados (alimentos y bebidas y productos de cuidado personal y limpieza). De acuerdo con esta base de datos, en mayo la inflación de alimentos y bebidas en los supermercados (incluyendo frescos como verduras, frutas y carnes) fue del 0,8\%, inferior al 0,9\% registrado en abril y 2,5\% de marzo. Es factible que uno los factores detrás de esta desaceleración haya sido justamente el impacto de Precios Máximos.

En primer semestre de 2020, los alimentos acumulan un crecimiento de tres puntos por encima del nivel general de precios; carnes, lácteos, aceites, golosinas e infusiones tienen un crecimiento aún por encima de los alimentos en conjunto, mientras que frutas, vegetales, bebidas y panificados y cereales acumulan un crecimiento algo inferior.

Tal como se analizó en el diagnóstico, el valor de la canasta básica de alimentos (CBA) experimentó un aumento de 7,4\% con relación al momento previo a la vigencia del ASPO (15,7\% con relación a diciembre 2019). En los mismos momentos, el conjunto de alimentos que integra el IPC aumentó 9,7\% y $17,5 \%$ respectivamente. La CBA sin embargo tiene una serie de características que, si bien son propias de su metodología, reflejan un modelo de dieta con amplias brechas en relación a un estándar saludable (ver anexo del Capítulo III). El último valor de la CBA (junio de 2020, \$18,030 mensuales para una unidad familiar de 2 adultos y 2 escolares) (INDEC, 2020b) representa dos terceras partes del costo mínimo de una versión saludable de canasta (junio de 2020, \$26,970 para la misma unidad fa$\left.\operatorname{miliar}^{74}\right)$.

\footnotetext{
${ }^{73}$ El Ministerio de Desarrollo Productivo -a través de la Secretaría de Comercio Interior- fijó "precios máximos de referencia" para ciertos productos esenciales, como alimentos, bebidas, artículos de higiene personal y de limpieza. El precio de comercialización de estos artículos (especificados en un listado para cada provincia) debía retrotraerse al valor que tenían el 6 de marzo de 2020 y congelarse hasta el 30 junio. En la misma línea se dispuso una prórroga al congelamiento de tarifas para el transporte y distribución de energía eléctrica (a través de la Secretaría de Energía) que estableció mantener los precios vigentes en 2019 hasta el mes de octubre de 2020. Anteriormente el gobierno prohibió la suspensión de servicios públicos (electricidad, agua y gas) por falta de pago, esto también en función de garantizar la provisión de los mismos en el contexto de aislamiento. Asimismo, el gobierno dispuso hasta el 30 de septiembre de 2020 el congelamiento de alquileres y cuotas de créditos hipotecarios, junto a la prohibición de desalojos y suspensión de ejecuciones de hipotecas.

${ }^{74}$ Estimación de la Cátedra de Economía, Escuela de Nutrición, Universidad de Buenos Aires.
} 
En la perspectiva de una dieta ajustada a las recomendaciones de las Guías Alimentarias para la población argentina, el $75 \%$ del valor de la misma canasta saludable (aproximadamente $\$ 20,000$ ) corresponde a los cinco grupos de consumo más recomendado: hortalizas, frutas, lácteos, carnes y legumbres y cereales. En el actual contexto, es probable que se haya profundizado el deterioro de la calidad de dieta de la población más vulnerable: su patrón alimentario era poco saludable antes de la pandemia, los precios de los alimentos de mejor calidad no son objeto de ninguna especial protección y los programas alimentarios que asisten a los más pobres no han mejorado la calidad de su consumo (incluso probablemente lo hayan empeorado).

\subsection{POLÍTICAS ALIMENTARIAS EN CONTEXTO COVID-19 EN EL MARCO DEL PLAN ARGENTINA CONTRA EL HAMBRE.}

A partir del 20 de marzo, en el marco del aislamiento social preventivo y obligatorio (ASPO), se generó una significativa modificación en la organización de los diferentes programas alimentarios. Hasta las semanas previas al inicio del ASPO la agenda social alimentaria se hallaba focalizada en el inicio de las acciones del Plan Argentina contra el Hambre (PACH) (ver Capítulos III y IV).

El objetivo del PACH es garantizar la seguridad y soberanía alimentaria de toda la población, con especial atención en los sectores de mayor vulnerabilidad económica y social. Entre sus objetivos específicos y líneas estratégicas se destacan la complementación de ingresos del hogar para comprar alimentos; el fortalecimiento de las prestaciones alimentarias ya establecidas por medio de programas gubernamentales o de organizaciones sociales; la promoción de la producción local de alimentos y su integración al $\mathrm{PACH}$; y el acompañamiento para la formación de hábitos saludables en las familias (MDS, 2020a y 2020b).

El Decreto 260 del 12 de marzo 2020 (ampliatorio de la emergencia sanitaria en virtud de la pandemia por COVID-19) estableció que el Ministerio de Desarrollo Social deberá articular los dispositivos para la asistencia en la emergencia con las recomendaciones de la autoridad sanitaria (Ministerio de Salud). En ese marco se creó un Comité de Emergencia Social para la planificación y seguimiento de las acciones que se desarrollen en los ámbitos jurisdiccionales entre el Gobierno nacional, los provinciales, municipales, organizaciones de la sociedad civil, religiosas y de distintos movimientos sociales. Los temas que forman la agenda de este Comité se relacionan con el conjunto de problemáticas y necesidades que se potencian por las condiciones de aislamiento impuestas por la pandemia.

A lo largo del período transcurrido en contexto de ASPO, este Comité realizó una serie de reuniones con autoridades municipales del conurbano de Buenos Aires y con autoridades de las áreas sociales de las provincias. La intención de las autoridades nacionales es que a nivel local se repliquen estos comités para intervenir en la identificación, análisis y resolución de los aspectos operativos inherentes a los programas y transferencias que efectúa el Ministerio de Desarrollo Social. De manera más o menos formal, esto ha ocurrido; sin embargo, una adecuada coordinación de acciones a nivel interjurisdiccional sigue siendo una materia pendiente.

En el marco de la crisis sanitaria ASPO-COVID-19 se destaca como acciones prioritarias del Ministerio de Desarrollo Social dos componentes del PACH orientadas al objetivo de garantizar la seguridad alimentaria en poblaciones vulnerables: i) el programa Alimentar y ii) la asistencia alimentaria directa a través de comedores escolares, merenderos y comedores comunitarios. 


\section{PROGRAMA TARJETA ALIMENTAR}

Del total de tarjetas, antes del inicio del ASPO se habían distribuido 1,1 millón y respecto del faltante (400 mil) se decidió transitoriamente asignarlo a través de la tarjeta de la Asignación Universal por Hijo y Embarazada (AUH), por los mismos montos previstos (\$ 4 mil o $\$ 6$ mil). El total de titulares de ese programa fue en julio 2020 de 1.530 .149 hogares beneficiarios, alcanzando a un conjunto de 2,8 millones de destinatarios (niños y niñas de 0 a 6 años embarazadas y personas con discapacidad que perciben la Asignación Universal por Hijo) (ver Cuadro 8). Este programa implica actualmente un gasto mensual de $\$ 7.719 .960 .000$, lo cual representará una erogación anual de más de 91.000 .000 .000 de pesos (MDS, 2020c).

La tarjeta Alimentar es un medio de pago para compras de alimentos, con excepción de bebidas alcohólicas y azucaradas. Mensualmente, los titulares de tarjetas disponen de $\$ 4$ mil (familias con un solo hijo hasta 6 años) o $\$ 6$ mil (más de un hijo) y pueden utilizarlo en cualquier comercio que disponga del correspondiente dispositivo electrónico que permita el procesamiento del pago. En abril se modificó la frecuencia de transferencia (carga de la tarjeta), que pasó a ser semanal (cuatro transferencias los viernes de cada semana). El objetivo de esta medida fue aumentar la liquidez con que cuentan las familias y a la vez evitar la concurrencia masiva al momento de comprar los alimentos. Sin embargo, esta medida fue revertida a finales de junio, volviendo a ser un pago mensual, dado que se observó que la mayor frecuencia reducía el manejo eficiente del gasto familiar.

En mayo se implementó un refuerzo económico extraordinario por única vez (de igual monto al de las transferencias habituales) con el objetivo de atender necesidades alimentarias adicionales atribuibles a la emergencia por COVID 19. Habiéndose llegado al umbral de población destinataria priorizada (MDS, 2020c). En ocasión de la entrega de tarjetas a sus titulares, se distribuyeron materiales gráficos (folletos) y recetas de preparaciones y se realizaron actividades breves de educación alimentaria, las que generalmente estuvieron siempre limitadas a ese primer y único contacto con las familias. Actividades que se suspendieron a partir del 20 de marzo.

Como se mencionó antes, el estudio de tipo panel a 500 hogares del Área Metropolitana de Buenos Aires (CABA y 30 partidos de la provincia de Buenos Aires), a cargo del Observatorio de la Deuda Social Argentina (ODSA-UCA, 2020a), mostró que los hogares y niños/as en situación de pobreza en 2019, que eran beneficiarios de AUH y programa Alimentar, se habrían visto menos afectados en reducir sus consumos básicos, o en caer o agravar un estado de inseguridad alimentaria, cuando se los compara con sus pares pobres con o sin AUH que no tienen el beneficio complementario de la tarjeta Alimentar. La evidencia abona la hipótesis de que esta herramienta es útil como mecanismo para elevar el piso de seguridad alimentaria en poblaciones y situaciones de riesgo social. Un dato relevante es que casi $30 \%$ de los hogares con niños/as o adolescentes es beneficiario de este complemento de ingresos en el AMBA. 
Cuadro 8. Tarjeta Alimentar: Titulares e Inversión Mensual (diciembre 2019 - julio 2020). En millones de pesos.

\begin{tabular}{|l|c|c|}
\hline \multicolumn{1}{|c|}{ Mes } & Titulares & Monto pagado \\
\hline Diciembre & 6.92 & $\$ 35.432 .000$ \\
\hline Enero & 407.487 & $\$ 2.074 .958 .000$ \\
\hline Febrero & 873.275 & $\$ 4.419 .008 .000$ \\
\hline Marzo & 1.444 .429 & $\$ 7.288 .678 .000$ \\
\hline Abril & 1.529 .700 & $\$ 7.717 .778 .000$ \\
\hline Mayo & 1.530 .153 & $\$ 7.719 .876 .000$ \\
\hline Mayo* & 1.529 .699 & $\$ 7.717 .774 .000$ \\
\hline Junio & 1.530 .152 & $\$ 7.719 .872 .000$ \\
\hline Julio & 1.530 .149 & $\$ 7.719 .860 .000$ \\
\hline Total & & $\$ \mathbf{5 2 . 4 1 3 . 2 3 6 . 0 0 0}$ \\
\hline
\end{tabular}

$\left(^{*}\right)$ Refuerzo extraordinario

Fuente: MDS (2020c)

\section{Consumos de los beneficiarios}

El Ministerio de Desarrollo Social recibe semanalmente reportes de los consumos y gastos que realizan los beneficiarios a nivel regional, provincial y local, con el objetivo de discriminar y analizar la calidad nutricional de las compras. Durante los meses de febrero, marzo y abril estos informes se realizaron sobre beneficiarios de tres áreas: Metropolitana de Buenos Aires, Santa Fe y Rosario. La tendencia general indica que el $38,8 \%$ de la cantidad de los productos adquiridos y el $50,9 \%$ de los gastos corresponden a alimentos que el Plan identifica como recomendables ${ }^{75}$. Un $20,7 \%$ del gasto total se destina a productos no recomendables (fundamentalmente productos alimentarios con altos contenidos de azúcar o sodio). Y el resto (aproximadamente $28 \%$ ) a otros productos, de calidad intermedia según la clasificación del Ministerio (MDS, 2020b).

Según los informes de consumos de la tarjeta Alimentar, para el Área Metropolitana de Buenos Aires (primeros días de marzo, inicio del ASPO y fines de abril) se observa que en el segundo período analizado cayó el consumo de alimentos frescos. Asimismo, se produjo un aumento del consumo de alimentos no perecederos (especialmente harinas, arroz y puré de tomates, dulces, aceites e infusiones). Sin embargo, el nivel de consumo de productos recomendados y de alimentos frescos volvió a aumentar en el momento en que el aislamiento social cumplía algo más de un mes. En el último tramo analizado (segunda semana de abril de 2020), el gasto en productos recomendados alcanzaba al $67 \%$ del total, con un $19,2 \%$ en productos no recomendados y un $13,8 \%$ en otros alimentos (MDS, 2020b).

Los diez primeros rubros de gasto en orden descendente son carnes (frescas y procesadas), lácteos, harinas y cereales (azucarados y no), aceite, productos azucarados (azúcar/jugos en polvo/dulces y golosinas), yerba, verduras, frutas, aderezos y puré de tomates (MDS, 2020a). Si bien los resultados

\footnotetext{
${ }^{75}$ Verduras, frutas, lácteos, proteínas animales, legumbres, agua y conservas de verduras y legumbres
} 
son parciales en tiempo y geográficamente, y aun cuando un $50 \%$ o $60 \%$ del gasto en productos recomendables es un porcentaje elevado, su reflejo en cantidades adquiridas $(38,8 \%$ en la tendencia general) es menor a la composición habitual de las compras de alimentos de los hogares (INDEC, 2020b).

Estas estimaciones surgen del CEPEA a partir de la información que proviene de la base de Precios Claros de la Dirección de Análisis y Evaluación de Mercados del Ministerio de Desarrollo Productivo y del análisis de la Encuesta de Gasto de Hogares (INDEC, 2018). Según datos de esta última encuesta, en la compra total (mensual), los mismos alimentos que Alimentar identifica como recomendables representan un $60 \%$ del volumen físico -excluyendo bebidas- (63\% en el quintil de más bajos ingresos) comparado con el $38,8 \%$ que surge de los registros del Plan oficial.

\section{ASISTENCIA ALIMENTARIA DIRECTA}

En el marco de sus acciones, el Ministerio de Desarrollo Social de la Nación mantiene un sistema de transferencias por convenios con Gobiernos y organizaciones sociales para refuerzos de comedores escolares, comunitarios y compra directa de alimentos. Esto le permitió responder en forma rápida y a gran escala al aumento registrado en la demanda alimentaria a partir de la crisis ASPO-COVID-19.

En este contexto, el Ministerio de Desarrollo Social reforzó la asistencia alimentaria a comedores escolares y comunitarios a través de la ampliación de las partidas presupuestarias en 2 mil millones de pesos. Además, se organizó un sistema de viandas o módulos alimentarios que respeta las prevenciones del distanciamiento social y se conformó un comité de seguimiento de la situación de los comedores comunitarios. Asimismo, se realizaron compras para comedores y merenderos de guantes descartables, lavandina, kits de limpieza y bandejas descartables para la elaboración de las viandas y se enviaron afiches para la difusión de las medidas de prevención del corononavirus (MDS, 2020c). Además de más de 19 mil comedores escolares, un número creciente de comedores populares fueron asistidos por estas medidas. Algunas estimaciones oficiales informan un número de comedores (y merenderos) cercano a los 10 mil en todo el país, de los cuales unos 5 mil se encuentran formalizados y reciben las transferencias en forma directa para comprar los alimentos en comercios de cercanía (ver Capítulo IV).

Según el estudio panel del ODSA-UCA en el Área Metropolitana de Buenos Aires antes citado (ODSAUCA, 2020a), mientras que en julio-octubre de 2019, el 9\% de los hogares de esta región recibían o recogían viandas o alimentos de un comedor escolar o comunitario, a principio de mayo de 2020 esta cifra ascendió al 16\% para esos mismos hogares. En el caso de los hogares con niños, niñas o adolescentes, el estudio registró que un $28 \%$ de ellos recibieron algún tipo de asistencia alimentaria directa (recibió o retiró vianda o comida de un comedor).

Más allá de que es evidente que estos programas han logrado una amplia cobertura e impacto social, no constituyen una política integrada en materia nutricional. Esto se debe a que la asistencia alimentaria mantiene una matriz similar a la preexistente tanto a la pandemia como a la actual gestión gubernamental. Los diferentes programas de comedores (escolares, comunitarios) y las transferencias a provincias, municipios y organizaciones sociales que tienen el mismo destino, no responden a un diseño nutricional superador de las brechas de calidad conocidas (amplios déficits en hortalizas, frutas, legumbres y lácteos y excesos en fuentes alimentarias de carbohidratos complejos de baja calidad y azúcares) (Britos, 2017). A la vez que las restricciones impuestas por el ASPO habrían potenciado estas características, que se resumen en un modelo de asistencia alimentaria de rasgos obesogénicos (en un 
contexto de $40 \%$ y $68 \%$ de exceso de peso en niños en edad escolar y adultos, respectivamente, según la Encuesta Nacional de Nutrición y Salud 2018) (ver Capítulo III).

\section{Comedores escolares}

El cierre de los establecimientos escolares, incluso cuando es temporal, es problemático por numerosas razones. Diez millones y medio de niños, niñas y adolescentes asisten a clases (el $70 \%$ en escuelas públicas). El $80 \%$ de las escuelas de gestión estatal ofrecen desayuno, almuerzo o refrigerio. Se estima que alrededor de 2 millones de familias están actualmente recogiendo viandas o alimentos de las escuelas. La prestación para comedores escolares tiene por objetivo el mejoramiento de los servicios alimentarios en las escuelas financiando un refuerzo de la alimentación en aquellas que se encuentran en situación de riesgo socioeducativo de acuerdo con los criterios fijados en los proyectos de financiamiento en el marco de los programas provinciales. Además, se está implementando el complemento de la dieta escolar a los comedores escolares en las provincias.

Con anterioridad a la emergencia COVID-19, la renovación por parte del Ministerio de Desarrollo Social de los convenios de Complemento de Comedores Escolares permitió la actualización y mejora de los montos de las prestaciones que, en su mayoría, no se reajustaban desde 2016, y que, además habían sido reducidos por efecto inflacionario. Asimismo, se acordó con las jurisdicciones el financiamiento total de una prestación o de un grupo de ellas o de localidades focalizadas. Durante el actual ejercicio se prevé la aplicación de una adenda que incremente los fondos destinados a la Actividad Comedores Escolares de un $15 \%$ a $25 \%$ sobre el monto de los convenios originales.

Ahora bien, las medidas de emergencia sanitaria implicaron el cierre de las escuelas y una rápida modificación en la logística de suministro de raciones en los establecimientos (mayormente desayunos y almuerzos). En este marco, el Ministerio de Desarrollo Social amplió de manera extraordinaria el presupuesto destinado al refuerzo alimentario de los comedores escolares provinciales, firmando convenios con quince provincias. La suma total de los convenios firmados con gobiernos provinciales destinados a comedores escolares asciende a \$7.301.361.155 (Cuadro 9). Actualmente, todos los meses se brinda asistencia financiera a 19.432 comedores escolares en todo el país, complementando las acciones realizadas por los gobiernos provinciales.

Al inicio de la emergencia, en la mayoría de las jurisdicciones se inició la entrega de viandas listas para consumir. Las familias de los escolares debían concurrir a retirarlas, operatoria que en algunas jurisdicciones se implementó solo unos pocos días. Las viandas se conformaban con preparaciones de consumo rápido y bajo valor nutricional (ej.: sándwiches o pizzetas) o bien una prestación con un lácteo (leche) y algún panificado (pan o galletitas), dependiendo de si se trataba de una prestación de desayuno o almuerzo. A las pocas semanas, en varias jurisdicciones la modalidad se modificó por otra basada en módulos (bolsones) distribuidos quincenalmente. En algunos casos los alimentos se repiten en forma idéntica en cada entrega y en otros se conforma una planificación mensual con distribución quincenal de productos variados. La conformación de los módulos se rige por algunos lineamientos que suelen privilegiar el aporte de productos de densidad calórica entre media y alta junto a alguna cuota de proteínas de origen animal. Son pocos los casos en que se agregan frutas o verduras en los módulos. En la actualidad coexisten ambas estrategias: viandas con comidas listas que se retiran en las escuelas y módulos generalmente quincenales.

Según estimaciones gubernamentales, el total de niños que comen en las escuelas y que transitoriamente son atendidos con viandas o módulos alimentarios son 3 millones (se entiende que estos números comprenden a 15 provincias con las cuales se han firmado convenios en 2020 , entre las cuales no 
se encuentra la provincia de Buenos Aires, que representa un porcentaje cercano al $40 \%$ del total país). El monto por beneficiario, en el caso de provincia de Buenos Aires se halla en el orden de \$50 diarios (U\$S $\left.0,71^{76}\right)$, mientras en otras provincias serían menores (aproximadamente $\$ 30$ diarios).

Cuadro 9: Montos por Provincia Conveniados Destinados a Comedores Escolares Provinciales (a julio de 2020).

\begin{tabular}{|l|c|c|}
\hline PROVINCIA & MONTO \$ (CONVENIO) & ESCUELAS \\
\hline BUENOS AIRES & 4.000 .000 .000 & 10.734 \\
\hline CATAMARCA & 109.966 .968 & 409 \\
\hline CHACO & 298.658 .700 & 46 \\
\hline CHUBUT & 24.003 .811 & 972 \\
\hline CÓRDOBA & 224.521 .043 & 614 \\
\hline CORRIENTES & 125.003 .205 & 924 \\
\hline ENTRE RÍOS & 143.283 .613 & 1.062 \\
\hline FORMOSA & 179.520 .000 & 308 \\
\hline JUJUY & 191.999 .341 & 25 \\
\hline LA PAMPA & 43.778 .400 & 289 \\
\hline LA RIOJA & 100.980 .960 & 200 \\
\hline MENDOZA & 207.765 .360 & 254 \\
\hline MISIONES & 127.997 .181 & 251 \\
\hline NEUQUÉN & 182.294 .389 & 63 \\
\hline RÍO NEGRO & 67.079 .794 & 191 \\
\hline SALTA & 102.004 .020 & 184 \\
\hline SAN JUAN & 185.083 .200 & 225 \\
\hline SANTA CRUZ & 170.426 .080 & 19.432 \\
\hline SANTA FE & 199.687 .831 & 57 \\
\hline SANTIAGO DEL ESTERO & 79.961 .200 & 74 \\
\hline TIERRA DEL FUEGO & 88.000 .000 & 545 \\
\hline TUCUMÁN & 449.346 .060 & 7.301 .361 .155 \\
\hline TOTAL & & \\
\hline
\end{tabular}

Fuente: Ministerio de Desarrollo Social, (2020c)

\section{Comedores sociales y merenderos}

Según las estimaciones gubernamentales del Ministerio de Desarrollo Social, la demanda global (nacional) de asistencia alimentaria se amplió de manera significativa. Según las máximas autoridades, se ha pasado de un total de 8 millones a más de 11 millones de personas atendidas (por fuera de la recepción de la tarjeta AlimentAR) a través de diferentes redes de comedores, merenderos y puntos de entrega de alimentos. En la emergencia por COVID-19, estos efectores, del mismo modo que lo ocurrido en las escuelas, han modificado su modalidad tradicional de comida en el lugar por una combinación entre distribución de viandas (comidas listas) y módulos de alimentos. Estos últimos se reparten

\footnotetext{
${ }^{76}$ Con el tipo de cambio al momento de escribir esta sección.
} 
en la mayoría de los casos con frecuencia quincenal a causa de una mejor organización logística y limitación de la movilidad de las personas.

El Ministerio de Desarrollo Social apoya mensualmente a 1.198 organizaciones comunitarias con asistencia técnica y financiera. Estas organizaciones brindan servicios alimentarios regulares a 230.397 personas en situación de vulnerabilidad social en todo el país. En el mes de junio, se dispuso una ayuda extraordinaria para la compra de alimentos secos para 707 organizaciones. Desde comienzos de 2020 se han transferido para ambos conceptos un total de $\$ 1.721 .123 .827$. Por otra parte, ante la emergencia, se firmaron 46 convenios con 707 organizaciones, a las cuales se apoyó con financiamiento extraordinario para la compra de alimentos secos destinados a comedores comunitarios (MDS, 2020c).

En el contexto de la pandemia COVID-19, se incorporó una cláusula en los nuevos convenios vinculada al componente de salud e higiene para autorizar la compra de artículos de higiene esencial. Además, se elaboró un instrumento con sugerencias en la manipulación de alimentos y medidas de cuidado e higiene para implementar y distribuir en los merenderos y comedores. También se autorizó la compra de elementos de limpieza y aseo personal para las personas que trabajan en los efectores.

Los lineamientos relacionados con la conformación de los módulos o viandas de comedores comunitarios suelen limitarse a la referencia de la canasta básica de alimentos (CBA), productos de base seca y no perecederos y la inclusión de una o dos variantes de fuentes proteicas de origen animal (generalmente leche en polvo y pescado envasado y más ocasionalmente huevos). Algunos municipios utilizan los fondos recibidos para realizar compras locales de alimentos frescos.

Además de la asistencia financiera a distintos comedores a través de los convenios específicos, efectores a través de sus respectivas organizaciones, otras dos líneas programáticas del Ministerio de Desarrollo Social son las compras centralizadas de alimentos para su distribución directa a comedores y merenderos y las transferencias a provincias y municipios para que estos compren alimentos.

A través de la compra centralizada y el envío directo de alimentos a granel para el armado de módulos a organismos gubernamentales y no gubernamentales, entre enero y mayo, se entregaron 2.639.163 módulos. En cuanto a la segunda de las líneas, se financió la adquisición de alimentos secos y frescos para cubrir las prestaciones alimentarias de familias en situación de vulnerabilidad social por un monto total de $\$ 600.000$ (100 mil módulos) (MDS, 2020c).

\subsection{OTROS PROGRAMAS ALIMENTARIOS-NUTRICIONALES EN CONTEXTO COVID-19.}

Antes del ASPO-COVID-19, el Ministerio de Desarrollo Social tenía en alta prioridad la necesidad de emprender una agenda orientada a fortalecer la producción y comercialización de alimentos de la economía local. Esta estrategia incluía el financiamiento y apoyo a productores locales y agricultura familiar y la promoción de su producción a través de la instalación de mercados populares y ferias barriales; vinculando además la producción local con las compras a través de la tarjeta ALIMENTAR. Hasta el momento y en particular por las implicancias del aislamiento obligatorio, estas iniciativas están suspendidas y sin recursos para su desarrollo.

Igual situación parece estar atravesando el ProHuerta, en tanto programa modelo del Ministerio de Desarrollo Social en conjunto con el Instituto Nacional de Tecnología Agropecuaria (INTA), en materia de desarrollo de agricultura familiar. Actualmente, este programa alcanza a un total de 686.970 huertas 
familiares, 16.338 huertas escolares, 1.838 huertas comunitarias y 5.108 huertas institucionales (ver Capítulo IV). Todas ellas reciben semillas y capacitación para el armado de la huerta. Apenas iniciado el ASPO se realizó la entrega de semillas de la temporada otoño-invierno, con el apoyo y acompañamiento de gobiernos locales, organizaciones y promotores, lo que permitió llegar a los distintos barrios durante el aislamiento obligatorio (MDS, 2020c).

También se realizaron actividades de entrega de animales de granja (para producción de huevos y carne), siguiendo protocolos de higiene sanitaria (por COVID-19) establecidos por el INTA. Durante la vigencia del ASPO, las capacitaciones para el seguimiento de las actividades del programa migraron a un formato virtual, cuyo desarrollo depende de las disponibilidades y funcionamiento de la conectividad de la población beneficiaria, sin que tuviera lugar ninguna iniciativa adicional a gran escala.

Asimismo, en el actual contexto de crisis sanitaria no han tenido especial prioridad programas nutricionales como el Materno-Infantil, a través de su prestación de leche fortificada (transferencia de fondos a las provincias para su adquisición), ni el Programa Nacional de Promoción de Alimentación Saludable y Prevención de Obesidad, ambos en ámbito del Ministerio de Salud (ver Capítulo III).

En cuanto al primero, no hubo ninguna modificación en el esquema de transferencias, aunque la actividad en cada provincia puede verse afectada en diferentes medidas por el hecho que los centros de atención primaria de salud (puntos de distribución de leche) están, como el conjunto del sistema de salud, priorizando la estrategia COVID-19. Esto puede afectar la regularidad de distribución de leche fortificada, sumado a la propia retracción de la asistencia de la población a los centros sanitarios a causa de la menor movilidad. Las compras de leche con destino a este programa son realizadas por el Ministerio de Desarrollo Social, el que se ha visto afectado en el lapso de los últimos tres meses por denuncias e irregularidades detectadas en los procedimientos de compra y que han alterado el ritmo de adquisiciones en general, lo cual también comprende las de leche fortificada.

La mayoría de las acciones del Programa de Promoción de Alimentación Saludable y Prevención de Obesidad no son propias de la emergencia alimentaria por COVID-19. Antes de la implementación del ASPO, el programa se hallaba en proceso de formulación de estrategias (y firmas de algunos convenios con las provincias) en las áreas de prevención de obesidad infantil, entornos escolares saludables, mejoramiento de la calidad nutricional en programas alimentarios y etiquetado frontal de alimentos. Al momento de ingresar al período de ASPO la nueva gestión de gobierno aún no había explicitado nuevas orientaciones y líneas estratégicas. El programa mantiene sus actividades, aunque más limitadas a la preparación de documentos e investigaciones convergentes con sus líneas de acción.

\subsection{INICIATIVAS NO GUBERNAMENTALES EN PROGRAMAS ALIMENTARIOS- NUTRICIONALES EN CONTEXTO COVID-19.}

\section{INICIATIVA SEAMOS UNO}

En el mismo contexto en que fueron desarrollándose distintas respuestas desde el ámbito gubernamental para el refuerzo de la asistencia alimentaria en la pandemia, en abril empezó a gestarse una iniciativa solidaria que reúne aportes de empresas y organizaciones del sector privado, instituciones religiosas de diferentes cleros y organizaciones sociales como Caritas, el Banco de Alimentos y el Centro de Investigación y Acción Social de la Compañía de Jesús. 
La Iniciativa se propuso reunir donaciones para asistir en forma rápida en la emergencia y aislamiento a 4 millones de personas del Área Metropolitana de Buenos Aires. El programa consiste en la distribución (directa a cada hogar) de una caja con 15 kilos de productos (alimentos y elementos de limpieza) que totalizan 56 raciones planificadas para una semana para una familia promedio. Todo el proceso logístico desde la recepción de donaciones, adquisición de los alimentos hasta su entrega en cada hogar es monitoreado en forma trazable. Las cajas se arman en dos centros logísticos especialmente dispuestos.

Los alimentos que integran las raciones son: 4 kilos de arroz/fideos secos, 2 kilos de harina, 2 unidades de puré de tomate, 2 unidades de latas de conservas, 1 kilo de lentejas secas o porotos, 3 litros de leche, 4 latas de picadillo de carne y 2 latas de frutas (además se entrega jabón y detergente); en general, lamentablemente, una selección de alimentos con bajo valor nutritivo.

Las empresas y organizaciones privadas tienen la responsabilidad de obtención de donaciones para la compra de alimentos a valores de costo y la logística necesaria (cajas, galpones, ensamble y distribución). Las organizaciones sociales están a cargo de la identificación de las familias beneficiarias en los diferentes barrios (priorizando aquellas con mayor vulnerabilidad social y que no fuesen receptoras de otras ayudas gubernamentales) y a la vez participaron con sus voluntarios del despliegue local de recepción de las cajas y su distribución. Todo el proceso cuenta con un seguimiento digital en tiempo real y georreferenciado. La iniciativa se encuentra en pleno desarrollo, habiendo alcanzado (al momento de redactar este documento) un $45 \%$ de distribución y $70 \%$ de obtención de fondos respecto al objetivo de 1 millón de cajas y 4 millones de beneficiarios.

\section{PROTEIN PLUS}

El programa Protein Plus es una iniciativa de la ONG Solidagro basada en una experiencia previa denominada "Soja Plus" y articulada con el sector privado de origen agropecuario (productores y exportadores de granos) y diversas organizaciones sociales (Barrios de Pie, Movimiento Evita, CCC, Movimiento Dignidad, Caritas, Misioneros de Francisco). Se basa en la gestión de donaciones por parte de productores, que se traducen en el procesamiento de legumbres (inicialmente soja y en proyecto otras como garbanzos y lentejas) en dos plantas de texturizado de proteínas vegetales. El producto obtenido se destina, fraccionado en bolsas de $15 \mathrm{~kg}$ y $20 \mathrm{~kg}$ a los comedores comunitarios.

El texturizado de proteínas es un producto de elevado valor nutricional, que por sus características físicas y palatables se utiliza como reemplazo parcial de carne, produciendo un ahorro del orden del 95\% en una porción equivalente ( $25 \mathrm{~g}$ de texturizado en seco = $100 \mathrm{~g}$ de carne); el diseño del programa supone que ese ahorro pueda ser utilizado para un mejoramiento nutricional de la prestación con mayor consumo de hortalizas y frutas.

Los comedores beneficiarios reciben material (recetarios) y en algunos casos capacitaciones para el mejor uso culinario del producto y su combinación en preparaciones habituales. El proceso cuenta con un sistema de monitoreo trazable de las donaciones desde su origen hasta su conversión en platos de comida en las instituciones y un dispositivo (App) que permite la comunicación y capacitación continua en tiempo real entre los comedores y nutricionistas.

Actualmente la iniciativa alcanza unos 1.800 comedores en diez provincias y atiende a unas 250 mil personas y acaba de iniciarse una prueba piloto (fase II de Protein Plus) que suma al texturizado de proteínas vegetales la adquisición y distribución de hortalizas estacionales de mínimo costo que se 
compran en mercados mayoristas bajo la modalidad de recupero de hortalizas que ya perdieron su destino y valor comercial.

\section{REFLEXIONES FINALES: BALANCE GENERAL Y PERSPECTIVAS POST- PANDEMIA COVID-19.}

Este informe hace un examen sobre los impactos socioeconómicos de la crisis generada bajo el escenario COVID-19 y el tipo de políticas compensatorias encaradas por el gobierno argentino durante el primer semestre de 2020, esto con el fin de contar con un balance particular en el campo de la seguridad alimentaria y nutricional y aprender de las respuestas dadas por el gobierno y por la sociedad civil.

La crisis sanitaria global provocada por el COVID-19 tiene efectos multidimensionales que alejan el cumplimiento de los diferentes objetivos de la Agenda 2030. En este marco, la pandemia ha generado un nuevo escenario global, que exige tomar medidas urgentes y evaluar los impactos de estas acciones. Tal como proponen los lineamientos globales propuestos en "Reconstruir mejor", elaborados por la oficina del Secretario General de Naciones Unidas (ONU, 2020b), y retomados por el Sistema de las Naciones Unidades en la Argentina, la crisis de la pandemia provocada por el COVID-19 requiere una respuesta eficaz en tres grandes frentes, que permitirá a la Argentina retomar un camino hacia la consecución de los ODS: el inmediato fortalecimiento de los gobiernos (en sus tres niveles) y las comunidades para contener la transmisión del virus; la mitigación del impacto socioeconómico, y el fortalecimiento de la capacidad del Estado para la recuperación.

Estos tres ejes aplican a muchos países en desarrollo, incluidos aquellos de ingresos medios como Argentina. Pero su situación presenta particulares retos. El país ya enfrentaba una seria contracción económica antes de la pandemia, con años de recesión, caída en el empleo y aumento de la pobreza. A la vez, la situación financiera del país, en plena renegociación de su deuda externa, lejos está de contar con la capacidad de atender todas las demandas internas, multiplicadas exponencialmente por la pandemia. La crisis de la actividad económica, la caída del consumo, la quiebra de empresas y la destrucción de empleos tienden a agudizar las tensiones preexistentes en el sistema socioeconómico argentino. La inversión, la demanda y el empleo se deterioraron en forma abrupta y casi generalizada, afectando especialmente -aunque no de forma exclusiva- a los sectores pobres informales y de la economía popular, trabajadores formales de pequeña y mediana empresa, pequeños empresarios, autónomos y profesionales independientes.

Como consecuencia de estos procesos, las medidas de ASPO-COVID-19 -incluyendo su prolongación para el Área Metropolitana de Buenos Aires- no sólo deja como saldo mayores niveles de desempleo y pobreza, sino también una inseguridad alimentaria y nutricional más extendida, a la vez que con menos capacidades para ser superada por la propia iniciativa económico-ocupacional de los hogares. La generalizada crisis en la oferta y demanda de bienes y servicios puso -por falta de trabajo y brusca caída de los ingresos corrientes- en estado de inseguridad alimentaria a sectores populares y clases medias relativamente incluidos en los mercados laborales formales.

La situación de mayor exclusión estructural -con mayor brecha de pobreza- deja a los hogares pobresinformales y no pobres vulnerables con mayor dependencia de la asistencia pública. En este marco, se profundiza la relación entre informalidad económica, pobreza y marginalidad social. Es evidente que 
la actual emergencia sanitaria agrava el estado de crisis estructural de un sistema socioeconómico desigual y estancado desde hace varias décadas. La situación tiene severas consecuencias económicas y sociales, en una sociedad que viene transitando un largo ciclo de crisis y estancamiento. Si bien las medidas parecen haber amortiguado el impacto de la actual crisis sobre las condiciones de vida, ellas no bastan para compensar la retracción económica, la destrucción de empleo y el aumento del empobrecimiento, en especial, entre los sectores sociales que se ven impedidos de mantener sus actividades laborales y carecen de un fondo de reserva.

En un sentido diferente, cabe tomar en cuenta que el acceso a un nivel adecuado de protección social es un derecho fundamental de todas las personas, reconocido por las normas internacionales del trabajo, el Pacto Internacional de Derechos Económicos, Sociales y Culturales y por las Naciones Unidas. Al respecto, la Argentina tiene una larga historia en esta materia y su sistema de protección social es uno de los más extendidos en América Latina y el Caribe, tanto en términos de su cobertura como por el abanico de sus prestaciones (ONU, 2020). Pero actualmente, su protección social es un complejo entramado de esquemas y programas que cubren los diversos riesgos sociales de gran parte de la población, aunque no en forma universal: vejez, invalidez, fallecimiento y acceso a servicios de cuidados de salud, desempleo, maternidad, riesgos de trabajo y enfermedades profesionales. El sistema de protección social para la niñez está fragmentado y responde a criterios y normas asimétricas. Mientras que las asignaciones familiares y la deducción de impuestos no demandan requisitos formales, la AUH requiere cumplir con condicionalidades en materia sanitaria y educativa y pone un tope máximo de cinco hijos/as. ${ }^{77}$

En este contexto, la política sanitaria adoptada por el gobierno bajo el escenario COVID-19 adoptó el supuesto que la mejor estrategia posible para enfrentar la pandemia era el aislamiento social y obligatorio (ASPO). Frente a esto, con el fin de aliviar el impacto regresivo de esta política, el gobierno lanzó una serie de medidas de protección y estímulo dirigidas a prácticamente todos los sectores sociales y productivos (empleadores, trabajadores en relación de dependencia, cuentapropistas, trabajadores informales e inactivos). La continuidad de los programas AUH, Alimentar, Salario Social Complementario y las Pensiones No contributivas, así como el Ingreso Familiar de Emergencia (IFE), el Programa de Asistencia al Trabajo y la Producción (ATP) y una serie de medidas laborales y comerciales regulatorias, fueron las principales estrategias desarrolladas de manera centralizada por el Estado para orientar las transferencias que se realizan a las familias más necesitadas. En ese marco, se amplió la asistencia alimentaria pública y privada directa a través de comedores escolares y comunitarios. En este caso, estas acciones tuvieron como principales protagonistas a las gobiernos provinciales-municipales, movimientos sociales y otras organizaciones de la sociedad civil. Todo ello bajo protocolos sanitarios, con recursos escasos, y por lo mismo, no menos restrictivos en cuanto a la posibilidad de una atención más focalizada y de mayor impacto nutricional.

Con relación a esta última dimensión, la Argentina previa al ASPO-COVID-19 arrastraba fallas de diseño en sus políticas alimentarias. Los programas que desde hace tiempo se ejecutan bajo los linea-

\footnotetext{
${ }^{77}$ La protección social vinculada con el aseguramiento del ingreso monetario para la niñez y adolescencia en la Argentina se estructura a partir de distintos componentes o sistemas. Por un lado, los/las trabajadores/as del sector formal con ingresos por debajo del mínimo no imponible del impuesto a las Ganancias perciben asignaciones familiares contributivas. Los/las trabajadores/as que se encuentran por encima de este mínimo cuentan con deducciones impositivas por hijas/os a cargo y se entiende que no requieren de otra asignación para asegurar sus ingresos monetarios. A partir de 2009, se implementó el subsistema no contributivo de AUH, destinado a aquellos niños, niñas y adolescentes menores de 18 años (o sin límite cuando se trate de personas con discapacidad), que no tengan otra asignación familiar y pertenezcan a grupos familiares que se encuentren desocupados, registrados como monotributistas sociales, personal de casas particulares o se desempeñen en la economía informal. En 2011, el alcance de la AUH se amplió a las mujeres embarazadas, y en 2016 a los monotributistas de ciertas categorías. Ver Capítulo I y II.
} 
mientos de la Ley 25724 (Plan Nacional de Seguridad Alimentaria) tienen poca consistencia con múltiples diagnósticos de la problemática nutricional que afecta a la población en general y los sectores más pobres en particular. En los últimos años la prevalencia de exceso de peso ha crecido hasta representar ocho veces más que el déficit de peso en niños menores de 6 años; y afecta al $40 \%$ de los escolares y el $68 \%$ de los adultos. Los componentes más deficitarios de la dieta integran en una baja proporción la oferta de comedores escolares, comunitarios, merenderos y bolsones o cajas de alimentos. Si bien no se trata de un programa con objetivos de nutrición, los listados de productos del programa de Precios Cuidados colisionan de manera directa con las recomendaciones de las guías alimentarias del Ministerio de Salud y la propia Canasta Básica de Alimentos que suele ser referencia para algunos diseños o presupuestos de programas difiere en grado significativo con una dieta saludable y preventiva de la problemática nutricional descripta.

Ninguno de estos aspectos (diseño nutricional de programas, consistencia de las acciones con las propias recomendaciones oficiales, equilibrio en la oferta alimentaria) han sido un objetivo priorizado en el marco del COVID-19, ni están siendo objeto de una elaboración específica para el período posterior a la pandemia actual causada por el COVID-19 (virus que, de todas maneras, seguirá presente en la sociedad). La falta de articulación entre los diagnósticos y recomendaciones de los especialistas y las áreas sanitarias y las respuestas sociales o económicas es una asignatura aún pendiente. Sin duda, los programas de apoyo al empleo, control de precios, protección social y asistencia alimentaria, emprendidos durante la emergencia sanitaria, ayudaron a amortiguar el impacto de la actual crisis sobre el consumo y las necesidades básicas de las familias, pero ellos no son suficientes para compensar la fuerte retracción económica y su impacto sobre la seguridad alimentaria y nutricional.

Aunque cualquier pronóstico resulta arriesgado, existen muchas dudas en cuanto al sendero que seguirán la situación sanitaria y la crisis economía post pandemia. El balance final en términos socioeconómicos dependerá de la duración de la política de aislamiento social, preventivo y obligatorio y del ritmo de recuperación económica posterior a la actual crisis. En cualquier caso, el resultado más probable es que tenga lugar un mayor deterioro de la seguridad alimentaria, tanto en sectores de pobreza estructural como de nueva pobreza.

Tal como quedó registrado en este capítulo, los efectos del COVID-19 afectan principalmente a las segmentos sociales y actividades económicas más vulnerables (mujeres, jóvenes, pueblos rurales pobres, pequeños productores, poblaciones rurales cuyos medios de vida dependen del turismo, trabajadores/as del sector informal, entre otras), que se encuentran menos equipadas para hacer frente a las disrupciones que la pandemia puede provocar en el sistema alimentario. Para ellos, el impacto del COVID-19 supone mucho más que la pérdida momentánea de ingresos: pone en jaque su seguridad alimentaria y nutricional. La actual amenaza es de una naturaleza distinta a las emergencias que estas poblaciones habitualmente enfrentan, en virtud de su escala global sin precedentes y al hecho de que afecta tanto a elementos de la oferta como de la demanda de alimentos. La cadena de suministro de alimentos es una compleja red que implica a productores/as, consumidores/as, insumos agrícolas y pesqueros, procesado y almacenamiento, transporte y comercialización. Cualquier alteración de esta red puede generar cambios en cualquier nodo de la red de distribución.

Asimismo, el cierre de las fronteras locales e internacionales, las cuarentenas, las interrupciones de los mercados y la cadena de suministro y el comercio limitan el acceso de las personas a fuentes de alimentos suficientes, diversas y nutritivas. En este desafiante escenario, resulta fundamental atender las necesidades de cada elemento que conforma la red de suministro de alimentos. Para ello, las indus- 
trias de alimentos y bebidas deben garantizar su producción, al mismo tiempo que priorizan la seguridad alimentaria y la de todo su personal. Una de las principales herramientas que los profesionales tienen en estas circunstancias es poseer un protocolo especial de higiene y desinfección contra brotes.

En este sentido, una importante lección que deja la pandemia es la necesidad de acortar las cadenas logísticas, fortalecer los mercados locales y la producción agroalimentaria de cercanía, lo cual, asimismo, señala oportunidades para la producción de alimentos más saludables y asequibles para la población y la creación de empleos más resilientes.

En el marco del diagnóstico que surge de este documento, en clave a los objetivos alimentarios planteados por el gobierno argentino a través del Programa Argentina Contra el Hambre (PACH), y otros previos en materia de salud nutricional, cabe formular algunas líneas de recomendación que se retomarán en el apartado de Conclusiones y Recomendaciones. Estas iniciativas procuran colaborar con el gobierno nacional, los gobiernos provinciales y municipales, y ayudar a las personas en situación de mayor vulnerabilidad.

- Contemplar en el Programa Argentina Contra el Hambre (PACH) un abordaje que favorezca la participación formalizada de productores/proveedores y organizaciones comunitarias locales de alimentos que puedan prestar servicios alimentarios destinados a la población en situación de pobreza y vulnerabilidad social.

- Asegurar un piso de calidad nutricional (acorde a la problemática prevalente) y fortalecer los diseños logísticos necesarios para asegurar una dieta saludable en los comedores escolares (empezando por el desayuno), de manera prioritaria para las regiones, sectores y grupos más pobres y vulnerables,

- Fortalecer a las organizaciones comunitarias y de la sociedad civil que brindan servicios alimentación y cuidado en función de aumentar su capacidad de gestión y a mejorar la calidad y las condiciones en que desarrollan la diversidad de servicios que prestan a sus comunidades.

- Promover la ampliación de la oferta alimentaria favoreciendo la inclusión de núcleos de productores de la economía local y popular como abastecedores del conjunto de políticas alimentarionutricionales, bajo marcos legales, reglas claras, estables y asequibles en el orden laboral, tributario, comercial y de prácticas de inocuidad alimentaria y de impacto ambiental.

- Ampliar el PACH al conjunto de los sectores vulnerables que seguramente, en el post COVID19 excederán a los beneficiarios de la Asignación Universal por Hijo; en particular, poblaciones de riesgo nutricional.

- Actualizar sus montos en forma periódica en base a un índice de precios que asegure la accesibilidad a una canasta priorizada de hortalizas, frutas, legumbres y lácteos (principales alimentos con brecha negativa de consumo en la población).

- Potenciar la vinculación del PACH a esa canasta priorizada de alimentos -clave no solo per se sino en términos de fortalecimiento del sistema inmune- antes de posibles rebrotes de COVID19.

- Ampliar significativamente la oferta de educación alimentaria a través de mensajes efectivos, concretos, persistentes y redundantes. 


\section{- BIBLIOGRAFÍA}

ANSES. (2020). Boletín IFE I-2020: “Caracterización de la población beneficiaria”. Dirección General de Planeamiento, Buenos Aires (julio 2020). Recuperado de: http://observatorio.anses.gob.ar/archivos/documentos/Boletin\%20IFE\%20l-2020.pdf

Arnau, J \& Bono, R. (2008). Estudios longitudinales de medidas repetidas: Modelos de diseño y análisis. Escritos de Psicología, 2(1), pp. 32-41.

BCRA (2020a). Resultados del Relevamiento de Expectativas de Mercado (REM), abril de 2020. Buenos Aires: BCRA.

------ (2020a). Resultados del Relevamiento de Expectativas de Mercado (REM), agosto de 2020. Buenos Aires: BCRA.

Bonfiglio, J.I y Vera, J; Salvia (2019). Pobreza monetaria y vulnerabilidad de derechos. Inequidades de las condiciones materiales de vida en los hogares de la Argentina urbana (2010-2018). 1a ed. - Ciudad Autónoma de Buenos Aires: Educa, 2019.

Britos S. y Borg A. (2017). Consumo de alimentos fuente de micronutrientes en la población argentina: adecuación a las recomendaciones de las nuevas guías alimentarias. DIAETA, 2017, 35 (159): 25-31

CAME (2020). "Producción de la Industria PYME. Resultados del mes de mayo 2020". Comunicado de la Confederación Argentina de la Mediana Empresa. Buenos Aires, junio 2020.

CEDLAS (2020). El Impacto Asimétrico de la Cuarentena. Documento de trabajo, abril 2020.

CEPEA (2020). Estudio exploratorio sobre hábitos alimentarios durante el aislamiento social, preventivo y obligatorio. Recuperado de: http://cepea.com.ar/cepea/wp-content/uploads/2020/05/reporte-habitos-en-aspo.pdf

CEPAL (2019). Balance preliminar de las economías de América Latina y el Caribe. Santiago de Chile: CEPAL. Recuperado de: https://n9.cl/a5w6x

CEPAL (2020). Actualización. Balance preliminar de las economías de América Latina y el Caribe. Santiago de Chile: CEPAL. Recuperado de: https://n9.cl/2inb1

Chitarroni, H. (2002). La regresión logística. Instituto de Investigación en Ciencias Sociales, Facultad de Ciencias Sociales, Universidad del Salvador.

Ecolatina (2020). Informe Económico Mensual, Julio 2020.

Ernst, C. y López-Mourelo, E. (2020). "El COVID-19 y el mundo del trabajo en Argentina: impacto y respuestas de política”. Nota técnica. Buenos Aires: OIT.

FAO (1996). Declaración de Roma sobre la Seguridad Alimentaria Mundial. Cumbre Mundial sobre la Alimentación. FAO: Roma. 
----- (2009). Estado de la Inseguridad Alimentaria en el Mundo. FAO: Roma.

FMI (2020). World Economic Outlook, April 2020: The Great Lockdown. Recuperado de https://n9.cl/gaqi

GCBA (2020). Ferias de la Ciudad. Recuperado de https://www.buenosaires.gob.ar/espaciopublicoehigieneurbana/espacio-publico/ferias/ferias-de-la-ciudad

INDEC (2018). Encuesta Nacional de Gastos de los Hogares (ENGHo).

(2020a). Informe Cuentas Nacionales, Vol. 4 n¹0. Estimador mensual de actividad económica, abril 2020.

(2020b). Informe Condiciones de Vida, Vol. 4, n 8. Valorización mensual de la canasta básica alimentaria y de la canasta básica total, mayo 2020.

(2020c). Informes Técnicos, Vol. 4, n². Índice de Precios al Consumidor (IPC), Junio 2020.

López-Roldán, P y Fachelli, S (2015). Metodología de la investigación social cuantitativa. Capítulo III.10: Análisis de regresión logística. Dipòsit Digital de Documents. Universitat Autònoma de Barcelona (UAB).

Maletta, H. (2012). Análisis de panel con variables categóricas. Universidad Nacional de Tres de Febrero.

Manzanelli, P., Calvo, D., Basualdo, E. Documento de Trabajo "Un balance preliminar de la crisis económica en la Argentina en el marco del Coronavirus". Centro de Investigación y Formación de la República Argentina (CIFRA); Área de Economía y Tecnología FLACSO. Junio 2020.

Ministerio de Agricultura, Ganadería y Pesca (2020). Lineamientos de Buenas Prácticas en distintas producciones agropecuarias, mayo 2020.

Ministerio de Desarrollo Social de la Nación (MDS) (2020a), Informe de Situación: prestaciones, transferencias y medidas del Ministerio de Desarrollo Social COVID 19. Buenos Aires: Ministerio de Desarrollo Social.

(2020b), Estado de Situación Plan Argentina contra el Hambre. Buenos Aires: Ministerio de Desarrollo Social (20 de mayo 2020).

(2020c), Respuestas sociales ante la pandemia COVID-19 en el marco de la estrategia de acompañamiento ante situaciones de emergencia. Buenos Aires: Ministerio de Desarrollo Social (4 de junio 2020).

Ministerio de Economía de la Nación (2020). Portal de Datos Económicos. Consultado en: https://www.economia.gob.ar/datos/ 
Ministerio de Desarrollo Productivo de la Nación (CEP XXI) (2020a). Informe de Panorama Productivo "Evolución de los principales indicadores de la actividad productiva". Centro de Estudios para la Producción, Ministerio de Desarrollo Productivo. Buenos Aires, junio 2020.

(2020b). Informe de Panorama Productivo "Evolución de los principales indicadores de la actividad productiva". Centro de Estudios para la Producción, Ministerio de Desarrollo Productivo. Buenos Aires, Julio 2020.

ODSA-UCA (2020a). Documento estadístico "La pobreza como privación más allá de los ingresos (20102019). Evolución de carencias monetarias y no monetarias a lo largo de la última década". Bonfliglio, J. Vera, J., Salvia, A. (coord). Observatorio de la Deuda Social Argentina, UCA. Buenos Aires, abril 2020.

(2020b). Informe técnico "Deterioro de las condiciones económicas de los hogares desigualdades sociales en tiempos de pandemia". Bonfliglio, J., Salvia, A., Vera, J. Observatorio de la Deuda Social Argentina, UCA. Buenos Aires, junio 2020.

(2020c). Informe técnico "Escenario laboral del Área Metropolitana de Buenos Aires en tiempos de cuarentena". Donza, E. Observatorio de la Deuda Social Argentina, UCA. Buenos Aires, junio 2020.

OIT (2020). EI COVID-19 y el mundo del trabajo. Segunda edición. Estimaciones actualizadas y análisis, 7 de abril de 2020. Recuperado de: https://n9.cl/5vylz

ONU (2015). Transformar nuestro mundo: la Agenda 2030 para el Desarrollo Sostenible. Nueva York: ONU.

(2020). COVID-19 en Argentina: Impacto socioeconómico y ambiental. Nueva York: ONU. Junio 2020. Recuperado de: https://www.onu.org.ar/stuff/Marco-de-recuperacion.pdf

(2020b). El impacto del COVID-19 en América Latina y el Caribe. Nueva York: ONU. Julio 2020. Recuperado de: https://www.un.org/sites/un2.un.org/files/sg policy brief covid lac spanish.pdf

PNUD (2020). Comunicado de prensa. Recuperado de: $\underline{\text { https://n9.cl/fem9 }}$

Salas Velasco, M (1996), "La regresión logística. Una aplicación a la demanda de estudios universitarios". Revista Estadística Española. Vol. 38, Núm. 141, 1996, págs. 193 a 217. 


\section{ANEXO I. PROGRAMAS DE PROTECCIÓN SOCIAL FRENTE A LA CRISIS EN CONTEXTO DE ASPO-COVID-19 EN EL ÁREA METROPOLITANA DE BUENOS AIRES.}

En este anexo se examina el nivel de cobertura y características de los hogares beneficiarios de los programas de asistencia económico-alimentaria desarrollados por el Estado argentino durante los primero 55 días cuarentena en el marco del ASPO-COVID-19 sobre los hogares y las poblaciones adultas e infantiles que residen en el Área Metropolitana de Buenos Aires (Ciudad Autónoma de Buenos Aires y 30 partidos del Conurbano Bonaerense). Para ello se aplicó -entre el 7 y el 14 de mayo de 2020- una encuesta denominada EDSA-COVID-19, a un panel de 500 hogares relevados por la EDSA Equidad entre julio y octubre de 2019 en dicha región; siendo dichos casos una muestra aleatoria estratificada de los 1776 casos que conforman el panel de estudio de la EDSA en el AMBA. La serie de estudios lleva el nombre de Impacto Social de las Medidas de Aislamiento Obligatorio por COVID19 en el Área Metropolitana de Buenos Aires.

\section{AI.1. NIVEL Y PERFIL DE LA ASISTENCIA ECONÓMICA Y ALIMENTARIA A LOS HOGARES DEL ÁREA METROPOLITANA DE BUENOS AIRES.}

Al estudiar la capacidad de subsistencia económica de los hogares en el contexto de emergencia sanitaria, resulta relevante reflexionar acerca del alcance de las ayudas sociales de transferencias de ingresos y asistencia alimentaria dirigidas a poblaciones que han sido especialmente afectadas por la política de aislamiento preventivo y obligatorio. Las políticas sociales compensatorias estuvieron presentes en el contexto de cuarentena a través del Ingreso Familiar de Emergencia (IFE) ${ }^{78}$, bonos extraordinarios a AUH, jubilados, Tarjeta Alimentar, Salario Complementario pagado por el estado, así como mediante la entrega de viandas y bolsones de alimentos o el retiro de estos de comedores escolares o comunitarios.

Los resultados obtenidos pretenden aportar elementos que contribuyan a evaluar en qué medida las políticas de protección social tuvieron éxito para compensar o atenuar los nuevos riesgos generados en el contexto de emergencia sanitaria. Entre los hallazgos más significativos (véase Gráficos Al.1 y Al.2 y Figura complementaria, se destacan los siguientes:

- La inseguridad alimentaria ha sido un problema con una incidencia particularmente elevada en los hogares con niñas/os y adolescentes. En ese contexto es que el gobierno que inicia su gestión en diciembre de 2019 se propone reforzar los programas de protección social a través de lo que se conoce como la Tarjeta Alimentar. Este programa se orientó especialmente a los hogares con niñas/os entre 0 y 6 años beneficiarios de la Asignación Universal por Hijo (AUH). En el contexto de la pandemia y las medidas de aislamiento social y obligatorio, este programa experimentó dificultades en su implementación, pero alcanzó una amplia cobertura.

- Asimismo, se ampliaron los montos de las transferencias preexistentes y se vehiculizaron las ayudas alimentarias directas a través de la entrega de bolsones de alimentos y viandas. Todas estas iniciativas se revelan insuficientes en el marco de una profundización de la crisis socioeconómica, abrupta caída de los ingresos de los hogares, y empobrecimiento de nuevos sectores sociales.

\footnotetext{
${ }^{78}$ Pueden encontrarse mayores especificaciones acerca del Ingreso Familiar de Emergencia en Ministerio de Economía (abril, 2020) "Ingreso Familiar de Emergencia. Análisis y desafíos para la transferencia de ingresos a trabajadores/as precarios". Para una evaluación de las características de sus beneficiarios, véase documento de ANSES [Diapositivas en PowerPoint] "Acceso al Ingreso Familiar de Emergencia".
} 
- El 53,1\% de hogares del AMBA recibió alguna ayuda social en mayo de 2020. Si se evalúa el alcance de las medidas distinguiendo el tipo de ayuda social, se observa que el $50,2 \%$ de los hogares del AMBA recibieron alguna ayuda social vinculada a transferencias de ingreso realizadas durante el período de aislamiento social obligatorio (IFE, bonos extraordinarios a AUH, jubilados, Salario Complementario y Tarjeta Alimentar).

- Asimismo, el 16,8\% de unidades domésticas del AMBA declaró haber recibido algún bolsón, vianda o haber retirado alimentos de comedores escolares o comunitarios. Si bien en ambos tipos de ayuda, es en los estratos más desfavorecidos en los cuales se evidencia mayor alcance de la ayuda social, la brecha entre sectores de la estructura social es mayor en lo que respecta a la recepción o retiro de alimentos.

- La mayor presencia de las ayudas sociales en los hogares con niños/as, en condición de pobreza en 2019, la clase trabajadora marginal y las unidades domésticas sin afiliación a la seguridad social señala la correcta focalización de estas medidas. Sin duda, las medidas adoptadas permiten amortiguar el impacto de la caída sobre las condiciones de vida. Sin embargo, los elevados niveles de déficit y vulnerabilidades persistentes evaluadas a través de los indicadores seleccionados reflejan la insuficiencia de estas medidas para lograr un nivel satisfactorio de bienestar, condiciones fuertemente agravadas en el actual contexto de aislamiento preventivo social y obligatorio.

Gráfico A-I.1. Asistencia Económica y Alimentaria a los Hogares ${ }^{1}$ según Región, Presencia de Niños/as y Condición de Pobreza en 2019. En porcentaje de hogares. Mayo 2020. AMBA*

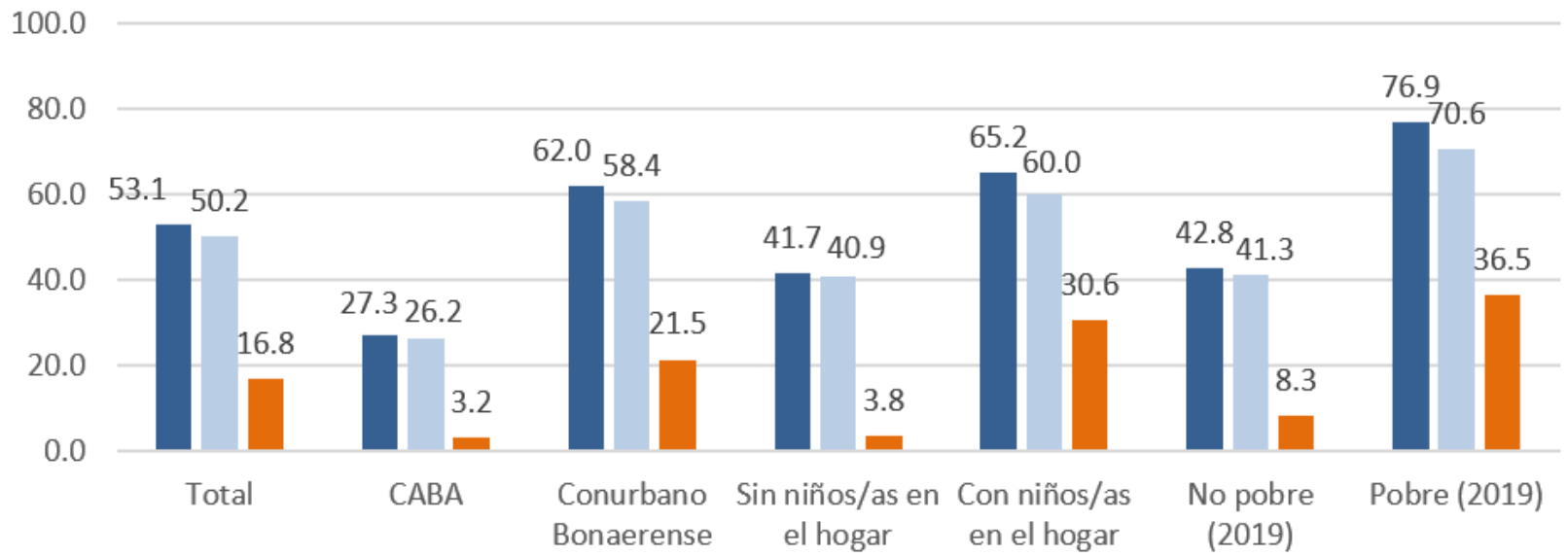

— Asistencia económica y alimentaria total $\square$ Transferencias de ingresos $\square$ Viandas, bolsones, retiro de alimentos

\footnotetext{
${ }^{1}$ La asistencia económica y alimentaria incluye: IFE, bonos extraordinarios por AUH o jubilaciones, Tarjeta Alimentar, salario complementario pagado por el Estado, ayudas extraordinarias al personal de la salud y/o de seguridad, viandas y/o bolsones de alimentos o retiro de alimentos de comedores escolares o comunitarios. Las transferencias de ingreso incluyen: IFE, bonos extraordinarios por AUH o jubilaciones, Tarjeta Alimentar, salario complementario pagado por el Estado, ayudas extraordinarias al personal de la salud y/o de seguridad. Se excluyen las viandas $\mathrm{y} / \mathrm{o}$ bolsones de alimentos o retiro de alimentos de comedores escolares o comunitarios.

Fuente: EDSA COVID-19, mayo 2020; empalme EDSA Agenda para la Equidad (2017-2025), Observatorio de la Deuda Social Argentina (UCA).

*Área Metropolitana de Buenos Aires (Ciudad de Buenos Aires y 30 partidos del conurbano bonaerense).
} 


\section{Gráfico A-I.2. Asistencia Económica y Alimentaria a los Hogares ${ }^{1}$ según Estrato Socio-} Ocupacional y Empleo Registrado y Seguridad Social en 2019. En porcentaje de hogares. Mayo 2020. AMBA*

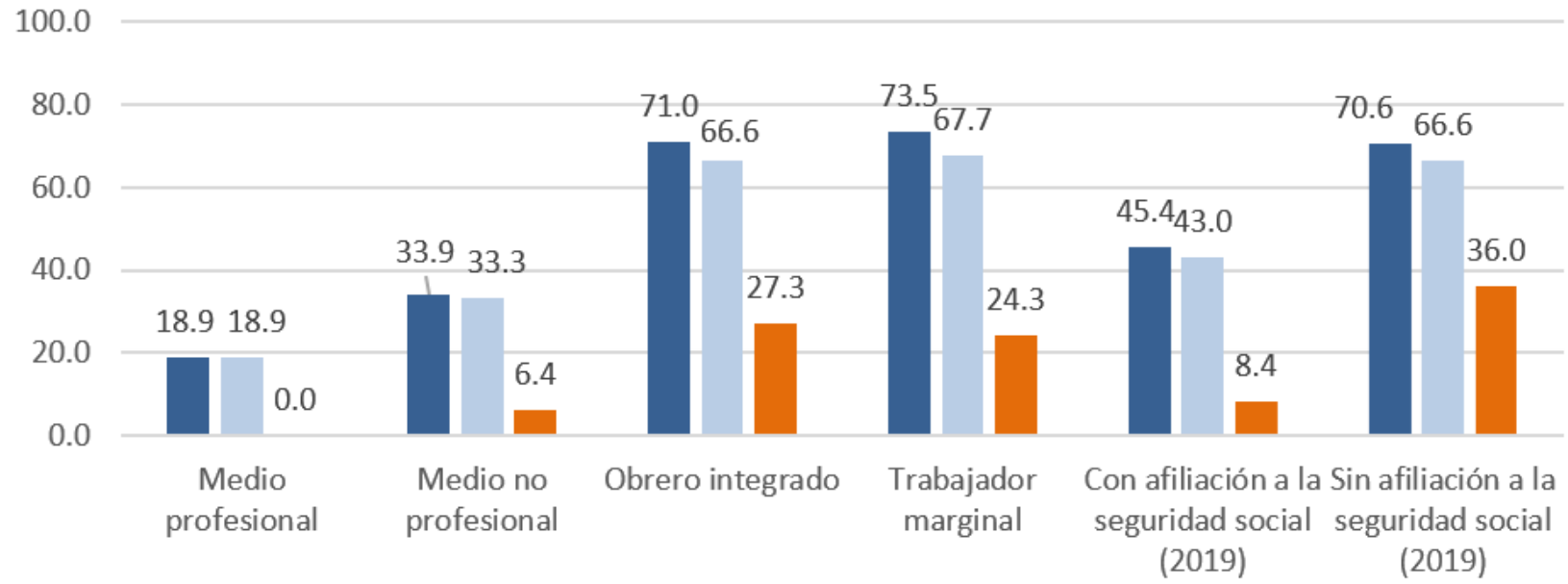

- Asistencia económica y alimentaria total $\square$ Transferencias de ingresos $\quad$ Viandas, bolsones, retiro de alimentos

\footnotetext{
${ }^{1}$ La asistencia económica y alimentaria incluye: IFE, bonos extraordinarios por AUH o jubilaciones, Tarjeta Alimentar, salario complementario pagado por el Estado, ayudas extraordinarias al personal de la salud y/o de seguridad, viandas y/o bolsones de alimentos o retiro de alimentos de comedores escolares o comunitarios. Las transferencias de ingreso incluyen: IFE, bonos extraordinarios por AUH o jubilaciones, Tarjeta Alimentar, salario complementario pagado por el Estado, ayudas extraordinarias al personal de la salud y/o de seguridad. Se excluyen las viandas $\mathrm{y} / \mathrm{o}$ bolsones de alimentos o retiro de alimentos de comedores escolares o comunitarios.
}

Fuente: EDSA COVID-19, mayo 2020; empalme EDSA Agenda para la Equidad (2017-2025), Observatorio de la Deuda Social Argentina (UCA).

*Área Metropolitana de Buenos Aires (Ciudad de Buenos Aires y 30 partidos del conurbano bonaerense). 
Cuadro A-I.1. Asistencia Económica y Alimentaria a los Hogares ${ }^{1}$. En porcentaje de hogares. Mayo 2020. AMBA*

\begin{tabular}{|c|c|c|c|}
\hline & $\begin{array}{c}\text { Asistencia } \\
\text { económica y } \\
\text { alimentaria } \\
\text { total }^{1}\end{array}$ & $\begin{array}{l}\text { Transferencias } \\
\text { de ingresos }{ }^{2}\end{array}$ & $\begin{array}{c}\text { Viandas, } \\
\text { bolsones, retiro } \\
\text { de alimentos }\end{array}$ \\
\hline \multicolumn{4}{|l|}{ TOTAL } \\
\hline Estadístico & 53,1 & 50,2 & 16,8 \\
\hline \multicolumn{4}{|l|}{ CARACTERÍSTICAS ESTRUCTURALES } \\
\hline \multicolumn{4}{|l|}{ REGIONES URBANAS } \\
\hline CABA & 27,3 & 26,2 & 3,2 \\
\hline Conurbano Bonaerense & 62,0 & 58,4 & 21,5 \\
\hline \multicolumn{4}{|l|}{ ESTRATO SOCIO-OCUPACIONAL (2019) } \\
\hline Medio profesional & 18,9 & 18,9 & 0,0 \\
\hline Medio no profesional & 33,9 & 33,3 & 6,4 \\
\hline Trabajador integrado & 71,0 & 66,6 & 27,3 \\
\hline Trabajador marginal & 73,5 & 67,7 & 24,3 \\
\hline \multicolumn{4}{|l|}{ NIVEL SOCIOECONÓMICO (2019) } \\
\hline Medio alto & 20,1 & 19,5 & 1,5 \\
\hline Medio bajo & 48,8 & 46,3 & 13,7 \\
\hline Bajo & 69,0 & 64,3 & 24,1 \\
\hline Muy Bajo & 78,5 & 74,3 & 29,6 \\
\hline \multicolumn{4}{|l|}{ POBREZA POR INGRESOS (2019) } \\
\hline No pobre & 42,8 & 41,3 & 8,3 \\
\hline Pobre & 76,9 & 70,6 & 36,5 \\
\hline \multicolumn{4}{|l|}{ CARACTERÍSTICAS HOGAR } \\
\hline \multicolumn{4}{|l|}{ EMPLEO DEL JEFE (2019) } \\
\hline Empleo pleno & 34,8 & 32,8 & 8,3 \\
\hline Empleo precario & 73,1 & 69,6 & 34,8 \\
\hline Subempleo/ Desempleo & 73,0 & 65,4 & 26,6 \\
\hline Inactivo & 54,9 & 52,8 & 8,5 \\
\hline \multicolumn{4}{|l|}{ SEXO DEL JEFE } \\
\hline Varón & 52,1 & 50,1 & 16,8 \\
\hline Mujer & 55,3 & 50,4 & 16,7 \\
\hline \multicolumn{4}{|l|}{ NIÑOS EN EL HOGAR } \\
\hline Sin niños & 41,7 & 40,9 & 3,8 \\
\hline Con niños & 65,2 & 60,0 & 30,6 \\
\hline \multicolumn{4}{|c|}{ SEGURIDAD Y ASISTENCIA SOCIAL EN EL HOGAR } \\
\hline \multicolumn{4}{|c|}{ EMPLEO REGISTRADO Y SEGURIDAD SOCIAL (2019) } \\
\hline Con afiliación al sistema de seguridad social & 45,4 & 43,0 & 8,4 \\
\hline Sin afiliación al sistema de seguridad social & 70,6 & 66,6 & 36,0 \\
\hline \multicolumn{4}{|l|}{ PROGRAMAS SOCIALES (2019) } \\
\hline No recibe programas sociales & 38,4 & 35,4 & 6,2 \\
\hline Recibe programas sociales & 88,6 & 85,6 & 42,2 \\
\hline
\end{tabular}

${ }^{1}$ La asistencia económica y alimentaria incluye: IFE, bonos extraordinarios por AUH o jubilaciones, Tarjeta Alimentar, salario complementario pagado por el Estado, ayudas extraordinarias al personal de la salud y/o de seguridad, viandas y/o bolsones de alimentos o retiro de alimentos de comedores escolares o comunitarios.

Las transferencias de ingreso incluyen: IFE, bonos extraordinarios por AUH o jubilaciones, Tarjeta Alimentar, salario complementario pagado por el Estado, ayudas extraordinarias al personal de la salud y/o de seguridad. Se excluyen las viandas y/o bolsones de alimentos o retiro de alimentos de comedores escolares o comunitarios.

Fuente: EDSA COVID-19, mayo 2020; empalme EDSA Agenda para la Equidad (2017-2025), Observatorio de la Deuda Social Argentina (UCA).

*Área Metropolitana de Buenos Aires (Ciudad de Buenos Aires y 30 partidos del conurbano bonaerense). 


\section{ANEXO II. RESULTADOS MODELO DE REGRESIÓN RIESGO DE EXPERIMENTAR INSEGURIDAD ALIMENTARIA.}

\section{Cuadro A-II.1. Factores Asociados al Riesgo Pasar a Experimentar Inseguridad Alimen-}

taria Total e Inseguridad Alimentaria Severa. Julio-octubre 2019 - mayo 2020. Panel de 500 hogares del Área Metropolitana de Buenos Aires*.

\begin{tabular}{|c|c|c|c|c|c|c|}
\hline $\begin{array}{c}\text { PASAR DE NO TENER A TENER } \\
\text { INSEGURIDAD ALIMENTARIA (TOTAL) }\end{array}$ & B & E.T. & Wald & $\mathrm{gl}$ & Sig. & $\operatorname{Exp}(B)$ \\
\hline \multicolumn{7}{|l|}{ Viven en $\mathrm{CABA} \odot$} \\
\hline Vivir en Conurbano & 1,146 & ,307 & 13,912 & 1 &, 000 & 3,145 \\
\hline Estrato medio profesional@ & & & 38,817 & 3 &, 000 & \\
\hline $\begin{array}{l}\text { Estrato medio no profesional } \\
\text { Trabajador integrado } \\
\text { Trabajador marginal }\end{array}$ & $\begin{array}{l}-, 013 \\
1,383 \\
1,788 \\
\end{array}$ & $\begin{array}{l}, 456 \\
, 440 \\
, 459 \\
\end{array}$ & $\begin{array}{r}, 001 \\
9,884 \\
15,192 \\
\end{array}$ & $\begin{array}{l}1 \\
1 \\
1 \\
\end{array}$ & $\begin{array}{l}, 978 \\
, 002 \\
, 000 \\
\end{array}$ & $\begin{array}{r}, 988 \\
3,987 \\
5,976 \\
\end{array}$ \\
\hline \multicolumn{7}{|l|}{ Con afiliación al sistema de Seguridad Social(C) } \\
\hline Sin afiliación al sistema de seguridad social & 1,089 & , 198 & 30,150 & 1 & ,000 & 2,970 \\
\hline \multicolumn{7}{|l|}{ No pobres en 2019@ } \\
\hline Pobres en 2019 &,- 214 & ,206 & 1,079 & 1 & ,299 & ,807 \\
\hline $\begin{array}{l}\text { Siguieron trabajando o trabajan más horas que antes de } \\
\text { cuarentena@ }\end{array}$ & & & 33,822 & 3 &, 000 & \\
\hline $\begin{array}{l}\text { Trabaja menos horas } \\
\text { Fue suspendido, o dejó de trabajar } \\
\text { No trabajaba }\end{array}$ & $\begin{array}{r}1,145 \\
1,091 \\
, 116 \\
\end{array}$ & $\begin{array}{l}, 366 \\
, 320 \\
, 332 \\
\end{array}$ & $\begin{array}{r}9,776 \\
11,626 \\
, 121 \\
\end{array}$ & $\begin{array}{l}1 \\
1 \\
1\end{array}$ & $\begin{array}{l}, 002 \\
, 001 \\
, 727 \\
\end{array}$ & $\begin{array}{l}3,141 \\
2,977 \\
1,123 \\
\end{array}$ \\
\hline \multicolumn{7}{|l|}{ No percibe tarjeta alimentaria@ } \\
\hline Percibe tarjeta alimentaria &,- 058 & ,230 & ,064 & 1 & ,800 & ,943 \\
\hline \multicolumn{7}{|l|}{ No percibe otras ayudas sociales $\bigodot$} \\
\hline Percibe otras ayudas. IFE, AUH, etc. & ,275 & ,206 & 1,785 & 1 & ,182 & 1,316 \\
\hline Constante & $-5,164$ &, 503 & 105,244 & 1 &, 000 &, 006 \\
\hline $\begin{array}{c}\text { PASAR DE NO TENER A TENER } \\
\text { INSEGURIDAD ALIMENTARIA SEVERA }\end{array}$ & $\mathrm{B}$ & E.T. & Wald & gl & Sig. & $\operatorname{Exp}(B)$ \\
\hline \multicolumn{7}{|l|}{ Viven en $\mathrm{CABA} \odot$} \\
\hline Vivir en Conurbano & ,968 & ,422 & 5,267 & 1 & ,022 & 2,632 \\
\hline Estrato medio profesionalC & & & 21,162 & 3 &, 000 & \\
\hline $\begin{array}{l}\text { Estrato medio no profesional } \\
\text { Trabajador integrado } \\
\text { Trabajador marginal }\end{array}$ & $\begin{array}{l}-, 793 \\
1,641 \\
1,780 \\
\end{array}$ & $\begin{array}{l}, 851 \\
, 671 \\
, 688\end{array}$ & $\begin{array}{r}, 869 \\
5,977 \\
6,692 \\
\end{array}$ & $\begin{array}{l}1 \\
1 \\
1 \\
\end{array}$ & $\begin{array}{l}, 351 \\
, 014 \\
, 010 \\
\end{array}$ & $\begin{array}{r}452 \\
5,161 \\
5,928 \\
\end{array}$ \\
\hline \multicolumn{7}{|l|}{ Con afiliación al sistema de Seguridad Social(C) } \\
\hline Sin afiliación al sistema de seguridad social & ,488 & ,236 & 4,278 & 1 & ,039 & 1,629 \\
\hline \multicolumn{7}{|l|}{ No pobres en 2019@) } \\
\hline Pobres en 2019 & ,769 & ,237 & 10,508 & 1 &, 001 & 2,158 \\
\hline $\begin{array}{l}\text { Siguieron trabajando o trabajan más horas que antes de } \\
\text { cuarentena(C) }\end{array}$ & & & 13,186 & 3 & ,004 & \\
\hline $\begin{array}{l}\text { Trabaja menos horas } \\
\text { Fue suspendido, o dejó de trabajar } \\
\text { No trabajaba }\end{array}$ & $\begin{array}{l}, 707 \\
, 968 \\
, 212 \\
\end{array}$ & $\begin{array}{l}, 506 \\
, 398 \\
, 414 \\
\end{array}$ & $\begin{array}{r}1,949 \\
5,907 \\
, 261 \\
\end{array}$ & $\begin{array}{l}1 \\
1 \\
1\end{array}$ & $\begin{array}{l}163 \\
, 015 \\
, 609 \\
\end{array}$ & $\begin{array}{l}2,027 \\
2,633 \\
1,236 \\
\end{array}$ \\
\hline \multicolumn{7}{|l|}{ No percibe tarjeta alimentaria $\bigodot$} \\
\hline Percibe tarjeta alimentaria &,- 866 & ,284 & 9,328 & 1 & ,002 & ,420 \\
\hline \multicolumn{7}{|l|}{ No percibe otras ayudas sociales@ } \\
\hline Percibe otras ayudas. IFE, AUH, etc. & ,028 & ,237 &, 014 & 1 & ,907 & 1,028 \\
\hline Constante & $-5,862$ & ,740 & 62,786 & 1 &, 000 &, 003 \\
\hline
\end{tabular}

*Área Metropolitana de Buenos Aires (Ciudad de Buenos Aires y 30 partidos del conurbano bonaerense).

Fuente: EDSA COVID-19, mayo 2020; empalme EDSA Agenda para la Equidad (2017-2025), Observatorio de la Deuda Social Argentina (UCA) 


\section{ACERCA DE LOS AUTORES}

Agustín Salvia. Doctor en Ciencias Sociales. Colegio de México. Director del Programa de la Deuda Social Argentina de la Universidad Católica Argentina. Investigador Principal CONICET. Profesor Titular en la Facultad de Ciencias Sociales de la Universidad de Buenos Aires. Profesor de Posgrado y Doctorado en la Facultad de Ciencias Sociales de la Universidad de Buenos Aires y de Maestría en la Universidad Tres de Febrero, FLACSO-Argentina y en la Universidad de la República de Uruguay. Coordinador del Grupo de Trabajo CLACSO Heterogeneidad Estructural y Desigualdades Sociales.

Sergio Britos. Licenciado en Nutrición, Prof. Asociado, Escuela de Nutrición, Facultad de Medicina UBA; Prof. Titular, Facultad de Bromatología, UNER; Prof. Adjunto, Facultad de Ciencias Médicas, UCA; Coordinador de la Licenciatura en Nutrición, Facultad de Bromatología, UNER; Director del Centro de Estudios sobre Políticas y Economía de la Alimentación (CEPEA); Docente Categorizado, Facultad de Medicina, UBA.

Eugenio Díaz-Bonilla. PhD in Economics, The Johns Hopkins University. Master of Arts in International Relations, School of Advanced International Studies. Licenciado en Economía. Facultad de Ciencias Económicas. Universidad de Buenos Aires. Exfuncionario y consultor de organismos internacionales (FAO, IICA, PNUD, Banco Mundial, BID) y ex diplomático de Argentina. Actualmente, dirige el Programa de América Latina y el Caribe del IFPRI

Ricardo Rapallo. Ingeniero Agrónomo y Doctor en Proyectos y Planificación Rural por la Universidad Politécnica de Madrid. En 2009 llega a la Oficina Subregional de la FAO para Mesoamérica, como Oficial Profesional Asociado de Asistencia para las Políticas. Posteriormente en 2011, se desempeña como Oficial de Seguridad Alimentaria en la Dirección de Economía Agrícola y del Desarrollo en la Sede de la FAO en Roma, y desde 2012 como Oficial de Seguridad Alimentaria y Nutricional de la Oficina Regional para América Latina y el Caribe en Chile. En 2020 fue nombrado Representante de la FAO en Guatemala

lanina Tuñón. Doctora del Programa de Doctorado en Ciencias Sociales de la Facultad de Ciencias Sociales de la Universidad de Buenos Aires. Docente e investigadora del Programa del Observatorio de la Deuda Social Argentina. Pontificia Universidad Católica Argentina. Docente e investigadora de Universidad Nacional de la Matanza, Universidad Católica Argentina y Universidad Nacional de Tres de Febrero.

Santiago Poy. Doctor en Ciencias Sociales, Facultad de Ciencias Sociales, Universidad de Buenos Aires. Becario posdoctoral del Consejo Nacional de Investigaciones Científicas y Técnicas (CONICET) con sede en el Programa del Observatorio de la Deuda Social Argentina de la Pontificia Universidad Católica Argentina. Profesor Adjunto. Departamento de Ciencias Políticas y Relaciones Internacionales, Facultad de Ciencias Sociales, Pontificia Universidad Católica Argentina.

Ayelén Borg. Licenciada en Nutrición (UBA). Diplomada en gestión de gobiernos locales para la infancia y la familia (UCA). Analista de investigación en CEPEA. Jefe de Trabajos Prácticos, Escuela de Nutrición, Facultad de Medicina (UBA). Profesora Adjunta en las carreras de Nutrición de las universidades UADE y UCES. 
María Eugenia Herrera Vegas. Maestría y Especialización en Educación. Maestría en Finanzas y Mercado de Capitales. ESEADE 1997. Licenciatura en Administración de Empresas. Universidad de Belgrano 1994. Coordinadora de la Red Sistemas Alimentarios Sostenibles, Capítulo Primera Infancia, de la Fundación Alimentaris y Potenciar - Plataforma de Impacto Colectivo. Fundación Los Grobo.

\section{AGRADECIMIENTOS}

Se agradece a la FAO por el financiamiento de este proyecto. Los autores agradecen al Observatorio de la Deuda Social de la Universidad Católica Argentina por las encuestas y bases de datos que nutrieron varios de los capítulos de este estudio, así como la última encuesta de mayo que permitió actualizar información en materia de seguridad alimentaria; al CEPEA (Centro de Estudios sobre Políticas y Economía de la Alimentación) que compartió bases de datos y la encuesta sobre dietas y consumo durante la pandemia; y a las Fundaciones Alimentaris y Potenciar que facilitaron estudios y datos para completar este trabajo. Se agradece también a los colegas de las instituciones participantes que hicieron comentarios durante este trabajo. De todas maneras, las opiniones son de los autores y no comprometen a sus respectivas instituciones u organismos a los que estén afiliados."
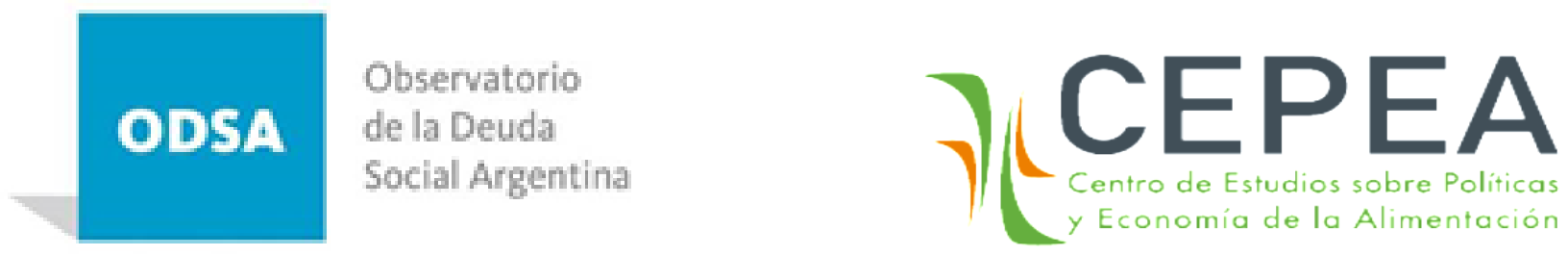

Funding for this work was provided by FAO. This publication has not been independently peer reviewed. Any opinions expressed here belong to the author(s) and are not necessarily representative of or endorsed by IFPRI, FAO or other institutions involved.

\section{INTERNATIONAL FOOD POLICY RESEARCH INSTITUTE \\ A world free of hunger and malnutrition}

IFPRI is a CGIAR Research Center 